\title{
Erfahrung der Modeme und Form des realistischen Romans
}

E ine Untersuchung zu soziogenetischen und romanpoetologischen Aspekten in den späten Romanen von Raabe, Fontane und Keller

Dissertation zur Erlangung des philosophischen Doktorgrades am Fachbereich Historisch-Philologische Wissenschaften der Georg-August-Universität zu Göttingen

vorgelegt von Jeong-Hee BAE aus Busan, Korea 
Ich versichere, daß ich die eingereichte Dissertation

E rfahrung der Modeme und Formen des realistischen Romans.

E ine U ntersuchung zu soziogenetischen und romanpoetologischen A spek ten in den späten Romanen von Raabe, Fontane und Keller

selbständig und ohne unerlaubte Hilfsmittel verfaßt habe. Anderer als der von mir angegebenen Hilfsmittel und Schriften habe ich mich nicht bedient. Alle wörtlich oder sinngemäß den Schriften anderer Autoren entnommenen Stellen habe ich kenntlich gemacht. 


\section{INHALTSVERZEICHNIS}

\section{ERSTER TEIL: W. Raabes}

Stopfk uchen. E ine See und M ordgeschichte (1893)

Problemstellung

A. Die gesellschaftliche und geschichtliche D imension der Moderne

I. „Ich saß mitten drin in meinem Ideal!“: Eigentumsthematik

1. Forschungsstand und Bedeutung der Eigentumsthematik

2. D ie bürgerlichen Charakterzüge der Eigentumsauffassung

3. Sozialkritischer G ehalt der Eigentumsauffassung

II. „K rieg gegen die Philister!“" D ie Rote Schanze und die Form der Öffentlichkeit

1. ,Pitaval' oder das Prinzip der Öffentlichkeit

2. Die Humanisierung der Ö ffentlichkeit: Erkenntniskritik, Utilitarismus und Toleranz

3. Sprengung der bürgerlichen Öffentlichkeitskritik

B. D oppelstruktur von D etektivroman und Seetagebuch

I. Schaumanns Detektivroman

1. Die Struktur der D etektion: Einheit von vita adiva und vita contemplativa

2. Die Struktur des auktorialen Erzählens

II. Eduards Seetagebuch 


\section{ZWEITER TEIL: Th. Fontanes}

F rau Jenny Treibel oder, W o sich H erz zum H erzen find't' (1892)

Problemstellung

A. Modaliät der Familie

I. E ine Parvenü-Physiognomie

1. Intimität der bürgerlichen Familie

$\begin{array}{lr}\text { 2. Salonkultur und politische E rziehungsarbeit des Bürgertums } & \text { S. } 50\end{array}$

3. Aushöhlung des bürgerlichen E rziehungsprogramms

II. Utopie der defizitären Familie

1. Bildungsbürgerliche Intellektualisierung der Erfahrung der Moderne

2. Die moderne Stopfkunst: D as neue Subjektsmodell

S. 56

3. Sentimentalität und der Zerfall der Familie

B. Die erzählte Komödie

I. Die ironische Funktion des Theatralischen

II. Abschied vom Formprinzip der organischen Geschlossenheit

S. 61

1. Die Auflösung der Handlungseinheit

S. 62

2. Simultaneität und O ffenheit zur Vergangenheit

S. 65

III. Die Form der kontingenten Welt der Moderne

S. 66

1. Der Romanschluß und der Wirklichkeitsbegriff im Wandel

S. 66

2. Ambivalenz der Kontingenz

S. 69 
D RITTER TEIL: G. Kellers M artin Salander (1886)

Problemstellung

A. Holistische Diktion der Moderne

I. Die organistische Harmonie der bürgerlichen O rdnung

II. Die Auflösung der Ordnung und ihre anthropologischen Ausdrucksformen

1. Der Massenmensch des D emokratismus

2. Der ,Proteus' des Finanzkapitalismus

III. Die Zukunftsordnung

1. Amolds ,Historismus'

2. Das Prinzip des ,Nach der Geschichte

3. Bildersprache des ,Nach der Geschichte'

B. Märchen als Paratext des Zeitromans

I. Myrrha: Kritik an der Funktionsgeschichte des Klassischen

1. Schöner Schein im Dienst des Wahren und Guten

2. Geschichtliche Referenzlosigkeit des Klassischen

II. Der auktoriale Erzähler

1. D er neutrale Reflexionsraum

2. Literarische G renze eines Öffentlichkeitsverständnisses

III. Maries Märchen: eine andere G eschichtsschreibung - ein anderes Erzählen 


\section{Methodische Vorbemerkung}

Die Realismus-Forschung der Nachkriegszeit kreiste nicht selten um die Frage, wie man den deutschen Realismus im Vergleich mit dem westeuropäischen Realismus verstehen und bewerten solle. Oft war, seitdem Auerbach ${ }^{1}$ mit seiner These über den deutschen Realismus des 19. Jahrhunderts als zweitrangigen Realismus die Diskussion entfacht hatte, die Antwort auf diese Frage ein Verweis auf ein weitergehendes Problem, daß nämlich - analog zur Verspätung der gesellschaftlichen Modernisierung - auch die Modernisierung der Literatur in Deutschland, im Sinne einer vom Erlebenssubjekt unabhängig zu betrachtenden Objektivierung der Erlebenswelt, nur bedingt erreicht sei. Diese inzwischen weit verbreitete Kritik am deutschen Realismus ist durchaus anfechtbar: Das Verhältnis von Literatur und Gesellschaft bzw. G eschichte wird damit vereinfacht.

Mit entscheidender Nachwirkung auf die Realismusforschung ging die Arbeit von Richard Brinkmann gegen diese Perspektive an, indem er sich gegen die Auffassung wandte, in der objektiven inhaltlichen Wiedergabe der tatsächlichen Wirklichkeit sei das „Materialobjekt des Realismus“2 zu erkennen, und statt dessen die Besonderheit poetischer Wirklichkeitskonstitution zur Geltung brachte. Die subjektivistischen Elemente im deutschen Realismus bedeuten Brinkmann zufolge dann nicht eine Unzulänglichkeit der ,nationalen Variante' im Spiegel der gleichzeitigen anderen Realismen, sondern dokumentieren durchaus gleichrangig, daß „die Dichtung die Wirklichkeit der ,dargestellten' Welt eben als ihre, der Dichtung eigene Wirklichkeit auferbaut [sic!].“3 In der Subjektivierungstendenz des deutschen Realismus weist sich nach Brinkmann das Kunstwerk als autonome Wirklichkeitsdarstellung aus. Wird die Kunst als eigengesetzliche Wirklichkeit im thematischen und strukturellen Sinn im Mittelpunkt der modernen Kunst zu Anfang des 20. Jahrhunderts stehen, so hat der deutsche Realismus diese künftige Entwicklung vorbereitet. Unter dem allgemeinen Eindruck der normgebenden Bedeutung der Moderne, des modernen Erzählens wird die Spannung zur literarischen Moderne, die dem deutschen Realismus wie den anderen Realismen innewohnt, einseitig formalistisch weggeglättet. Die Geschichtlichkeit jener Spannung wird verdeckt, der Noch-nicht-Realismus des deutschen Realismus wird zur Schon-Modeme aufgewertet.

Als Literatur mit dem Anspruch auf Wirklichkeitsbezug ist dabei der Forschungsgegenstand des Realismus besonders abhängig davon, wie bewußt man mit dem Widerspruch zwischen der gestalteten und der empirischen Realität umgeht: Der Realismus richtet sich auf bestimmte Gegenstände der Realität, bildet aber nicht sie selbst ab, sondern „das semantische Feld ihrer D arstellung gemäß den außerliterarischen Diskursen, die in der Realität, was Realität ist, definieren. " ${ }^{4}$ D ieser D oppelbezug auf Realität als Resultat interpretativer Transformationen erfordert und erschwert es zugleich, die realistische Literatur mit der G eschichte zu vermitteln, d.h. die immanente Bewegung der D arstellungsweise des Realismus in ein Funktionsverhältnis zur G eschichte, zur geschichtlichen Realität, zu setzen.

An der für die Realismusforschung kennzeichnenden Pendelbewegung, mit der die Kunst von dem Extrem unmittelbarer Widerspiegelung zum anderen Extrem der Kunstautonomie im Sinne des Formalismus ausschlägt, ist gerade die praktische Schwierigkeit der methodischen Vermittlung zwischen Historie und Literaturgeschichte ablesbar. Freilich ist dies nicht ein Problem der Realismusforschung allein. Es zeigt eher die Grenze und zugleich Aufgabe der allgemeinen literaturwissenschaftlichen Reflexion über das Verhältnis von Geschichte und Literaturgeschichte an,, - eine Überlegung, die wegen ihrer methodischen $\mathrm{G}$ rundsätzlichkeit in mehr oder weniger jeder konkreten Forschung angestellt wird.

In der Orientierung an der normgebenden Bedeutung der literarischen Moderne übernimmt oftmals die Realismusforschung deren Position, indem auch sie den Bruch zwischen Moderne und Realismus postuliert. ${ }^{6}$ Die Gegenüberstellung von Realismus und literarischer Moderne entspricht aber mehr dem Habitus der künstlerischen Moderne, sich gegen das vermeintlich Traditionelle abzugrenzen. Als literaturwissenschaftlicher ,Raster, verliert diese Gegenüberstellung immer dann an Schärfe, wenn auf die Vielfalt des modernen Erzählens verwiesen wird. Es ist unmöglich, von dem modernen Roman zu sprechen,7 der dem realistischen Roman gegenüberzustellen wäre. Und

1 E. Auerbachs Mimesis. D argestellte W irklichk eit in der abendländischen Literatur (Bern 1946) stellt wie Lukács, Probleme des Realismus I-III (Neuwied 1964f.) die frühe Phase eines Forschungsweges dar, der den Blick auf das europäische Ausmaß der Realismusproblematik lenkt und somit die G eschichtlichkeit der europäischen Gesellschaften als O rt des Wirklichkeitsbezugs des Realismus hervorhebt.

2 R. Brinkmann, Wirklichkeit und Illusion. Studien über Gehalt und Grenzen des Begriffs Realismus für die erzählende Dichtung des neunzehnten Jahrhunderts. Tübingen $1966^{2}$

3 Ebd., S. 79.

4 H. Turk, D ie Schrift als Ordnungsform des E rlebens. D iskursanalytische Ü berlegungen zu A dalbert Stifter, in: J. Fohrmann / H. Müller (Hrsg.), D isk urstheorien und L iteraturwissenschaft. Frankfurt/ M. 1988. S. 400-417, hier S. 401.

5 Zum dialektischen Verhältnis zwischen der G eschichte der Kunst und der Historiographie siehe H. R. Jauß, G eschichte der Kunst und H istorie, in: ders., L iteraturgeschichte als Provok ation. Frankfurt/ M. 19744. S. 208-251.

6 Theoretiker der Moderne (Th. W. Adorno, U. Eisele und P. Bürger) verstehen den Realismus als rein vormoderne Opposition zum modernen Erzählen. Näher dazu siehe W. Rohe, Roman aus D isk ursen. G ottfried Keller ,D er grüne H einrich' (E rste Fassung; 1854/ 55). München 1993, bes. S. $237 f$.

7 Vgl. V. Zmegac, Zum Problem der Romantheorie, in: P. M. Lützeler (Hrsg.), D eutsche Romane des 20. Jahrhunderts. N eue Interpretationen, 
noch gegenstandsloser wird diese Gegenüberstellung durch den Hinweis auf jenen Konsens der Realismusforschung, daß man zwischen dem programmatischen Realismus und der poetischen Praxis bei Raabe, Fontane und Keller zu unterscheiden habe. ${ }^{8}$ Der Begriff des Realismus hat nämlich in der Umsetzung viel von seiner anfänglichen programmatischen Verbindlichkeit verloren. Ihre volle künstlerisch-individuelle Entfaltung fand die Erzählkunst der Realisten in der Ablösung vom Epochenbegriff des Realismus, insbesondere in der Distanzierung von der Verklärungsästhetik. ${ }^{9}$ Bei dieser Ablösung des Realismus vor allem in der Spätphase ist die Bewegung hin zum modernen Erzählen schwer zu formulieren, geschweige denn zu formalisieren: Die Übergänge vom Realismus zur Moderne sind eben vielfältig. Jedoch wird bei dem allgemeinen Eindruck der Progressivität des modemen Erzählens das Ankommen an den Ufern des modernen Erzählens in der Form poetologischer Kritik regelrecht ,erwartet'.10 Retrospektiv wird für das Verständnis des späteren realistischen Romans die danach eintretende Entwicklung der Erzählkunst zum Maßstab genommen. Häufig wird dabei der moderne Roman zum psychologischen Roman bzw. Bewußtseinsroman singularisiert. Singularisierung und Retroperspektivismus sind nun einmal unsere üblichen Denkfehler beim Verstehen von Geschichtlichkeit. Der Geschichtlichkeit kann auch die Literaturgeschichte nicht entrinnen.

Die Suche nach der Modernität, die dem in der letzten Zeit zunehmenden Forschungsinteresse an den realistischen Spätwerken generell zugrundeliegt, schließt sich unwillkürlich an einen literaturwissenschaftlich inzwischen etablierten Begriff an: den D isk urs. Die diskursanalytische Deutung lenkt die Aufmerksamkeit darauf, daß das Sprachmaterial im Roman nicht, unschuldig' ist, sondern im diskursiven Zusammenhang steht. Der vorgeprägte Redecharakter des Romans, der gerade in der realistischen Prosa besonders zum tragen kommt, wirft die Frage der Schriftlichkeit der Romanform auf, etwa im Unterschied zum Epos. Für die Gattung des neuzeitlichen Romans, die ihren Ursprung - anders als traditionsreichere Gattungen wie Epos oder Lyrik - in einer Zeit hat, als sich die schriftliche Kommunikation durchsetzte und von Typographen befördert wurde, ist Schriftlichkeit beinahe ,gegeben'. Die Geschichte des Romans im 19. Jahrhundert ist damit u.a. als die Geschichte der Selbstvergewisserung dieser genuin schriftlichen Kunstform gegenüber der Oralität begreifbar, als ein Prozeß, um die Schriftlichkeit des Romans auszubauen.

Auch für die romantheoretische Reflexion des 19. - sowie im übrigen auch unseres eigenen - Jahrhunderts ist diese Tendenz kennzeichnend. Das an der Schriftlichkeit orientierte Romanverständnis behandelt den Redecharakter des Romans und dessen Konsequenz für die Entwicklung des modemen Romans stiefmütterlich, d.h. nur im Sinne von ,Aufstörung des schriftlichen Prinzips des Romans'. In weit stärkerem Maße als von der romanpoetologischen Forschung heute berücksichtigt, konfrontiert die literarische Moderne als erste deutlich Rede- und Schriftcharakter. So gesehen kann die Konstellation 0 ralität-Schriftlichkeit einen weiteren Anhaltspunkt dafür bieten, ,Übergänge' zwischen dem realistischen Erzählen eines Raabe, eines Fontane und eines Keller, um nur einige zu nennen, und dem modernen Erzählen zu beleuchten.

Diese Forschungsperspektive wird im folgenden mit Hilfe von zwei romantheoretischen Ansätzen, jeweils mit dem Schwerpunkt auf Schriftlichkeit bzw. O ralität, näher erläutert. Die relativ detaillierte Beschäftigung mit dem Komplex O ralität-Schriftlichkeit sei nun in dem Sinne zu verstehen, daß damit ein kommunikationstheoretischer, romanpoetologischer Rahmen von allgemeiner historischer Bedeutung abgesteckt wird, um das ,Realistische' und das literarisch ,Moderne' im Übergang zu denken. Es geht also um Erstellung eines kategorialen Kontextes, in dem solche Begriffe wie Funktion, Technik und Realismus sowie literarische Moderne aufeinander bezogen gedacht werden können.

\section{II}

Zunächst möchte ich eine Romantheorie vorstellen, die den Roman grundsätzlich auf Schriftlichkeit festlegt und somit den Redecharakter der Sprache im Roman und dessen Konsequenzen systematisch leugnet. Es ist dies die romangattungstheoretische und -geschichtliche Reflexion, die man bei dem Philosophen Hans Blumenberg findet. Ihr liegt eine Typologie verschiedener Wirklichkeitsbegriffe zugrunde, die Blumenberg historisch ableitet. Die von

Königstein/ Ts. 1983, S. 15-30, hier S. 25.

8 Z ur realistischen Programmatik: Realismus und G ründerzeit. Manifeste und D okumente zur deutschen Literatur 1848-1880, M. Bucher / W. Hahl u. a. (Hrsg.), 2 Bde., Stuttgart 1975f.; U. Eisele, Realismus und Ideologie. Zur Kritik der literarischen Theorie nach 1848 am Beispiel des "deutschen M useums". Stuttgart 1976. Zur realistischen Programmatik in der späteren Entwicklung und Konfrontation mit der poetischen Praxis siehe ders., D er D ichter und sein D etektiv. Raabes „Stopfk uchen“ und die Frage des Realismus. Tübingen 1979. Zu den Gemeinsamkeiten zwischen realistischer Programmatik und realistischer Praxis siehe H. Widhammer, Realismus und klassizistische Tradition. Zur Theorie der L iteratur in D eutschland 1848-1860. Tübingen 1972, besonders S. 27.

9 So stellt F. Martinis literaturgeschichtliche Epochendarstellung (D eutsche L iteratur im bürgerlichen Realismus 1848-1898. Stuttgart 19621, 19814), durch die das gegenwärtige Epochenverständnis geprägt ist, die unterschiedliche Art und Weise der Auflösung des programmatischen Realismus bei den späteren Realisten in die Nähe des modernen künstlerischen Individualismus.

10 Als Beispiel für eine solche Verfahrensweise sei hier auf die Arbeit von E. Graef (M artin Salander. Politik und Poesie in Gottfried Kellers $\mathrm{G}$ ründerzeitroman. Würzburg 1992) hingewiesen, auf die ich im Keller-Teil eingehen werde. 
ihm herausgearbeiteten vier Gestalten des Wirklichkeitsbegriffs sind die "Realität der momentanen E videnz",11 die „garantierte Realität", 12 die Realität als „Realisierung eines in sich einstimmigen Kontex tes" 13 und die „Realität als das dem Subjekt nicht $\mathrm{G}$ efiugige". ${ }^{14}$ Sie werden von Blumenberg jeweils unterschiedlichen Epochen zugeordnet: der Antike, dem Mittelalter, der Neuzeit und der Moderne. Unter den vier Konzeptionen tritt die dritte insofern hervor, als Blumenberg dem dritten Wirklichkeitsbegriff, der Realität „als sich konstituierende[m] Kontext",15 eine Leitfadenfunktion in der europäischen Kunsttradition zuschreibt. Insbesondere für die Romangattung, für die die Form der linearen Konsistenz in einem Raum-Zeit-System gattungsnotwendig sei, ${ }^{16}$ spielt sie eine konstitutive Rolle. Es ist „ein der immer idealen G esamtheit der Subjekte zugeordneter G renzbegriff, ein Bestätigungswert der in der Intersubjek tivität sich vollziehenden Erfahrung und Weltbildung ". ${ }^{17} \mathrm{Im}$ Gegensatz zu den antiken und mittelalterlichen Wirklichkeitsbegriffen eröffnet dieser Wirklichkeitsbegriff dem menschlichen Bewußtsein den „übergreifende[n] und umgreifende[n] Horizont der Zeit“.18 Dabei stellt der vierte Wirklichkeitsbegriff nur die Konsequenz der Eigenschaft dar, die der dritte Wirklichkeitsbegriff mit einem Zeitbezug besitzt. Der Einbruch der widerständigen, beunruhigenden und nicht selten bedrohlichen Realität des vierten Wirklichkeitsbegriffs wird im dritten Wirklichkeitsbegriff zwar vorbereitet, ${ }^{19}$ geschieht aber gleichwohl unerwartet. Für Blumenberg ist dieser ,Punkt des Umschlages' mit einer, Unmöglichkeit des Erzählens' verknüpft. D estruierend wirke der Übergang vom dritten zum vierten Wirklichkeitsbegriff für den Roman. Gerade darin konstatiert Blumenberg das Ende der Romangattung, in ihrer besonderen Leistung für den Wirklichkeitsbegriff. Blumenberg skizziert eine Art Bewußtseins- bzw. Geistesgeschichte aus, in der die Romankunst als besonders geeignetes Medium für eine Entwicklungsstufe des Bewußtseins entsteht und abstirbt. Seine historische Wirklichkeits-Typologie und die darauf basierende Romantheorie stützen sich also besonders auf die bewußtseinsformierende Wirkung der Geschichte. Abweichend von der Blumenbergschen philosophiegeschichtlichen Konzeption, sind aber die Wirklichkeitskonzepte, wie wir sie in der Literatur vorfinden, gleichzeitig vorhanden. Dies wird deutlich beim realistischen Roman: Durch die D arstellung der Realität, in der die historischen Wirklichkeitsbegriffe eine Rolle spielen, bedient sich der realistische Roman des Repertoires der verschiedenen Wirklichkeitsbegriffe. ${ }^{20}$ Es besteht also keine monolithische Beziehung zur neuzeitlichen kontextuellen Realität, sondern im Roman können auch „ältere Realitätskonzepte als Form für moderne Realitätserfahrungen gewählt werden “. ${ }^{21} \mathrm{D}$ as bedeutet, daß sich der Roman schon längst vor seiner Krise der Alleinherrschaft des dritten Wirklichkeitsbegriffs entzogen hat - oder daß er von Anfang an ihr entrückt gewesen ist.

Den heterogenen Wirklichkeitsbegriff erkennt Blumenberg nur als eine die Wirklichkeitskonzeption des offenen Kontextes ablösende, moderne und dem Subjekt widerstehende Realität an. Sie tritt als die enttäuschende Realitätserfahrung in vielen Romanen der europäischen Realismen auf, in denen es um ,Desillusionierung' geht.22 Auf die Romanform wirkt sich diese Erfahrung der Realität nach Blumenberg aber erst dann aus, wenn sie "nicht nur als die Erfahrung des Berührens", „sondern auch und in letzter Zuspitzung in der logischen Form des Paradoxes"23 auftritt. Die Auswirkung des Paradoxes auf die Romanform ist für Blumenberg gerade gattungdestruierend. D as Paradox und der heterogene Wirklichkeitsbegriff sind Blumenberg zufolge ungeeignet für den Roman: „D as Ideal der perfetta deformità ist für den Roman undurchführbar.“24 Dabei ist das Paradox ein Verweis auf die seit der Antike wirkende Erfahrung der Realität als das dem Subjekt Unverfügbare, darin dem überkommenen Modell des ,Schicksals' vergleichbar. So wie das Paradox traditionell „zur bevorzugten Zeugnisform der Theologie werden konnte, die gerade in der Ärgerlichkeit und Anstößigkeit des logisch inkonsistenten Gehaltes den Ausweis einer letzten, das Subjekt niederzwingenden und zur Selbstaufgabe fordernden Realität sieht", 25 bezieht es sich auf jene Art der Begegnung mit dem Fremden, welche die Preisgabe der einstimmigen Kontextualität

11 H. Blumenberg, W irk lichk eitsbegriff und Möglichk eit des Romans, in: H. R. Jauß (Hrsg.), N achahmung und Illusion. Poetik und H ermeneutik Bd. I. München 1969, S. 9-27, hier S. 10.

12 Ebd., S. 11.

13 Ebd., S. 12.

14 Ebd., S. 13.

$15 \mathrm{Ebd}$.

16 Vgl. ebd., S. 23.

17 Ebd., S. 13.

18 Ebd.

19 Vgl. ebd., S. 24.

20 H. Turk, D ie Schrift, S. 401.

$21 \mathrm{Ebd}$.

$22 \mathrm{G}$ enau in diesem Sinne schreibt Lehrer dem letzten Wirklichkeitsbegriff von Blumenberg eine Schlüsselposition sowohl in der Literatur des gesamteuropäischen wie auch des deutschen Realismus zu. (Vgl. ders., Intellektuelle A porie und literarische Originalität. W issenschaftsgeschichtliche Studien zum deutschen Realismus: Keller, Raabe und F ontane. Berkeley 1986, S. 2.)

23 H. Blumenberg, W irk lichk eitsbegriff, S. 14. Lehrer weist auch darauf hin, daß die vierte Realitätserfahrung in der Intensität und den logischen Konsequenzen als Paradox nicht als allgemeines Charakteristikum des deutschen oder europäischen Realismus zu gelten habe, sondern in ihrer jeweiligen Ausprägung in einzelnen Werken von Keller, Raabe und Fontane als Besonderheit dieser Autoren zu betrachten sei. (Vgl. M. A. Lehrer, Intellek tuelle A porie, S. 2f.)

24 H. Blumenberg, W irk lichk eitsbegriff, S. 27.

25 Ebd., S. 14. 
erzwingt. Anstelle der perspektivischen Einstimmigkeit, der geschlossenen Sinneinheit und des konsequenten D enkens tritt nun das Rätsel des Lebens auf: „das Paradox, die Inkonsistenz der Träume, die ostentative Sinnwidrigkeit“ .26 Diese „im W iderstand okkurrierende Wirklichkeit“ werde, so Blumenberg, für den Roman nicht wirklich zum Thema, da er sich „besonders resistent gegen die paradoxystische Konsequenz des Prinzips“27 erwiesen hat. Der Roman könne aufgrund der „Zugehörigkeit [...] zum Wirklichkeitsbegriff der immanenten Konsistenz", sich „nicht einfach am [sic!] Widerspruch zu dem, was jeweils der Wirklichkeit als signifikanter Ausweis zugeschrieben wird, realisieren. “28 So schreibt Blumenberg dem Roman einen Realismus aus der Perspektive der Wirklichkeit als ,Realisierbarkeit' zu. Es ist dies ein Realismus, der Blumenberg zufolge nichts mit dem Ideal der Nachahmung zu tun und sich aus der Gattungsgesetzlichkeit des Romans heraus entwickelt hat. Blumenbergs Freisprechung des literarischen Realismus vom Nachahmungsideal zielt so auf den Realismus des Romans als Text, auf den Realismus des Textes. Dieser Realismus ist nämlich ein durch textuelle G eschlossenheit zu gewährender und korrespondiert so mit der Idee der Autonomie des Ästhetischen, deren konsequente Durchführung aber dem Roman als Kunst der Schriftlichk eit verwehrt ist. Der Roman, dem Blumenberg als Gattung das Ende bzw. die Krise ankündigt, ist nur auf einen bestimmten Romantyp beziehbar. Es ist dies der Roman, bei dem das sich formierende Bewußtsein zum vollen Tragen kommt, der also mit dem Prinzip der Schrift zutiefst verbunden ist.29 Die ,Schwierigkeit' des Romans mit dem Paradox, die Blumenberg zur gattungsgenetischen erklärt, ist nichts anderes als jene Schwierigkeit, welche das Prinzip der Schrift selbst mit seinem Anderen hat. Den literarischen Gegenbegriff des Heterogenen und Synkretistischen, um den es hier letztlich geht, kann man aber mit Hilfe des Paradoxes nur unzulänglich herausarbeiten: Indem das Paradox sich auf jene Q ualität der Realiät bezieht, die den Wirklichkeitsbegriff als einstimmigen Kontext sprengt, suggeriert der Begriff des Paradoxes unausweichlich die Totalität, das System. Er hebt gerade den Ausnahme-Charakter der als paradox zu bezeichnenden Realität hervor und bestätigt - paradoxerweise stillschweigend den Universalanspruch der einstimmigen Kontextualität. D as Wort Paradox deckt das Phänomen der literarischen Synkretisierung nicht ab, sondern zeigt jenes lediglich an, und zwar mit einem negativen, eben ,bedrohlichen' Nebengeschmack, entsprechend seiner abseitigen Rolle in der abendländischen Philosophiegeschichte. Ähnlich wie der Romanautor in der Krise des Romans für die Notwendigkeit dieser Krise eintritt, plädiert Blumenberg in der philosophischen Sprache für die strukturell notwendige Krise zwar nicht der Philosophie, wohl aber des Schreibromans. In der Krise des Romans drückt sich dann die Krise des modernen Individuums als des erlebenden und denkenden Subjekts aus. In dieser Verschränkung zeigt sich die aristotelische Tradition, die die ästhetische Illusion mit der ästhetischen Erfahrung schlechthin gleichsetzt und damit den Wert des Erzählens auf die Form der kontextuell illusionistischen Welthaftigkeit des Romans reduziert.

Der Blick auf eine andere ästhetische Dimension des Erzählens, welche in der europäischen Kulturtradition zunehmend verlorengegangen ist, öffnet sich erst mit der Perspektivenverlagerung auf andere Traditions- und Kulturräume. Angesichts der nichteuropäischen Moderne und ihrer Romane erweist sich die Gattung des Romans letztendlich doch als paradox-kompatibel. So werden in der postmodernen Fiktion die Paradoxe zum Gesetz des Universums erklärt, wie das Paradox zum Gesetz des Erzählens. ${ }^{30}$ D amit verbunden ist der erzählerische Umgang mit der Welt, der sich im synchronisierenden Austausch mit anderen Stimmen letztlich dem Oralitätsprinzip annähert. Wie die Vergangenheit des Erzählten bei der kommunikativ-mündlichen Vermittlung von Erfahrungen von der G egenwart des Erzählens nicht abgekoppelt ist, sondern deren Verhältnis zueinander ,lebendig` bleibt, ist hier der disours der histoire im Erzählen nicht einseitig untergeordnet.

Das Erzählen als kulturellen Diskurs entdeckt man zudem im Rahmen des europäischen Romans in seiner Variante als D iskursroman, in dem die histoire durch den disours, d.h. das G eschichtenerzählen durch die Analyse der kulturellen Bedeutung des Geschichtenerzählens, ersetzt wird. Neben dem Erzähltyp eines dem disoours vorgeordneten Sinnzusammenhangs stellt der Diskursroman gleichsam einen Roman zweiter Ordnung dar: Dieser parodiert das dramatische, realistisch-illusionistische Erzählmodell. Über eine das histoire-Erzählen parodierende Narration hinaus geht der Diskurscharakter des europäischen Romans erst dann, wenn die Krise des Romans zum großen Teil von der Bestrebung begleitet wird, auf die vormoderne Form des Epos zurückzugreifen: Die Wiederkehr des Epos im Sinne der O ralität als eigentlich moderner Q ualität führt den Roman in den ,oralen D isk urs'.

Die Möglichkeit der postmodernen Fiktion und die Möglichkeit des Romans als Diskursformation verweisen auf nichts anderes als auf die innere Spannung, die dem modernen Roman innewohnt. Faßt man, wie Blumenberg, diese Spannung ausschließlich von der Perspektive der Schriftlichkeit und der ihr entsprechenden Wirklichkeitsvorstellung her auf, dann wird der Zusammenhang zwischen dem Wirklichkeitsprinzip und der bestimmten Romanform nicht in seinem Funktionswert begriffen, sondern als substantiell, etwa als das Romanhafte

26 Ebd., S. 26.

27 Ebd., S. 22f. (Fn. 15)

28 Ebd., S. $26 f$.

29 W. Benjamin nennt das gleiche Phänomen in genetisch-romantheoretischer Perspektive den Schreibroman. Näheres dazu später.

30 Vgl. C. Rincón, Borges und Garća Márquez oder: das periphere Z entrum der Postmoderne, in: R. Weimann / H.U. Gumbrecht (Hrsg.), Postmoderne - globale D ifferenz. Frankfurt/ M. 1991, S. 246-264, hier S. 255. 
schlechthin oder als "gattungsnotwendig", ${ }^{11}$ verabsolutiert. Die Bindung von Wirklichkeitskonzept und Romanform ist u.a. medialer Art, daher funktional, d.h. von ihrer mentalen zivilisatorischen Bedeutung her, zu verstehen.

\section{III}

Diese Perspektive wird bereits von W. Benjamin und W. Ong ${ }^{32}$ vertreten, allerdings mit unterschiedlichen Akzenten und Konsequenzen. Diesen wird im folgenden die Aufmerksamkeit gewidmet.

Das theoretische Umfeld, in dem Benjamin das mediale Bedingtsein des Erzählens und des Erzählten in seiner kulturkritischen Prägnanz thematisiert, ist dabei durchaus aktuell. Es bezieht sich auf die Epochenproblematik der Moderne als einer kulturellen und gesellschaftlichen Erfahrung, die jetzt, in einem neuen historischen, ja globalen Z usammenhang, nämlich im Rahmen der Postmoderne, emeut gestellt wird. ${ }^{33}$ Die Vertreter der Postmoderne leiten den Umschlag der Industriegesellschaft in die nachindustrielle ,Kulturgesellschaft' von dem Wandel in den Kulturverhältnissen, den weltweiten Prozessen der Veränderung auf der Ebene der gesellschaftlichen Kommunikation ab. Gegen den Paradigmenwechsel von der Moderne zur Postmoderne setzen die Vertreter der Moderne noch auf die zivilisatorische Synchronisierung der Mentalitäten untereinander unter den Bedingungen der Industriegesellschaft. 34

Die Synchronisation der Mentalitäten stellt gleichwohl die Fordenung verschiedener historischer und politischer Konzepte der 20er Jahre zur Überwindung der Modeme dar, nämlich das Bedürfnis nach dem Sich-Austauschen der modernen Individuen, die Suche nach der E inswerdung. D as Sich-Ö ffnen der literarischen Wahrnehmung gegenüber ihrer Umgebung, der Lebensweise der Industriegesellschaft, durch die beide sychronisiert werden können, bildet den Leitfaden jener romantheoretischen Überlegung, die Benjamin als einer der Vertreter der konsequenten Moderne lieferte: Von der herrschenden Tradition einer Geschlossenheit bis hin zur Selbstbezüglichkeit war auch die Entwicklungstendenz der Erzählweise des im 18. Jahrhundert entstehenden modernen Romans geprägt. Von E. v. Kahler mit der Formel von der „Verinnerung des E rzählens“"35 gekennzeichnet, liegt dieser Entwicklung - die in der avantgardistischen Moderne, im Euvre Becketts und in der G attung des N ouveau roman gipfelt -, abgekürzt gesagt, das Prinzip des cartesianischen Subjekts zugrunde, dessen Cogito mehr auf die Entdeckung des eigenen Selbst als auf die Außenwelt gerichtet ist.

Benjamin bezeichnet, vor dem Hintergrund des gesamtkulturellen Kontextes der Folgen von Verschriftlichung der Literatur und der Normierung von Sprache durch den Buchdruck, ${ }^{36}$ jene Romantradition mit dem Begriff des Schreibromans. Unter dem Begriff des Schreibromans, der die Schriftlichkeit, aber auch die damit verbundene Krise der kulturellen Moderne am reinsten ausdrückt, sind neben dem Bildungsroman auch der objektive ,realistische' Roman des 19. Jahrhunderts in seiner kanonbildenden Bedeutung sowie dessen Fortsetzung im 20. Jahrhundert subsumierbar. Es ist dies jene Romantradition, die unterdessen in die ,K risis' eingemündet ist. ${ }^{37}$

Für Benjamin bedeutet die Verstärkung der Schriftlichkeit gerade das, was eigentlich „den G eist des Erzählens“ verstört, ja „zum gefährlichen Verstummen des inneren Menschen“38 am meisten beigetragen hat. Freilich liegt hier die poetologisch gehaltvolle Opposition von ,Erfahrung und Erlebnis'39 zugrunde, und zwar um die Medialiät verschärft: Die Schriftlichkeit als mediales Prinzip für die Nicht-Kommunikation des modernen Individualismus, für die Nicht-Mitteilbarkeit des individuellen Erlebens, im Kontrast mit der O ralität als Prinzip für die Kommunikation,

31 H. Blumenberg, W irk lichk eitsbegriff, S. 27.

32 Ein wichtiger Vertreter des Forschungsfeldes von Oralität und Schriftlichkeit. Zum Überblick über diese Forschungsrichtung, insbesondere hinsichtlich der Forschungsergebnisse als auch offener Forschungsaufgaben, eignet sich W. O ngs 0 ralität und L iteralität. D ie Technologisierung des W ortes, O pladen 1987. Zum Einblick in einzelne Forschungsarbeiten siehe den Aufsatzband von J. Goody / I. Watt / K. Gough: E ntstehung und F olgen der Schriftkultur. Mit einer Einleitung von H. Schlaffer, Frankfurt/ M. 1991.

33 Diese epochenproblematische Bedeutung des Begriffs der Moderne gilt auch für die vorliegende Arbeit insgesamt: Ich benutze den Begriff der Moderne in dem umfassenden Sinne einer kulturellen und gesellschaftlichen Erfahrung. Was ich mit der Titelformulierung „Erfahrung der Moderne“ anvisiere, sind nicht etwa die Herausforderungen durch die neuen naturwissenschaftlichen Erkenntnisse oder durch die Denkrevolutionen, die sich mit dem Namen Nietzsche verbinden. Es sind in erster Linie Sozialerfahrungen, die mit Institutionen wie „Eigentum“, „,Öffentlichkeit", „Familie“, „D emokratismus“ u.a. im Zusammenhang stehen.

34 Vgl. hierzu H. Lethen, L ob der Kälte. E in M otiv der historischen A vantgarden, in: D. Kamper / W. Reijen (Hrsg.), D ie unvollendete V ernunft: M oderne versus Postmoderne. Frankfurt/ M. 1987, S. 282-375.

35 Siehe dazu E. v. Kahler, D ie V erinnerung des E rzählens, in: ders., U ntergang und Ü bergang. E ssays. München 1970, S. 52-197.

36 Vgl. W. Benjamin, D er E rzähler. Betrachtungen zum W erk N ikolai L essk ows; Krisis des Romans. Zu D öblins ,B erlin A lex anderplatz', in: ders., G esammelte Schriften. Bd. II. 2. Hrsg.v. R. Tiedemann / H. Schweppenhäuser. Frankfurt/ M. 19893, S. 438-445 und Bd. III. S. 230-237. Zu Benjamins romanpoetologischem Konzept im Interesse der kommunikationstheoretisch-romanpoetologischen Position siehe A. Poltermann, Künstlerisch avancierte V erfahren perspek tivischen E rzählens in der deutschsprachigen Literatur des 18. und 19. Jahrhunderts. H istorische Beobachtungen und poetologische Ü berlegungen, in: D. Kullmann (Hrsg.), E rlebte Rede und impressionistischer Stil. E uropäische E rzählprosa im V ergleich mit ihren deutschen Ü bersetzungen, Göttingen 1995, S. 29-69, hier besonders S. 29-37.

37 Benjamin sieht in André Gides Idee vom roman pur, die dieser im autobiographischen Kommentar seines letzten Romans Tagebuch der Falschmünzer entwickelt, das Ideal der modernen Romantradition im Sinne Flauberts: den reinen Schreibroman. Vgl. W. Benjamin, Krisis des Romans, S. 231f.

38 W. Benjamin, Krisis des Romans, S. 231.

39 Siehe dazu W. Benjamin, 0 sk ar M aria G raf als E rzähler, in: ders., G esammelte Schriften. Bd. III., S. 310. 
d.h. Mitteilbarkeit der gesellschaftlichen Erfahrung. Die ins Intérieur eingegangene Selbstbezüglichkeit des Subjekts im Sinne Adornos ${ }^{40}$ korrespondiert mit der Kommunikationssituation des Schriftstellers des modernen Schreibromans, der arm an mitteilbarer E rfahrung ist und an dem Widerspruch zwischen seiner isolierten Arbeitssituation sowie der Vermittlung seines Produktes als Ware - des Schreibromans - an den Leser leidet.

So knüptt der neue epische Roman Benjamins unter den Bedingungen der Moderne an das Konzept der mündlichen Vermittlung von Erfahrungen an, an die orale, öffentliche Dimension als Erbe der dem Erzählen eigenen Erfahrungsorientierung. Das Epische des epischen Romans wird von Benjamin wie Döblin in seinem ursprünglichen, etymologischen Sinn gedacht, nämlich als ,Orales', ,Stimmliches',11 im Gegensatz zum Epischen als gemeinschaftsstiftende Darstellung und Totalität, das bekanntlich von vielen Romantheorien des 19. Jahrhunderts propagiert wurde.

Bei dem modernen Erzählen läßt sich übrigens, unter dem Gesichtspunkt der Opposition von Oralität und Schriftlichkeit, eine doppelte Linie feststellen. Der moderne Roman überwindet nämlich die Krise der Moderne in der Form einer Ästhetik des geschriebenen Wortes oder einer Ästhetik des mündlichen Geschichtenerzählens. Setzt die erste ästhetische Position die Schriftlichkeit fort bzw. forciert sie diese, löst die zweite sie durch das O ralitätsprinzip ab. ${ }^{42}$ Benjamins neuer epischer Roman und Döblins praxisbezogenes Romanprogramm sind der zweiten Linie zuzurechnen. ${ }^{43}$ So, in seiner vollen Zustimmung zum Döblinschen „Erstarken[] des Radikal-Epischen" ${ }^{44}$ rät Benjamin dem Leser davon ab, bei der ungewöhnlichen "Gischt der wirklichen gesprochenen Sprache" in Döblins Erzählen "mit Kunstausdrücken zu operieren, vom ,dialogue intérieur' zu reden oder auf Joyce zu verweisen.. ${ }^{45}$ D enn in „Wirklichkeit handelt es sich um etwas ganz anderes“, nämlich um das „Stilprinzip [...] [der] Montage" ${ }^{46}$ welches sich nicht für den modemen psychologischen Roman eignet, sondem das im Gegenteil seine Alternative eröffnet.

Gegenüber einem solchen offenen, bewußten Zugeständnis an die Oralität, das bei den modernen ,Epikern', Benjamin und Döblin, vorliegt, bezeugt der Roman des 19. Jahrhunderts lediglich partielle Erfahrungen mit der O ralität. D ie Berufung auf die orale Kultur geht im Kontext des 19. Jahrhunderts meistens über eine romantische Zivilisationskritik nicht hinaus. Sie scheint auch romanästhetisch unfruchtbar geblieben zu sein. Die tatsächliche Produktion richtete sich vorrangig auf die ,Schriftlichkeit' in ihren psychodynamischen Konsequenzen. Den unterschiedlichen Romantypen, die durch das 19. Jahrhundert hindurch entwickelt wurden, wie der objektive ,dramatische' Roman sowie der Bildungsroman, liegt jeweils eine Vorstellung von der richtigen, ,realistischen' D arstellungsweise ${ }^{47}$ zugrunde. D iese zielt letztlich auf die Verschmelzung von Illusionismus und Textualität im Sinne einer (Ab)-G eschlossenheit.48

Wie sich diese romanpoetologische Bedeutung der Schriftlichkeit im späten realistischen Roman in dessen Abgrenzungs- bzw. Übergangsposition zur literarischen Moderne manifestiert, ist die Frage, die sich hier anschließt.

Als Teil der modernen G eschichte gilt freilich für die Literaturgeschichte die allgemeine Dynamik der Moderne: In der Geschichte der Moderne und ihrer Gesellschaft werden Bewegung und Veränderung vor allem in der Weise

40 Th. W. Adorno, Kierkegaard. Konstruktion des Ä sthetischen. Frankfurt/ M. 19862. Zur ästhetisch konstitutiven Bedeutung für den modernen Roman, die das Intérieur als Innenraumsymbolik erhält, siehe C. Becker, Zimmer-Kopf-W elten. M otivgeschichte des Intérieurs im 19. und 20. Jahrhundert. München 1990, besonders Vorwort, S. 9.

41 Siehe zur Frage von Begriffsüberschneidung und -unterschied zwischen O ralität und Epos W. Ong, O ralität und L iteralität, S. 21. Ong greift, um die widerspruchsvolle Bezeichnung der ,oralen Literatur' zu klären - eine Bezeichnung, in der sich das allgemein verbreitete Unverständnis gegenüber dem Unterschied zwischen O ralität und Literalität widerspiegelt -, auf Northrop Frye (T he A natomy of Critiscism, Princeton 1957) zurück. Wie Frye kann man, so Ong, „alle rein orale Kunst mit dem Wort ,Epos' bezeichnen, das die gleiche urindoeuropäische Wurzel, wekw-, wie das lateinische vox und sein englisches Äquivalent, voice' (Stimme) hat und somit fest im Vokalen, im Oralen verankert ist". Diese Möglichkeit sei jedoch unzureichend, u.a. weil bei der geläufigeren Verwendung der Begriff ,epos' als eine festgefügte $G$ attungsbezeichnung für die (orale) epische Dichtung gebraucht werde. Es bleibe deswegen unverändert bei dem Fehlen eines G attungsbegriffs, „der sowohl rein orale Kunst als auch Literatur umschlösse.“ (Ebd.)

42 Vgl. D. Scheunemann, Romank rise. D ie E ntstehungsgeschichte der modernen Romanpoetik in D eutschland. Heidelberg 1978, S. 107.

43 Döblin verkündet „die Parole: Los vom Buch“ (ders., D er Bau des epischen W erk s, in: ders., A ufsätze zur L iteratur., Olten; Freiburg 1963, S. 103-132, hier S. 132): „[I]ch [halte] die Befreiung des epischen Werkes vom Buch für schwierig, aber nützlich [...], nützlich insbesondere in Hinsicht auf die Sprache. Das Buch ist der Tod der wirklichen Sprache. Dem Epiker, der nur schreibt, entgehen die wichtigsten formbildenden Kräfte der Sprache." (Ebd.)

44 W. Benjamin, Krisis des Romans, S. 231.

45 Ebd., S. 232.

46 Ebd.

47 Mit der richtigen, ,realistischen' Darstellungsweise standen üblicherweise solche Termini bzw. Gesichtspunkte wie die epische Objektivität, der Ausschluß von Reflexion und Ironie sowie die epische Totalität im engen Zusammenhang. Das Zurücktreten des Erzählers, die Bevorzugung des Dialogs und die dramatische Einheit der Handlung durch die Vermeidung des beschreibend ausgemalten Details sowie jeder anderen Art funktionsloser Digression wurden dabei u.a. als Verfahrensweise angesehen, durch die die ,realististische ${ }^{\prime}$ Darstellung erreicht Effekt wird. (D azu siehe A. Poltermann, V erfahren, S. 52f.).

48 Zum widersprüchlichen Verhältnis von Kunstwerk und Realität als Dilemma des illusionistischen Realismusverständnisses siehe F. Gaede, Realismus von Brant bis Brecht. München 1972, S. 8: „Wie der Gegenstand nicht in seinem Begriff, so kann die Wirklichkeit nicht in ihrem Abbild aufgehen. Das Verhältnis von Kunstwerk und Realität ist dialektischer Natur: je wahrscheinlicher und geschlossener ein literarisches G ebilde wirkt, je mehr es Eigenwelt ist, desto weniger läßt es sich als realistisch begreifen. Die Überlegungen zum Realismus müssen deshalb von dem Widerspruch ausgehen, der zwischen gestalteter und empirischer Realität besteht. Nicht in den Möglichkeiten der Entsprechung, sondern in ihrer Unmöglichkeit liegt der Kern des Problems." 
vorangetrieben, daß nicht das Alte durch das substantiell Neue abgelöst wird, sondem daß nur die Konstellation zwischen den ungelöst bestehenden Problemen sich stets wandelt. Die heute geführte Debatte über ,Moderne' und „Postmoderne' differenziert und modifiziert unseren Begriff der Moderne. Dabei schärft sich vor allem der Blick für die innere Struktur des Phänomens der ,Ungleichzeitigkeit', das auch für das Urteil über den ,zweitrangigen' deutschen Realismus einschlägig ist. Die Ungleichzeitigkeit beschränkt sich jedoch keinesfalls auf Deutschland und auf das 19. Jahrhundert, sondern sie trifft auf alle Gesellschaften, insbesondere außerhalb des westeuropäischen und nordamerikanischen Raums, gerade auch im 20. Jahrhundert zu. Dabei wird die Moderne unter der Bedingung der nachkolonialistischen Abhängigkeit von größerer ,Ungleichzeitigkeit', von schärferen Widersprüchen und unvorhersehbareren Folgen bestimmt, als die europäische Moderne sie kennt. Potenziert werden die Ungleichzeitigkeit und damit die Desorientierung dieser weiten Teile der Welt durch den westlicherseits erklärten Vollzug und Abschluß der Moderne hin zur Postmoderne. Paradoxa des Projekts der Modeme an der Peripherie und die Widersprüche der K rise der Modernisierung unter den Bedingungen postkolonialer Abhängigkeit sind, wenn man so will, ,paradoxer' als in der westlichen Gesellschaft. Im Bewußtsein solcher Komplexität, die bei all jenen Gesellschaften zu finden ist, die noch am bloßen Anfang ihrer Modeme stehen, kann die Behandlung des deutschen Realismus einen Dialogcharakter zwischen der europäischen Erfahrung der Moderne und der Moderne-Erfahrung anderer Kulturen annehmen.

Vor diesem geweiteten Horizont tritt die O pposition von Schriftlichkeit und Mündlichkeit umso gehaltvoller auf. Während Benjamin sie romanpoetologisch und kulturkritisch, d.h. europäisch kultur- und mentalgeschichtlich perspektiviert, wird sie von der späteren Forschungsrichtung durch Ong u.a. in ihrer die gesamte Menschheit umfassenden historisch-kommunikationstechnischen Dimension vertreten. Von dem technologischen Umbruch durch die Elektronik beeindruckt, zeichnet diese Forschungsrichtung zu Schriftlichkeit und Oralität nach, welch tiefgreifende Wirkung die Materialität der menschlichen Kommunikation auf die Gesamtkultur hat. Diesem Ansatz zufolge schärft sich nämlich der Blick für die Entstehung und die Folgen der Schriftkultur angesichts der ,zweiten O ralität', d.h. angesichts der kulturellen Konsequenzen der Ablösung von Schreiben und Lesen durch medial vermitteltes Sehen und Hören. Mehr deskriptiv als kulturkritisch betrachtet Ong den Prozeß der Verstärkung der Schriftlichkeit. So sieht Ong, vor der Folie der technischen Perfektionierung der G eschlossenheit des Erzählplanes, im Kriminalroman den literarischen Inbegriff bzw. Gipfel der Schriftlichkeit.49

Trotz ihrer romanpoetologisch divergierenden Konsequenzen überschneiden sich die beiden Theorien von Benjamin und Ong in einem Punkt. Es ist dies die formkonstituierende Bedeutung der Schriftlichkeit im Spannungsverhältnis zur O ralität, eine produktive Spannung, die vom Inneren des modernen Romans heraus zu dessen steter Wandlung beiträgt. Die Divergenz zwischen Schriftlichkeit und Oralität, die modernes Erzählen programmatisch aufgreift, wird im späten realistischen Roman zwar nicht primär ,ästhetisch', d.h. als Form und Medium, perspektiviert. Sie taucht aber auf, wenn auch verschränkt mit den Divergenzen auf der Inhaltsebene, d.h. so, wie diese im gesellschaftlichen Modernisierungsprozeß entstehen. Diese Verschränkung, in der sich der Unterschied der Kommunikationsweisen als bedeutend erweist, überrascht wenig: Schriftlichkeit und Mündlichkeit implizieren einen unterschiedlichen psychodynamischen Stellenwert, woraus sich ergibt, daß die Relation zwischen oraler und literalisierter Kommunikationsweise immer wieder zur Opposition von ursprünglicher und entfremdeter Seinsweise funktionalisiert wird. Was das moderne Erzählen ausschließlich in der literarischen Form ,mediatisiert', tritt hier noch in der Form und in der Bedeutung seiner sozialpsychologischen Funktionsimplikate auf. Man kann darin das Verhältnis von Funktion und Technik erkennen: als zusammengehörig, doch trennbar. Der Übergang bzw. die Kluft zwischen Realismus und Moderne präzisiert sich hier als Verschiebung von der Funktion zur Technik.

\section{IV}

Dieser spätrealistische Übergangscharakter zwischen Funktion und Technik, Bedeutung und Zeichen verweist darauf, daß der spätrealistische Roman sowohl von seinem Sujet als auch von der ,realistischen' Darstellungskonvention aus zu betrachten ist: Man muß „Darstellungsweisen mit Realitätsdefinitionen und Sujetwahlen korrelieren". 50

Zur in dieser Arbeit durchgeführten Korrelierungspraxis kann folgendes im Sinne einer methodischen Voraussetzung gesagt werden: Das Auswahlkriterium für die behandelten Romane ist - neben dem chronologischen Stellenwert, den Raabes Stopfkuchen. E ine See und Mordgeschichte (1893), Fontanes Frau Jenny Treibel oder ,W o sich H erz zum Herzen find't' (1892) und Kellers Martin Salander (1886) bei jedem Autor in der letzten Schaffensperiode bekommen haben - in einem noch nicht diskutierten Sinn ,realistisch', d.h. ,sujetorientiert'. Die Verknüpfung der Romane mit ihrer jeweiligen sujetmäßigen Akzentsetzung richtet sich auf das Gesamtbild eines geschichtlich-gesellschaftlichen Ganzen. Gemeint ist jenes moderne gedankliche Konstrukt der Gesellschaft als Gesamtheit der 
getrennten Handlungsbereiche wie Privatsphäre, Ökonomie und Politik. Dieser Dimensionierung entspricht der Begriff des Menschen als homme, bourgeois oder atoyen, und in einer solchen Orientierung sind die Romane in ihrer Verschiedenheit einander zugeordnet. Raabes Art, im Stopfkuchen vom Menschen episch zu sprechen, rückt mehr jenen bildungsbürgerlich geprägten Privatmenschen, den homme, in den Vordergrund, weniger sein wirtschaftliches und politisches Pendant, den bourgeois sowie den atoyen. Während Fontanes Erzählen in der Sujetwahl das Gewicht mehr auf den Sozialcharakter des bourgeois als auf die anderen beiden Typen legt, steht in der epischen Menschengestaltung Kellers der Idealtyp des atoyen im Mittelpunkt. Insofern verhält sich die Textauswahl zum Totalitätsanspruch der zu untersuchenden Epoche mimetisch. Freilich verschafft diese Betrachtungsweise nur einen ersten Einblick in das Verhältnis der Romane zur geschichtlichen E poche, das in Wahrheit komplizierter ist, als man mit dem Begriff der ,Mimesis' zum Ausdruck bringt. In der eigentlichen Interpretation des jeweiligen Romans werde ich deswegen zeigen, wie die auf der O berfläche vorherrschende Perspektive des homme, bourgeois oder atoyen die jeweils anderen Seinsweisen integriert oder diese vielmehr abblendet. Was so auf der Ebene der Handlung mit ihrem seit Aristoteles betonten Stellenwert thematisiert wird, soll, so die Verfahrensweise der folgenden Arbeit, auf der poetologischen Ebene als Frage der Romanform weitergeführt, verdeutlicht und transformiert werden. D ank seines gattungsimmanenten Anspruchs auf Referenzialisierbarkeit bewahrt der späte realistische Roman den problematischen Welt- und Realitätsbezug des modernen Individuums. Dieser Charakter muß in der Interpretation näher gekennzeichnet werden, nicht in dem Sinn, daß der Weltbezug authentisch wäre, sondern in der geschichtlichen Bedeutung, d.h. im Kontext des modernen Individuums: Das moderne Romanschreiben versucht diese problematische Lage zu verschärfen, oder es wendet sich gänzlich von ihr ab, um sich für andere Arten des Weltbezuges zu entscheiden. D er romanpoetologische Teil der Interpretation wird vor Augen führen, wie der späte realistische Roman von der erst mit dem modernen Roman konsequent auftretenden Problematik der kulturellen Modeme tangiert wird und wie er ihr als Romanform zu begegnen versucht. Die Opposition O ralität-Schriftlichkeit steht jedoch nicht im Mittelpunkt der Behandlung, wird nicht bei jedem Roman durchgängig herausgearbeitet. Die vorliegende Arbeit begnügt sich damit, den Komplex O ralität-Schriftlichkeit für die romanpoetologische Frage von Übergängen zwischen Realimus und literarischer Moderne fruchtbar zu machen. Oralität und Schriftlichkeit bilden damit eher Bezugs- als Kernpunkt meiner Argumentation. Mit ihrer Hilfe soll es gelingen, die Struktur der Übergänge zwischen Realismus und literarischer Moderne darzulegen.

Jede vorgenommene Einzelinterpretation gliedert sich aus diesem Grund in zwei Schritte, in die sujetorientierte Interpretation und in die Frage nach der Romanform. Den zwei Interpretationsstufen geht noch eine ,Problemstellung' voraus, in der ich aus dem jeweiligen Forschungszusammenhang eigene Fragestellungen zu entwickeln versuche. Wie alles Entscheidende sich zwischen den Zeilen befindet, liegt der Schlüssel der Romaninterpretion wohl in der Z wischenstufe der Überführung vom ersten zum zweiten Kapitel. In diesem Sinne versteht sich die Methode meiner Arbeit, obwohl sie sich stark auf soziologische und sozialgeschichtliche E rkenntnisse stützt, nicht als Literatursoziologie, sondern als Interpretation. 


\section{ERSTE R TEIL: W. Raabes Stopfkuchen. Eine See- und Mordgeschichte (1893) ${ }^{51}$}

\section{Problemstellung}

Innerhalb der Raabeforschung der zweiten Hälfte dieses Jahrhunderts nimmt der Stopfkuchen den Stellenwert eines Romans ein, an dem man die ganze Forschungsgeschichte in nuœ nachzeichnen kann. Die Interpretation dieses Romans ist nämlich von einer verstärkten Umschichtung des Interesses vom ethischen Gehalt zu Fragen des erzählerischen Verfahrens geprägt, wie sie für die Raabeforschung der Nachkriegszeit im Abgrenzungszwang zu der früheren Rezeption von Raabe als deutschem Idylliker - insbesondere im Zusammenhang mit der nationalsozialistischen Ideologie - insgesamt gilt. Der Z wiespalt zwischen dem idealistisch-humanistischen Menschenbild und der modernen Erzählstruktur ist, wie immer wieder von der Literatur festgestellt, das Wesentliche des Romans, ja dessen Charakteristikum geworden. So hat sich der Stopfkuchen inzwischen als literarisches Phänomen etabliert, bei dem die Dissonanz zwischen Form und Inhalt eo ipso die Modernität nahelegt, d.h. die - um mit der von $\mathrm{H}$. Plessner ${ }^{2}$ geprägten Formulierung zu sprechen - ,Ungleichzeitigkeit des Gleichzeitigen'.

Mit der Hinwendung zum Erzählverfahren hängt die Neubewertung der Nebenfigur Eduard zusammen. Vor dem Hintergrund von Raabes modernem Erzählbewußtsein, das man sogar in die Nähe von James Joyce und Thomas Mann zu rücken versucht hat,53 wird Eduard als Erzählinstanz problematisiert. Der realistische Erzählmodus des Ich-Erzählers Eduard als Biographen der Heldenfigur wird inzwischen in seiner Glaubwürdigkeit als Garant der realistischen Zeugenschaft angezweifelt, was zur gravierenden Änderung im Verständnis des Romans führt. So liegen mehrere Arbeiten ${ }^{54}$ vor, die hinter der Kulisse der emphatischen Heroisierung des Protagonisten durch seinen Freund Eduard ein recht diffuses Verhältnis beider zueinander entdeckten und das versteckte Spiel zwischen den beiden Freunden als eigentlichen, sozialpsychologisch fundierten Hintergrund bzw. als Inhalt des Romans hervorheben. Eduard vertritt dieser Interpretationsrichtung zufolge das moderne Bewußtsein schlechthin. In ihm als Figur und in seiner subjektivistischen Erzählform als Ich-Erzähler sollen sich die spätbürgerliche Subjektivität und die unausweichliche Erfahrung der modernen Auflösung niedergeschlagen haben.

Im Unterschied zu Eduards Aufstieg zum problematischen bürgerlichen Subjekt ist der Status der Heldenfigur Heinrich Schaumann mit dem Spitznamen Stopfkuchen, dem die Forschung oft auch heute noch einen überzeitlichen, doch offensichtlich anachronistischen moralischen Glanz verleiht, fast unberührt geblieben. Von diesem antiquierten Stopfkuchen-Bild endgültig Abschied nahm U. Eiseles Studie D er Didhter und sein D etektiv mit dem Hinweis auf die Modemität in der Figur des Stopfkuchen. ${ }^{55}$ Bei G erhart v. G raevenitz ${ }^{56}$ wird Eiseles Zuordnung Stopfkuchens zum modernen Helden bestätigt und konkretisiert, indem G raevenitz den dicken Helden Stopfkuchen nach seinem ikonographischen Typus in die Nähe der Bilder und Figuren von Benjamin und Baudelaire rückt. ${ }^{57}$ So wird die moderne Allegorie gerade als eine Anschauungsweise oder -form in Raabes realistischem Text nachgewiesen, ${ }^{58}$ und die Modernität des Stopłk uchen wird, über die formale Modernität hinaus, als die erzählerische Grundstruktur des Romans herausgearbeitet. Mit Graevenitz' Versuch scheint Stopfkuchens langer Weg zum modernen Text einen gewissen Höhepunkt erreicht zu haben, wobei es vor allem um die ästhetische Moderne geht.

Vor diesem Hintergrund der Forschungsgeschichte erhebt sich eine Frage, die von der Forschung mit der Fokussierung der ästhetischen Moderne häufig verdrängt wurde: Was bleibt von dem Menschenbild der Hauptfigur, von ihrer schillernden Idealität, nachdem sie zum ikonographischen Typus der kulturellen Moderne entpolitisiert würde? Die Frage richtet sich auf die Dimension der geschichtlichen und gesellschaftlichen Moderne, d.h. auf Idee und Struktur der modernen bürgerlich-individualistischen Emanzipation, wie sie in der Hauptfigur zum Ausdruck gebracht wird. Es gibt durchaus Forschungsergebnisse zu dieser Sinndimension des Romans. Parallel - wenn nicht abseits - zur Durchsetzung der ästhetischen Moderne als Forschungstrend sind einige wichtige Beobachtungen

51 W. Raabe, Stopfk uchen. E ine See und M ordgeschichte, in: ders., Sämtliche Werke, i.A. der Braunschweig. Wissenschaftl. Gesellschaft. Hrsg. v. K. Hoppe. 20 Bde. 3 Erg.-Bde. Freiburg; Braunschweig (ab 1960 Göttingen) 1959ff. 18. Bd. (Göttingen 1969). Im folgenden wird der Text nach den Zitaten in Klammern mit der Seitenzahl angegeben. Um den Romantitel von der Titelfigur zu unterscheiden, wird der Titel kursiv gesetzt.

52 H. Plessner, D ie verspätete N ation. Ü ber die politische V erfuhrbark eit bürgerlichen G eistes.(1935/ 1959), in: ders. G esammelte Schriften. Hrsg. v. G. Dux. 10 Bde. 1980-85. Bd. VI (1982).

53 Vgl. V. Sander, Illusionszerstörung und W irklichk eitserfassung im Roman Raabes, in: R. Grimm, D eutsche Romantheorien. Beiträge zu einer historischen Poetik des Romans in D eutschland. Frankfurt/ M. 1968, S. 218-246, hier S. 232.

$54 \mathrm{H}$. O hl, E duards H eimk ehr oder L eV aillant und das Riesenfaultier. Zu W ilhelm Raabes Stopfk uchen, in: H. Helmers (Hrsg.), Raabe in neuer Sicht. Stuttgart 1968; P. Detroy, W ilhelm Raabe. D er H umor als G estaltungsprinzip im Stopfkuchen. Bonn 1970; E. Meyer-Krentler, D er Bürger als Freund. E in sozialethisches Programm und seine Kritik in der neuen deutschen E rzählliteratur. München 1984; W. Zirbs, Strukturen des E rzählens, Studien zum Spätwerk W ilhelm Raabes. Frankfurt/ M. 1986.

55 U. Eisele, D er Dichter und sein D etektiv. Raabes "Stopfkuchen" und die Frage des Realismus. Tübingen 1979, besonders Kapitel 2. D iskurs$\mathrm{L}$ eben/ Ü berlebens-D isk urs.

56.G. v. Graevenitz, D er D ick e im schlafenden Krieg. Zu einer Figur der europäischen M oderne bei W ilhelm Raabe, in: JbdRG 1990, S. 1-21.

$57 \mathrm{Vgl}$. ebd., II, III und IV

58 Vgl. ebd., V. 
besonders von $\mathrm{H}$. Ohl und D. Kafitz gemacht worden. Jedoch hat es m. E. noch keinen Versuch gegeben, die Gesamtinterpretation des Romans stringent unter dem Gesichtspunkt der Moderne als GesellschaftlichGeschichtliches darzulegen, geschweige denn, darauf basierend, das vielbesprochene widerspruchsvolle Verhältnis zwischen Form und Inhalt des Romans näher zu betrachten oder gar zu erklären. Diese Forschungslücke ist Ausgangspunkt meiner folgenden Lektüre. Ist die Moderne im Stopfkuchen als geschichtliche und gesellschaftliche Frage und als literarästhetische Formfrage so divergierend, wie die Forschung suggeriert? Meine These ist, daß es im Stopfkuchen mehr um eine Art Entsprechung bzw. Vermittlung zwischen der gesellschaftlichen, geschichtlichen Moderne (als Gehalt) und der ästhetischen Moderne (als G estalt) geht, die erst als solche erkannt werden muß. Vor diesem Hintergrund ist es überhaupt unvermeidlich, sich zunächst mit der Moderne im gesellschaftlichen und moralischen Sinne in diesem Roman zu befassen. Dabei handelt es sich um zwei Aspekte des Emanzipationsmodells à la Heinrich Schaumann, die etwa mit den Begriffen von Eigentum und Ö ffentlichkeit erfaßt werden können. Die beiden Kategorien haben im Lauf der Emanzipationsgeschichte des Bürgertums nicht nur eine entscheidende Rolle gespielt, sondern sie selbst waren innerhalb der Entfaltungsgeschichte der bürgerlichen Gesellschaft auch einem inhaltlichen Wandel ausgesetzt. Dieser Prozeßcharakter des Begriffs der bürgerlichen Emanzipation scheint die Freiheitsidee im Stopfk uchen zu konstatieren. So entspricht die nicht ganz fraglose Idealität des Emanzipationsmodells à la Heinrich Schaumann der inneren Differenzierung, Bedeutungsverschiebung und Brechung, die dem bürgerlichen E manzipationsprozeß eigen sind. Meine Interpretation versucht den einseitig formalistisch spurengesicherten Weg des Stopfk uchen zur Moderne von der Perspektive der geschichtlichen Modeme her zu vervollständigen.

\section{A. Die gesellschaftliche und geschichtliche Dimension der Modeme}

\section{I. „Ich saß mitten drin in meinem Ideal!“59: Eigentumsthematik}

\section{Forschungsstand und Bedeutung der E igentumsthematik}

Das Soziale bei Raabe hat durch eine Reihe von Arbeiten aus den 70er Jahren, die sich mit dem Begriff des Eigentums in Raabes Werk befaßt haben, seine Bedeutung neu gewonnen. D abei geht es um zwei Richtungen von Anregungen für die Forschungsperspektive des Sozialen, des Geschichtlichen bei Raabe. Die erste ist die Entdeckung und Etablierung des Terrains der Eigentumsthematik als Zentralachse des Sozialen und Historischen bei Raabe sowie deren sozialgeschichtliche Beleuchtung. ${ }^{60} \mathrm{D}$ ie zweite Richtung besteht im ebenfalls bislang unbeachteten Zusammenhang zwischen Eigentum und der literarästhetischen Zentralkategorie bei Raabe, dem Idyll.61 Im folgenden soll auf Sprengels Untersuchung zum Phänomen des Eigentums in Raabes Spätwerk eingegangen werden, da sie in der Analyse dieses Komplexes bislang am fortgeschrittensten ist und daher besondere Beachtung verdient.

Sprengel stellt unter dem Gesichtspunkt des E igentums eine inhaltliche Kontinuität des Raabeschen Spätwerks systematisch und historisch auf, die aus drei Etappen bestehen soll. Diese drei Entwicklungsetappen sind Eigentumsverlust, Wiedergewinnung des Verlorenen und sonstiger Eigentumserwerb und Eigentumsmüdigkeit nach Scheitern des Erwerbs mit der je entsprechenden inneren Befindlichkeit. Sie beziehen sich jeweils auf Texte aus der Zeit von 1873 bis 1884 (darunter Prinzessin Fisch), auf Texte von 1884 bis 1889 und schließlich auf den zwischen 1893 und 1895 entstandenen Roman D ie A kten des V ogelsangs.62 Mit seiner systematischen und zugleich chronologischen Nachzeichnung der Entwicklung, die Raabes Eigentumsproblematik durchlaufen hat, konnte Sprengel die für das 19. Jahrhundert zentrale Bedeutung des Eigentums im Verhältnis zur bürgerlichen Subjektivität, Innerlichkeit und Identität überzeugend darlegen.

Die methodische Grundlage bilden für Sprengel zweierlei Aspekte, bei denen es sich um die Verbindung von Eigentum, Innenraum und Innerlichkeit als Belege für Eigentumsverhalten als Weltverhalten handelt. Zum einen ist es die Reaktualisierung der Lukácsschen These von der Übereinstimmung Raabescher Eigentumsproblematisierung mit der Marxschen Analyse des Kapitalisierungsprozesses in D eutschland. Zum anderen orientiert sich Sprengel an Adornos Theorie zur ,Soziologie der Innerlichkeit', die dieser im Rahmen seiner Auseinandersetzung mit der Kierkegaardschen Innerlichkeit aufgezeichnet hat. ${ }^{33}$ Sprengel will bei seiner Anlehnung an Adornos Kierkegaard-

59 W. Raabe, Stopfk uchen. Bd. 18, S. 146.

60 P. Sprengel, Interieur und E igentum. Zur Soziologie bürgerlicher Subjek tivität bei W ilhelm Raabe, in: Jahrbuch der Jean Paul Gesellschaft. 9. Jg. München 1974, S. 127-176; G. Folkers, Besitz und Sicherheit. Ü ber E ntstehung und Z erfall einer bürgerlichen Illusion am Beispiel $\mathrm{G}$ oethes und Raabes. Kronberg/ Ts. 1976.

61 U. Heldt, Isolation und Identität. D ie Bedeutung des Idyllischen in der E pik W ilhelm Raabes. Frankfurt/ M. 1979.

62 Vgl. P. Sprengel, Interieur, S. 147f.

63 Die Innerlichkeit bei Kierkegaard ist, Adornos Interpretation zufolge, nichts anderes als die objekt- und weltlose Subjektivität, die Befindlichkeit jenes Subjekts, dem Dinge wie ,Sinn nicht, unmittelbar' erfahrbar sind. Aus dem beginnenden Hochkapitalismus soziologisch herleitbar ist diese Innerlichkeit nach Adorno in dem Sinne, daß jener nur noch Waren kennt, in denen an die Stelle ihres 
Interpretation weniger nach dem gesellschaftlichen Standort des Autors Raabe als nach dem der dargestellten Personen fragen und diese zudem auf ihre Stellung zum Eigentum verengen. ${ }^{64}$ Entsprechend dem Adornoschen Hinweis auf die Bedeutung des Intérieurs, das dazu dient, objektiv-gesellschaftlich Verlorenem nachzutrauern, repräsentiert für Sprengel das Intérieur beim späteren Raabe die mit dem Eigentumsverlust verbundene Flucht in die Phantasiewelt, den Illusionscharakter der Innerlichkeit.

Im Unterschied zu Sprengels sozialgeschichtlich ausgerichteter Exegese, die die Affinität zwischen Raabescher Darstellung und der Marxschen Kapitalismusanalyse betont, wende ich mich der Frage nach der Eigentumsauffassung Raabes im Stopfk uchen zu, die von der spezifischen Verstehens- und Umgangsweise abzuleiten ist, welche die Heldenfigur gegenüber seinem Eigentum, der Roten Schanze, und dem Prozeß von deren Besitzergreifung zeigt. D as Ziel der unter dieser Leitfrage stehenden Untersuchung liegt keinesfalls darin, die deutliche Ähnlichkeit zwischen Raabes Darstellung und dem sozialgeschichtlichen Prozeß des 19. Jahrhunderts zu widerlegen. Die sozialgeschichtlich orientierte Betrachtungsweise ist als zunächst sinnvolle und notwendige Begrenzung eines komplex vorliegenden Forschungsfeldes auf eine bestimmte und grundlegende Perspektive zu verstehen. Sie dient nämlich dazu, überhaupt ein Profil von dem Problemkomplex zu gewinnen. Dabei begnügt sie sich aber bezüglich dessen, was das Besondere bei Raabes Eigentumsauffassung angeht, mit dem Hinweis, daß sein Eigentumsbegriff die „Personengebundenheit des Eigentums' zu erkennen gebe. Unter diesem Blickwinkel konnte zwar der Kritikpunkt der Eigentumsproblematik bei Raabe, nämlich die spezifisch bürgerliche Entfremdung des Eigentums vom Eigentümer, die „Zerstörung der Aura des persönlichen Eigentums durch die Umwandlung des Gebrauchs- in Tauschwert"65, verdeutlicht werden. Aber dadurch wird Raabes Verbundenheit mit der Tradition der bürgerlichen Eigentumsauffassung vernachläßigt, wenn auch nicht gleich vergessen. In bezug auf seine Bürgerlichkeit hinsichtlich dieser Problematik hat man sich nur noch mit dem Hinweis auf den unerschütterten Anspruch auf Privateigentum begnügt, den die Romanfiguren häufig im Sinne einer Lebensaufgabe erheben. Speziell für die Eigentumsauffassung Raabes, eine Vorstellung, die in der Forschung heute noch stillschweigend vorausgesetzt und daher nicht genug differenziert wird, scheint der Stopfkuchen besonders aufschlußreich zu sein. Unter sozialgeschichtlichen G esichtspunkten wird der Roman mit der entfalteten Problematisierung des Eigentums in die mittlere Phase des Entwicklungsschemas im Sinne Sprengels eingeordnet. Diese Phase soll durch Raabes Versuch einer positiven Lösung der Eigentumsproblematik bestimmt sein. Die Erfahrung der historischen Gefahr, daß mit dem Verlust des Eigentums das Individuum auch seiner Möglichkeiten der Freiheit und Selbstverwirklichung beraubt werden könnte, ${ }^{66}$ hat Raabe im Stopfkuchen aktiv überwinden wollen. Die den Roman durchlaufende äußere (auf der Ebene der Handlungsstruktur) und die entsprechende innere Entwicklung (in der Form von Subjektivität) wird von Sprengel als „Eigentumserwerb - Öffnung des Interieurs - Überwindung der Innerlichkeit“ ${ }^{\prime 67}$ bezeichnet. Mir scheint die Eigentumsthematik des Stopfkuchen weit über diese von der Handlungsstruktur bestimmte Begriffstrias hinauszugehen. Im Stopfkuchen geht es Raabe nicht nur um die gelungene Herstellung des unentfremdeten Verhältnisses zwischen Eigentum und Eigentümer. Mit diesem Roman scheint es Raabe eben auch daran gelegen zu haben, ein Modell dafür anzubieten, was ein eigentliches, nicht-entfremdetes Verhältnis zum Eigentum in seinem Sinn sein könnte. Raabe hat der von ihm immer wieder künstlerisch gestalteten Eigentumsthematik, die er sonst ex negativo, d.h. im gescheiterten Eigentumsverhalten angezeigt hat, diesmal einen positiven Ausdruck verliehen. Darin kann man die Bedeutung der Eigentumsthematik vom Stopfkuchen innerhalb der Raabeschen Eigentumsthematik überhaupt feststellen.

Auf welche Weise und inwiefern wird der Eigentumserwerb als Haupttriebmotiv in der Lebensgeschichte der Heldenfigur strukturiert? Die folgende Rekonstruktion der Geschichte des Helden wird jene Motive und Bedingungen besonders deutlich machen, welche den Erwerb des Bauernhofes, den er selbst als „Eroberungsgeschichte der Roten Schanze“ bezeichnet, unter dem Gesichtspunkt des Eigentums interessant machen:

Das einzige Kind eines Subbeamten, des Registratoren Schaumann und seiner Frau, ist dick, gefräßig und für die Schule zu faul und unfähig. Er wird vom Lehrer als schlechtes Beispiel vor der Klasse hingestellt und von seinen Schulkameraden mit dem Spitznamen ,Stopfkuchen' gehänselt. Für den körperlich und geistig Unfähigen ist die Rote

G ebrauchswerts der bloße Tauschwert, das Abstrakteste, tritt. D em der objektiv-gesellschaftlichen Unmittelbarkeit beraubten und so auf sich zurückgeworfenen Subjekt bietet sich sein Intérieur als Raum von Innern zur Kompensation des Verlorenen. D as Intérieur spiegelt die Außenwelt jedoch nur in Bildern wider, verwandelt sie zur bloßen Scheinwelt: „Alle Raumgestalten des Intérieurs sind bloße Dekoration; fremd dem Zweck, den sie vorstellen, bar eigenen Gebrauchswertes, erzeugt allein aus der isolierten Wohnung". Als „objektloses Innen“ akzentuiert sich das Intérieur „gegen den Raum“. „D er Raum fällt nicht ins Intérieur. Er ist allein dessen G renze. [...] Wie die äußere G eschichte ,reflektiert' in der inwendigen, ist im Intérieur der Raum Schein." Im Intérieur "werden verlorene Objekte im Bild beschworen." Die Flucht des bürgerlichen Subjekts aus der Warenwelt ist so der inneren Dialektik unterworfen; „D as Selbst wird im eigenen Bereich von Waren ereilt und ihrem geschichtlichen Wesen. Deren Scheincharakter ist geschichtlich-ökonomisch produziert durch die Entfremdung von Ding und G ebrauchswert." (Th. W. Adorno, Kierk egaard. Konstruktion des Ä sthetischen. Frankfurt/ M. 19862, S. 65.)

64 Vgl. Sprengel, Interieur, S. 146

65 Ebd., S. 138.

66 Vgl. ebd., S. 157.

67 Ebd., S. 157. 
Schanze, der Bauemhof, in seiner bitteren Verlassenheit der einzige Trost. Der Bauemhof wird trotz seines Reichtums wegen des Mordverdachts seines Besitzers Quakatz von der Gegend verabscheut. Stopfkuchens Sympathie für die Rote Schanze entwickelt sich zur engen Freundschaft mit der einzigen Erbin und Tochter des Bauern, Valentine Quakatz; er nimmt die Rolle des schützenden Ritters für die von den Dorfkindern gehetzte ,Prinzessin der Burg Rote Schanze' ein. Stopfkuchen verläßt die Heimatstadt für das Theologiestudium an der Universität. Er kehrt aber nach kurzer Z eit wieder zurück, wird von seinem Vater vor die Tür gesetzt. Der Aussteiger aus dem ,Brotstudium' und ausgestoßene, d.h. enterbte Sohn geht auf den Bauemhof, rettet die Jungfer Q uakatz vor dem Gesinde, angesichts dessen sie um ihr Leben und Eigentum fürchtet, und heiratet sie. Von da an übernimmt er die volle Macht über die Rote Schanze, stellt eine neue Ordnung her. Bei dem Begräbnis seines inzwischen gestorbenen Schwiegervaters Q uakatz vernimmt Schaumann zufällig etwas, das ihm als Schlüssel für die Entdeckung des wahren Mörders dient. Unverhofft und ohne seinerseits etwas dafür getan zu haben, kann er Schritt für Schritt das $\mathrm{G}$ eheimnis der ganzen Geschichte des ungeklärten Mordfalls erschließen. Mit dieser nachträglichen Aufklärung befreit er seinen Bauernhof, die ehemalige ,Mordschanze', von dem Last der Vergangenheit. Er entdeckt außerdem die paläontologische Bedeutung der Roten Schanze und der dazugehörigen Gegend. So beschäftigt er sich körperlich und geistig mit dem Sammeln und Erforschung ausgegrabener Fossilien. Inzwischen hat der wissenschaftliche Wert den Preis des Grundstückes erhöht, dessen Besitzer sein Land einer Zuckerfabrik zu verkaufen gedenkt, um als ihr Aktieninhaber seine späteren Jahre in Frieden zu verbringen.

Diese Rekonstruktion verschafft einen Überblick über den Prozeß und die Umstände, wie der in jeder Hinsicht Unfähige den Reichtum eines großen Bauernhofes erwerben konnte. Sie macht zugleich bewußt, daß Eigentumserwerb als Handlungseinheit im Text ziemlich im Dunkel bleibt, was großenteils auf die ,erzählerische Eigenart' des Ich-Erzählers Schaumann zurückzuführen ist. Wodurch wird nun tatsächlich die Perspektive des IchErzählers Schaumann gekennzeichnet? Wie präsentiert bzw. verstellt er seine Geschichte? Im Vordergrund der Erzählung, in dem fast zwei D rittel der ganzen Erzählung ausmachenden Monolog von Schaumann, steht die Eroberung der Roten Schanze nicht als Besitzergreifung von Reichtum im Sinne von sozioökonomischem Handeln. Im Zentrum der erzählten Lebensgeschichte steht Schaumanns früh entstandene, der Umgebung unergründliche Bindung an dem Bauernhof der Roten Schanze, und zwar nicht im Sinn bloßer Habgier.68 Vielmehr ist sie von verschiedenen subjektiven Wertungsfragen geprägt. Es ist damit jedoch nicht gemeint, daß bei dem Ich-Erzähler Schaumann von Eigentum ex pressis verbis kaum oder nicht die Rede wäre. Allein Schaumann als Ich-Erzähler spielt diesen Aspekt der Sache etwas herunter. D as macht den Text interpretationsbedürftig bzw. interpretationswürdig. Es bedarf gerade einer solchen Interpretation, die darauf angelegt ist zu zeigen, daß es sich bei der ganzen Geschichte Schaumanns um eine Verschiebung dessen handelt, was das Eigentum bedeutet, und zwar nach dem bürgerlichmodernen Verständnis. Die Verschiebung findet in doppelter Weise statt, die genau zu charakterisieren die Aufgabe der folgenden Interpretation ist. Zum einen kehren mit der Verschiebung die Komponenten der bürgerlichmodernen Eigentumsauffassung in metaphorischer Verkleidung wieder. Zum anderen verschiebt Raabe die bürgerliche Eigentumsauffassung so, daß sie mit der diesbezüglichen epochenspezifischen Praxis der bürgerlichen Gesellschaft in Deutschland der Zeit konvergiert. Das heißt, Raabe verschiebt ,bildungsbürgerlich'. In dem Sinne kann man den Stopfkuchen als einen interessanten Fall verstehen, bei dem zu beobachten ist, wie das „Bildungsbürgerliche' das Eigentum, das ursprünglich ,nicht-bildungsbürgerlich', d. h. besitzbürgerlich Bürgerliche, erkennt und sich aneignet.

\section{D ie bürgerlichen Charak terzüge der $E$ igentumsauffassung}

Bevor die bildungsbürgerliche Verschiebung der bürgerlichen Eigentumsauffassung im Stopfk uchen dargestellt werden kann, muß man zunächst einmal mit der allgemeinen Frage beginnen; was genau ist unter Eigentum und E igentumsauffassung zu verstehen? Z unächst muß zwischen ,Eigentum' und ,Besitz' unterschieden werden, die zwar gleichermaßen die Unterwerfung einer Sache unter den menschlichen Willen bezeichnen, aber sich auf unterschiedliche Weise mit dem Sachverhalt befassen. Das Eigentum ist eine rechtliche, rechtstitelgebende Unterwerfung einer Sache unter den menschlichen Willen, während Besitz eine faktische Unterwerfung bezeichnet. „Besitzer ist schon der, welcher tatsächlich die Gewalt über eine Sache hat, während Eigentümer nur der ist, dem diese G ewalt auch rechtlich zusteht." 69

68 Habgier oder Habsucht ist eine „übersteigerte Form des D ranges nach Vermehrung des Besitzes, der immer mehr zum Selbstzweck wird". (Brodkhaus E nzyk lopädie in 20 Bden. Siebzehnte völlig neubearbeitete A uflage. 8. Bd. H - K. F. A. Brockhaus Wiesbaden 1969, S. 19.) Eigentum als Manifestation von Habgier wird bereits von Platon kritisiert. Sein Vorwurf lautet: Eigentum beruht auf Eigennutz; Eigennutz ist moralisch verwerflich; also ist Eigentum moralisch verwerflich. (Dazu A. Künzli, Mein und D ein. Zur Ideengeschichte der E igentumsfeindschaft. Köln 1986, S. 84f.)

69 M eyers Konversations-L ex ik on, 6. Aufl., Leipzig; Wien 1908, Bd. II, S. 755. 
So heißt es in der Tat nach dem zivilrechtlichen Verständnis: Eigentum ist ein Ding, ein Gegenstand. Eigentumsrecht ist Herrschaftsrecht (D ominium) gegenüber einer Sache. ${ }^{70}$ Eigentum beschreibt also ein Verhältnis zwischen Mensch und Sache. Es bedeutet nicht ein Verhältnis zwischen Mensch und Sache im allgemeinen, sondem das Verhältnis zwischen einem bestimmten Menschen und einem bestimmten Ding. Als Herrschaft des Menschen über eine Sache enthält aber das Eigentum ein über das Mensch-Sache-Verhältnis hinausgehendes, soziales und geschichtliches Verhältnis, nämlich ein Verhältnis zwischen Menschen. Denn das Herrschaftsrecht einer bestimmten Person über eine Sache impliziert die Ausschließung eines Herrschaftsrechtes eines anderen über dieselbe Sache. So schließst das Eigentumsrecht per definitionem ein zwischenmenschliches Verhältnis - in Hinsicht auf das betreffende Ding - in sich ein. Herrschaft und Ausschließung widersprechen sich nicht, sie sind zwei Seiten ein und desselben Phänomens. ${ }^{71}$

Diesen beiden unterschiedlichen Auffassungsweisen des Eigentumsbegriffes entsprechen die zwei Linien der ,Eroberungsgeschichte' der Roten Schanze durch die Hauptfigur, die in der Forschung ,Rote Schanze-Symbolik' genannte Vielschichtigkeit des Verhältnisses zwischen Schaumann, der Roten Schanze und seiner Umwelt. Eine Linie ist dabei die Erwerbsgeschichte des E igentums, in der es um das Verhältnis von Subjekt und Objekt geht. Stellt die Eroberungsgeschichte als Erwerbsgeschichte des Eigentums durch die Hauptfigur den Weg des Subjekts zur Eigenbestimmung über das Subjekt-O bjekt-Verhältnis dar, verhält sich darin die Rote Schanze-Symbolik ähnlich wie jedes gelungene Symbol. Die Einheit von Sache und Bedeutung, Natur und Geist, die das Gelingen eines Symbols fundiert, ist auch für die Rote Schanze-Symbolik konstitutiv, wobei es hier speziell um die eigentumsrechtlich vorgeprägte Einheit von Sache und Person geht. Die andere Linie der Symbolik ist die Entwicklungsgeschichte der Beziehung zwischen der Hauptfigur und seiner Umgebung, also deren Entstehung, Veränderung und Auflösung. Dieser Gesichtspunkt bezieht sich auf den zwischenmenschlichen Aspekt des Eigentumsrechts, nämlich die Ausschließung der Fremdbestimmung. In der geophysischen Gestaltung von auffälliger Höhe und ihrer Entstehungsgeschichte als Kriegsschanze versinnbildlicht die Rote Schanze den Willen des Eigentümers, der sich, dabei den Willen eines dritten - hier durch die D orfbewohner repräsentiert - ausschließend, dagegen behauptet. ${ }^{72}$

Um den oben herausgestellten Charakter des Verhältnisses zwischen der Heldenfigur und der Roten Schanze zu erhärten und näher zu bestimmen, wird im folgenden versucht, den Text vor der Folie der bürgerlichen, d.h. modernen natur- und vernunftrechtlichen Eigentumstheorie zu lesen. Dabei wird die Eigentumstheorie von J. Locke, I. Kant und G.W.F. Hegel in ihren spezifischen und für die weitere Entwicklung der bürgerlichen Eigentumsauffassung signifikanten Punkten als zentral und als für das Verhältnis der Heldenfigur zur Roten Schanze konstitutiv angenommen.

Bevor die genannte repräsentative bürgerliche Eigentumsauffassung in die Textinterpretation miteinbezogen wird, muß hier der Rahmen abgesteckt werden, in dem sich unser Verständnis dieser Philosophen und ihrer Eigentumsphilosophie bewegen soll. E rst mit dieser thematischen Eingrenzung kann die dann folgende Darstellung vor der $\mathrm{G}$ efahr, die üblicherweise in einem solchen Versuch lauert, abgesichert werden, nämlich: unversehens in die D ebatte um spezifische Fragen verwickelt zu werden. D as generelle Prinzip bei der D arstellung der drei D enker ist, daß ich mich grundsätzlich an die Forschungsergebnisse anlehne, die in einer liberalen Interpretationstradition stehen. Für Locke ergibt sich daher, daß man bei der Interpretation seiner Philosophie zu dem Ergebnis kommt, daß er bezüglich der Frage nach dem Verhältnis ,seines' Naturrechts im Vergleich mit der traditionellen Konzeption des Naturrechts der Stoa und Scholastik ein Wegbereiter des bürgerlichen Individualismus war. Obgleich Locke sich von der scholastischen Philosophie nicht ganz befreien konnte, ist sein Naturrechtsverständnis doch bürgerlicher Prägung in der Weise, wie er eben von der alten Scholastik abweicht. ${ }^{73}$

D ie liberale Kant-Interpretation bemüht sich, anstatt Kants sozialphilosophisches D enken mit der sozialen und politischen Rückständigkeit Deutschlands gleichzusetzen, vor dem Hintergrund der Rückständigkeit D eutschlands den bürgerlichen Kern seiner Sozialphilosophie herauszuarbeiten. Bezüglich Kants Eigentumslehre, die er in der M etaphysik der Sitten entfaltet hat, werden in der Forschungsgeschichte zwei Aspekte kontrovers diskutiert. Zum einen ist es die Frage nach dem Zusammenhang zwischen der M etaphysik der Sitten und der Erkenntnistheorie bzw. der

70 D azu vgl. H.-R. Hagemann, Stichwort „Eigentum“, in: A. Erler / E. Kaufmann (Hrsg.), H andwörterbuch zur deutschen Rechtsgeschichte. Bd. 1, Berlin 1971, 883f.

71 Aus diesen beiden Aspekten des Eigentums resultieren die zwei unterschiedlichen Typen von Begründungstheorien für das Eigentum. Die eine Theorie sieht Eigentum als Herrschaftsrecht an und begründet Eigentum aus dem Subjekt-O bjekt Verhältnis. Sie nennt sich die Arbeitstheorie des Eigentums und erscheint zum ersten Mal bei J. Locke. Die andere Theorie sieht das Wesentliche des Eigentums in der Ausschließung des fremden Einflusses auf den Eigentumsgegenstand und begründet das Eigentum als Übereinkunft zwischen Menschen. Diese Begründungstheorie nennt sich Okkupationstheorie, zu der sich H. Grotius, S. Pufendorf und später mit transzendentalphilosophischer Begründung auch I. Kant bekennen. Siehe M. Brocker, A rbeit und E igentum. Darmstadt 1992, bes. E inleitung, S. 1-11.

72 Ich meine aber damit keineswegs, daß der Antagonismus zwischen der Heldenfigur und ihrer Umgebung, der D orfgemeinschaft, allein die Eigenständigkeit und Isolation des Eigentümers gegenüber der bürgerlichen G esellschaft darstelle. Es soll nur festgestellt werden, daß die soziale, zwischenmenschliche Dimension der Roten Schanze-Symbolik mit der Eigentumsthematik eng verschränkt ist. Das soziale, z.T. aggressionsbeladene Verhältnis, in dem die Hauptfigur zu der D orfgemeinschaft steht, ist noch komplizierterer Natur und impliziert weitere sozialpolitische und zeitgeschichtliche Prämissen, um ganz in dem Besitzindividualismus aufzugehen. Das II. Kapitel über die Ö ffentlichkeit wird der eingehenden Analyse dieses Komplexes gewidmet sein.

73 Siehe z.B. W. Euchner, N aturrecht und Politik bei John L odk e. Frankfurt 1979, bes. Einleitung, S. 1-45. 
Eingebundenheit jener in diese. ${ }^{74}$ Auf diese spezifische Frage wird im Rahmen dieser Arbeit nicht eingegangen werden. Wichtiger in unserem Kontext ist der zweite Punkt, der mit Kants Einspruch gegen Lockes Eigentumstheorie zusammenhängt. Aufgrund seiner Abweichung von der Lockeschen Arbeitstheorie steht Kant im ideengeschichtlichen Horizont der Eigentumslehre nicht in einer Beziehung der Weiterentwicklung zu Locke, wie dies etwa bei Hegel der Fall ist. Kant hingegen greift auf die alte Okkupationstheorie zurück. ${ }^{75}$ Ebenso wie Locke und später Hegel versteht aber auch Kant Eigentum im Sinne der Freiheitsidee. Darin liegt die Gemeinsamkeit und ideelle Weiterentwicklung in der Eigentumslehre der drei Philosophen.

Für das Verständnis von Hegel stütze ich mich auf das neue Hegel-Bild nach dem Zweiten Weltkrieg in Deutschland, das sich von der Auffassung Hegelscher Rechtsphilosophie als offizieller Staatsphilosophie des Preußentums absetzt.7 ${ }^{7}$ Bei Hegels Eigentumslehre beziehe ich mich in dem Sinne ausschließlich auf seine Berliner Rechtsphilosophie.77

D as eigentümliche Verhältnis Stopfkuchens zur Roten Schanze, von der Entstehung seines Jugendtraums bis zu dessen Verwirklichung in Form von Besitznahme wird als ,Rote Schanze-Symbolik' in der Forschungsgeschichte unterschiedlich gedeutet. Die Bezeichnung der Symbolik geht auf eine Aussage von Raabe selbst zurück. Mit der Rote Schanze-Symbolik vergleicht Raabe in einem Brief an P. Heyse seine eigene Schreibkunst und Künstlerexistenz, wobei die lebenslange Zielstrebigkeit und deren letztendliche Erfüllung den Anhaltspunkt des Vergleichs bilden.

Nehmen Sie die Rote Schanze als die deutsche humoristische Weltanschauung und den dicken Schaumann als den dürren Raabe, so haben Sie eine ganz feine Symbolik.78

Im folgenden sollen die Interpretationsansätze zu dieser Symbolik, welche die Forschung bisher hervorgebracht hat, skizziert werden, um anschließend zu zeigen, daß gerade der Eigentumserwerb die zentrale Sinnstruktur jener "feine[n] Symbolik“ ist.

Die Darstellung der Roten Schanze als Raum, die mit der inneren und äußeren Lebenslage der Heldenfigur einen vielfältigen Verweisungszusammenhang bildet, wurde in der älteren Raabe-Forschung häufig mit der moralischen und weltanschaulichen Wertkategorie der Idylle aufgefaßt.79 $\mathrm{D}$ aß die räumliche Geprägtheit der inneren Welt bei Raabe, besonders im Stopfkuchen, sich von der alten Idylle unterscheidet, wurde übersehen. Besonders systematisch verdrängt wurde es unter dem Einfluß des Nationalsozialismus, der das Regionale und Vormoderne der literarischen Welt des Autors als die ,deutsch-idyllische' Empfindung vereinnahmte.

Die neuere Forschung der Nachkriegszeit versucht unter dem starken Abgrenzungszwang zu der früheren formalistisch zu neutralisieren, nämlich die Bedeutung und die Funktion des Räumlichen im Sinne eines epischen Gerüstes zu technisieren. O bwohl man den ,Raum' als die mit dem ,menschlichen Sinngehalt' geladene Örtlichkeit von der wertlosen leeren Tatsächlichkeit des Raums als „Lokal“80 unterscheidet, wird im Rahmen dieser Interpretationsrichtung angestrebt, den Raum weitgehend der Schwere der wie immer gearteten ,Sinnfrage' zu entheben. So hat man der Raum-Frage oft mit einer rein formalen Analyse der Raumgestaltung im engeren Zusammenhang mit der Zeitgestaltung81 Genüge getan. Dabei kam verständlicherweise der unübersehbar vorhandene menschliche Sinngehalt der Raum-Symbolik zu kurz. Er wurde als sinnliche, geophysisch symbolische

74 Zur aktuellen Forschungslage vgl. M. Brocker, Kants Besitzlehre. Zur Problematik einer transzendentalphilosophischen Eigentumslehre. Könighausen/ Neumann 1987, S. 41f.

75 D azu vgl. W. Kersting, W ohlgeordnete F reheit. Immanuel Kants Rechts- und Staatsphilosphie. Berlin/ New York, 1984, S. 154f. Im G egensatz dazu entfaltet R. Saage eine besitzindividualistische Kant-Interpretation, die Kants Rückwendung zur okkupationstheoretischen Tradition durch die Rückständigkeit des Status quo des damaligen Deutschlands zu erklären versucht. Siehe dazu ders., E igentum, Staat und G esellschaft bei Immanuel Kant. Stuttgart; Berlin; Köln; Mainz, 1973, bes. Einleitung, S. 7f.

76 In der Tat gab es unmittelbar vor der Zeit des Nationalsozialismus in D eutschland auch solche Kreise, die Hegels Rechtsphilosophie als offizielle Staatsphilosophie verstanden haben wollten. D azu vgl. J. Binder/ M. Busse/ K. Larenz, E infuhrung in H egels Rechtsphilosophie. Berlin 1931. Nach dem Z weiten Weltkrieg ist die Bemühung um ein neues Hegel-Bild vor allem durch Joachim Ritters Abhandlung $H$ egel und die französische Revolution eingeleitet worden. Ritter versteht Hegel nicht mehr als reaktionären Staatstheoretiker, sondern als einen Denker, dessen Philosophie bis in die innersten Antriebe eine Philosophie der Revolution gewesen sei. Nach Ritter hat Hegel im Schnittpunkt von Tradition und Revolution den Versuch unternommen, die durch die industrielle und politische Revolution bewirkte Auflösung der einheitlichen menschlichen Lebenswelt und die Entzweiung von Staat und Gesellschaft vor dem Hintergrund der antikchristlichen Tradition zu begreifen. D azu vgl. J. Ritter, H egel und die französische Revolution. Köln 1957; ders., M etaphysik und Politik. Studien zu A ristoteles und H egel. Frankfurt/ M. 1969. Dieses liberale Interpretationskonzept von Hegels praktischer Philosophie beeinflußte eine Reihe von Arbeiten. So unternahm es Manfred Riedel, die begriffs- und ideengeschichtlichen Verbindungen zwischen Hegel und der traditionellen Philosphie herzustellen, den historischen Standort von Hegels Philosophie im geschichtlichen Kontext zu Beginn der ,modernen Welt' zu bestimmen und jene von Ritter behauptete ,Entzweiung' anhand von Einzelanalysen der politischen Schriften Hegels zu präzisieren. Vgl. M. Riedel, Theorie und Praxis im D enk en Hegels. Stuttgart 1965; Studien zu H egels Rechtsphilosophie. Frankfurt 1969; Bürgerliche G esellschaft und Staat bei H egel. Neuwied 1970; System und G eschichte. Studien zum historischen Standort von H egels Philosophie. Frankfurt 1973.

77 Außerdem sind viele verschiedene rechtsphilosophische Vorlesungen Hegels bekannt. Vgl. dazu z.B. D. Henrich, Hegel. Philosphie des Rechts. Frankfurt 1983.

78 W. Raabe, Brief an Paul Heyse am 13.3.1892, in: ders., Stopfk uchen. Bd. 18. Anhang, S. 499.

79 Vgl. das Vorwort von H. Helmers, in: ders. (Hrsg.), Raabe in neuer Sicht, S. 9.

80 R. Petsch, W esen und Formen der E rzählk unst. 2. Aufl., 1942. Zur Bedeutung von Petschs Studie siehe H. Meyer, Raum und Z eit in W ilhelm Raabes E rzählk unst (1953), in: H. Helmers (Hrsg.), Raabe in neuer Sicht, S. 98-129, hier S. 101.

81 Siehe beispielsweise F. C. Maatje, D er Raum als konstituierendes M oment in W ilhelm Raabes „H ungerpastor“, in: H. Helmers (Hrsg.), Raabe in neuer Sicht, S. 185f.; so auch H. Meyer, Raum und Z eit, S. 98f. 
Wirkung des Raumbildes auf den Menschen ${ }^{82}$ naturalisiert. Von der Sensualisierung des ,menschlichen Sinngehalts' wendet sich Heldts Studie über "die Bedeutung des Idyllischen in der Epik Wilhelm Raabes" 83 ab und hin zur gesellschaftlichen Dimension des ,menschlichen Sinngehaltes'. Es ist nicht der Typus der alten Idylle, als deren utopische Substanz eine wie auch immer verstandene Natur gilt, in der sich Mensch und Umwelt relativ unkompliziert als ein höheres Gemeinsames zusammenfinden. ${ }^{84}$ Die Idylle bei Raabe, die im ganz engen Sinne der Idylle nur deren Erscheinungsformen umfaßt, verweist eher in ihren Negativbildern des isolierten idyllischen Daseins auf die Isolation des Individuums in der bürgerlichen G esellschaft. Die von Raabe gestaltete Idylle ist nach Heldt somit nur Privatgeschichte und Privatbesitz, das, was aus dem ehemals gemeinschaftlich bewohnten Arkadien, dem kollektiv im Mythos beschworenen ,Goldenen Zeitalter'85 geworden ist. In dem Sinne weist Heldt darauf hin, daß die Identifikation mit der Roten Schanze bei Schaumann, im Unterschied zu der idyllisch vorgestellten Identität mit dem Raum, durch ihn konkret, per Handlung, vollzogen wird. Er bleibt in seiner Identität mit dem Raum nicht bloß in betrachtender Distanz, sondern erwirbt sich den Raum tätig, und zwar durch Arbeit.86

D en oben vorgestellten Interpretationsansätzen der ,Symbolik der Roten Schanze' ist trotz ihrer methodischen Unterschiede eines gemeinsam: Sie nehmen alle die Materialität des Symbolträgers (zu) ernst, und rücken damit den Raumcharakter der Roten Schanze in den Vordergrund. Im Unterschied zu ihnen betone ich als zentrale Dimension dieser Symbolik die lebenslange Zielstrebigheit und deren letztendliche Erfüllung, also die Handlung und Handlungsgeschichte der Heldenfigur. Dabei orientiere ich mich an jenem bereits erwähnten Auslegungshinweis Raabes zur Symbolik der Roten Schanze.

Es ist der L ebenswerkcharakter der Roten Schanze, der die Symbolik dem Autor, nach seinem Verständnis, sinnhaft macht. Dabei wird die Frage, ob das geschaffene Werk etwa räumlich-materieller oder geistiger und künstlerischer Art ist, eher sekundär. Von primärer Bedeutung ist nur, daß es etwas der Person, dem Subjekt Eigenes, Eigentümliches ist, daß der Lebende und das gelebte Leben und das geschaffene Werk untrennbar in eins verschmolzen werden. In diesem Sinne betrachtet, stellt die Rote Schanze die Vorstellungsbreite des Eigentums überhaupt dar, der vor allem anderen die Eigentümlichkeit der Person in ihrer Bedeutungsvielschichtigkeit zugrunde liegt.

Wie die emanzipatorische Potenz der bürgerlichen Eigentumsauffassung in ihrem die ganze Person umfassenden Eigentumsbegriff liegt, ist der Prozeß der Besitznahme der Roten Schanze für die Heldenfigur die Befreiung, die die Person als Ganzheit betrifft. So bedeutet dieser Befreiungsprozeß auch den Bildungsweg der Person, jedoch nicht in dem Sinne, daß die Bildung das erste und letzte Ziel der E roberung der Roten Schanze ist, wiewohl der Roman teilweise als Bildungsroman anmuten kann. Die E roberung der Roten Schanze ist ohne Zweifel Bildungsgeschichte, aber nicht einzig und allein, sondern nur unter anderem.

Bei J. Locke findet man zum ersten Mal im bürgerlichen Denken und deswegen in einer paradigmatischen Dignität jenen L ebenswerk charak ter des Eigentums, der für die Einheit von Eigentum und Person plädiert. In seiner bahnbrechenden Bedeutung für die moderne bürgerliche Eigentumsauffassung geht Locke, darin noch an die christliche eigentumstheoretische Tradition gebunden, von der von Gott der gesamten Menschheit zur Verfügung gestellten Erde aus: „Die Erde und alles, was auf ihr ist" von Gott „den Menschen zum Unterhalt und Genuß ihres Daseins gegeben"(§ 26).87 Da die Welt von Gott den Menschenkindern zu gemeinsamer Nutzung übergeben ist, räumt Locke die ursprüngliche Unmöglichkeit des Privateigentums ein: „[N]iemand hat ursprünglich ein persönliches Herrschaftsrecht mit Ausschluß aller übrigen Menschen über irgend etwas, da es sich so im natürlichen Zustand befindet".(Ebd.)

„Doch da Güter den Menschen zu ihrem Gebrauch verliehen wurden, muß es“, so leitet Locke die Notwendigkeit des Privateigentums von dem dem Menschen naturrechtlich verbürgten Recht auf Selbsterhaltung ab, „notwendigerweise Mittel und Wege geben, sie sich irgendwie anzueignen, bevor sie dem einzelnen Menschen von irgendwelchem Wert oder überhaupt nützlich sein können." (Ebd.)

Um für den Unterhalt seines Lebens von irgendwelchem Nutzen sein zu können, müssen die Güter jemandem gehören, „und zwar so gehören, d.h. als ein Teil von ihm, daß kein anderer länger ein Recht darauf beanspruchen kann“ (ebd.), sie müssen jemandes Privateigentum werden. „Erst dann“, nämlich erst als Privateigentum, „können sie ihm für den Unterhalt seines Lebens von irgendwelchem Nutzen sein". (Ebd.)

Die tiefe Sehnsucht der Heldenfigur nach dem reichen Bauemhof ist Ausdruck eines verborgenen Zusammenhangs im Sinne der Lockeschen Begründung des Anspruches auf Eigentum, daß nämlich das Naturrecht

82 Z.B. H. Meyer, Raum und Zeit, S. $98 f$.

83 So lautet der Untertitel der Studie von U. Heldt.

$84 \mathrm{Vgl}$. U. Heldt, Isolation, S. 23: So resümiert Heldt, daß „die Isolation - als eines der Hauptmerkmale des Raabeschen Idylls - nicht als Rückzug oder Flucht aufgefaßt werden [muß], sie ist vielmehr eine klare Konsequenz aus dem von Raabe konstatierten Zustand der bürgerlichen G esellschaft". (Ebd., S. 267)

85 Vgl. ebd., S. 19.

86 V gl. ebd., S. 26 .

87 J. Locke, Z wei A bhandlungen über die Regierung. Hrsg. v. W. Euchner, Frankfurt/ M. 1977, Z weite A bhandlung. Bei weiteren Locke-Zitaten, soweit sie aus der zweiten Abhandlung stammen, wird im Text anschließend nur die Zahl der Paragraphen (§) in Klammern angegeben werden. 
auf Selbsterhaltung allein durch den Weg über das Privateigentum erfüllt werden könne. Daß es sich hier um ein in dieser Hinsicht besonders problematisches Individuum handelt, welches gefräßig und gleichzeitig zu dumm und unfähig ist, um unter den „Schnellfüße[n]“ (S. 89) der modernen Konkurrenzgesellschaft voller Mobilität mitzulaufen und sich so zu erhalten, darin scheint diese eigentlich programmatische und ideologische Gleichsetzung von Selbsterhaltungsrecht und Eigentumsrecht gerade durch deren Gefährdung zugespitzt. Eine Übertragung des naturrechtlichen Anspruchs auf Selbsterhaltung auf die geistige Ebene ist daran zu erkennen, daß von dem ebenfalls in übertriebener Weise erhobenen Anrecht auf Ideale gesprochen wird. Der auch geistig unbewegliche junge Schaumann meint, sein Ideal unbeirrbar in seiner nächsten Umgebung, nämlich im Bauernhof, bereits gefunden zu haben, während die anderen „Schnellfüße" ihr Ideal in der weiten Welt zu suchen und zu finden haben.

Bemerkenswert ist hier, daß in der Roten Schanze das Begehren nach Eigentum mit dem Bedürfnis nach Identität zusammenfällt. Dies manifestiert sich darin, daß in Schaumanns Aussage das Possessiv-Verhältnis des Eigentums ins Räumliche von Sitzen und ,D rinsein' übergeht: „Ja, ich hatte es nun, was ich hatte haben wollen. Ich saß mitten drin in meinem Ideal".(S. 146)

Neben der Rechtfertigung des Eigentumsrechtes durch das Selbsterhaltungsrecht findet man bei Locke noch ein anderes Argument. In ihm liegt wohl die Bedeutung, die Lockes Eigentumslehre für die weitere Entwicklung des bürgerlichen Denkens hat. Die andere Quelle, worauf sich die Individualisierung der ursprünglichen Gütergemeinschaft gründet, leitet Locke her von der Erwägung: „O bwohl die Erde und alle niederen Lebewesen allen Menschen gemeinsam gehören, so hat doch jeder Mensch ein E igentum an seiner eigenen Person. Auf diese hat niemand ein Recht als nur er allein. Die Arbeit seines Körpers und das Werk seiner Hände sind, so können wir sagen, im eigentlichen Sinne sein Eigentum“ (§ 27). „Was immer er also dem Zustand entrückt, den die Natur vorgesehen und in dem sie es belassen hat" (ebd.), hat der Mensch „mit seiner Arbeit gemischt und ihm etwas eigenes hinzugefügt".(Ebd.) Da er dem gemeinsamen Zustand, in den ihn die Natur gesetzt hat, enthoben wurde, ist ihm durch seine Arbeit etwas hinzugefügt worden, was das gemeinsame Recht der anderen Menschen ausschließt. Da die Arbeit unbestreitbar dem Arbeiter als sein angeborenes Eigentum gehöre, könne „niemand außer ihm ein Recht auf etwas haben, was einmal mit seiner Arbeit verbunden ist." (Ebd.) Locke betrachtet so die Arbeit als Mittel und Weg der Aneignung von Privateigentum: „Er [der Arbeiter; J.-H. B.] ${ }^{88}$ hat es somit zu seinem Eigentum gemacht“.(Ebd.)

Kurz gefaßt sieht diese später als Arbeitstheorie des Eigentums benannte Lockesche Argumentation folgendermaßen aus: Im Arbeitsprozeß eignet sich das Individuum ein Stück ursprünglichen $\mathrm{G}$ emeinguts an, und zwar derart, daß es ein bearbeitetes Objekt durch Investition individuellen Vermögens transformiert. ${ }^{89} \mathrm{Die}$ Aneignung der Welt wird in dieser Perspektive in einer rudimentänen Subjekt-O bjekt-D ialektik gesehen. Auf der einen Seite steht ein durch sein individuelles Arbeitsvermögen qualifiziertes Subjekt, auf der anderen Seite ein vorab als Gemeingut gefaßtes Objekt. Diese Konstellation gerät durch die Verausgabung individueller Arbeit in Bewegung. ${ }^{90}$ D ie Arbeit ist - so kann man das Lockesche Verständnis von Arbeit, welches seither eine neue Denkkategorie in der Sache des Eigentums darstellt, fassen - eine vom Körper des einzelnen abtrennbare Substanz. Sie ist also etwas Transponierbares, in dem Sinne, daß sie vom Subjekt aus ins Objekt eindringt. Indem sie mit dem bearbeiteten Gegenstand vermischt wird, transformiert die Arbeit ein Objekt mit dem Status des Gemeingutes in Privateigentum. Diese konstruierte Relation zwischen Person, Arbeit und Eigentum bildet die Kernstruktur der Lockeschen Eigentumstheorie. ${ }^{91}$ Dieses durch die Arbeit verliehene Eigentumsrecht bezieht sich bei Locke allein auf den ursprünglichen Erwerb von $\mathrm{G}$ emeingut im Naturzustand, also auf die Entstehung des Privateigentums. Für das Privateigentum im bürgerlichen Zustand, das nicht den ursprünglichen Erwerb, sondern den abgeleiteten Erwerb bedeutet, gilt nicht dasselbe, vielmehr „[regelten] [die] einzelnen $\mathrm{G}$ emeinschaften [...] durch eigene Gesetze das private Eigentum innerhalb ihrer Gesellschaft, und entschieden so durch Vertrag und Übereinkunft die Frage des Eigentums, das seinen Ursprung in der Arbeit und im Fleiß hatte“.(§ 45) In der historischen gesellschaftlichen Wirklichkeit wird also das Eigentum durch die auf dem Gesetz basierende Legaltheorie erklärt: „D enn in Staaten regeln die Gesetze das Eigentumsrecht, und der Landbesitz wird durch positive Satzungen genau bestimmt".(§ 50) Wichtig bei dieser Unterscheidung von Naturzustand und bürgerlichem Zustand mit der entsprechenden unterschiedlichen Legitimation des Eigentums - einmal durch Arbeit, zum anderen durch positives Recht - ist die Struktur des Arguments, nämlich daß die arbeitstheoretische Eigentumsbegründung im Naturzustand gerade den Inhalt des Naturgesetzes konstituiert, welches die Gesetzgeber des bürgerlichen Zustandes einzuhalten haben. ${ }^{92}$ Die Lockesche arbeitstheoretische Eigentumsbegründung zielt auf eine naturgesetzliche Bindung des Gesetzgebers. Falls der Staat das Privateigentum des Bürgers nicht schützt, wie es nach Locke der eigentliche Zweck der Staatenbildung sein sollte, kann der bürgerliche Zustand des Staates jederzeit in den Naturzustand zurückfallen. D er Bürger hat nämlich

88 Diese und weitere mit J.-H. B. versehenen Ergänzungen sind von mir.

89 Vgl. hierzu G. Plumpe, E igentum-E igentümlichk eit. Ü ber den Z usammenhang ästhetischer und juristischer Begriffe im 18. Jahrhundert, in: A rchiv für Begriffsgeschichte 23 (1979), S. 175-196, hier S. 190.

90 Vgl. ebd., S. 191.

91 Seit Locke ist die Ableitungsbeziehung zwischen Person, Arbeit und Eigentum in die Tradition der bürgerlichen Eigentumsauffassung eingegangen, obgleich sie von Theoretiker zu Theoretiker unterschiedlich ausgelegt und betont wird. Zur Rezeption der Arbeitstheorie des Eigentums in der Philosophie der Klassik und Romantik vgl. besonders M. Brocker, A rbeit und E igentum. Darmstadt 1992, S. 319f. 92 Siehe dazu J. Locke, Z weite A bhandlung, § 135. 
das Recht, gegen einen Staat, der sich nicht in der Lage befindet, das Eigentum seiner Bürger zu sichern, zu rebellieren, ihn aufzulösen - so lautet die Lockesche Widerstandstheorie, der die naturrechtliche, gerechtigkeitstheoretische und arbeitstheoretische Eigentumsauffassung zugrunde liegt. Darin liegt wohl der $\mathrm{G}$ rund dafür, warum die Arbeitstheorie, obwohl sie auf den ursprünglichen Erwerb im Naturzustand bezogen und darauf beschränkt ist, den Mittelpunkt der ganzen Gesellschafts- und Eigentumstheorie bei Locke einnimmt.

Vergleichbar mit dieser Struktur der Eigentumsbegründung bei Locke, bei der ein rein ideell konstruierter Naturzustand als Leitfaden dient, wäre der Vorgang des Erwerbs der Roten Schanze durch Schaumann: Die reale Legitimation von Schaumanns E rwerb der Roten Schanze beruht auf der Wirkung des positiven Rechts, nämlich auf seiner Heirat mit der einzigen Erbin des Bauernhofes. Daß sein Erwerb auf Erbrecht basiert, wird schon in der Abschiedsszene vorbereitet bzw. vorweggenommen: Als der junge Schaumann bei dem gemeinsamen Gang mit Eduard zur Roten Schanze von seiner Freundin Abschied nimmt, bevor er zum Studium an der Universität seine Heimatstadt verläßt, versichert ihm die Tochter des Bauem und Besitzers der Roten Schanze, daß er allein, neben ihrem Vater und ihr selbst, Herr der Roten Schanze sein solle. Dabei fordert die Erbtochter den anwesenden Eduard auf, später als ein rechtswirksamer Zeuge zu fungieren:

Wollen Sie so gut sein, Herr Eduard, da Sie heute mitgekommen sind, daß Sie es später einmal vor dem Gerichte mit bezeugen, daß die Rote Schanze, wenn mein Vater und ich nichts mehr von der Welt brauchen, einzig und allein Herrn Schaumann gehört? (S. 44)

In dieser Abschiedsszene redet der junge Schaumann seinerseits auch bereits von „alle[n] meine[n] Rechte[n]“, die die vollkommene Verfügungsgewalt im rechtlichen Sinne, also das Eigentumsrecht auf die Rote Schanze, nahelegen:

Da hast du meine Hand darauf, Jungfer Quakatz: ich komme wieder und behalte mir bis dahin alle meine Rechte hier an dieser Erdstelle vor, und den seligen Kienbaum soll doch noch mal der Teufel holen. Sage es deinem Vater, wenn er nach Hause kommt, daß ich es gesagt habe, Tinchen! (S. 48)

Jedoch spielt dieser Umstand eher die Rolle einer äußeren, objektiven Rahmenbedingung für die Erwerbsgeschichte der Roten Schanze durch Schaumann. Unmißverständlich ist also, daß es sich in der ganzen Geschichte nur vordergründig um den erbrechtlichen Eigentumserwerb durch das Einheiraten in die Familie handelt, und in Wahrheit um den aktiven Einsatz der gesamten Persönlichkeit als Mittel und zugleich Prozeß des Eigentumserwerbs. Wichtig ist dabei anzumerken, daß die G estaltung der Liebe selbst der juristischen Konstruktion privaten Eigentums unterworfen ist, welche, mit Hilfe von Arbeit, die Einheit von Person und Eigentum, eine Art von Subjekt-O bjekt-Dialektik, herzustellen versucht. D ie geschlechtliche Liebe an sich, die der Heldenfigur durch die Einheirat in die vermögende Familie und das davon ausgehende Erbrecht auf das Vermögen ermöglicht wird, entzündet sich erst durch sein inniges Verhältnis zur Roten Schanze, in welches sich, wie gesagt, das Begehren des Eigentums projiziert. Die eheliche Liebe zwischen Stopfkuchen und Tinchen trägt also nicht zufällig den Charakter einer Beziehung zwischen Erzieher und zu Erziehendem innerhalb eines patriarchalisch ausgeprägten Geschlechterverhältnisses von Mann und Frau. Was hier auf der Ebene der zwischenmenschlichen Beziehung widergespiegelt wird, ist Eigentum in Lockescher D efinition, eine D urchdringung von Subjekt und O bjekt. Wie das Subjekt dem Objekt - einem beliebigen Gemeingut im natürlichen Zustand - jenen Stempel aufdrückt, der seinen Eigentumsanspruch markiert, zieht der Mann - der in seinem besonderen Vermögen individualisierte Mensch - die noch gesichts- und kulturlose Kindfrau auf, haucht ihr seinen G eist ein, der schließlich seinen Eigentumsanspruch auf sie als sein Werk markiert.

Die Adjektive, mit denen Tinchen Quakatz als Mädchen aus Eduards Perspektive beschrieben wird, sind symptomatisch für den erwähnten Sachverhalt der Frau als Bearbeitungsobjekt in Analogie zum Eigentum. Die Beschreibung richtet sich exklusiv auf die ,Unbesetztheit' und ,Unfertigkeit' der jungen Quakatz in ihrem Charakter:

Nicht groß und nicht klein, nicht mager und nicht fett, nicht hübsch und nicht häßlich, nicht städtisch und nicht dörfisch, nicht Kind und nicht Jungfrau stand sie, Valentine Quakatz, des Mordbauem Andreas Quakatzen einzige Tochter. (S. 36)

Daß sich Schaumanns Liebe analog zu jener Eigentum stiftenden Arbeit im Sinne Lockes verhält, läßt sich auch unter einem anderen Gesichtspunkt beobachten. Schaumanns Arbeit weist sich nämlich als an die Liebe gebunden aus. D er dicke, bewegungsfaule Schaumann arbeitet zum ersten Mal in seinem Leben als Großknecht der Roten Schanze, um seiner Liebe beizustehen. Die Arbeit fällt bei ihm mit der Erfahrung der Liebe, des Inbegriffs des Personseins, zusammen. Seine Arbeit ist personengebunden, wie die Arbeit im Lockeschen Sinne. Dies zu bemerken, ist zur E rhärtung der These von der Affinität zwischen Locke und Stopfk uchen wichtig, da gerade nach Locke nicht jede Arbeit das Eigentum begründet. Die Arbeit desjenigen, so die Differenzierung bei Locke, der kein Eigentum an seiner eigenen Person und somit an seiner Arbeit hat, wie z.B. Knecht oder Lohnarbeiter, die das angeborene Eigentum der Arbeitskraft verkauft haben, ist nicht imstande, Eigentum zu begründen. ${ }^{33} \mathrm{D}$ araus ergibt sich, daß die Arbeit, die dem Eigentum zugrunde liegt, nicht Arbeit schlechthin ist, sondern mit dem Willen des Arbeiters verbunden sein soll. Die Arbeit ist nur dann mit Eigentum gleichzusetzen, wenn sie als Willensakt, also in der 
Verbindung mit dem eigenen Willen des Arbeiters, sich die Sache anzueignen, getan wird. Bei Schaumann heißt es, daß seine Arbeit an der Roten Schanze wie seine Liebe zu Quakatz' Tochter ein von ihm selbst initiierter Willensakt ist. In ihrem wirtschaftlich verwüsteten Zustand ist die Rote Schanze in eine Art Naturzustand zurückgekehrt, in dem nach Locke das ursprüngliche Eigentum entsteht. Dieser "Naturzustand' der Roten Schanze rückt emeut Schaumanns Arbeit an der Roten Schanze in die Nähe der Lockeschen Vorstellung der Eigentum begründenden Arbeit. Wie einer die Wüste dem gemeinsamen Zustand entzieht und durch seine Arbeit zum Privateigentum macht, so kultiviert Schaumann die verwüstete Rote Schanze. Wie bei Locke das Konzept des Naturzustandes als eine normative Bestimmung der positiv-rechtlichen Eigentumsordnung fungiert, spielt auch hier das Element der Kultivierungsarbeit und, als deren Vorbedingung, der Verwüstung eine für die Erwerbsgeschichte konstitutive Rolle.

Zusammenfassend betrachtet stützt sich meine Lektüre der Symbolik der Roten Schanze als Symbolik der bürgerlichen Eigentumsauffassung auf die erweitete Bedeutung von Eigentum, die für die Lockesche Eigentumstheorie charakteristisch ist. Die Lockesche arbeitstheoretische Begründung des Eigentums (estate) bedeutet der Konstruktion nach die D reieinheit von Person, Arbeit und Eigentum. Hierauf gründet sich der erweiterte Begriff von Eigentum (property), der Leben (life), Freiheit (liberty) und Eigentum (estate) $)^{4}$ umfaßt. Wie das Recht auf Selbsterhaltung und das auf Eigentum bei Locke nicht getrennt werden, so steht Eigentum (property) bei ihm als der gemeinsame Name für Leben, Freiheit und Güter, wenn er auch häufig nur in einem engeren Sinn als Privateigentum verstanden wird. Der Schutz und die Erhaltung des teils in einem weiteren, teils in einem engeren Sinn begriffenen Eigentums ist der eigentliche Zweck des Gesellschaftsvertrags, „weshalb Menschen sich zu einem Staatswesen zusammenschließen und sich unter eine Regierung stellen."(§ 124) Der einzelne hat seine natürlichen Rechte nur deshalb auf die Staatsgewalt übertragen, um dadurch eine größere Sicherheit für sein Leben und sein Eigentum zu erlangen. Eigentum im engeren Sinne ist in der Lockeschen Theorie ein nicht in den Gesellschaftsvertrag eingebrachtes unveräußerliches Menschenrecht.

Die Symbolik der Roten Schanze als Identität zwischen der Person und dem gelebten Leben und dem Lebenswerk wird von Raabe suggeriert und nach ihm von vielen Interpreten supponiert. Vor dem Hintergrund der Lockeschen Arbeitstheorie des Eigentums, die das Recht auf Selbsterhaltung, Selbstentfaltung der Person und das Recht auf Eigentum nicht trennt, sondern gerade als Gleiches deutet, ist der komplexe Charakter der Symbolik der Roten Schanze einleuchtend. Wenn bei der Arbeit Schaumanns auf der Roten Schanze nicht die Arbeit im Lockeschen Sinne, sondern die Kultivierung, und zwar nicht die des Bodens, sondern die der Erbin, in den Vordergrund gerückt wird, braucht diese unverkennbar bildungsbürgerliche Konstitution nicht gleich gegen das ,Besitzbürgerliche' bei Locke ausgespielt zu werden. Denn die Lockesche ,besitzbürgerliche' Arbeit ist, wie schon erwähnt, nicht körperliche Arbeit schlechthin, sondern sie muß in Verbindung mit einem eigenen Willen auftreten und ist daher keine Lohnarbeit, keine Sklavenarbeit. Als solche mit eigenem Willen verbundene Arbeit begleitet die ,besitzbürgerliche Arbeit' auch die geistige und pädagogische Arbeit, welche im Nexus mit der Vernunft zu verstehen ist. ${ }^{95} \mathrm{Da}$ weder in der Lockeschen noch in den anderen frühbürgerlichen Theorien des 17. Jahrhunderts die Trennung von Besitz und Bildung problematisiert ${ }^{96}$ wird, ist diese klassische Einheit von Besitz und Bildung der weitere Horizont, vor dem der Vergleich von Locke und Raabe gedacht werden kann. Raabes Verschiebung der (besitz-)bürgerlichen Konstitution des Eigentums à la Locke ins Bildungsbürgerliche ist die Antwort auf den sozialgeschichtlichen Wandel, in dem die Einheit von Besitz und Bildung nicht mehr selbstverständlich wie noch bei Locke ist. ${ }^{7}$ Schaumanns Erwerbsgeschichte der Roten Schanze in ihrer Einheit mit der Bildungsgeschichte formuliert, so kann man resümieren, die Lockesche Eigentumsauffassung geschichtlich und damit auch literarisch neu. Das hier entwickelte Textverständnis zeigt, warum man im Stopfkuchen hinsichtlich der Rote Schanze-Symbolik trotz der nicht- oder sogar antibürgerlich anmutenden Züge von klassischer Bürgerlichkeit als von nur noch handlungtheoretischem Individualismus sprechen kann und muß.

Eine weitere strukturelle Affinität zur klassischen Tradition philosophischer Eigentumstheorie ist auf einer anderen Ebene der Symbolik der Roten Schanze zu konstatieren, nämlich der, die sich auf die konkrete Lebensform bezieht. Die Lebensform, die die Hauptfigur in ihrer Jugendzeit auf die Rote Schanze projiziert und später als ihr „Herr[], Eigentümer und Besitzer"(S. 64) verwirklicht hat, spiegelt eine bestimmte Freiheitsvorstellung des Individuums wider: D as Individuum ist insoweit frei, als es Eigentümer seiner Person und seiner Fähigkeiten ist. D as menschliche Wesen zeichnet sich durch Freiheit von der Abhängigkeit vom Willen anderer aus, und diese Freiheit ist eine Funktion des Eigentums.

Die auf der Roten Schanze ausgelebte Freiheit drückt sich, wie jeder emphatisch erträumte Idealzustand, phänomenologisch so aus, daß sie ihre Schattenseiten zu erkennen gibt: Selbstgefällige Überlegenheit, Isolation und Aggressivität, wie es in der geophysischen Eigenschaft der herausragenden Höhe oder der Geschichtlichkeit der Roten Schanze als Kriegsaufwurf vorgegeben wird, sind die spezifischen Erscheinungsformen dieser Freiheit. Die

94 Siehe dazu ebd., § 123; § 87; § 173; § 222. Vgl. auch, K. O livecrona, The Term Property in L ocke's Two Treatises of G overnment, in: Archiv für Rechts- und Sozialphilosophie. 1975, LXI/ 4, S. 109-115.

95 Näher dazu J. Tully, A D iscourse on Property. Cambridge 1980, S. $104 f$.

96 D azu U. Haltern, Bürgerliche G esellschaft. Sozialtheoretische und sozialhistorische A spek te. D armstadt 1985, S. 43f.

$97 \mathrm{G}$ enau genommen kamen Kultivierung und Bildung später, im 18. Jahrhundert hinzu. 
überindividuelle, epochengemäße Gültigkeit dieser Freiheitsvorstellung für das 19. Jahrhundert bereitet sich nicht zuletzt eigentumstheoretisch in der freiheitstheoretischen Begründung des Eigentums durch Kant und Hegel vor. Bei den deutschen Philosophen handelt es sich mehr um die freiheitsstiftende und -sichernde bzw. -gewährende Bedeutung des Eigentums als um die Rechtfertigung der ungleichen Güterverteilung, wie es bei dem Oxforder Philosophen J. Locke der Fall ist. Denn die Unterscheidung zwischen dem inneren und dem äußeren „Mein“ und „Dein" (RL. Einl., WW IV, S. 345) bei Kant98 entspricht dem, was bei Locke die Unterscheidung zwischen angeborenen und erworbenen Rechten heißt. Die angeborenen Rechte, also das innere „Mein“ und „D ein“, d.h. das, nach Kant, „was jedermann von Natur zukommt“, reduziert er auf ein einziges: die Freiheit als „Unabhängigkeit von eines anderen nötigender Willkür" bzw. die Gleichheit „als Q ualität des Menschen, sein eigener Herr (sui iuris) zu sein." (RL. Einl., WW IV, S. 345). O rientiert an dem inneren Mein und D ein, das anders als bei Locke, bei dem das angeborene Eigentum sich auf die empirische Tatsache der eigenen Person und der eigenen Fähigkeit bezieht, von Kant als Gleichheits- und Freiheitsprinzip bezeichnet wird, bleibt seine Eigentumsbegründung freiheitstheoretisch. D ie Entstehung des Eigentums erklärt Kant nicht mit dem direkten Zusammenhang zwischen Person und Sache, der aufgrund der ,Arbeit' besteht.99 Anders als Locke verneint Kant die Existenz einer direkten rechtlichen Beziehung zu einer körperlichen Sache. Wie Locke sieht auch Kant den Übergang von Gesamtbesitz zum Privateigentum als notwendig an. Die Entstehung des Eigentums bezieht sich dabei auf die individuelle Freiheitssphäre. Die ursprüngliche Erwerbung ist also O kkupation mit G ewaltmotiv, die jedoch "mit jedermanns äußeren [sic] Freiheit nach einem allgemeinen Gesetz zusammenstimmt[e]" (RL § 7, WW IV, S. 354). Nicht die Arbeit ist ,eigentumsstiftend'. Sie ist „nichts weiter als ein äußeres Zeichen der Besitznehmung, welches man durch viele andere, die weniger Mühe kosten, ersetzen kann" (RL § 15, WW IV, S. 376). Das Possessivpronomen ,mein' bedeutet also nicht nur eine natürliche, erfahrbare Zugehörigkeit, sondern das ,mein' ist ein besitzanzeigendes Pronom mit rechtlicher Bedeutung, das Eigentum ist der rechtmäßige Besitz, also „das Mein und Dein nach der

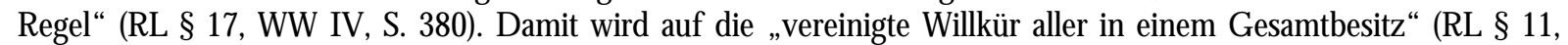
WW IV, S. 371), also die volonté générale, hingewiesen, welche erst das Recht auf Eigentum verbürgt. Mit der Idee eines a priori vereinigten Willens aller wird der Vernunftsanspruch des Erwerbs fundiert. Der ursprüngliche Erwerb ist bei Kant Zwangsakt der Okkupation, „Folge von einseitiger Willkür“ (RL § 7, WW IV, S. 369) des Individuums, dem der gemeinschaftliche Wille als provisorisch-rechtlicher Garant zustimmt. Von der gesamten Konstitution seiner Theorie her handelt es sich deswegen bei Kants Eigentumsdeduktion nicht mehr um dieselbe vor-lockesche, Grotiussche O kkupation. Kants Rückgriff auf die Okkupation bekommt einen sozialen Stellenwert innerhalb seiner Eigentumstheorie. Das von Kant konstruierte Eigentum als solches ist insofern das individuelle Recht des einzelnen, das das Prinzip größtmöglicher individueller Freiheit und das Prinzip des Erfordernisses der Kompatibilität individueller Freiheitssphären vereint. Die mit Eigentum konsolidierte Freiheit des Individuums ist deswegen bei Kant die Freiheit gegenüber jedem D ritten, negativ gewendet, die Ausschließung der bzw. die Abwehr von der Fremdbestimmung durch Dritte. Sie kommt aus der Vernunftidee der allgemeinen Akzeptierbarkeit von Normen, der Idee des vernünftigen Konsenses, d.h. der volonté générale, und wird auch durch diese garantiert. Lockes Eigentumstheorie stellt sich als Subjektivierungsmodell dar, welches das $\mathrm{O}$ bjekt vermittels der Handlung, der Arbeit subjektiviert und personifiziert. Demgegenüber versteht sich Kants Eigentumstheorie als Konsenstheorie,100 die versucht, Eigentum als Vernunftbegriff, d.h. als eine Idee, genauer eine praktische Idee, d.h. eine solche, der von Vernunft wegen Realität verschafft werden soll, zu begründen.101 Die Kritik von Kant an Lockes Eigentumstheorie richtet sich auf eine ihr zugrunde liegende „Täuschung, Sachen zu personifizieren“(RL § 17, WW IV, S. 380).

Auf den Stopfk uchen bezogen erschließt der Vergleich mit Lockes Theorie die personifizierte Seite der Symbolik der Roten Schanze, nämlich die Identität von Leben und Eigentum als Lebenswerk. Demgegenüber hilft Kants Eigentumsauffassung, die Form der Sozietät der Roten Schanze nicht zuletzt als an den dem bürgerlichen Eigentum zugrundeliegenden Konsens, an die Sozietät gebunden, zu verstehen. Die ,Sozietät' bleibt aber schwach bei der Roten Schanze, wie es in der bürgerlichen G esellschaft allgemein außerhalb der Eigentumsauffassung bei Kant war. Bekanntlich gehört innerhalb der bürgerlichen Tradition von jeher die Konsensfrage, die Frage nach der kommunikativ-kollektiven Vernunft, hauptsächlich einer anderen Denk- und Handlungskategorie als der des Eigentums an: der Kategorie der Öffentlichkeit. Auch Raabe thematisiert die kommunikativ-kollektive Vernunft nicht im Zusammenhang mit dem Eigentum, sondern bezüglich der zunehmenden Verselbständigung der Ö ffentlichkeit.

Im Zusammenhang mit dem Stopfkuchen ist Kants Eigentumstheorie eher in seiner Abwendung von der Lockeschen Arbeitstheorie hin zur Okkupationstheorie, in seiner Reaktualisierung des Okkupationsmoments, interessant. Okkupation ist denn auch bei der Roten Schanze-Symbolik ein dominantes sprachliches Phänomen, da

98 Die hier benutzte Ausgabe ist I. Kant, M etaphysik der Sitten, Rechtslehre, in: ders., W erk e in sechs Bänden. Hrsg. v. W. Weischedel, Frankfurt 1991, 9. Aufl. Bd. IV. (Abkürzung: RL [=Rechtslehre] WW IV.)

99 Vgl. RL §§ 13-17.

100 Vgl. dazu W. Kersting, E igentum, V ertrag und Staat bei Kant und L ocke, in: M. P. Tompson (ed.), John L odke und/ and Immanuel Kant. Berlin 1991, S. 109-134.

101 Vgl. RL §§ 1-5. 
hier stets von der ,Eroberung' - nicht von dem ,Erwerb'- die Rede ist. Offensichtlich operiert Raabe mit dem brutalen Moment der Okkupation, die nicht in ihrem ursprünglichen Sinn der Theorie von Grotius oder Pufendorf, ${ }^{102}$ sondern der Schopenhauers ${ }^{103} \mathrm{zu}$ verstehen ist. So führt Raabe die Okkupation als historischempirische Erklärung des Ursprungs des Eigentums ein: Die Rote Schanze hat als Schlachtfeld während des siebenjährigen Krieges gedient.

Die beschworene ,Eroberung', das Programm der gewaltigen Aktion der O kkupation, soll aber unsere Einsicht in die bürgerlich-modeme arbeitstheoretische Tiefenstruktur der Roten Schanze nicht trüben, die wir oben in Analogie zu Lockes Theorie gewonnen haben. Die Gleichzeitigkeit der beiden unterschiedlichen Ansätze in der Metapher der Roten Schanze gestaltet sich eher so, daß sich um den arbeitstheoretisch fundierten Kern der leichte Mantel der O kkupation hüllt.

Versucht Kant, Eigentum als eines der Vernunftprinzipien zu entwickeln, nach denen die rechtliche Realität gestaltet werden soll, so liegt es Hegel daran, das Prinzip des Eigentums als ein der rechtlichen Realität immanentes Vernunftprinzip zu begründen und systematisch darzustellen. ${ }^{104}$ Für die Lektüre des Stopfk uchen interessiert vor allem die Tatsache, daß auch bei Hegel der Anspruch des Individuums auf Eigentum freiheitstheoretisch begründet wird. Anstatt den ursprünglichen Erwerb mit Hilfe einer Rekonstruktion des Naturzustandes zu erklären, betrachtet Hegel das Eigentum vor allem als Zueignungsrecht gegenüber der Natur, das für die Befriedigung der natürlichen Bedürfnisse notwendig ist. Weil der Mensch im Prozeß des tätigen Zurichtens der Natur die „strenge[] Naturnotwendigkeit der Bedürfnisse" (Rhpil, § 194)105 durchbricht, bedarf die Person der Sache, in die sie ihren Willen legt, damit sie den „Schein von Selbständigkeit"(Rphhil, § 44), den die Außendinge im Bewußtsein haben, durch die wahre Wirklichkeit des freien Willens ersetzt. Damit "Ich als freier Wille“ zu "wirkliche[m] Wille[n]" (Rphil, § 45) werden könne, solle sich die Person eine „äußere Sphäre der Freiheit“ (Rphil, §41) schaffen. Dies formuliert Hegel folgendermaßen: „Die Person muß sich eine äußere Sphäre ihrer Freiheit geben, um als Idee zu sein" (Rphil, § 41). In dieser Willens- und Persönlichkeitsgebundenheit hebt sich nach Hegel das Eigentum von dem Besitz ab, wie es auch der späteren terminologischen Unterscheidung von Besitz und Eigentum entsprechend ist:

$\mathrm{D} a ß$ ich etwas in meiner selbstäußeren $\mathrm{G}$ ewalt habe, macht den Besitz aus, so wie die besondere Seite, daß Ich etwas aus natürlichem Bedürfnisse, Triebe und der Willkür zu dem Meinigen mache, das besondere Interesse des Besitzes ist. Die Seite aber, daß Ich als freier Wille mir im Besitze gegenständlich und hiermit auch erst wirklicher Wille bin, macht das Wahrhafte und Rechtliche darin, die Bestimmung des Eigentums aus. (Rphil, § 45)

Die Auffassung vom Eigentum als äußerer Sphäre, die die Person nötig hat, um selbst Idee zu sein, um die eigene Identität zu verwirklichen, diesem Gedanken kommt eine Aussage Schaumanns sehr nahe. Er verknüpft die Rote Schanze mit der Vorstellung des freien Spielraums für die Entfaltung seiner Individualität. Seine Persönlichkeit, von den andern verkannt und als "gemütliches Fett" aufs rein Leibhafte herabgestuft, deklariert Schaumann als Ideelles, welches ironisch als Lyrisches und Episches literarisiert wird.

Für alles, mit welchem ich meinerseits da unten in der Stadt und in eurer Schule nicht aus mir herauskommen durfte, hatte ich hier oben freiesten Spielraum. Da entwickelte sich, was ich an Lyrischem und Epischem in dem hatte, was ihr da unten als mein gemütliches Fett zu bezeichen pflegtet. (S. 115)

Hier besteht offenbar eine Affinität mit der Hegelschen Vorstellung von der inneren Freiheit der Person, sich „als Idee“ zu entfalten, und zwar durch Eigentum als Ort für das „D asein der Persönlichkeit“. ${ }^{106}$ Eigentum ist bei Hegel der Definition nach das "Objektivwerden der subjektiven Freiheit" (Rphil, §49). In seiner freiheitstheoretischen Rechtfertigung des Eigentums versucht Hegel, der dem bürgerlichen Eigentum immanenten Spannung zwischen ,besitzindividualistischem ${ }^{\prime 107}$ Egoismus und Gemeinwohl Rechnung zu tragen. So wird die bürgerliche Gesellschaft bei Hegel - wie bei den anderen bürgerlichen D enkern auch - als Zusammenschluß „freier und gleicher Individuen“ definiert, „die zueinander in Beziehung stehen als Eigentümer ihrer eigenen Fähigkeiten und dessen, was sie durch deren Anwendung erwerben"(Rphil, § 182). Dieser Aspekt des Gemeinwohls, des gegenseitigen Abhängigkeitsverhältnisses, scheint aber im Stopfk uchen völlig auszubleiben bzw. ist nicht aktualisiert, da hier die Beziehung unter den Individuen als Eigentümem vordergründig als Konkurrenzverhältnis von „Schnellfüße[n]" aufgefaßt wird.

102 Nach der Okkupationstheorie von Grotius und Pufendorf gründet sich die Rechtmäßigkeit des ursprünglichen Eigentumserwerbs nicht auf das bloße Faktum der Eroberung, sondern auf einen ausdrücklichen oder in der Regel stillschweigenden Vertrag, der jenes Faktum einer ersten Besitznahme als Rechtstitel ersetzt. Vgl. dazu R. Brandt, E igentumstheorien von G rotius bis Kant. Stuttgart; Bad Cannstatt 1974, S. 31f.; M. D ießelhorst, Z um V ermögensrechtssystem Samuel Pufendorfs. Göttingen 1976, S. $21 f$.

103 Schopenhauer versteht unter dem Begriff der Okkupation ein Faustrecht; so kritisiert er fälschlicherweise Kants okkupationstheoretische Begründung des ursprünglichen Erwerbs: „D aß Kant die Inhabung oder das in meiner G ewalt seyn, als Princip des Eigenthum-Rechts setzt, ist grundfalsch: dies ist das Princip des Faustrechts." (A. Schopenhauer, D er handschrifliche N achlaß. Band 2. Frankfurt/ M. 1967, S. 262).

104 Allgemein zur Eigentumstheorie Hegels vgl. W. Euchner, E goismus und G emeinwohl. Frankfurt/ M. 1973, S. 132f.

105 G.W.F. Hegel, G rundlinie der Philosophie des Rechts. in: ders., W erke in 20 Bänden. Hrsg. v. E. Moldenhauer / K. M. Michel. Bd. 7. Frankfurt/ M. 1986. Wie vorher bei Locke wird die Q uelle der weiteren Hegel-Zitate in einer dem Text angeschlossenen Klammer angegeben. Nach der Abkürzung ,Rphil' folgt die Ziffer des Paragraphen.

106 G. W. F. Hegel, Rphil § 51.

107 Zur Terminologie des ,Besitzindividualismus' vgl. C. B. Macpherson, D ie politische Theorie des Besitzindividualismus. Frankfurt/ M. 1990. 


\section{Sozialk ritischer $G$ ehalt der E igentumsauffassung}

Um die halb verborgene, halb offensichtliche Bedeutung der Roten Schanze als bürgerliches Eigentum zu explizieren, wurde bis jetzt versucht, die modernen natur- und vernunftrechtlichen Eigentumstheorien von Locke, Kant und Hegel zur Interpretation der Symbolik der Roten Schanze hinzuzuziehen. Nicht beabsichtigt wurde, ihre Theorien als solche zu referieren; statt dessen wurden die Hauptthesen der Theoretiker, wie sie als G rundzüge der bürgerlichen Eigentumsauffassung in deren weitere Entwicklung eingegangen sind, als begriffliches und juristisches A priori bestimmt und betrachtet. Vor dem Hintergrund dieses ideologischen A priori konnte klar werden, daß die Symbolik der Roten Schanze als eine literarische Konzession an das bürgerliche Eigentum gelesen werden soll. Die Rote Schanze-Symbolik ist eine Übersetzung eines bestimmten Freiheitsbegriffs, der aus dem bürgerlichen Eigentumsbegriff mit seiner historisch-ideellen Emanzipationsfunktion stammt. Dieser inneren Spannung der Idee der Freiheit durch Eigentum kann man etwa mit der ironisierenden Formulierung der Freiheit als Freiheit der Isolation von der bürgerlichen Gesellschaft durch die bürgerliche Daseinsform den passenden Ausdruck geben. Ebenso wohlgeordnet und zugleich isoliert wirkt die Lebensführung der Heldenfigur als Herr der Roten Schanze. Die öfter bemerkte Spannung bzw. Diskrepanz der Roten Schanze zur alten Idylle des Gemeinwesens könnte auf dieses Isolationsmoment zurückgeführt werden: $\mathrm{Da}$ in der bürgerlichen $\mathrm{G}$ esellschaft sich eine Sozialwelt erst über den Markt bildet, d.h. daß Individuen sich als Eigentümer, also nur aufgrund einer Marktbeziehung und damit indirekt zueinander verhalten, ist eine zwischenmenschliche Isolation für das bürgerliche Eigentum gerade konstituierend. Es ist deswegen nicht mit der Isolation von der Natur der alten autarkischen $\mathrm{Gemeinschaft} \mathrm{zu} \mathrm{verwechseln.} \mathrm{Die}$ bürgerliche Isolation, wie Schaumanns Rote Schanze sie darstellt, ist also die Form der individuellen Unabhängigkeit. Die Isolation von der Dorfgemeinschaft, in der Schaumann und seine Frau ihr Leben führen, ist anderer Natur als das aufgezwungene Alleinsein in seiner Jugendzeit. Sie bedeutet eine freiwillige, selbst gestaltete und insofern eine stilisierte Lebensform, hinter der der besitzindividualistische Freiheitsbegriff der Lockeschen Eigentumsauffassung zu stehen scheint.108

Allerdings muß dieses Verhältnis wohl modifiziert werden. Die D orfgemeinschaft ist schwerlich als die bürgerliche $G$ esellschaft aufzufassen, auf die sich die besitzbürgerliche Freiheitsidee vermeintlich richtet. Sie ist eher auf die deutsche Realität des ausgehenden 19. Jahrhunderts zugeschnitten und besteht aus besitzlosen, kleinbürgerlichen Massen, während die Lockesche Eigentumstheorie als theoretischer Ausdruck seines zeitgenössischen Umfeldes zu verstehen ist und sich damit noch auf die gesellschaftlichen Verhältnisse zwischen selbständigen Kleinbauern bezieht.109 Es handelt sich deswegen eher um eine Strukturähnlichkeit zwischen der ,besitzindividualistischen' Freiheit durch eine marktwirtschaftlich vermittelte Isolation und Schaumanns Freiheit auf der Roten Schanze in Form einer ausgeprägten, teilweise aggressiven Distanz zur Gemeinschaft. Zudem ist, wie schon bezüglich Kants erwähnt, die Distanz Schaumanns zur Dorfgemeinschaft mehr von einem Problembewußtsein gegenüber der zeitgenössischen Ö ffentlichkeit geprägt, worauf ich später eingehen werde.

Im folgenden sollen noch einige kontrovers diskutierte Aspekte beleuchtet werden, um meine Interpretation der Roten Schanze als im Grunde durchaus bürgerliches Eigentum weiter zu fundieren. Dabei handelt es sich im Vordergrund um die begriffliche Verwirrung, auf die die Dissonanzen zwischen Forschungsmeinungen im Untersuchungsfeld der Eigentumsproblematik zum großen Teil zurückführbar sind. Z.B. ist die Beobachtung an sich richtig, daß Schaumanns Rote Schanze alles andere sei als das auf Nützlichkeit gerichtete, durch Umwandlung des Gebrauchswertes in den Tauschwert gekennzeichnete Eigentum, da sie zutiefst mit der Persönlichkeit der Figur verbunden ist. Ein Irrtum ist es aber dann, wenn man meint, aus der Beobachtung schließen zu können - wie dies manchmal in der Forschungsliteratur der Fall ist -, daß diese Eigentumsauffassung nicht als ,bürgerlich' zu bezeichnen sei. Ich habe ausgeführt, daß die Rote Schanze gerade aufgrund der Art ihrer Personengebundenheit für das ,bürgerliche' Eigentumsverständnis steht. Der Irrtum besteht nach meinem Dafürhalten wohl darin, daß man die ,bürgerliche' Eigentumsauffassung überhaupt mit der ,kapitalistischen' gleichsetzt. Z.B. verwendet Sprengel den Terminus ,vorbürgerlich' für Raabes offensichtlich nicht-kapitalistischen, persönlichen Eigentumsbegriff. Er beruft sich dabei auf Marx und dessen Analyse der Zerstörung der agrarischen und handwerklichen Eigentumsverhältnisse im Kapitalismus. Sprengel scheint das agrarische, handwerkliche Eigentum als mit dem ,vorbürgerlichen' Eigentum deckungsgleich zu verstehen. $\mathrm{Zu}$ dem vorbürgerlichen Eigentumsbegriff gehört aber auch die feudalistische Eigentumsauffassung, die keineswegs auf Raabes Auffassung, weder auf den Stopfkuchen noch auf andere Werke, anwendbar ist. Das ,Vorbürgerliche', wie Sprengel den Begriff gebraucht, ist außerdem ein an sich problematischer Epochenbegriff, dem eine gewisse epochale Geschlossenheit fehlt: Das agrarische und handwerkliche Eigentum hat sich nicht so ausgebildet, daß es als Epocheneinheit in der Abgrenzung sowohl zum eigentlich feudalistischen als auch zum bürgerlich-kapitalistischen Eigentum begriffen werden könnte. Damit zusammenhängend ist der sogenannte Oikos, das ganze Haus des G eschlechts, das als Eigentums- und Sozialform der ,Vorbürgerlichkeit' oft

108 Zur Zuordnung von Kants Eigentumslehre zur Tradition des liberalbürgerlichen Besitzindividualimus vgl. R. Saage, E igentum, Staat und G esellschaft bei Immanuel Kant, S. 7f. Zur Plausibilität dieser Interpretationsrichtung vgl. W. Kersting, W ohlgeordnete F reiheit, S. $154 f$.

109 Vgl. dazu C. B. Macpherson, D ie politische Theorie, S. 295f.; näher eingehend vgl. N. Wood, John L ocke and A grarian Capitalism. Berkeley 1984. 
utopisch gegen die Entfremdung und Abschottung durch das kapitalistische Eigentum ausgespielt wird. Hier wäre darauf hinzuweisen, daß bezüglich der Roten Schanze von einem Bauernhof im Sinne einer Knechte und Gesinde einschließenden alten Lebens- und Produktionsform gar nicht zu sprechen ist. Die Rote Schanze ist von der offenen Sozial- und Produktionsform O ikos entfernt. Sie ist ein ausschließlich (klein-)bürgerlicher, landwirtschaftlicher Hof, was Sprengel auch mit dem Begriff der "kleinfamiliale[n] Behaglichkeit"110 Schaumanns anmerkt. Dabei stellt Quakatz' Rote Schanze die mißlungene Variante der bäuerlich-bürgerlichen Ordnung dar, da in ihr die veraltete feudale (Un-)O rdnung überlebt und zeitweise unkontrollierbar wuchert. Dies betrifft besonders den letzten Zustand des Hofes, bevor Schaumann die durch häufige Abwesenheit des Besitzers wirtschaftlich ruinierte Rote Schanze und deren junge Herrin von der drohenden $G$ ewalttätigkeit der Knechte befreit:

[...] der Knecht hatte mir [der Tochter Quakatz; J.-H. B.] an dem ganz besondern Nachmittage wieder mal die Faust unter die Nase gehalten und die Magd mir den Kochlöffel vor die Füße geworfen. Einen von den Hunden wenigstens hatte ich ja immer bei mir, um mich mit ihm im letzten Notfall zu wehren; aber an dem Sonntage hatten sie mir auch gedroht, sie mir alle zu vergiften. Ei freilich, wenn sie dieses ausgeführt hätten, ehe Heinrich kam, so wäre ich freilich bis dahin ganz verraten und verkauft und in ihren Händen gewesen. (S. 126)

Der Übergang des Besitzes der Roten Schanze von den Quakatzens zu Schaumann ist unter diesem Aspekt die Vergewisserung bzw. Etablierung oder der Ausbau der bürgerlichen O rdnung. Zudem ist die bäuerliche Form gegenüber dem bürgerlichen Element sekundär. So stellt sich die Frage, ob die Produktionsform Bauernhof die unabdingbare Substanz des Eigentumsbegriffs der Roten Schanze darstellt. Schließlich verkauft der Protagonist sein G rundstück an eine Zuckerfabrik, um als Aktieninhaber dieser Fabrik seinen Lebensabend abzusichern. Diese Art von Wandel der Eigentumsform läßt nicht zu, die in der Roten Schanze entfaltete Eigentumsauffassung in jene auf ,Grund und Boden' fixierte bäuerliche Eigentumsauffassung einzugrenzen. Unmißverständlich ist dabei auch, daß das Wesentliche der Eigentumsvorstellung in der Roten Schanze in ihrem Antagonismus zu der kapitalistischen Entwicklung liegt. D er Ausgangspunkt der Kritik, die Raabe als Reaktion auf den weitgehenden Eigentumsverlust der Massen übt, ist deswegen nicht, vorbürgerlich', weder auf den Oikos bezogen, noch bäuerlich, sondern antikapitalistisch, aus der klassisch bürgerlichen Position heraus. Wenn Schaumanns Rote Schanze in die inzwischen aufkommende kapitalistische Eigentumsform der Fabrikaktien übergeht, so rührt diese Kompatibilität mit der Produktions- und Eigentumsform der Zeit von der Tatsache her, daß der bürgerlich-ideale und der kapitalistische Eigentumsbegriff zwar begrifflich auseinanderzuhalten sind, aber einander nicht ausschließen müssen, so wenig wie sie notwendig zusammengehören müssen. Die sich nun durchsetzende kapitalistische Form von Eigentum ist einerseits die Konsequenz des bürgerlichen Eigentums, andererseits hebt sie selbiges auf. Mitten in der Akkumulationsbewegung des Privateigentums trägt die personengebundene Eigentumsform des unabhängigen Besitzbürgers bereits ihre Krise in sich. Die sozioökonomische Metamorphose der Roten Schanze, ihre Verwandlung in vergesellschaftetes Kapitaleigentum (Aktien der Zuckerfabrik) verkörpert gerade den Selbstentfaltungs- und zugleich Selbstauflösungsprozeß der bürgerlichen, persongebundenen Eigentumsform. Die eigentliche Zielscheibe der in der Roten Schanze proklamierten Eigentumsvorstellung ist gerade der Verlust der Personengebundenheit des Eigentums im Kapitalismus.

An der üblichen Etikettierung Raabes als eines konservativen Sozialkritikers kann nach dem hier vorgelegten Forschungsergebnis kaum weiter festgehalten werden. Dies betrifft besonders die Feststellung, daß die ,antikapitalistische' O rientierung seines Eigentumsbegriffs rückwärtsgewandt, retrospektivistisch und reaktionär sei.111 Seine Eigentumsauffassung in der Eigentumsform der Roten Schanze ist eine, allgemein-bürgerliche ${ }^{t}$ Auffassung in ihrer ursprünglich ,besitzbürgerlichen' Ausprägung, was seine Sozialkritik als eine durchaus idealbürgerliche Kritik an der bürgerlichen Wirklichkeit in Deutschland charaktersieren läßt. Diese Konvergenz mit der klassischen Form der Bürgerlichkeit des 17. Jahrhunderts ist die Grundlage bzw. der Ausgangspunkt von Raabes bildungsbürgerlicher Verschiebung. Während bei Locke die Einheit von Bildung und Besitz stillschweigend vorausgesetzt wird,112 bedeutet ihre Einheit unter der Bedingung der zunehmend divergierenden Kategorien von Besitz und Bildung im Deutschland des ausgehenden 19. Jahrhunderts keine Voraussetzung mehr. Sie stellt sich vielmehr dem Künstler als Aufgabe seiner künstlerischen Formierung dar. Den Anspruch auf Repräsentativität für die Zeit kann Raabe in dem Sinne für sich in Anspruch nehmen, indem er die ursprünglich ,besitzbürgerliche' Kategorie des Eigentums im Augenblick ihrer realen Auflösung bildungsbürgerlich neu konstituiert. Die Zeitbe-

110 P. Sprengel, Interieur, S. 163.

111 Z war einzelnen Beobachtungen Sprengels bezüglich Raabes Eigentumsthematik zustimmend kritisiert Irmgard Roebling (W ilhelm Raabes doppelte Buchfürung. Paradigma einer Spaltung. Tübingen 1988, S. 201f.) jedoch auch Sprengels etwas vereinfachende Interpretation von Raabes Tendenz zur Regression in vorbürgerliche Produktionsverhältnisse. Ihr Anhaltspunkt ist dabei E. Blochs Kategorie von ,gleichzeitigen' und ,ungleichzeitigen' Widersprüchen, nämlich die Einsicht in die Wichtigkeit des geschichtlichen Kontextes der deutschen G esellschaft der Zeit, von dem ein dichterisches Werk nicht isoliert betrachtet werden kann. Bloch nennt D eutschland im 19. und frühen 20. Jahrhundert „das klassische Land der Ungleichzeitigkeit" mit dem „unüberwundenen Reste älteren ökonomischen Seins und Bewußtseins" (Zitiert nach I. Roebling, S. 202). Schildert Raabe vordergründig die rückwärts gewandten Ideale, so geschieht dies, so Roebling, nicht unkritisch-unbewußt, nicht als "wirkliche[r] Ansatzpunkt zur Lösung", sondern "durch verschiedene poetologische Strategien signalisiert" (ebd., S. 203), gleichsam als reflektierte Widerspiegelung der ,ungleichzeitigen' Wirklichkeit.

112 D azu U. Haltern, Bürgerliche G esellschaft, S. 43f. 
zogenheit der Symbolik der Roten Schanze als Symbolik des bürgerlichen Eigentums funktioniert aber nicht nur in affirmativer Weise, d.h. der bildungsbürgerlichen Grundtendenz der Zeit entsprechend. Im programmatischen Schlagwort der ,Eroberung' holt Raabe jenes G ewaltmotiv des Ursprungs des bürgerlichen Eigentums wieder ein. Die Reaktualisierung der Okkupation à la Schopenhauer an der Oberfläche der tiefenstrukturell besitz- und bildungsbürgerlichen Eigentumsauffassung ist polemisch intendiert. Mit der Reaktualiserung des Gewaltmotives wird darauf angespielt, daß im Zeitalter der bürgerlichen Eigentumsauffassung und der Arbeitstheorie das Konzept der O kkupation immer noch real gültig ist. D ie Anspielung zielt wohl auchauf die Zeitgeschichte des Kolonialismus und deren hohe Aktualität der O kkupation. Dies ist die widersprüchliche Realität des bürgerlichen Eigentums zwischen Jenseits und Diesseits der bürgerlichen Gesellschaft - innerhalb der bürgerlichen Gesellschaft setzt sich die Arbeitstheorie durch, in Übersee im Expansionszug der bürgerlichen Gesellschaft die O kkupation. ${ }^{113}$

\section{II. „Krieg gegen die Philister!" 114: Die Rote Schanze und die Fom derÖffentlichkeit}

Die Eroberungsgeschichte der Roten Schanze ist neben dem Eigentumserwerb zugleich der Prozeß, in dem sich der Held Heinrich Schaumann gegen Mißachtung und Bedrängnis von seiten seiner philisterhaften Umgebung behauptet und am Ende als der wirklich gebildete, ethisch wertvolle, geistig überlegene Mensch über seine Umgebung triumphiert.115 Die gar programmatisch ausfallende Antinomie zwischen der Heldenfigur und seiner Umgebung wird in der Forschung häufig allzu ,textnah' aufgefaßt, d.h. als Anklage gegen die Gewalt der Gesellschaft im Sinn eines psychologisierenden und moralisierenden Individualismus; die zeitgeschichtliche, sozialkritische Dimensionierung dieser Antinomie trat in den 80er Jahren hinzu. Dabei stand die Erscheinung der bei Raabe häufig auftretenden ,Außenseiterfigur' - so kann man auch Heinrich Schaumann in seiner Gegenposition zur Umgebung nennen - im Mittelpunkt der Betrachtung.

E in Teil der Forschung beschäftigt sich mit der Einordnung der Außenseiterfigur in den zeitgeschichtlichen aktuellen Kontext. ${ }^{116}$ D ie andere Forschungsperspektive bemüht sich um eine ideengeschichtliche Erhellung. Dieter Kafitz versucht in Ergänzung seiner Habilitationsschrift den „wiederkehrenden Figurentypus" des Außenseiters bei Raabe "genauer zu erfassen und geistesgeschichtlich einzuordnen“.117 Ihm zufolge ist Raabes Außenseiter als Plädoyer für das individualistische Prinzip gegen die uniforme Gesellschaft im Sinne des englischen Liberalen John Stuart Mill zu verstehen. Kafitz liegt daran, die sozialkritische Position der Raabeschen Figur des Außenseiters vor der Folie sozialphilosophischer Überlegungen von Mill, besonders im Rahmen von dessen verbreiteter Abhandlung 0n L iberty (1859), zu verdeutlichen, ohne dabei die Problemstellung auf die Ebene der Rezeption bzw. Wirkung reduzieren zu wollen. Kafitz' Vergleich stellt den G emeinplatz einer inhaltlichen Verbindung beider Autoren klar, ein Inhalt, der aber sicherlich nicht allein von diesen beiden vertreten wurde, sondern der für das individualistische Menschenbild des 19. Jahrhunderts überhaupt Gültigkeit besitzt. Mit dem Hinweis auf die Strukturähnlichkeit mit Mills Kritik hat Kafitz in Wirklichkeit nur den ersten wichtigen Schritt getan, um Raabes spezifische Form der Antinomie des Ausnahmemenschen und seiner Gegenfigur im Kollektiv in ihrem liberalistischen Kern zu durchdringen. Im folgenden geht es darum, Raabes ,Kritik an der Ö ffentlichkeit' in ihrer spezifischen Gestaltung und Gerichtetheit qua differenzierender Unterscheidung von dem liberalistischen sozialtheoretischen Denken der Zeit zu präzisieren.

\section{1. ,Pitaval' oder das Prinzip der Ö ffentlichk eit}

Das Mißtrauen gegenüber der Öffentlichkeit setzt die Institutionalisierung der Öffentlichkeit voraus. Der Prozeß geht historisch mit der Erkenntnis der potentiellen Gefahr einer Ö ffentlichkeit einher, die in eine Tyrannei der Mehrheit umschlägt. In Frankreich ist es Alexis de Tocqueville, „ein Liberaler sondergleichen“, 118 der mit dem

113 Hinzuweisen ist jedoch darauf, daß auch die Arbeitstheorie ein die koloniale Erschließung der Erde rechtfertigendes Argument enthält. D azu siehe besonders J. Locke, Z weite A bhandlungen, § 45; „Und dennoch lassen sich immer noch große Bodenflächen finden, die brach liegen. [...] Diese Flächen sind größer, als die darauf wohnenden Menschen wirklich gebrauchen oder nutzen können, und sind aus diesem G rund auch jetzt noch Gemeingut." Ein solches Argument rechtfertigt unmißverständlich die Kolonialisierung von Nordamerika und Australien, aber m.E. nicht die Kolonialisierung von Indien.

114 W. Raabe, Sämtliche W erke, Erg. Bd. II, S. 183.

115 Vgl. D. Kafitz, Figurenk onstellation als M ittel der W irk lichk eitserfassung. D argestellt an Romanen der zweiten H ältte des 19. Jahrhunderts (F reytag. Spielhagen. F ontane. Raabe). Kronberg/ Ts. 1978, S. 217.

116 Z ur biographischen Beleuchtung besonders der Stuttgarter Zeit als Nachzeichnung der politischen Entwicklung Raabes im Jahrzehnt vor der Reichsgründung siehe, H ie W elf! H ie W aiblingen! W ilhelm Raabe in Stuttgart 1862-1870. Bearbeitet v. Jochen Meyer, in: Marbacher Magazin 20/1981.

117 D. Kafitz, D ie A ppellfunk tion der A ußenseitergestalten: Zur näheren Bestimmung des Realismus der mittleren und späten Romane W ilhelm Raabes, in: L. A. Lensing / H.-W. Peter, W ilhelm Raabe. Studien zu seinem L eben und W erk. Braunschweig 1981, S. 51f., hier S.74.

118 A. Jardin, A lex is de T ooqueville. L eben und W erk. Frankfurt/ M.; New York 1991, S. 496. 
Engländer Mill vergleichbar ist. Sie sahen beide in der ersten Hälfte des 19. Jahrhunderts ihre Gesellschaft im Zug der Demokratisierung mit vielen unerwarteten Wirkungen konfrontiert. Jedoch unterscheiden sich ihre Diagnosen der Zukunft der Gesellschaft voneinander, was sich wohl auch auf die individuelle Besonderheit jedes Landes in seiner geschichtlichen Erfahrung mit der Institution der Öffentlichkeit zurückführen läßt. Die Abwendung von der Öffentlichkeit geht aber sowohl bei Mill als auch bei Tocqueville mit der Ausdehnung der politischen Gleichheitsrechte auf alle sozialen Klassen einher.

Ihre Kritik an der Öffentlichkeit markiert nämlich den Beginn der Entwicklung der bürgerlichen Öffentlichkeit zur Massendemokratie. Die liberale Kritik an der Öffentlichkeit von Mill und Tocqueville bewegt sich nun in der Spannung von Publizitäts- bzw. Vernunftsprinzip der Öffentlichkeit und seiner Verwirklichung: Sie „werten den Vorgang, den sie um des Prinzips der Öffentlichkeit willen bejahen, in seinen Auswirkungen um desselben Prinzips willen wieder ab." ${ }^{119}$ Nicht die Demokratie selbst wird bei Tocqueville und bei Mill verneint, sondern es wird befürchtet, daß die Allmacht der öffentlichen Meinung und die Herrschaft der Mehrheit einen Konformismus begünstigen würden, in dem der einzelne als räsonnementfähiges Subjekt verschwindet. So sehr sie aber in ihrem individualistischen Standpunkt übereinstimmen, so verschieden sind doch ihre einzelnen Beobachtungen bezüglich der jeweiligen gesellschaftlichen Bedingungen und Tendenzen.

Führt Tocqueville die Tyrannei der Mehrheit auf die durch die ,Gleichheit der Bedingungen' gekennzeichnete demokratische Revolution zurück, ${ }^{120}$ so argumentiert Mill mit dem allgemeinen Fortschritt, der höheren Zivilisation durch den industriellen Fortschritt und der Ausweitung der Bildungschancen, die Mill gemäß der sozialen Entwicklung in England als von dem "Geist der Reform"121 getrieben betrachtet.

Das wilhelminische Deutschland bietet wiederum anders geprägte Voraussetzungen für die kritische Auseinandersetzung mit der Öffentlichkeit, als dies beim viktorianischen England für Mill oder dem damaligen Frankreich Tocquevilles der Fall ist. Bei Raabe findet man die Kritik auf die Bildung als soziale und geistige Basis für eine konforme Gesellschaft konzentriert. Schaumann nennt das Gymnasium eine "gymnastische Affenrepublik“(S. 89) und einen „Kulturpferch“(S. 116), aus dem „europäische[] gezähmte[] Esel[], Affen und Rhinozerosse[]” (S. 116) ins öffentliche Leben entlassen werden.

Nicht nur die Entfaltung und Erhaltung der Individualität ist vom Konformismus gefährdet, sondern dem folgt auch der Mißstand des öffentlichen Lebens. Es verdient Aufmerksamkeit, daß Raabes Kritik an der Bildung ausdrücklich auf die Kritik an der gebildeten Gesellschaftsschicht als den Hauptschuldigen für die Misere des öffentlichen Lebens hinausläuft:

Jeder Blick in eure Gerichsstuben, auf eure Schulkatheder und Kirchenkanzeln und in eure Landtage und vor allem in den deutschen Reichstag zeigt, was dabei herauskommt, soweit es unsere leitenden gelehrten Gesellschaftsklassen anbetrifft. (S. 130)

Man sieht, daß hier der Reichstag, die deutsche Wirklichkeit des Parlamentarismus, mit der Bildung unmittelbar in Zusammenhang gebracht wird. Man kann aber nicht näher bestimmen, was genau der Kritikpunkt in bezug auf den Reichstag im Sinne Raabes sein soll. Jedoch ist es schwierig, dies im Sinne einer totalen Ablehnung des Parlamentarismus überhaupt zu verstehen, wie D. Kafitz unterstellt.122 Eher scheint Raabe sich auf die konformistische und kompromistische Praxis des Reichstags gegenüber der Kanzlerbürokratie bezogen zu haben.

Vergleichbar mit Raabes Bedenken gegenüber dem Konformismus in der parlamentarischen Praxis des Reichstags ist die Weitsicht von Tocqueville. Tocquevilles Kritik am Konformismus geht über die soziale Einschränkung der Entfaltung der Persönlichkeit des Individuums hinaus. Er betrachtet das Phänomen in Verknüpfung mit der Zentralisierung der Verwaltungsgewalt und erkennt in der Bürokratie die politische Gefahr der modernen $\mathrm{G}$ esellschaft in ihrer zivilisatorischen Tragweite.123

Anders akzentuiert dies bereits das viktorianische England Mills. Damals herrschte eine fast völlige Einflußlosigkeit des Staates in Angelegenheiten, die das Privatleben betrafen; es gab kaum Steuern, keine Regulierung des Wirtschafts- und Soziallebens, und ein fast völliger Mangel an Zwang durch öffentliche Gewalt war die Regel.124 So konzentriert Mill seine Konformismuskritik ausschließlich auf die soziale Gewalt gegenüber dem Individuum.

An dieser Stelle sei auf diese weitere Zielrichtung von Raabes Bildungskritik hingewiesen, die bis jetzt in der Forschung kaum wahrgenommen worden ist. Denn die Forschung hat bezüglich des Bildungsthemas bei Raabe

119 J. Habermas, Struk turwandel der Ö ffentlichk eit: Untersuchungen zu einer Kategorie der bürgerlichen G esellschaft. Frankfurt/ M. 1990, S. 213.

120 Vgl. A. de Tocqueville, II T eil. 7. Kapitel. Ü ber die A llmacht der M ehrheit in den V ereinigten Staaten und über ihre W irk ungen, in: ders., Ü ber die D emok ratie in A merika $(1835,1840)$. 2 Bde. Zürich 1987. Bd. 1.

121 J. St. Mill, D ie Freiheit. Hrsg. v. A. Grabowsky. Zürich 1945. S. 206.

122 Vgl. D. Kafitz, D ie A ppellfunktion, S. 53; „D as Ziel einer freien Entfaltung des einzelnen führte zur Abneigung gegen jegliche Art von Institutionalisierung, worunter Raabe auch den Parlamentarismus zählte."

123 Der Prozeß der Zentralisierung hat für Tocqueville bereits im feudalen Zeitalter eingesetzt. Daß und wie die Revolution selbst Konsequenz und Vorzeichen des langwierigen Prozesses der Zentralisation ist, ist Tocquevilles Hauptgedanke in seiner Analyse von D er alte Staat und die Revolution (1856).

124 Vgl. H. Rausch, J. St. Mill, in: ders. u.a. (Hrsg.), Klassiker des politischen D enkens. Bd. II. Von Locke bis Max Weber. München 1968. S. 240-261, hier S. 246. 
immer wieder nur von dem „Bildungsindividualismus“125 gesprochen. Daß Raabes Standpunkt sich mit dem Tocquevilles in seiner Furcht vor einer zentralisierten Verwaltungsgewalt in Staat und Regierung berührt, ist hinsichtlich der deutschen gesellschaftlichen Entwicklung seiner Zeit plausibel und dürfte als realistische Einschätzung verstanden werden. Diese Annahme wird dadurch gestützt, daß im Stopfkuchen der Subbeamte der Reichspost, Landbriefträger Störzer - der fügsame Untertan des allmächtigen Staates - , in engem Zusammenhang mit der konformen $\mathrm{G}$ esellschaft steht.

Raabes Öffentlichkeitskritik zeigt trotz der Vergleichbarkeit mit Mill und Tocqueville eine eigene Perspektive. Bei der Gestaltung der Zeiterscheinung der bürgerlichen Öffentlichkeit, die in ihrem kritischen Potential nach und nach durch wachsenden Konformismus zerstört wird, lehnt sich Raabe an das Bild des konsumierenden Lesepublikums in der zeitgenössischen literarischen Szene an. Die Öffentlichkeit tritt hier nicht politisch, sondern in der Form einer dörflichen Gemeinschaft auf, die sich anläßlich eines Mordfalls als Meinungskollektiv präsentiert. In der über den Mordfall kommunizierenden Gemeinschaft findet sich ein Prototyp der literarischen Ö ffentlichkeit widergespiegelt. Es ist dies die literarische Öffentlichkeit, die, mit den literarischen Bearbeitungen der ,merkwürdigen' Kriminalfälle, sich mehr oder weniger in den Dienst der Wahrheit und Menschenkunde zu stellen hatte, und insofern für die gleichen Funktionen wie der juristische Bericht versehen wurde.

Der Begründung des Genres der ,Kriminalgeschichte' in der deutschen Literatur in der zweiten Hälfte des 18. Jahrhunderts lag eine Vorstellung darüber zugrunde, welchen besonderen gesellschaftlichen Nutzen das öffentliche Gespräch über Kriminalfälle bringen könnte. Als Vorlage für dieses Genre diente die mehrmals übersetzte Sammlung von Rechtsfällen des französischen Juristen F. Gayot de Pitaval (1734), deren Titel dann als Genrebezeichnung für Sammlungen von Kriminal- und Strafrechtsfällen jeder Art benutzt wurde. So entsteht in der Mitte des 19. Jahrhunderts die deutsche Version, der neue Pitaval.126

Die Entwicklungsgeschichte der $\mathrm{G}$ attung der Kriminalliteratur zeigt, daß sich aus einer unspezifischen Praxis literarischer Verständigung über Kriminalität Mitte des vergangenen Jahrhunderts ein differenziertes Spektrum von Erwartungshaltungen herausbildete. ${ }^{127}$ Die verbreitete literarische Auseinandersetzung mit der Kriminalität bezog sich "auf elementare Vergehen an Leben und Eigentum“, war "festgelegt auf die Einschätzung des Verbrechens als Folge ,kranker Moralität' des Individuums oder der ,Macht des Bösen'.." 128

Gemäß der literarischen Erfahrung erwartete auch die Dorfbevölkerung vom Fall Kienbaum ein Verbrechen, das auf das ökonomische Interesse des Täters zurückzuführen ist, dessen kranke Moralität charakterologisch verankert ist. Dem populärliterarischen D eutungsmuster der Kriminalität der Zeit als Opfer anheimgefallen ist der verschlossene Bauer der Gegend, Quakatz. Schaumann nennt seinen verstorbenen Schwiegervater eine „mißtrauische, stänkerhafte, auf Kisten und Kasten hockende Bauernseele vom faulsten Wasser"(S. 119): Diesem „mißglückten Ebenbilde Gottes" „einen Mord als sein kleinstes Verbrechen zuzutrauen“ (ebd.), wäre der Welt leicht gefallen, meint Schaumann selbst. Aus Vorurteilen heraus hält die D orfgemeinschaft den eigentlich unschuldigen Bauem Quakatz für den Mörder Kienbaums. Die Hauptfigur, selbst Opfer ähnlich oberflächlicher Denk- und Verhaltsweisen, geht zu dieser Verurteilung auf Distanz. Hier werden dieselben Grundprinzipien der Gesellschaft deutlich, die die Heldenfigur ihrer „körperlichen Anlagen wegen“ (S. 89) als närrischen Kerl und personifiziertes ,Faultier' verkennen. Diese weicht der Meinung der Umgebung bewußt aus. Selbst wenn die Suggestion der Wahrheit entspräche, will er darin nur einen Fall wie seinen eigenen sehen, der sein Mitleid verdient:

[...] was Quakatzen anbetrifft, so mache ich mir gar nichts daraus, was die ganze Welt über ihn spricht. [...] Und übrigens bewiesen ist ihm ja von keinem Gericht was, und wenn jetzt die ganze Welt auf ihn hetzt, beweist das gar nichts gegen ihn. Auf mich hetzt auch die ganze Welt [...].(S. 27)

In der Dorfgemeinschaft wird der Funktionswandel der literarischen Öffentlichkeit offenbar: Aus dem Publikum, das über die Kriminalität und die Rechtspraxis räsoniert, ist das Lesepublikum der sensationell-unterhaltenden Kriminalliteratur geworden, die in den Tageszeitungen und Wochenzeitschriften der Zeit genügend angeboten wurde. So nennt Schaumann selbstironisch seine Aufklärungsaktion "höchste[ ] Verpflichtung, diese Idylle heute abend noch in den nächsten Band des neuen Pitaval zu bringen!"(S. 156) D iese Analogie zwischen der D orfgemeinschaft und dem Lesepublikum der Kriminalliteratur, der Ö ffentlichkeit schlechthin, ist zu konstatieren vor dem Hintergrund dessen, was Habermas in seinem Struk turwandel der Ö ffentlichk eit. Untersuchungen zu einer Kategorie der bürgerlichen $\mathrm{G}$ esellschaft darlegte: D ie private Sphäre ist, von der Verfassung der frühbürgerlichen G esellschaft her, die Sphäre der Ö konomie, des Marktes, und die Familie ist der Kern der privaten, intimen Sphäre. Das Publikum in seinem Selbstverständnis räsonierende Privatleute - zeigt die Ambivalenz der Privatsphäre der bürgerlichen

125 Vgl. K. Wirschem, D ie Suche des bürgerlichen Individuums nach seiner Bestimmung. Frankfurt/ M. 1986, S. 56.

126 D er neue Pitaval. E ine Sammlung der interessantesten Criminalgeschichten aller L änder aus älterer und neuerer Z eit. Hrsg. v. Julius Eduard Hitzig und Wilhlem Häring (W. Alexis). Ab Band 31 fortgesetzt von Anton Vollert. 60 Bände. Leipzig 1842-1860.

127 Vgl. J. Schönert, Kriminalgeschichten in der deutschen Literatur zwischen 1770 und 1890. Zur E ntwicklung des G enres in sozialgeschichtlicher Perspek tive, in: G eschichte und G esellschaft 9 (1983). H eft 1. S. 49-68, hier S. 60.

128 Ebd. S. 61. 
Gesellschaft auf: Die intime Sphäre der Familie wird ihrem Selbstbewußtsein nach von der Sphäre des Marktes unabhängig gedacht, während sie in Wahrheit tief in die Bedürfnisse jener Sphäre verstrickt ist.129

Wichtig ist in unserem Kontext Habermas' Hinweis auf jene, trotz dieser D ifferenz, allgemein geltende Einheit der literarischen und der politischen Öffentlichkeit: „Die entfaltete bürgerliche Öffentlichkeit beruht auf der fiktiven Identität der zum Publikum versammelten Privatleute in ihren beiden Rollen als Eigentümer und als Menschen schlechthin."130 Diese ,Fiktion'131 ist die geschichtsgestaltende und -treibende Fiktion. Sie hat gewissermaßen als realisiert zu gelten insofern, als das Publikum der politischen Öffentlichkeit im Laufe des 19. Jahrhunderts um einen weiteren Bevölkerungsteil ausgedehnt wurde. Im D eutschland nach der Reichsgründung hat die Verwirklichung der Freiheit einen um so trügerischeren Schein nach sich gezogen: Der Reichstag wurde zwar in allgemeiner, direkter (und männlicher) Wahl - zum ersten Mal in der deutschen Geschichte - gewählt. Diese moderne demokratische Institution war jedoch bekanntlich kein Machtzentrum, sondern ein Deckmantel, um die konservativ-monarchische O rdnung Preußens in den neuen Staat und in die neue Epoche hinüberzuretten. Die politische Öffentlichkeit des kaiserlichen deutschen Reichs besonders unter Bismarck war daher einerseits massendemokratisch - im Sinne eines plebiszitären Demokratismus nach dem französischen Modell Louis Napoleons -, andererseits traditionell autoritär.

Diese Gleichsetzung bzw. Analogie zwischen dem literarischen und dem politischen Publikum ist dem bürgerlichen Denken eigen. Und der plebiszitäre Demokratismus, für den das von Bismarck eingeführte Wahlrecht einsteht, versichert der literarischen Öffentlichkeit auch das Prinzip der Allgemeinheit, nämlich des ,bloß Menschlichen' - in Absehung von allen sozial und politisch präformierten Rängen - als Prinzip der Öffentlichkeit. Die ursprüngliche Zwiespältigkeit der Privatheit als bourgeois und als homme, in der sich das Publikum einer bürgerlichen G esellschaft findet, übersieht Raabe nicht. So spricht die Heldenfigur von der D ivergenz zwischen dem moralischen Interesse an menschlicher $\mathrm{G}$ erechtigkeit und den ökonomischen Interessen bei der D orfbevölkerung:

Es [das Volk; J.-H. B.] hat so was, [...] von Zeit zu Zeit nötig, um sich selber vor sich selbst eine ethische Haltung zu geben. Du lieber Himmel, wie waren sie mit dem Andreas Quakatz, mit Kienbaums Mörder, trotzdem daß sie gar nichts von ihm wissen wollten, in Geldangelegenheiten intim umgegangen! Was alles hatte sich vertraulich, Zutrauen gegen Zutrauen setzend, an ihn gemacht mit schlechten und guten Aktien, mit Pfandscheinen, Hypotheken, Bürgerschaften und was sonst im wechselnden Verkehrsleben vorkommt. Bei drei Feuerversicherungsagenten hatte der alte Herr die Rote Schanze versichert, weil sie ihm versichert hatten, daß sie fest überzeugt seien, er habe Kienbaum nicht totgeschlagen. (S. 147)

Dies berührt aber kaum die Tatsache, daß sich auch Raabes Standpunkt in seiner Kritik an der Öffentlichkeit auf die prinzipielle Gleichsetzung der literarischen Öffentlichkeit mit der politischen stützt. Darin zeigt er sich deutlich der bürgerlichen Tradition der Ö ffentlichkeitsauffassung verhaftet.

\section{D ie H umanisierung der Ö ffentlichk eit: E rk enntnisk ritik, U tilitarismus und T oleranz}

D en $O$ pponenten zum Konformismus bildet bei Mill wie bei Raabe das exzentrische Individuum: D em sonderlichen und exzentrischen Individuum als G egner und Erzieher der öffentlichen allgemeinen Meinung wird eine besondere pädagogische Rolle und Bedeutung zugeteilt.

Im folgenden wird der Vergleich zwischen den beiden Autoren erneut versucht werden, was als Vertiefung und Ausweitung von Kafitz' These verstanden werden kann. Dabei werde ich den Akzent mehr in die Richtung einer Frage nach der Öffentlichkeit verschieben. Mill legt in seiner Überlegung über den Verfall der Öffentlichkeit eine systematische, der demokratischen Entwicklung entsprechend revidierte Vorstellung von der bürgerlichen Ö ffentlichkeit dar. Seiner Überlegung liegt die Frage zugrunde, wie die Öffentlichkeit in Zukunft als demokratische soziale Institution fungieren kann. Ein kräftiges Antriebsmotiv dieses sozialen Prozesses soll für Mill nicht irgendeine politische, organisierte und vom Staat initiierte Maßnahme, sondern etwas Soziales, Unorganisiertes sein. So ist für Mill der Mensch, nicht der Staatsbürger, d.h. der Privatmensch, also das Individuum, der Träger der (Re)D emokratisierung und Humanisierung der Ö ffentlichkeit.

Neben diesem individualistischen Prinzip findet man noch drei weitere Prinzipien bzw. Blickrichtungen, in denen die Humanisierung der Ö ffentlichkeit als sozialreformistische Praxis von Mill gedacht wird: Erkenntnistheorie, Utilitarismus und Toleranz.132 Unter dem Eindruck der Parallelität zwischen Mill und Raabe, die von Kafitz auf der Ebene der großen Bedeutung des exzentrischen Individuums für die Demokratisierung der Öffentlichkeit nachgewiesen wird, liegt es nahe zu fragen, ob hier eine weitere Parallele zu ziehen wäre.

129 Vgl. J. Habermas, Struk turwandel, S. 111.

130 Ebd., S. 121

131 Ebd., S. 120f.: „Als Privatmann ist der Bürgerliche beides in einem: Eigentümer über Güter und Personen sowie Mensch unter Menschen, bourgeois und homme. Diese Ambivalenz der Privatsphäre zeigt auch noch die Öffentlichkeit; je nachdem nämlich, ob sich die Privatleute im literarischen Räsonnement qua Menschen über Erfahrungen ihrer Subjektivität verständigen; oder ob sich die Privatleute im politischen Räsonnement qua Eigentümer über die Regelung ihrer Privatsphäre verständigen."

132 Vgl. Z weites Kapitel: V on der D enk- und Redefreiheit, S. 138-186, in: J. S. Mill, F reiheit. 
Wie läßt sich Raabes literarische Lösung der Öffentlichkeitsproblematik, von mir Raabes Humanisierungskonzept der Öffentlichkeit genannt, mit Hilfe von Mills systematischen Argumentationen rekonstruieren?

Im Stopfkuchen wird die Humanisierung der Öffentlichkeit anhand der ,Mordgeschichte' exemplifiziert. Ich beschränke die Mordgeschichte gemäß des hier darzustellenden Zusammenhangs auf die von Schaumann inszenierten, außergewöhnlichen Umstände, unter denen sie von ihrer Entdeckung bis zur öffentlichen Klärung der entdeckten Tatsachen stattfindet.

Der erste Aspekt, unter dem Schaumanns Mordgeschichte betrachtet wird, ist erkenntnisbezogen. Von einer Erkenntnislehre war in der Forschung schon oft die Rede gewesen, allerdings meistens von der Methode des E rkennens, von der epistemologischen Konzeption für das richtige Erkennen der Realität und schließlich von der daraus folgenden Kunst- und Realismusauffassung des Romans und des Autors. ${ }^{133}$ Im Unterschied zu dieser Forschungsrichtung, bei der es sich um die Erkenntnis des als Individuum gedachten Subjekts handelt, wird hier das Erkennen primär als sozialpolitische Handlung aufgefaßt, deren Subjekt die gesamte Gesellschaft, also ein Kollektiv ist. Die Öffentlichkeit ist nach dem liberalistischen Glauben der O rt, wo verschiedene gesellschaftliche G ruppen von unterschiedlichen Meinungen und Erkenntnissen der Wirklichkeit sich begegnen und kommunizieren, und zwar auf dem langen, aber zielgemäßen Weg zur Wahrheit. Von einem perspektivistischen, pluralistischen und prozeduralen Wahrheitsbegriff ausgehend schreibt Mill jeder Meinung ein Wahrheitsmoment zu, welches nun nicht nur inhaltlich, sondem auch funktional, prozedural zu verstehen ist. ${ }^{134}$ Eine Meinung, falls sie inhaltlich nicht wahr ist, diene mittelbar der Wahrheit, weil sich durch sie eine Irrtumsmöglichkeit auf dem Weg der Suche nach der Wahrheit manifestiere und sie damit letztlich abgesichert werde. D er Druck auf die freie Meinungsäußerung, sei es von der Regierung oder von dem Volk in der Form einer Meinung der Mehrheit, ist an und für sich unberechtigt. Die Meinung der Minderheit, wenn sie auch nur in einer einzigen Person bestehen mag, ist genauso berechtigt wie die Meinung der Mehrheit, weil sie als Meinung ein Moment der Wahrheit in sich trägt. Zum Schutz und zur G leichberechtigung der Meinung der Minderheit gegenüber der Z wangsgewalt der herrschenden Meinung pocht Mill auf die konsequente Anwendung des Prinzips der freien Meinung(-säußerung), indem er sie durch die relativistische pluralistische Erkenntnislehre untermauert. So spielt eine erkenntniskritische Begründungsweise bei Mill die wesentliche Rolle bei seiner Kritik der Ö ffentlichkeit als Gewalt der Meinung der Mehrheit.

Raabes Kritik an der Öffentlichkeit geht über eine solche Art des methodisch begründeten, relativistischen und pluralistischen Wahrheitsbegriffs hinaus. Die Mordgeschichte hat die radikal polemische Funktion, die öffentliche Meinung als falsche Meinung zu entlarven und damit ihrem Wahrheitsanspruch den Boden zu entziehen. $\mathrm{Zu}$ beachten ist hier, daß es sich um ein bei Raabe immer wieder zu beobachtendes Phänomen handelt, nämlich daß „die öffentliche Meinung als falsche und trotzdem gesellschaftlich bestimmende Kraft" ${ }^{\prime \prime 35}$ erscheint. D er Vorwurf gegen die öffentliche Meinung wird hier faktisch begründet und legitimiert: Die Falschheit und die Irrtümlichkeit der öffentlichen Meinung ist mittels dieser Binnengeschichte handfest zu beweisen. Zur Kritik an dieser Öffentlichkeit wird nichts anderes als ihre schrille Falsifizierung verwendet. In dieser schlichten, gar plakativen Bankrotterklärung der öffentlichen Meinung liegt die erkenntniskritische Funktion der Mordgeschichte, wobei es letztendlich um die Verteidigung und Gleichberechtigung der Minderheit bzw. des einzelnen gegenüber der G ewalt der Mehrheit geht.

Ein zweiter Aspekt, den Mill in seine kritische Betrachtung der Entwicklung der Öffentlichkeit miteinbezieht, ist die sozialethische Begründung. Er ist genauer betrachtet das Komplement der als erstes genannten erkenntiskritischen Begründung. Mill argumentiert für die Gleichberechtigung der Meinung der Minderheit gegenüber der der Mehrheit durch ihren Beitrag zum Glück der gesamten Menschheit, welchen er in ihrer Wahrheitsfindung sieht. Für Mill liegt „das eigentliche Übel der Unterdrückung einer Meinung“ darin, „daß dadurch ein Raub an der Menschheit geschieht, an der künftigen wie an der gegenwärtigen Generation." ${ }^{136}$ Raub also, weil damit der Menschheit eine Chance, sich der Wahrheit zu nähern, für immer weggenommen wird. Dabei wird die Wahrheit in ihrem Nutzen für das Glück des gesellschaftlichen Ganzen aufgefaßt: „D ie Wahrheit einer Meinung ist ein Teil ihrer Nützlichkeit."137

Mit diesem für Mills sozialethische Haltung grundlegenden Utilitaritätsprinzip, ${ }^{138}$ welches für die Gleichberechtigungsfrage der einzelnen Meinung rahmengebend ist, scheint die Haltung Schaumanns vergleichbar. Sie ist von dem Bewußtsein um eine nur schwer zu bewältigende Aufgabe begleitet. Dieses Pflichtbewußtsein wird besonders an einer Stelle deutlich, wo Schaumann - angesichts des sich nähernden Augenblicks der Enthüllung der lang geheimgehaltenen Geschichte - eingesteht, ihm sei neben seiner "Macht" eigentlich auch die "höchste[] Verpflichtung“ bewußt, an jenem Abend die Stadt mit seiner Entdeckung zu konfrontieren, die „Idylle" der

133 Diesem Problem werde ich im Kapitel über die Mordgeschichte als formästhetische und epistemologische Strukturfrage den nötigen Raum widmen.

134 Vgl. J. S. Mill, Freiheit, S. 140-145.

135 D. Kafitz, D ie A ppellfunk tion, S. 60.

$136 \mathrm{~J}$. S. Mill, Freiheit, S. 104.

137 Ebd., S. 147.

138 Millscher Utilitarismus ist „durchaus ein sozialethisches, keineswegs ein rein egoistisches Prinzip“. (L. von Wiese, A rt. John Stuart M ill, in: HdSW VII, 344.) 
abendlichen Stadt „in den nächsten Band des neuen Pitaval zu bringen!"(S. 156). Diese Rolle sei ihm „unangenehm“, und ihm sei es fürchterlich "gegen die Natur", „daß gerade [ihm] die endliche Abwicklung der Sache aufgeladen worden [sei]!" (S. 157)

Der höhere Wert, um dessentwillen Schaumann diese unangenehme Rolle als ,Pflicht' annimmt, anders gesagt, die Frage, wem konkret er diese Pflicht schuldet, wird als begleitende Frage bei seinem Umgang mit der Geschichte stets präsent bleiben. Um was für einen Wert handelt es sich hier? Es scheint Raabe daran zu liegen, das Öffentliche als die Kategorie des Gesellschaftlichen schlechthin zu begreifen. Der Sache gemäß fühlt sich Schaumann weder seinen konkreten Mitmenschen der Gemeinschaft noch der ewigen $G$ erechtigkeit gegenüber verpflichtet:

Ich sah mir [...] die Zeitgenossenschaft an und nahm jeden aus der letztern, soweit sie um die Rote Schanze herum wohnte, vor. Um nachher von der Gesamtheit keinen Vorwurf zu verdienen, nahm ich es mit jedem einzelnen emst; und - ich fand nicht einen darunter, dem ich persönlich verpflichtet gewesen wäre, ihm sofort bekanntzumachen, wer in der Tat Kienbaum totgeschlagen hatte. ,Aber die ewige Gerechtigkeit?' wirst du fragen, Eduard. Ja, sieh mal, lieber Freund, in deren Belieben hatte es, meiner Meinung nach, denn doch lange genug gelegen, das Ihrige zur Sache zu tun. Da sie es nicht getan hatte und den Vater Quakatz allein hatte suchen lassen, so hatte sie von seinem Schwiegersohn gar nichts zu verlangen. (S. 180, 181); [...] wenn ich mir dabei vorstelle, was für eine Menge Volks ich im Namen der sogenannten ewigen Gerechtigkeit in das himmlischste Entzücken versetze! D enke dich in meine Nächte, wie ich mir die Leute sämtlich persönlichst in der Phantasie vor die Seele halte und bei jedem einzelnen mich frage: ,Was? D em zum Spaße? Dem zum Vergnügen? Dem zur Genugtuung?' (S. 157)

Nicht im Glauben an den metaphysischen Wert der ewigen Gerechtigkeit und trotz des Abscheus vor den konkreten Mitmenschen mit ihren Gelüsten auf Sensationen bringt er die Geschichte nachträglich zur Veröffentlichung. Er gehorcht dem Handlungsmodus, der der Sphäre zugehört, die zwischen der ewig gültigen, abstrakten Sphäre und der flüchtigen, in die unbedeutende Alltäglichkeit aufgehenden Sphäre, zwischen dem unerreichbaren Weltganzen und dem engen Lebenskreis liegt: die Sphäre der Gesellschaft, der Öffentlichkeit und des Sozialen. Schaumanns Umgangsweise mit der entdeckten Wahrheit des Mordfalls wird durch dieses Bewußtsein von der Gesellschaft geprägt. Unübersehbar ist dieses Bewußtsein von der Gesellschaft utilitaristischen, pädagogischen Charakters. Die utilitaristische Handlungsmaxime, die Raabe der gesellschaftlichen Sphäre, der Öffentlichkeit, zuspricht, muß und kann deswegen nicht zu dem führen, was die Justiz um der Gerechtigkeit willen verlangt. So setzt er sich über die juristische Ordnung hinweg: Er macht von der Aufklärung des Mordfalls der Justiz keine Mitteilung. Ebensowenig wird das persönliche Glück oder Unglück der am stärksten beteiligten Person, der geborenen Q uakatz, berücksichtigt. Schaumann erwähnt zwar „eine gewisse Verpflichtung gegen das Herz - ich meine meine Frau -" (S. 157), für deren nachträgliche Rehabilitierung er trotz seines Widerwillens gegen die Sensationslust der Dorfgemeinschaft die Sache auf sich nehmen möchte. Jedoch läßt Schaumann seine höchst beunruhigte Frau allein auf der Roten Schanze zurück, um erst in der Stadt die G eschichte zu Ende zu erzählen. Sie soll die endgültige Enthüllung später durch andere erfahren. Die Spannung, die der eigenwilligen Gestaltung der Aufklärung als öffentlichem Ereignis innewohnt und die sowohl zur staatlich-rechtlichen Institution als auch zur menschlichen Barmherzigkeit besteht, bedeutet den Widerspruch bzw. die Spannung zwischen der Moral und der Politik, zwischen dem Bereich des homme und dem des atoyen. In dieser Spannung spiegelt sich doch nichts anderes als jene Dialektik wider, in der sich die soziale Sphäre der Öffentlichkeit, in Abgrenzung zur Justiz und zur Intimsphäre, zu entfalten hat. So betrachtet ist Schaumanns Umgang mit der Mordgeschichte in Richtung eines Handlungsmodells auf der Ebene der Öffentlichkeit aufzuwerten. Es ist ein Handlungsmodell des bürgerlichen Subjekts, wobei diese Handlung sui generis privat, außerhalb des Staates und auch außerhalb der unmittelbaren Privatheit, eben in jener Zwischensphäre der Öffentlichkeit zu verorten ist. Was Schaumann in bezug auf seine eigene Kunstfertigkeit in der Sache der öffentlichen Aufklärung der Mordgeschichte gesagt hat, trifft gerade für den (im Sinne der Ö ffentlichkeit) sozialen Charakter seiner ganzen Handlung zu: „Wenn sich Zürnen und Wohlwollen im gegebenen Falle vereinigen ließen, war das mir wahrhaftig recht!"(S. 183). D abei faßt er den Status seiner Handlung als eine Mischung bzw. Versöhnung der schmerzhaften persönlichen Betroffenheit als Privatmensch mit dem utilitaristisch-pädagogischen Prinzip als Gesellschaftsmenschen auf. D em wirklichen Verhältnis der zerfallenen bürgerlichen Öffentlichkeit steht er in seiner Kritik individualistisch gegenüber, und zwar am bürgerlichen Individuum als Staatsbürger orientiert. Für die bürgerliche Öffentlichkeit als Idee bzw. Ideal plädiert Raabe mit der dramatischen Enthüllung des wahren Mörders: Wie die bürgerliche Öffentlichkeit sich als autonomer ,Z wischenbereich' auffaßt, der keinen besonderen gesellschaftlichen Lebenszusammenhang in spezifischer Weise ausdrückt, um das gesellschaftliche Ganze zu repräsentieren, ${ }^{139}$ beruft sich Schaumann bei seiner nachträglichen Enthüllung der Mordgeschichte, aus seiner persönlich-privaten Verstricktheit mit der Geschichte heraustretend, auf die sich selbst aufklärende Gesellschaft als das $\mathrm{G}$ anze. Hierin stimmt Raabe dem liberalen Programm, der historischen Funktion der bürgerlichen Ö ffentlichkeit voll zu und weist $\mathrm{G}$ emeinsamkeiten mit der Öffentlichkeitskritik der liberalen Gesellschaftskritiker Mill und Tocqueville auf. 
Stellen die sozialethischen Überlegungen von Mill sowohl das grundsätzliche Kriterium als auch das Endziel der bürgerlichen Ö ffentlichkeit auf, zeigt demgegenüber Raabe durch Schaumann die schmale Praxismöglichkeit dieses Handlungsmodells vor dem Hintergrund der deutschen Lebenswelt im ausgehenden 19. Jahrhundert.

\section{Sprengung der bürgerlichen Ö ffentlichk eitsk ritik}

Die deutsche Lebenswelt, d.h. der private, institutionell noch unstrukturierte Raum, spielt im Stopfk uchen nicht nur die Rolle eines Hintergrundes im Sinne der sozialpolitischen Realität als Widerspuch zur Idee und zum Handlungsmodell der bürgerlichen Öffentlichkeit. Die gewisse Radikalität, die in Raabes Kritik wohnt, liegt im Moment der Umkehrung, eben darin, daß die Lebenswelt ihrerseits die Grundidee der bürgerlichen Öffentlichkeit, nämlich gerade deren prinzipielle Ausschließung der Lebenswelt, in Frage zu stellen scheint. So droht der durchaus liberal einzuordnende Standpunkt Raabes zur Öffentlichkeit im Stopfkuchen den Rahmen der liberalen Ö ffentlichkeitskritik zu sprengen.

Beispielhaft dafür sind die Szenen in der Kneipe. Es handelt sich dabei zunächst um soziale Verkehrsformen, räumlich zwei verschiedenen Kneipen zugewiesen, deren Bedeutungen sich auf die abstrakte Ebene der Öffentlichkeit übertragen lassen. Bereits bei ihren sprechenden Namen kann man die kontrastierende Intention des Autors spüren: Die eine heißt „Zum goldenen Arm“, die andere „Brummersumm“. Während im „Zum goldenen Arm", wie der Name suggeriert, etwas geschieht, das als Handlung einen hohen sozialen Wert beansprucht, findet im „Brummersumm“ der landesübliche Stammtisch-Abend statt. Hier die alltägliche Geselligkeit, dort die produktive soziale Interaktion im Sinne des Ideals der bürgerlichen Öffentlichkeit. Die kritische Funktion im Sinne der aufklärerischen bürgerlichen Öffentlichkeit erfüllt der "Goldene Arm" als imaginärer Raum, der mit der Realität der politischen Ö ffentlichkeit in ihrer fortgesetzten Liquidierung kontrastiert. Im "Goldenen Arm" wird die wahre Version der Mordgeschichte von der Heldenfigur mit der gesamten D orfbevölkerung als Zielscheibe erzählt. Die philiströse Dorfmeinung hat den wahren Mörder Störzer als Exempel der bürgerlichen Tugenden Fleiß und Tüchtigkeit gelobt und einen falschen für den Mörder gehalten. Es ist Schaumann, der Dümmste, Faulste, G efräßigste, Langsamste in der Jugendzeit, der schließlich die Abwicklung der Sache in die Hand nimmt und jetzt „aller Philistergesinnungen den Fuß auf den Kopf setzen“ (S. 197) sollte. Die soziale Zielgerichtetheit seines Erzählens wird dann deutlich, wenn Schaumann die immer wieder verschobene endgültige Enthüllung des Mordfalls im "Goldenen Arm" als Schlußakt einsetzt. Schaumann gibt der angespannt lauernden Kellnerin mit ihrem wiederum sprechenden Namen „Meta“ (S. 181) den Auftrag, die Geschichte der Versammlung der Stammgäste und der D orfgemeinde weiterzuerzählen. Indem er den Fall Kienbaum-Störzer der Öffentlichkeit präsentiert, verwirklicht er genau das, was sein alter Wunsch gewesen war, nämlich: „Bombardieren [...] das Philistertum da unten“ (S. 38), nur daß es diesmal nicht um die Reminiszenz an die Rote Schanze als einstigen Kriegswall geht, sondern um eine sprachliche Kanonenkugel. Das Wirtshaus zum "Goldenen Arm" wird für den die Mordgeschichte erzählenden Schaumann, sonst durchaus verhinderter Täter, buchstäblich sein verlängerter, zum Handeln ausgestreckter Arm.

Neben der Aufklärung des Mordfalls bringt Raabe bei der Kneipenszene „Zum goldenen Arm“ das von der bürgerlichen Öffentlichkeit von jeher verdrängte Problem des plebejischen Lebenszusammenhangs ins Blickfeld, ohne dabei an eine proletarische Ö ffentlichkeit appellieren zu wollen. Die Rede ist von "jenem historischen Abend“ (S. 134), den Schaumann in der Kneipe „Goldener Arm“ erlebt hat. D er junge Schaumann wurde nämlich, nachdem er, im Studium gescheitert, heimkehrte, von seinem Vater aus dem Haus gewiesen. Ihm wird nun der Emst seiner eigenen Lebenslage, der Eigentumsverlust oder die Eigentumslosigkeit, und der drohende soziale Tod in der bürgerlichen G esellschaft klar. Dies verbindet er zunächst mit dem Wort des Schicksals, welchem er als Individuum in seinem Da- und Sosein wehrlos ausgeliefert wird:

Ich stand plötzlich mit sehr beunruhigtem Gewissen [...] draußen in der Straße im wehenden Sturm und treibenden Schnee und konnte dreist von neuem die bittere Frage an das ewige D unkel und die gegenwärtige Finsternis stellen: Wer hatte eigentlich das Recht, dich so als geistigen und körperlichen Kretin so hier hinzustellen: so! ? (S. 133)

In so „, bewandter Lebenslage“(S. 134) findet er im Dunkel „[g]lücklicherweise“ ein Licht, das in der Dorfkneipe zum "Goldenen Arm“ leuchtet. In dem Moment, „wo mir [Schaumann; J.-H. B.] aller Welt Schönheit, Weisheit und Tugend zu gar nichts von Nutzen gewesen sein würde"(S. 133), findet er in der Gesellschaft der Dorfkneipe den Trost und unverhofft auch die Lösung der eben aufgeworfenen Frage seiner Existenz. Ermuntert von dem Kreis in der Kneipe kommt er zu der Entscheidung, auf die Rote Schanze zu gehen. Selbstverständlich spiegelt sich hier, daß in der Kneipengeselligkeit der Zeit in zunehmendem Maß die ökonomische Lebenspraxis ins Zentrum des G esprächs rückte. ${ }^{140}$

140 „Nach der Gründung des Deutschen Reichs gehen die Redeschlachten in den Bürger- und Volksparlamenten der Kneipen und Bierhäuser weiter, nur das Thema ist ein anderes geworden, bezeichnenderweise kreisen die Gespräche und Reden um G eld, genauer: um die Frage nach dem Verhältnis vom sozialen Notstand und finanziellem Wohlstand." (D. Arendt, Wilhelm Raabe und der romantische Schlachtruf: „Krieg den Philistern!“, in: Revisionen, Festschrift zum 150. G eburtstag W ilhelm Raabes. Hrsg. v. H.-J. Schrader u.a. Braunschweig 1981, 
Jedoch spielt bei Schaumanns Zusammentreffen mit dem Kneipenpublikum noch ein etwas anderes Moment mit als beim üblichen Kneipengespräch über G eld und Arbeit. Die Kneipenszene stellt eine gelungene Form von Kommunikation, eine wünschenswerte soziale Interaktion in der gemeinschaftlichen Suche nach Wahrheit dar. Als Projektion und Idealvorstellung der sozialen Kommunikation ist diese Szene Ausdruck eines fundamentalen gesellschaftlichen Bedürfnisses, welches für Raabes Darstellung und seine Kritik der Öffentlichkeit eine wesentliche Rolle zu spielen scheint. Es ist die Integration einer neuen Lebenserfahrung, der die breite Bevölkerungsschicht der Zeit der fortschreitenden Industrialisierung immer stärker ausgeliefert wurde. Für die Integration und Organisation jener Erfahrung gab es selbstverständlich die Arbeiterbewegung in der zweiten Hälfte des 19. Jahrhunderts in ihrer zunehmenden Bedeutung und Stärke. Raabe verhielt sich aber, trotz mancher Sympathieäußerungen, grundsätzlich distanziert zur Arbeiterbewegung und damit zur denkbaren „proletarische[n] Öffentlichkeit“. ${ }^{141}$ Eher scheint Raabe hier an dem gelegen, was man als eine im geschichtlichen Prozeß gleichsam unterdrückte Variante einer plebejischen Ö ffentlichkeit bezeichnet.142

In der spontan gelungenen plebejischen Öffentlichkeit braucht man die „Gabe“, die „betreffende[n] Reden und Redensarten an [s]ich herankommen zu lassen, das dazu passende Gesicht dabei zu machen und nötigenfalls mit den darauf passenden Gegenbemerkungen aufzuwarten“ (S. 134). Ihm, dem "die Götter so vieles versagten“, haben sie doch, so Schaumann über sich selbst, die Gabe gegeben. Es geht um die Fähigkeit, sprachlich kommunikativ zu handeln. Schaumann verfügt über die Sprache als „Organ eines tranzendentalen Gemeinsinns“ und als „Medium eines öffentlichen Konsensus", 143 eine Fähigkeit, die er mit seinem „Humor" (S. 134, 135) in Zusammenhang bringt.

Im vollen Bewußtsein seiner kommunikativen Fähigkeiten wirkt er der spießbürgerlichen Gesellschaft in der Kneipe entgegen. "Mit dem Humor der Verzweiflung“, , „schenkte" er "ihnen denn reinsten Wein ein", und "nahm" er "diesen Herren vom Spieß diese ihre edle Väterwaffe ab und ließ sie kneipengerecht drauflaufen" (S. 134). So verwandeln sich die spießigen Bierbürger am Stammtisch in einen mitfühlenden, mitdenkenden Kreis. Schließlich gelingt ihm mit Hilfe dieses spontan entstandenen Kreises, „die genauen Umstände“ seines Mißgeschicks „nunmehr in das rechte Licht" (S. 134) zu stellen. Er zieht das Fazit seines bisherigen Lebens und Schicksals, welches das Konkurrenzprinzip der bürgerlichen Welt und die Diskrepanz zwischen innerem Ideal und der Existenz in dieser Welt verdeutlicht:

Eduard, ich hatte Humor an jenem Abend! Nicht den des Satans, aber den eines armen Teufels, welchen ein Mißverständnis zwischen körperlicher und geistiger Veranlagung faktisch unfähig machte, mit dem, was gedeihlich durch den Lebenstag hastet, wettzulaufen. Ja, denen zeigte ich an jenem Abend, wie man einer öden Welt auf dem Wege zum Ideal voranlaufen und welche zu üble Folgen ein zu gutes Beispiel in dieser Hinsicht haben könne. (S. 135)

Das Fazit ist aber an sich noch keine Lösung, sondern legt eine resignierte Haltung nahe, in der er „spaßhaft in das Nichts zu sehen" (S. 136) meint.

Was Schaumanns Begegnung mit dem Stammtisch erst zum „historischen Abend“ (S. 134) seines Lebens macht, liegt in jenem Moment, als von der teilnehmenden Kneipengesellschaft einzelne auf die Rote Schanze hinweisen. Einer sagt: „Nu, was ich sage, und worin mir die andern Herren hier am Tische beistimmen werden: so wie du jetzt bist, können sie [die Q uakatzs; J.-H. B.] gerade jetzt dich wirklich vielleicht recht gut da brauchen." (S. 136) Es ist nicht bloße Meinung des einzelnen, wie es derselbe betont, sondern da sprechen „durch ihn die Tausende hinter ihm" (S. 136). Somit entsteht ein Meinungskollektiv, welches aber diesmal, im Gegensatz zum Meinungskollektiv in der Mordgeschichte, eine durchaus positive Bedeutung erlangt. So wird der ,Vernunft' des Kneipenpublikums gehuldigt, wenn bezüglich dieses fruchtbaren Vorschlags Schaumann "Volkes Stimme" als „Gottes Stimme“ (S. 136) zelebriert. Die ,Vernunft' der Öffentlichkeit ist aber in diesem Lande nicht als solche garantiert und (an-)erkannt. Anstatt von der ,Vernunft' des Kollektivs zu sprechen, meint auch Schaumann selbst, daß „hier in Deutschland [...] man immer dann nachher von Intuition, Führung von oben, Zuge [sic] des Herzens, Stimme des Schicksals, Vorsehung und dergleichen [spricht]" (S. 136). Die ,Vernunft des Kollektivs' wird damit irrationalisiert und kann höchstens im Zweifelsfall im kleinbürgerlichen Erwerbs- und Alltagsleben zur Geltung kommen, so daß sie am Ende doch mit dem spießbürgerlichen Überlebenssinn zusammenfällt: „Willst du genau erfahren, Eduard, was im bürgerlichen Leben das Richtige ist, so frage nur beim nächsten Spießbürger an“. (S. 136)

Die Szene behandelt die Funktionsweise einer proletarischen Öffentlichkeit, die eigentlich keine ist: In der Geschichte hat sich die kollektive Erfahrungs- und Interessensgrundlage der Mehrheit der Bevölkerung nicht zur proletarischen Öffentlichkeit als Kristallisationspunkt der gesamten Gesellschaft entwickelt. Bei Raabe wird die

\section{S. 66.)}

141 Näher zum Begriff der proletarischen Öffentlichkeit, O. Negt / A. Kluge, Öffentlichk eit, S. 7f.; besonders zu ihrer unterschiedlichen Verwendung in der Geschichte der Arbeiterbewegung im Unterschied zur Parteiöffentlichkeit, S. 10f., Fn. 3.

142 „Die Entstehung der plebejischen Öffentlichkeit bezeichnet eine spezifische Phase in der historischen Entwicklung des Lebenszusammenhangs der klein- und unterbürgerlichen Schichten. Sie ist einerseits eine Variante der bürgerlichen Ö ffentlichkeit, weil sie das emanzipatorische Potential der bürgerlichen Ö ffentlichkeit in einem neuen sozialen Kontext zur Entfaltung bringt. Die plebejische Öffentlichkeit ist gewissermaßen eine bürgerliche Öffentlichkeit, deren soziale Voraussetzungen aufgehoben sind." (G. Lottes, Politische A ufk lärung und plebejisches Publikum. München 1979, S. 110, zitiert nach J. Habermas, Struk turwandel, S. 16).

143 E. Manheim, D ie T räger der öffentlichen M einung. Wien 1923, S. 88 und S. 92, zitiert nach J. Habermas, Struk turwandel, S. 95. 
Wirklichkeit der proletarischen E rfahrungen und Interessen auf ihrem Höhepunkt gebrochen, indem der Prozeß der kollektiven Meinungsbildung teils irrationalisiert wird, teils als Spießbürgertum entpolitisiert wird. Hiermit läßt sich die Beobachtung bestätigen: „Proletarisches Leben bildet keinen Zusammenhang, sondern ist durch die Blockierung

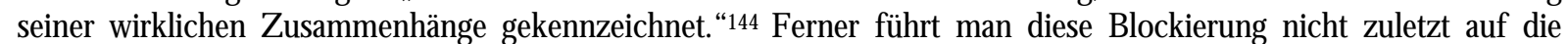
bürgerliche Öffentlichkeit zurück: „D ie Form des gesellschaftlichen Erfahrungshorizontes, die diesen Blockierungszusammenhang nicht aufhebt, sondern befestigt, ist die bürgerliche Ö ffentlichkeit". 145

D er enge Zusammenhang zwischen der plebejischen und der bürgerlichen Ö ffentlichkeit ist in unserem Text auch feststellbar. Dies drückt sich vor allem darin aus, daß als Bedingung für das kommunikative Handeln im Sinne der auf der gemeinsamen Lebenserfahrung basierenden ,plebejischen' Öffentlichkeit besonders die Subjektivität Schaumanns betont wird. Schaumanns , Gabe', sich sprachlich gut vermitteln zu können, schreibt denn nichts anderes als die Qualität des bürgerlichen Subjekts als Publikum der bürgerlichen Öffentlichkeit um. Erst durch seinen ,Humor', sein spezifisch sprachliches Vermögen, verwandelt sich das spießbürgerliche Kneipenpublikum in das, was die an sich rudimentäre Alternative der bürgerlichen Ö ffentlichkeit, die plebejische Ö ffentlichkeit, nahelegt.

Die Ö ffentlichkeit im „Zum goldenen Arm“ stellt nicht die proletarische Öffentlichkeit dar, sondern das Ideal der bürgerlichen Öffentlichkeit. Dennoch geht sie nicht restlos im liberalen Programm auf. Sie hebt in ihrer spezifischen Gestaltung die konzeptionelle Basis der bürgerlichen Öffentlichkeit, nämlich die strikte Trennung der Ö ffentlichkeit von dem substantiellen Lebensinteresse des Ö konomischen, auf, welches aber auf verdeckte Weise in die bürgerliche Öffentlichkeit hineinwirkt. „Zum goldenen Arm“ steht für den Handlungsmodus der Kommunikation und damit der Ö ffentlichkeit, der die Erbmasse der bürgerlichen Ö ffentlichkeit aufbewahrt, ohne die Erfahrung der erdrückenden Mehrheit der Bevölkerung auszublenden. Das ,Goldene' dürfte als Metapher für die Aufhebung der der bürgerlichen Öffentlichkeit eigenen,Widersprüchlichkeit zwischen der Öffentlichkeit und der Erfahrung ${ }^{1} 146$ gelesen werden. Das ,Goldene' steht bei Raabe im Zeichen des Bildungsbürgerlichen: Der beruflich gescheiterte Theologe, das bildungsbürgerliche Subjekt zeitgenössischer Prägung, spielt die führende Rolle bei der Bildung dieser neuen Öffentlichkeit. Der Widerspruch zwischen dem bildungsbürgerlich orientierten Ö ffentlichkeitsideal und der Lebenswelt bildet so den Standpunkt Raabes.

Jedoch fehlt bei Raabe nicht die Kritik an jener zeitüblichen kulturellen Erscheinung, nämlich am Widerspruch zwischen dem bildungsbürgerlich orientierten Öffentlichkeitsideal und der Lebenswelt. Sie bedeutet gerade ein weiteres Leitmotiv bei der Gestaltung der Kneipenszene. Hier spielt der Begriff ,Philister' oder ,Spießbürger' ${ }^{\prime 147}$ eine entscheidende Rolle als Kristallisationspunkt der Kritik. Als kulturknitischer Kommentar seit seiner romantischen Ausprägung begleitet der Begriff die ganze geistesgeschichtliche Entwicklung des 19. Jahrhunderts. Mit Ausnahme der relativ einheitlich bestimmbaren Substanz der romantischen Philisterkritik ist der Begriff von verschiedenen epochalen und individuellen Variationen geprägt. Bei Raabe tritt der Philister in literarischer Reminiszenz an die Romantik auf, ${ }^{148}$ problematisiert aber gleichzeitig die Fragwürdigkeit der romantischen Konstellation von Poeten und Philistern an sich. So handelt es sich bei Raabe eher um den ununterdrückbaren Abgrenzungszwang und die ebenso unverkennbare Schwierigkeit der Abgrenzung zum Philister. Diese Ambivalenz liegt der Reflexion Eduards zugrunde, der seinen ersten Abend in der Heimatstadt im „Brummersumm“ verbringt. Mehr schweigsam beobachtend als teilnehmend an der Runde versinkt Eduard in Erinnerungen an seinen verstorbenen Vater, der den regelmäßigen Kneipenbesuch pflegte. Es schaltet sich nun eine Art von alltags- und kultursoziologischer Betrachtung über die deutsche Geselligkeit in der Kneipe ein:

Nämlich als Kind schon begleitete ich meinen jetzt längst verstorbenen Vater dorthin. Er hatte seine Pfeife da stehen, doch dann und wann hatte ich ihm auch eine neue hinauszutragen. Viele Leute werden nun sagen: D er selige alte Herr gab da seinem Jungen ein recht sauberes Beispiel! Und sie haben recht und wissen gar nicht, wie sehr sie recht haben. Er tat es auch und gab mir ein nettes Beispiel - freilich nicht bloß in dieser Hinsicht. Ich bin also Stammgast des Brummersumms von Kindsbeinen an gewesen und habe schon um dessentwegen mit geheiratet, um gleich dem wackeren alten Vater allerlei von dorther an meine eigenen Jungen drunten im ,heißen Afrika' weitergeben zu können. (S. 12)

D as „Kulturmoment" (S. 12) der Kneipengeselligkeit wird wie andere Kulturereignisse und Verhaltensnormen regionalen, traditionalistischen Charakters hauptsächlich vom Kleinbürgertum getragen, dessen kulturkritisches Schmähwort ,Spießbürger' heißt. Eduards Erinnerung an seinen Vater umfaßt auch sein: „Ja, so ein richtiger deutscher Spießbürger in seiner Kneipe!" (S. 12).

Aber wer genau ist dieser Spießbürger? Wie scharf die Polemik gegen diese Kulturfigur auch klingen mag, so bleibt die Frage nach einer eindeutigen Konturierung oder nach Unterscheidungskriterien unbeantwortet. Denn sie

144 O. Negt/ A. Kluge, Ö ffentlichk eit, S. 10.

145 Ebd. S. 10.

146 Vgl. ebd., S. $20 f$.

147 ,Philister' ist schon im Alten Testament als Name für ein fast übermächtiges Volk und gefährliche Feinde Israels bekannt. D er Begriff hat im Mittelalter in der Studentensprache weitergelebt und ist seit Anfang des 18. Jahrhunderts mit dem Spießbürger-Begriff synonym gebraucht worden. (Vgl. G. Stein, Philister-Kleinbürger-Spießer. N ormalität und Selbstbehauptung. Frankfurt/ M. 1985, S. 13).

148 So schreibt Raabe am 2. März 1875 an Paul Heyse: „Ich habe den alten romantischen Schlachtruf: ,Krieg d(en) Philistern!' sehr ernst genommen." (E rg. Bd. II, S. 183). 
hat ihre primäre Funktion darin, sich gegen die sich vollziehende Modernisierung, gegen die sich befestigende bürgerliche, d.h. industrielle Ordnung polemisch zu verhalten, und zwar von der romantisch-intellektuellen Perspektive aus. Im Laufe der Zeit ist die (früh)-romantische Grenzziehung zum philisterösen Gegenüber immer schwieriger geworden, so daß sie den Weg der Verinnerlichung beschreitet. Der frühromantische Gegensatz zum Philister wandelt sich vor dem Hintergrund einer nahezu absoluten Vormachtstellung der wuchtigen PhilisterWirklichkeit zur immer tieferen inneren Z wiespältigkeit des Daseins. So geht unter den deutschen Spießbürgem in der Kneipe immer wieder und leicht die Verwirrung um: „Man zieht die Achseln nur deshalb über ihn [den deutschen Spießbürger; J.-H. B.], weil man selbstverständlich stets den unrichtigen für den richtigen nimmt." (S. 12)

Im Dunkeln der Kneipe der Philister-Gesellschaft läuft es schließlich auf eine Auseinandersetzung mit sich selbst hinaus, bei der man einen großen „Krieg gegen die Philister“, gegen die ganze philiströse Welt zu führen meint:

Wo in aller Welt als wie so im Brummersumm läßt sich denn der Spieß leichter umdrehen, auf daß man die langweilige, die dumme, die abgeschmackte, die boshafte, die neidische Welt drauflaufen lasse? Und wo kann man kräftiger nachstoßen, um das überleidige Untier völlig zu Boden zu bringen? (S. 12)

Die Rede ist von einer wichtigen sozialpsychologischen Funktion der Kneipen für das kleinbürgerliche Milieu: Abfuhr bzw. Ablenkung der Aggression und Entspannung im lapidaren Kapitalisierungsprozeß, in dem das „Glück und Unglück“ des einzelnen „als Spielball der G eschichte" ${ }^{\prime 149}$ zu erfahren ist. Der erinnernden Reflexion fehlt nicht der Einblick in die geschlechtsspezifische Form der Kneipengeselligkeit - das Kneipenleben war zu der Zeit ausschließlich Männersache - , was wiederum auf die oben genannte psychologische Funktion bezogen werden kann.

Wie sich freilich die Frau Spießbürgerin zu dem Brummersumm verhält, das steht auf einem ganz anderen Blatte. Auf einem ganz besonderen Blatte aber steht, wie sich meine selige Mutter zu ihm verhielt. Erst in reifern Jahren natürlich habe ich den Sachverhalt herausgekriegt durch wehmütig-fröhliche Rückerinnerung, und da ist der G esamteindruck ein höchst erfreulicher. Das brave Weib hatte sich nicht nur mit dem Brummersumm abgefunden, sondern es ermahnte dann und wann meinen Vater: „Du, es ist wohl Zeit für deinen Abendweg!“ Und seltsamerweise geschah dieses am häufigsten dann, wenn Sorge, Kummer und Verdruß unser Haus in der Stadt umkrochen und böser Lebensdunst sich darüber und also zumeist über ihrem teuren Haupte zusammengezogen hatte. Es gibt wohl nichts, was mehr für die Frau und den Brummersumm spricht. (S. 13)

In Raabes Darstellung des "Spießbürger[s] in seiner Kneipe“ ist zweierlei vereint: einerseits das kritische Moment gegenüber dem damals verbreiteten Phänomen der Hochstilisierung der deutschen Bildung und Kultur, andererseits die sozialpsychologische Beleuchtung der Funktionsweise desselben Phänomens im Alltag. Damit besteht ein Vergleichspunkt mit Nietzsche, der unter den zeitgenössischen Zeitkritikem am schärfsten die Disknepanz zwischen dem Öffentlichkeitsbewußtsein des Bildungsbürgertums und seiner E rfahrungswelt attackiert hat. In seiner Diagnose kann man wohl Raabes Darstellung als parallel mit Nietzsches Kritik der „Pseudo-Kultur“ und mit dessen Warnung vor der „Exstirpation des deutschen Geistes zugunsten des ,deutschen Reiches' ${ }^{\prime \prime} 150 \mathrm{zu}$ lesen. Jedoch ist Raabe die elitäre Ausprägung der Idee bei Nietzsche wesensfremd, ${ }^{151}$ wenn dieser von jenen „ernste[n] Menschen“ redet, die „im Dienste einer völlig emeuten und gereinigten Bildung und in gemeinsamer Arbeit, auch wieder zu Gesetzgebern der alltäglichen Erziehung - der Erziehung zu eben jener Bildung - werden".152 Sublimiert Nietzsche die Philister-Figur zum Bildungsphilister, um diesem den „echten Kulturmenschen“, 153 ja den Übermenschen entgegenzusetzen, so versucht Raabe, die Philister-Figur als das durch die gesamte öffentliche Sphäre durchziehende Motiv zu modifizieren und dabei die Grenzen zunehmend aufzuheben. Die fließende Grenze zwischen dem Philister und dem Nicht-Philister ist der innergesellschaftliche Aspekt der mentalen kulturellen G esamtsituation einer nach Übersee expandierenden bürgerlichen kapitalistischen Kultur. Wie sich zwischen Außen und Innen, zwischen Eigenem und Fremden unaufhaltsam alles hin- und herbewegt, stets sich austauscht, so verlieren viele Dinge im eigenen Inneren an ihrer ehemaligen Schärfe, an Unterscheidbarkeit. Nicht von ungefähr ist es der A uswanderer Eduard, der das erlebt: „Wo in aller Welt [...] läßt sich denn der Spieß leichter umdrehen“(S. 12), fragt er sich im Brummersumm, im D unkel der tiefen Gemütlichkeit der deutschen Heimatstadt.

149 D. Arendt, Schlachtruf, S. 67.

150 F. Nietzsche, U nzeitgemäße Betrachtungen. W erk e in drei Bänden. Hrsg.v. Karl Schlechta. München: Hanser 1954ff. I. $191,137$.

151 Zum Verhältnis Raabes zu dem berühmten Zeitgenossen Nietzsche in Biographie und Ideenverwandtschaft siehe D. Arendt, KünstlerFigurationen im W erk W ilhelm Raabes oder: „E r war überhaupt k eine ausgesprochene Künstlernatur", in: JbdRG 1987, S. 46-83, hier S. 80-83; ders., Schlachtruf, bes. S. 60 .

152 F. Nietzsche, N achgelassene Schriften 1870-73. Fünf V orreden zu funf ungeschriebenen Büchern, in: ders., Gesamtausgabe. D ritte Abteilung zweiter Band. Hrsg. v. Giorgio Colli und Mazzino Montinari, Berlin; New Y ork 1973.

153 F. Nietzsche, Betrachtungen. 138. 


\section{B. Doppelstruktur von Detektivroman und Seetagebuch}

Die Erzählung der Lebensgeschichte der Hauptfigur, von ihr selbst die Geschichte der Eroberung der Roten Schanze genannt, lehnt sich an eine bestimmte literarische Form an. Die Wahl dieser literarischen Form kann unter zwei G esichtpunkten beleuchtet werden.

Indem die erzählte Geschichte gewollt als "die plane Aufdeckung [eines] Kriminalfalls"154 ausgewiesen wird, stellt sie eine Parodie auf die Kriminalliteratur des ausgehenden 19. Jahrhunderts dar. Auf deren publikums- und öffentlichkeitsbezogene kritische Intention bin ich schon ausführlich eingegangen.

Der zweite Gesichtspunkt rückt die symbolische Bedeutung der Detektivgeschichte für die erzählte Lebensgeschichte in den Mittelpunkt. Hier geht es um die Form-Inhalt-Dialektik des Romans. Vorausgesetzt sei hier die Festellung, daß dieser Werdegang die frühbürgerliche Emanzipationsvorstellung des ökonomischen und politischen Individuums unter der besonderen Bedingung der gesellschaftlichen Verhältnisse im ausgehenden 19. Jahrhundert in Deutschland darstellt. Idee und Struktur dieses bürgerlichen Subjekts orientieren sich am Maß der erreichten Freiheit auf der ökonomischen und politischen bzw. öffentlichen Handlungsebene. Meine These ist, daß sich dieser Werde- und Bildungsgang des Subjekts unter formalästhetischen Gesichtspunkten rekonstruieren läßt. Dies läßt sich sowohl am D etektionsvorgang als auch an dessen erzählerischer G estaltung nachweisen.

Der komplexen Erzählstruktur der doppelten Erzählerschaft entspricht schließlich noch ein dritter Gesichtspunkt. Er betrifft die Form des Romans. Zwischen die eigentliche Erzählung der Lebensgeschichte in der Form der Mordgeschichte tritt immer wieder der Bericht des Ich-Erzählers Eduard als Biograph und Freund der Hauptfigur. Parallel zur eigentlichen, von der Heldenfigur mündlich erzählten Geschichte und deren gesteigerte Spannung willkürlich unterbrechend, tritt so eine andere Geschichte, nämlich Eduards Seegeschichte als Geschichte der Transformation von Schaumanns oraler Erzählung in einen Roman. Die Seegeschichte berichtet von den Begleitumständen des Schreibaktes auf dem Schiff, der vom Ich-Erzähler Eduard selbstironisch als "ungewohnte“ (S. 8) und „absonderliche“ (S. 118, 119) Rolle des Schreibers kommentiert und problematisiert wird.

Die Ereignisse dieser Seegeschichte sind die historisierte Schreibhandlung Eduards. Sie ist also mehr als ein gelegentlicher Hinweis auf die vermittelnde Erzählinstanz und darf nicht als eine blasse, durchsichtige, also dem Schreibduktus des ,Realismus' untergeordnete Rahmenkonstruktion unterschätzt werden. Über die Authentisierung der Entstehung des Textes hinaus hat sie die Funktion einer Dramatisierung des Romanschreibens. D er bürgerliche Eduard ist von seinem Freund Schaumann begeistert und stilisiert ihn zum ,Übermenschen'. Hinter dieser harmlosbiederen Haltung blickt die Ausweglosigkeit des um Handlungsfähigkeit und Identitätsfindung bemühten spätbürgerlichen Subjekts hervor, das von handlungsfähigen Individuen fasziniert ist, aber deren geschichtliches Selbstverständnis nicht mehr zu teilen vermag. Die Beziehung zwischen Detektiv- und Seegeschichte, mündlicher Erzählung und Niederschrift offenbart die Inkongruenz zweier Subjekts- und G eschichtskonzeptionen und damit den geschichtlichen Gehalt der Form des Romans. In ihr reflektiert sich nämlich der geschichtliche Prozeß, der darin besteht, daß die Spielräume autonom bestimmten Handelns im ausgehenden 19. Jahrhundert immer kleiner werden, so daß für das spätbürgerliche Subjekt die Sphären des Privaten und Intimen immer größeres Gewicht erhalten. Keineswegs ist es deswegen zufällig, sondern geradezu als formale Entsprechung symbolisch, wenn Schaumanns verkleidete Mordgeschichte in Eduards Seetagebuch eingeht.

Im folgenden wird versucht zu zeigen, daß die Spannung der unterschiedlichen Ich-Prinzipien zweier IchErzähler, d.h. die Spannung der beiden Modi der Subjektiviät, sich in der Opposition von D etektivgeschichte und Tagebuch fortsetzt. Die berühmte erzählerische Komplizierung bei Raabe wäre - so könnte ich den Beitrag meiner folgenden Auseinandersetzung zur Klärung der Kardinalfrage der Raabeforschung nach dem Verhältnis zwischen weltanschaulicher Traditionsgebundenheit und Modernität der Erzählform umreißen - einer künstlerischen Situation entsprungen, in der die authentische Vermittlung zwischen frühbürgerlich geprägter Identität und eindringender psychischer Erfahrung der Diskontinuität der Moderne angestrebt wurde. Diese widerspruchsvolle, spannungsaufgeladene Situation scheint dem Autor einen enormen Aufwand an erzähltechnischen Mitteln abverlangt zu haben.

\section{Schaumanns Detektivroman}

\section{D ie Struk tur der D etektion: E inheit von vita activa und vita contemplativa}

Die Anwendung der literarischen Form der Detektivgeschichte in Raabes Stopfkuchen wird in der Forschungsgeschichte zum ersten Mal von U. Eisele ernsthaft behandelt. Ernsthaft in dem Sinne, daß E isele erkennt, daß es sich bei dieser Romanform um mehr als ein bewußtes Spiel mit Lesererwartungen handelt, also um etwas über

154 H. O hl, E duards H eimk ehr, S. 258. 
die provokative Geste des Autors gegenüber dem literarischen Markt Hinausgehendes und mit dem Roman als Ganzem tief Zusammenhängendes. Der innere Zusammenhang der Detektivgeschichte mit dem gesamten Roman bietet sich für Eisele als die dem Roman inhärente Erkenntnislehre dar, da D etektion „an sich immer schon kaum kaschierte Epistemologie"155 bedeute. Die Struktur der Detektion deckt sich aber nicht mit derjenigen der Detektivgeschichte im exakten Sinne, worauf Eisele auch mit Recht hinweist. ${ }^{156}$ Sie weicht von der typischen D etektivgeschichte ab. Im Gegensatz zur rationalen D echiffrierungskunst etwa bei Auguste D upin in D er D oppelmord in der Rue M orgue von Edgar Allan Poe ${ }^{157}$ ist bei Schaumann das für die Detektivgeschichte charakteristische analysierende und kombinierende D enken nicht besonders ausgeprägt. Was fungiert statt dessen hier als Schlüssel für den Aufklärungsvorgang, wenn nicht die kritische, recherchierende Rationalität?158 Bei Schaumanns Entdeckung des eigentlichen Täters ist die unmittelbare Erfahrung der Augenzeugenschaft ausschlaggebend: Bei der Beerdigung des alten Q uakatz sieht Schaumann, daß der Briefträger Störzer „die drei Schaufeln für den Toten mit dem Zeichen Kains auf der Stime verweigert" (S. 174). Niemand sonst, nur die Heldenfigur allein beobachtet das Unterlassen dieser rituellen Handlung, was sie wiederum zu einer Erkenntnis führt, auf die niemand sonst gekommen wäre.

Aufgrund des Vorranges der unmittelbaren Anschauung, die für die Detektion hier eine entscheidende Rolle spielt, kann man zu Recht vom E mpirismus als Erkenntnislehre des Romans sprechen. ${ }^{159} \mathrm{Es}$ ist dies der Empirismus, für den nicht das „kombinierende[] Nachdenken und rationale Dechiffierungskunst" ${ }^{160}$ sondern die "sinnliche[] Aufmerksamkeit" ${ }^{\prime 161}$ in Anschlag zu bringen ist. Diesem E mpirismus, ja dessen Konzeption der Erkenntnis liegt, so Eisele, das „G egensatzpaar innen/ außen sowie das Verhältnis dieser beiden Elemente zueinander" ${ }^{\prime 162}$ zugrunde. D as Grundmuster der Enthüllung, das dem Text als einer D etektivgeschichte ohnehin und von vornherein inhärent ist, läßt sich abgewandelt und in Variationen als offener oder latenter Konflikt zwischen Innen und Außen, Oberfläche und Tiefe an zahlreichen Orten und in mehrfacher Hinsicht bestätigt finden, so daß es in einem ganz wörtlich zu nehmenden Sinne darum geht, an den Kern zu kommen. ${ }^{163}$

Diese empiristische Ausprägung, die sich in der Erkenntnis der Realität als „Herausschälen[] eines essentiellen Kerns aus einer inessentiellen Schale "164 manifestiert, bildet ohne Zweifel für die im Roman modellhaft in der Entdeckung der Mordgeschichte verfochtene Erkenntnislehre die Rahmenbedingung. Es genügt aber nicht, die „idealtypische Ausprägung empiristisch realistischer Epistemologie“165 als einzige Begründung der die Detektion bestimmenden D enk- bzw. Handlungsstruktur heranzuziehen. Schließlich kann der Empirismus immer und überall die Künste beeinflussen. ${ }^{166}$ Der literarische Realismus ist ganz allgemein „durch den zunehmenden Empirismus im 18. Jahrhundert heraufgeführt worden“ und stellt „dessen eigentlichen Kulminations- und Gipfelpunkt"167 dar. Eine vom Idealtypus ausgehende Lektüre übersieht ein anderes, vielleicht noch wichtigeres Moment des Detektionsvorgangs, das dem erkenntnistheoretischen Erklärungsansatz entgegensteht.

Näheren Aufschluß gibt die Analyse der verborgenen Lücke der ,Erfahrung' im Sinne der ,Augenzeugenschaft', die den Ausgangspunkt der Detektion bildet und insofern die Detektion selbst nachhaltig bestimmt. Schaumann beobachtet zunächst nur das Unterlassen einer rituellen Handlung. D as ist noch Zufall. Die eigentliche Detektionsleistung liegt im nächsten Schritt, der von der bloßen Beobachtung des absonderlichen Verhaltens des „braven alten Biedermann[s] und Dummkopf[es]" (S. 176) Störzer zu einer Mutmaßung führt. Der Beobachter mißt dem Verhalten Störzers eine geradezu magische Bedeutung bei, um von hier aus auf ein schwerwiegendes Motiv für die Verletzung des Rituals und eine G eschichte ,dahinter' schließen zu können: Eine Verkettung, die ebenso originell wie absurd ist, da sie die Leichtgläubigkeit und die Leichtfertigkeit des Urteils, kurzum die „Philistergesinnung' der

155 U. Eisele, D er D ichter, S. 4.

156 Vgl. U. Eisele, D er D ichter, S. 2.

157 Diese berühmteste Kriminalerzählung der Zeit befand sich in Raabes Besitz: Vgl. D. Bänsch, D ie Bibliothek Wilhelm Raabes nach Sachgebieten geordnet, in: JbdRG 1970, S. 87f., hier S. 135.

158 Bei der typischen Detektivgeschichte fungieren nach Zmegac der Detektionsprozeß als „rationaler Kult“ und der Held als „Verkörperung des reinen Verstandes“. (V. Z megac, A spekte des D etek tivromans. Statt einer E inleitung, in: ders. (Hrsg.), D er wohltemperierte M ord. Z ur Theorie und G eschichte des D etek tivromans, Franktfurt/ M. 1971, S. 9-34. S. 14f.)

159 Vgl. Eisele, D er D ichter, S. 3 - 19.

160 U.Eisele, S. 2.

161 U. Eisele, S. 3.

162 Vgl. ebd., S. 5.

163 Vgl. ebd., S. 6

164 Ebd., S. 5.

165 Ebd., S. 27.

166 Siehe F. Sengle, D eutsche L iteratur im Spannungsfeld zwischen Restauration und Revolution 1815-1848. Bd. 1 (Biedermeierzeit I), Stuttgart 1971, bes. S. 257: Hier betont Sengle die Notwendigkeit der klaren und prinzipiellen Unterscheidung zwischen "Realismus' und ,Empirismus', um zu einem ge schichtlich begründeten und begrenzten Realismusbegriff kommen zu können.

167 C. Heselhaus, D as Realismusproblem, in: B egriffsbestimmung des literarischen Realismus. Hrsg. v. R. Brinkmann, D armstadt 1969, S. 337-364f., hier S. 343: Ebenso beachtenswert ist die Bemerkung von Hermann Kinder in bezug auf den zunehmenden Empirismus in der Kunst seit dem 18. Jahrhundert; siehe ders., Poesie als Synthese. A usbreitung eines deutschen Realismus-V erständnisses in der Mitte des 19. Jahrhunderts. Frankfurt/ M 1973, bes. S. 31: „Faßt man den Realismus des 19. Jahrhunderts allgemein [...] als ,Widerspiel des zivilen Lebens', so liegt eine wesentliche Wurzel dieses Realismus im 18. Jahrhundert. D em Jahrhundert, das traditionelle Voraussetzungen und Weisen der Darstellung von Wirklichkeit zugunsten der Integration eines empirischen Erfahrungshorizontes in der Kunst abgebaut hat." 
D orfbevölkerung auf den Kopf stellt. Schaumann sagt selbst: „Die Sache ist eigentlich zu dumm, und es wird einem selber immer dummer [sic], je mehr man drüber nachdenkt".(S. 176)

Seine Schlußfolgerungen und seine Rekonstruktion einer Geschichte ,dahinter' sind ein gedanklicher Sprung, der mit seiner sonstigen Lebenslage, ,dumm' und ,trotzig vom Gewöhnlichen abzuweichen', korrespondiert. Er denkt so, wie er ist. Es ist jene in der Forschungsliteratur mehrfach festgestellte Affinität zwischen der G eisteshaltung und der Lebenshaltung der Hauptfigur. Jedoch wird diese Affinität häufig nur oberflächlich konstatiert, wobei dies m.E. zum großen Teil darauf zurückzuführen ist, daß man Schaumanns G eisteshaltung kaum als selbständige Perspektive des erkenntnistheoretischen Gehalts des Romans von der Lebenslehre des Werkes getrennt betrachtet. Im G egensatz dazu stellt Eisele die Lebenslehre und die Erkenntnislehre des Werkes als zwei verschiedene Ebenen der Aussage des Werkes dar: „Statt unverzüglich zu einer in Raabes Roman etwa enthaltenen [Lebenslehre] überzuleiten, ist es m.E. nicht allein sinnvoll, sondern geradezu unabdingbar, länger bei diesem scheinbar kruden, vordergründigen Motiv zu verharren und vor allem die mit dem D etektorischen verbundene [Erkenntnislehre] einer genaueren Betrachtung zu unterziehen. ${ }^{\prime 168}$ Im Anschluß an Eisele unterscheidet sich mein Lektürevorschlag darin von der älteren Forschung, daß ich das literarische Formelement der D etektivgeschichte hervorhebe und die vom Gattungstypischen abweichende individuelle Struktur der Detektion genauer untersuche. Wie die Suche eines vorhandenen, von der feindlichen Umgebung zu befreienden Ichs das letzte Ziel seines Lebens ist, so fungiert jenes Ich als die letzte Begründung des richtigen Erkennens. Anders als die ältere Forschung, die diesen Z usammenhang von Lebenshaltung und Geisteshaltung als organische Einheit des in sich einheitlichen Individuums versteht und als solche bestätigt, möchte ich ihn als Struktur der Subjektivität problematisieren. Die Forschung macht in diesem Sinne eine dialektische Entwicklung: Betrachtet Eisele - gegen die überwiegende Forschungsmeinung, die methodisch zwischen der Lebenslehre und der Erkenntnislehre des Werkes nicht unterschied - die zwei verschiedenen Ebenen der Aussage des Werkes getrennt, so zeige ich, obwohl diese zwei Ebenen an sich getrennt sind, sich zueinander in der Tiefenstruktur dennoch wieder einheitlich verhalten.

In diesem Zusammenhang soll eine Stelle, die oft von der älteren Forschung zitiert wird - vermutlich deswegen, weil die Einheit der Lebenslehre und der Erkenntnislehre organisch, d.h. in der symbolischen Sprache als Einheit der Person, des Subjekts ausgedrückt wird - erneut reflektiert werden. Die Stelle lautet:

Ich war feist und faul, aber doch nun grade, euch allen zum Trotz noch vor meiner Kenntnisnahme des Weisen von Frankfurts bester Table d'hote ein Poet ersten Ranges: der Begriff war mir gar nichts; ich nahm alles unter der Hecke weg, mit dem Sonnenschein des D aseins warm auf dem Bauche, aus der Anschauung! (S. 117)

Diese salopp den Begriff als das Sammelbecken jeglicher rationalen, systembildenden Denkweise ablehnende und die Anschauung preisende Haltung erinnert an die zentrale Bedeutung der ,Intuition' bei dem hier als „Weisen von Frankfurts bester Table d'hote" apostrophierten Schopenhauer. In der Tradition des philosophischen D enkens sehr verschieden interpretiert, kommt die Intuition hier weniger als epistemologische Begründung richtiger E rkenntnis, sondern eher als rhetorisches Konzept in Frage. Denn gleichgültig, ob sie gegen das rationale D enken ausgespielt oder als eine besondere Form des rationalen Erkennens interpretiert wird, wird der intuitiven Erkenntnis Unmittelbarkeit zugesprochen, Unmittelbarkeit als gegebene ,Gewißheit' oder „Evidenz'. Diese Unmittelbarkeit berührt das Vorstellungsfeld, in dem von je Gott und das Göttliche oder das Absolute gedacht werden. In der Ablehnung des Begriffs und in der darin implizierten Bekenntnis zur Intuition ist nun die Apotheose des Subjekts vorbereitet bzw. abgerundet. Der D etektion liegt, so gesehen, eine Idee des Subjekts zugrunde, welches zugleich Deuter und Programmierer des Sinns ist. D euter, insofem man „vorhandenen“, verborgenen Sinn aufdeckt und festlegt, Programmierer, insofern man Sinn und damit Handlungsziele entwirft. Es ist die Erhöhung des Subjekts zu einem zentralen Mittelpunkt in der Analogie zu Gott. D iese Implikation findet auch darin ihre äußere Bestätigung, daß die anderen Schaumanns ungewöhnliche Leistung der Detektion als die eines "göttlichen“(S. 202) Finders und Erfinders bezeichnen. Der Göttliche als Finder und Erfinder verweist allerdings auf die Tradition der Gottesvorstellung bei Aristoteles: 169 Gott bzw. Gottheit als der Eine Seiende, an dem, nach einem berühmten Satz des Aristoteles, die W elt und die $\mathrm{N}$ atur hängen, ist bei ihm auf das Begreifen der Wahrheit, also auf das rein Geistige hin angelegt. Gottheit als N ous, der göttliche G eist des U nbewegten Bewegers wird rhetorisch-metaphorisch aktuell, wenn das Subjekt im Verhältnis zu seinem Werk das Nicht-Tun, die Inaktivität und Zufälligkeit vertritt. So spricht Schaumann über seine Tat der Aufklärung:

Aber das steht auch fest, [...] daß ich es beiläufig und fast ohne mein Zutun herausgekriegt habe: wer Kienbaums Mörder gewesen ist - wer Kienbaum totgeschlagen hat. (S. 93; Hervorhebung von J.-H. B.)

\section{D ie Struktur des auk torialen E rzählens}

168 U. Eisele, D er D ichter, S. 4.

169 Siehe zum Gottesbegriff bei Aristoteles, A ristoteles / A ristotelismus, in: Theologische Realenzyk lopädie. Hrsg. von G. Krause und G. Müller. Berlin; New Y ork. Bd. 3. A nselm von L aon - A risteteles/A ristotelismus. 1978, S. 726f., hier S. 737f. und S. 748-750. 
Wie läßt sich das erzählerisch Besondere bei Schaumann charakterisieren? Es wurde schon mehrfach herausgestellt, daß bei Raabe der Mensch im allgemeinen, hier im besonderen Schaumann, im monologischen Sprechen seine inneren Konturen gewinnt. ${ }^{170}$ Schaumann enthüllt sich sprechend, und er interpretiert sich bzw. sein Leben sprechend. So liegt bei der überwiegend monologischen Erzählstruktur die große Bedeutung des Aktes einer Sich-Setzung, SichVergewisserung nahe. Diese sich selbst erzeugende Bedeutung des Redens ist der inneren Struktur der erzählten G eschichte der D etektion entsprechend: Die Apotheose des Subjekts als D euter und Programmierer des Sinns liegt der Erzählweise der Detektivgeschichte zugrunde. Der Ich-Erzähler verfügt über eine Vollmacht über den Erzählvorgang und macht dies deutlich, indem er sein Gegenüber, Eduard und seine Frau, in die passive Objektposition des eigenen Willens zwingt. Schaumann ist, wie Eduard im Nachhinein einsehen mußte, nicht nur zum Herrn der Roten Schanze, sondern auch zum „Herrn der Rede“, ${ }^{171 ~ „ z u ~ e i n e m ~ S e l b s t r e d n e r ~ s o n d e r g l e i c h e n “ ~(S . ~ 62) ~}$ geworden. Seine Rede ist die sprachlich praktizierte Machtausübung. Schaumann ist ein Sprachtäter. Eduard, sein Gesprächspartner, der anfangs so ahnungslos diese Selbstrednerei seines Freundes als "große Bequemlichkeit" (S. 62) empfand, sieht schließlich in dem Erzähler einen „Unmensch[en]“ (S. 150), „Folterer" (S. 181) und "feisten Folterknecht" (S. 177). Noch betroffener ist wohl seine Frau. Sie sagt:

Du erzählst freilich den ganzen Tag durch nach deiner gewöhnlichen Art das Schlimmste und das Beste, das Herzbrechendeste und das Dummste [sic], wie als wenn man einen alten Strumpf aufriwwelt; aber jetzt solltest du damit aufhören und Rücksicht auf mich nehmen, grade wenn du mich auch zu allen übrigen Frauen auf Erden rechnest. Es ist mein Vater, von dem du so erzählst! Es ist meine kümmerliche Kinderangst und Jugendnot, von der du so sprichst! (S. 150)

Schaumanns Rede und die Gegenrede seiner Zuhörerschaft, Eduard und Tine, oszillieren zwischen einem rhetorisch-metaphorischem Gewaltakt172 und leisem und wildem Protest. Die Vorwürfe der Zuhörer bleiben jedoch erfolglos. Schließlich resignieren sie: „Es hilft uns nicht; wir müssen ihm seinen Willen und Weg lassen“ (S. 98). Wie man so wenig „wider Gott und Groß-Nowgorod" kann, so war für sie "gegen den Menschen nicht anzuerzählen." (S. 115) Sie „ließen ihm seinen Willen und Weg, und er watschelte auf dem letztern weiter, mit dem sichem Bewußtsein, uns in seiner Hand zu haben." (S. 98)

In solch einer erzählerischen Physiognomie, d.h. im monologischen Impetus seiner Pseudo-Dialogizität und in seiner Selbstschöpfung und Selbstsetzung im E rzählen, ist Schaumann eine metaphorische, ja eine allegorische Figur. In ihm scheint das auktoriale Erzählen mit der traditionellen humoristischen Prägung - der humoristische auktoriale Erzähler - Körper geworden zu sein. Schaumanns humoristische Erzählweise173 ist in diesem Sinn ,Mimesis' der humoristischen Erzähltradition, deren auktorialer Erzähler mit der bürgerlichen Subjektivität in ihrer Blütephase korrespondiert.

Der metaphorische Charakter Schaumanns als Erzählerfigur läßt sich noch weiter verfolgen und präzisieren. D azu soll ein Blick auf den Zusammenhang zwischen Leiblichkeit und praktizierter Erzählweise geworfen werden.174 So lautet ein Selbstkommentar des Erzählers: „Ich bin ein wenig breit - auch in meiner Schöne-GeschichtenErzählungsweise." (S. 183)

Das für die Körperlichkeit und die Erzählweise gemeinsam angewendete Adjektiv „breit“ spielt dabei auf die herben Urteile über Raabes eigentümlichen Schreibstil an, die er von den Literaturkritikern seiner Zeit oft zu hören bekam. An Schaumann, sowohl in seinem starken Leibesumfang als auch in der ihm zugedachten Rolle eines endlosen, weitschweifigen Erzählers, demonstriert Raabe sein „breites“ Erzählen in vollem, ja übertriebenem Ausmaß. Die langweilige, stets wiederholende, abschweifende und verschiedene Zeitebenen gleichzeitig zusammenbindende Darbietungsweise ist die auf die Spitze getriebene „allgemeine Struktur", „die seit langem dem E rzählen als ,wesensgemäß ${ }^{\prime}$ zuerkannt worden ist". ${ }^{\prime 17}$ So folgt Schaumanns Erzählen, und zwar in einer plakativen Weise, dem "Gesetz der Retardation“ als "Grundbedingung und Grundgegebenheit des Epischen“. Jedoch nicht allein das „körperlich eingesetzte und sprachlich umgesetzte" ${ }^{176}$ Breite gilt als Besonderheit seines literarischen Stils.

Die Allegorisierung bzw. Metaphorisierung erstreckt sich weiter auf das zeitgemäße Ideal des epischen E rzählens. Mit dem ,realistischen' Duktus des Illusionismus vermittels szenischen oder dramatischen E rzählens geht, wobei das Dargestellte spontan im Hier und Jetzt entsteht und von sich aus die Ordnung der conseatio temporis aufweist, das Ideal mündlicher Unmittelbarkeit und Authentizität einher. Diesem Ideal folgt der Roman durch die

170 Zum Beispiel F. Martini, D eutsche L iteratur im bürcerlichen Realismus, S. 687.

171 H. Turk / F.A. Kittler, U rszenen. L iteraturwissenschaft als D isk ursanalyse und D isk ursk ritik, Frankfurt/ M. 1977, Einleitung, S. 32.

172 Vgl. U. Eisele, D er D ichter, S. 21; zu diesem Aspekt siehe A. Schweckendiek, W ilhelm Raabes ,Stopfk uchen'. E ine ketzerische Betrachtung, in: JbdRG 1974, S. 91f.

173 Zum ,Humor' im Stopfkuchen siehe: W. Preisendanz, H umor als dichterische E inbildungskraft. Studien zur E rzählkunst des poetischen Realismus, München 1963, bes. S. 242f.; P. D etroy, W ilhlem Raabe. D er H umor als G estaltungsprinzip im „Stopfk uchen“. Bonn 1970.

174 Eine solche unmittelbare Symbolisierung zwischen leiblicher Üppigkeit und Mündlichkeit bzw. Literarität findet sich auch in einem anderen Werk Raabes, nämlich im D räumling (1872), und zwar in dessen wohlbeleibtem, literarisch wie körperlich sehr fruchtbarem Helden, Rektor Fischarth, der eine Vorstudie zu Heinrich Schaumann darstellt. (Vgl. M. G oetz-Stankiewicz, D es D ichters ,Pflicht'. G edank en zu Raabes E instellung zum Kunstwerk, in: JbdRG 1971, S. 21-48, hier S. 28.)

175 U. Eisele, D er D ichter, S. 27.

176 W. Zirbs, Struk turen des E rzählens, S. 189. 
mündliche erzählerische Vorherrschaft Schaumanns gegenüber dem sich ihm unterordnenden Schreiber-Erzähler Eduard. Dieses Ideal der Unmittelbarkeit und der Authentizität des mündlichen Erzählens wird aber auch durch Schaumann zu einem elementaren biohumanen Wert materialisiert. Das Erzählen Schaumanns wird als eine allgemein anthropologische, seinen anderen primären Körperfunktionen äquivalente Verhaltensweise dargestellt.177 So nähert sich sein Erzählen der Nahrungsaufnahme und -ausscheidung an: Schaumann „hatte die Geschichte von Kienbaums Morde nicht bloß mit seiner dröhnigen, langweiligen Redegabe von sich gegeben, er hatte sie auch ausgeschwitzt, sie durch die Poren aus sich herausgelassen“" (S. 195).

Schaumanns körperliche Verortung ist als Allegorie des idealen Erzählens begreifbar. Es bleibt zu fragen, ob diese Allegorie als negative Physiognomie einer bestimmten Erzählpraxis zu ,entmythisieren' ist. Die Klärung dieser Frage kann sinnvollerweise erst erfolgen, wenn der Erzählhabitus des anderen, in seiner ,Uneigentlichkeit' eigentlichen Erzählers, Eduard, betrachtet wird.

Ebenso scheinen sich die an die Person des Erzählers gebundenen Körperfunktionen metaphorisch auf künstlerische Produktionsformen, ja auf die Bedingung der Kunst selbst übertragen zu lassen. So tritt in Schaumanns Erzählhabitus gerade das auf, was dem modernen Roman als Schreibroman uneinholbar entrückt ist und welchem er nostalgisch nachtrauert. 


\section{Eduards Seetagebuch}

\section{D as Schreiben und die bürgerliche Identitätsk rise}

Stehen dem Erzähler der Detektivgeschichte die Einheit von Erfahrung und Weisheit, die Harmonie von vita ontemplativa und vita adiva, und die Einheit von egozentrischem und sozialem Sinn des Erzählens zu, so wird der Zerfall dieser Einheit gerade für Eduard, den Erzähler der anderen Geschichte, genannt die Seegeschichte, kennzeichnend. Das Schreiben des Ich-Erzählers Eduard ist eine innerlich motivierte Handlung. D abei wird diese seine innere Verfassung sowohl für den Leser als auch für ihn selbst teils offenbar, teils bleibt sie verborgen.

Diese offensichtlich realistische Situierung von Eduards Schreibgegenwart nehme ich weder als die Intention noch als die Position des Schreibers an. Vielmehr ist in der Diskrepanz zwischen der realistischen Passage und der eigenen Begeisterung der Ausdruck des dubiosen Standpunktes des Biographen zu sehen. ${ }^{178}$ Dies führt zu der für die folgende Untersuchung grundlegenden Annahme, daß „Eduards Erzählkompetenz nicht ganz zu trauen sei und daß sich hinter seiner Niederschrift mehr verberge als er wahrhaben will“. ${ }^{179}$

Es handelt sich dabei nicht um seine Authentizität, jedenfalls nicht um eine bewußte Verfälschung des Faktischen. ${ }^{180}$

Vielmehr handelt es sich um die versteckte Selbstbezogenheit des Ich-E rzählers, also die spezifische Art und Weise, wie die Erfahrung seiner Begegnung mit der alten Heimat und mit der Vergangenheit überhaupt verarbeitet wird, was sich in der gewählten Form der Seegeschichte manifestiert. Was ist, anders gesagt, seine Erfahrung, deren Verarbeitung ihn zum Schreiben, und zwar ausgerechnet in dieser Form, wie sie seine Aufzeichnung angenommen hat, geführt hat?

Es scheint, als ob die unverhofft ihrer Unschuld beraubte Kinderfreundschaft'181 zu Störzer in Eduard die grundsätzliche Fragwürdigkeit seiner Lebensordnung aufgeworfen hätte, als ob seine bürgerlich erfolgreiche Existenz schließlich auf die von der Fluchtphantasie des Mörders beförderte Sehnsucht nach der Ferne zurückzuführen wäre.

Wie schmerzlich und unaufhaltsam sich ihm die Einsicht in die Gebrechlichkeit des Seins auch aufdrängt, so scheint doch die innere Erschütterung durch Schaumanns Geschichte als solche noch nicht der unmittelbare G rund dafür zu sein, daß Eduard übereilt nach Afrika aufbricht und davor zuerst in seiner Niederschrift zu sich selbst zurückzukehren versucht. Noch in derselben Nacht, nach der Abschiednahme von Schaumann, stellt sich Eduard vor, in der Lage zu sein, sich nachträglich die Lebenslehre Stopfkuchens anzueignen, und zwar als für ihn selbst bekömmliche Jugendgeschichte in neuer Version. Eduard findet sogar in Schaumann ,einen neuen Freund im Sinne eines besseren Ich', also einen Freund in einem ganz anderen Sinne, als er bei seinem Gang zur Roten Schanze von seinem „Kindheits-, Feld-, Wald- und Wiesenfreund Stopfkuchen“ (S. 26) spricht.

Kurz und bündig zieht er das positive, ja für ihn immerhin verdauliche Fazit aus der ganzen G eschichte:

Da überlegte ich mir in dieser Nacht, erst außerhalb des Wirtshausbettes und dann in demselben, den mir eben vergangenen Tag noch einmal von Stunde zu Stunde, von Wort zu Wort. Und mehr und mehr kam mir wieder zum vollen Bewußtsein der alte ganz richtige Satz vom zureichenden Grunde, [...]. „Nichts ist ohne Grund, warum es sey." - Wie mich der Le Vaillant [...] zu den Buren in Pretoria gebracht hatte, so hatte der Steinwurf des Störzers Hand nach Kienbaums Kopfe den Freund zu Tinchen Quakatz geführt und ihn zum Herrn der Roten Schanze gemacht. Und so, wenn Kienbaum nicht Kienbaum, wenn Störzer nicht Störzer, wenn Stopfkuchen nicht Stopfkuchen und Tinchen nicht Tinchen gewesen wären, so wäre auch ich nicht ich gewesen und hätte gegen Morgen über dieser Mordgeschichte in den ruhigen Schlaf versinken und daraus erwachen können mit den beruhigenden Gedanken an das „afrikanische Rittergut“ und an mein Weib und meine Kinder daheim: „Nun, die Sache hat sich ja noch ganz erträglich gemacht." (S. 197f.)

Mit diesem beruhigenden Fazit wäre er wohl nicht zum Entschluß der Abreise, noch weniger zur Niederschrift der „nette[n] E rinnerung an die alte gemütliche Heimat" (S. 167) gedrängt worden. Schon in der nächsten Z eile wird aber diese wohl gesetzte Meinung als vorschneller Irrtum zurückgenommen. Die Sache gestaltet sich denn doch nicht so „erträglich“, jedenfalls nicht so, wie er oben sinnierte. Eduard kommt von der Sache nicht so einfach los: „Fertig war ich freilich noch nicht mit ihr, der Sache nämlich." (S. 198) Und zwar sieht er am folgenden Morgen durch ein Gespräch mit dem Wirt ein, welche unangenehme Vermittlerrolle er der Neugier der Welt gegenüber zu spielen hat. „Stopfkuchen hat Eduard zum Mitwisser der Heillosigkeit menschlicher - und insbesondere philiströser

178 Vgl. E. Meyer-Krentler, D er Bürger als Freund. E in sozialethisches Programm und seine Kritik in der neuen deutschen E rzählliteratur. München 1984: „D er Mittelpunkt, in dem Eduard als Erzählender steht, ist vielmehr der einer durchschaubaren Beglaubigungspose, in der ein Betroffener und Getroffener erzählend die Unheimlichkeit des Helden und seine eigene Beteiligung an einem keineswegs ,behaglichen' Geschehen von sich wegschiebt" (S. 266).

179 Ebd., S. 267.

180 Vgl. W. Zirbs, Strukturen des E rzählens, S. 128: „Immerhin gibt es keinerlei grundsätzlich relativierende Aussagen, die ein partielles oder gar vollständiges Infragestellen der Korrektheit von Eduards Vermittlungstätigkeit zuließen."

181 Vgl. E. Meyer-Krentler, Bürger als F reund, S. 268. 
- Existenz gemacht und zwingt ihn, den Bürger und Mittler, sich als Hehler der peinigenden Neugier der Welt auszusetzen". ${ }^{182}$

Eduard denkt nach. Erst in diesem Augenblick kommt er zum Entschluß, schnell abzureisen. Er überlegt:

Und nun kannst auch du mit ausbaden, was der Dicke hinter aufgezogener Zugbrücke der Welt so lange als möglich so schnöde als möglich vorenthalten hat! Und der Feistling ist auch jetzt noch imstande, seine Schanze um sich und sein Weib herum noch mehr in Verteidigungszustand zu setzen, die Bulldoggen, Fleischer- und Schäferhunde, die giftigen Spitze, kurz, alle die bissigen Wächter seines seligen Schwiegervaters wieder aus der Gruft zu beschwören und dir, Eduard, es ganz allein zu überlassen, die Sache Störzer-Kienbaum gegen die Menschheit auszutragen! (S. 199f.)

Es ist nichts anderes als der von Schaumann, dem, göttlichen' Finder und Erfinder, dem Freund heimtückisch zugedachten Rolle zu entfliehen, wenn Eduard plötzlich abreist. Ohne daß Eduard den wahren Sinn verstanden haben konnte, hat Stopfkuchen ihm schon am Vorabend den entsprechenden Auftrag gegeben:

Nun, was ist deine Meinung, Eduard? Seinen Schlaf störe ich nicht dadurch: soll ich jetzt die Welt da von der Gasse hereinrufen an sein Kissen? Soll ich nun selber von dieser Stelle aus ore rotundo das Geheimnis ihr kundmachen? Oder findet sich doch noch ein passenderes Organ der Mitteilung? Oder - vielleicht - wünschest du selber - (S. 164)

Eduard flieht vor dieser Rolle, der Vermittlerrolle, wenn er sich folgende Ausflucht einredet: „Wie wäre es denn, wenn du den Kopf aus der Geschichte zögest, Eduard, und dein Teil daran sofort mit auf das Schiff nähmest?"(S. 200). So entsteht seine Niederschrift als Fluchtversuch vor der ihm durch Schaumann aufgezwungenen Rolle und als dafür abzulegende Rechenschaft, nämlich als sein Anteil an der Sache:

„Ich gehe!" sagte ich, und - ich ging wirklich und wahrhaftig. Stille Vorwürfe ließ ich dabei außer acht, und für laute war ich ja immer noch in Afrika zu finden und hätte da gern jedem Rechenschaft abgelegt, das heißt ihm dies mein Schiffstagebuch zu lesen gegeben. (S. 200)

Klar geworden ist mit dem bisher Erwähnten, daß Eduard nicht wegen der Erschütterung der bisherigen Sicherheit seiner bürgerlichen Lebensvorstellung oder gar vor dem ,eindeutigen Sieg' Stopfkuchens flieht. Die Bodenlosigkeit des bürgerlich-philiströsen Lebensprinzips, die einzugestehen Eduard durch den Helden gezwungen wurde, gibt er bereits zu; wenn auch in einer selbsttäuschenden Übertreibung und Beschönigung: Sobald ihm die Illusion der Kindheits- und Heimatidylle in Störzer zerstört wird, gerät Eduard in das „Hinauflügen“ des Zerstörers Schaumann selbst „bis zur übermenschlichen Göttlichkeit", 183 er gerät in die neue Idylle ${ }^{184}$ der aufgeklärten Mordgeschichte als Kindheitsgeschichte. D as ,Hinauflügen' geschieht deswegen, weil die unterdrückte Erkenntnis von der verhängnisvollen Selbstgerechtigkeit und Selbstgefälligkeit bei Schaumann auch ihm unabweislich ist. Dies ist psychologisch dadurch begründbar, daß „sich das ,bessere Ich' mit dem fremden Geschick identifiziert und das blinde Urteil, das von außen über die Person gefällt wird, nach innen gegen ein schlechteres Ich noch einmal vollstreckt (Identifikation mit dem Angreifer), um das Bewußtsein der moralischen Reinheit bewahren zu können." ${ }^{185}$

O hne sich der bereits unhaltbar gewordenen neuen Idylle à la Stopfkuchen bewußt werden zu können, erinnert Eduard sich jedoch an Stopfkuchen als (selbst-)gerechten Rächer. Denn er begegnet, unterwegs zum Bahnhof, dem Leichenzug Störzers, der die schnelle, unbarmherzige Wirkung der Geschichte Stopfkuchens auf die Welt verdeutlicht:

Dieser arme Sarg - jetzt mit einem G efolge, das nur aus einer Frau mit einem Kinde auf dem Arm und einem an der Schürze bestand!... Sie hatten alle das G eleit verweigert, die sonst wohl dazu gehört haben würden. Auch die Kaiserliche Post hatte es nicht mehr für schicklich erachtet, ihre niedern Bediensteten dem alten Weltwanderer, dem guten Beamten, aber sehr verstohlenen Mordgesellen hinterdreinzuschicken ;[...]. (S. 203)

Gerade in der „völlige[n] Vernichtung aller Fluchtmöglichkeiten selbst als persönlich nicht erreichbarer Idyllen“"186 findet Eduards Abreise statt. Ihm wird nun klar, daß „auch die G egenwart des Helden in ihrer vorgegebenen Behaglichkeit der aufrechterhaltenen, zur Selbstisolation vorangetriebenen Isolation keine Chance mehr läßt, sich in dieser Richtung eine bessere Gegenwelt aufzubauen".187 Eduard flieht vor der ihm von Stopfkuchen zugedachten Rolle, die anti-bürgerliche Utopie Stopfkuchens in der Sache Störzer-Kienbaum der Welt zu vermitteln. In diesem Sinne scheint Eduards Flucht sich vielmehr auf die skeptische Bewußtseinssituation des orientierungslos gewordenen bürgerlichen Subjekts zu beziehen. Es ist dies die Situation, durch die die in dem retrospektiven Erzählen systematisch betriebene selbst- und fremdtäuschende "Freundesheroisierung' von seinem rationalisierten Erzählvorgang verdrängt wird. Sie wird aber innerhalb des erzählten Ablaufs mitgeteilt und repräsentiert.

182 Ebd., S. 274

183 P. D erks, RaabeStudien. Beiträge zur A nwendung psychoanalytischer Interpretationsmodelle: Stopfk uchen und das 0 dfeld, Bonn 1976, S. 66.

184 Ähnliches, aber in einer deutlichen Ironisierung der Heimatidylle, sagt Stopfkuchen beim Abschied nach der Entlarvung von Kienbaums wahrem Mörder: "Was tut man so einem lieben, alten fremdgewordenen Freund nicht alles zu Gefallen, um ihm das alte Nest wieder heimelig und vertraulich zu machen!" (S. 196)

185 K. Moormann, Subjek tivismus und bürgerliche G esellschaft. Ihr geschichtliches V erhältnis im früheren Prosawerk G ottfried Kellers, Bern 1977, S. 109. 186 E. Meyer-Krentler, D er Bürger als Freund, S. 272.

187 Ebd., S. 273. 
Repräsentiert ist sie vor allem in Schaumann, einer Erscheinung, die sich jedem festen Zugriff entzieht: ein ,Vexierbild'. In der vexierbildhaften Erscheinung Schaumanns liegt nicht nur die Thematik der Doppelbödigkeit bürgerlich-nichtbürgerlicher Existenz, in ihr wird auch auf die Bewußtseinsthematik des erkennenden bürgerlichen Subjekts in G estalt des Ich-Erzählers verwiesen.188

Man kann daher die Interpretation nur noch mit Einschränkung gelten lassen, daß Eduard, erschreckt angesichts der inneren Übereinstimmung seiner Weltwanderer-V orstellung mit der philiströsen Gesellschaft in ihrer Blindheit, vor Stopfkuchen fliehe, weil dieser sich in dem engeren Bereich der Heimat, in seiner allzu seßhaften Lebensweise und in gefährlicher Nähe zur philiströsen E ingeschränktheit als eigenständiger, freier Mensch entpuppt habe. 189 Wenn Eduard trotz des überaus zwiespältigen Heldenbildes seinen Freund zum endgültigen Gegenwert des Philistertums emporlobt, 190 ist dabei auf die Darstellungsgrenze des Ich-Erzählers hinzuweisen. Es ist die Grenze der Sprache des orientierungslos gewordenen Subjekts, das sich nun nur noch in einer kraß vorangetriebenen Selbsttäuschung an der Oberfläche einer nicht mehr bis auf den $\mathrm{G}$ rund auszuleuchtenden Geschichte mühsam über Wasser hält.191

Der Ich-Erzähler verkörpert daher nicht die realistische, sich einzig dem Erlebten gegenüber adäquat verhaltende Sichtweise, ${ }^{192}$ sondern er steht für eine subjektive Verarbeitung. Sie folgt demselben Prinzip, welches die häufigen strukturellen Gegensätze und Antinomien auch in anderen späten Werken Raabes darstellt, „um die Vielschichtigkeit der Reaktionen zu vergegenwärtigen, in denen der Mensch auf das Antinomische der Wirklichkeit je nach seiner Art, die wiederum im Subjektiv-Psychologischen typologisch bestimmt wird, antwortet." ${ }^{193}$

Wie oben ausführlich behandelt wurde, geht bei Eduard die subjektive Verarbeitung der Begegnung mit Schaumann ausschließlich in seiner psychologischen Schutzreaktion auf. Der springende Punkt dabei ist, daß diese Schutzreaktion als E rzählerperspektive in ihrem sozialpsychologischen Verweisungszusammenhang des ausgehenden 19. Jahrhunderts auf „die Subjektivität gerade des bürgerlichen Subjekts, das Abhandenkommen aller Möglichkeiten der G eborgenheit und des Sich-Verbergens in der Wirklichkeit" ${ }^{194}$ zurückzuführen ist.

In dem Erzähler Eduard, genauer gesagt in seiner sich selbst täuschenden Euphorie über seinen Sonderlingsfreund, spiegelt sich die Flucht des bürgerlichen Subjekts aus der bürgerlichen Wirklichkeit. Zurückschreckend vor dem absoluten Abhandenkommen aller Fluchtwege, die noch verfügbar wären, greift das bürgerliche Subjekt resigniert zur Feder. „Was bleibt" sonst außerhalb der Möglichkeit, „schreibend die Fassaden der zerstörten Idylle wieder aufzurichten - wie es in der Seegeschichte geschieht"? 195 D er Bürger kann sich nun die immer begrenzter werdende Möglichkeit der Identitätsfindung letztlich nur in einem idealen Gegenüber, in seinem heroisierten Freund, und das auch nur in einer erinnerten Vergangenheit als bloßer Bewußtseinswirklichkeit aneignen. ${ }^{196}$

Für dieses erzählerische und zugleich existentielle Befinden steht das Farb-Symbol „blau'. Während seiner überstürzten Abfahrt zieht Eduard die blauen Fenstervorhänge seines Eisenbahnabteils zu; er sitzt im abgedunkelten Abteil, tief betroffen. D iese Gemütslage steht als seelischer D auerzustand hinter seiner ganzen Niederschrift:

Aber noch etwas will ich nicht leugnen: nämlich, daß mich das blaue Licht oder die lichtblaue Dämmerung, in der ich bei der Abfahrt von der Heimat die Augen schloß, um mich erst wieder an die rechte Beleuchtung zu gewöhnen, trotz dieser G ewöhnung dennoch bis Hamburg, bis auf das Schiff - bis in diese Stunde begleitet hat. (S. 206)

Es handelt sich hier deshalb um „eine Flucht in eine historisch gewordene Utopie der Idylle, um einen weltabgewandten privaten Trost durch die Literatur" ${ }^{\prime 197}$ Eduards Schreibakt ist eine bedrängte Selbsthilfe inmitten der bürgerlichen Identitätskrise, eine Aktion, die von der melancholischen Farbe Blau begleitet wird. Mit einer solchen nachträglich identitätswiederherstellenden Lebenshilfe-Funktion ${ }^{198}$ hat sich der subjektive private Charakter der Literatur intensiviert. Die Niederschrift geschieht nicht umsonst in der Form eines Tagebuches. Den privaten,

188 Vgl. ebd., S. 275.

189 Als Vertreter dieser Interpretation vgl. H. O hl, E duards H eimk ehr, S. 271: D aß „der im Zeichen des ,Riesenfaultiers' stehende Mensch innerlich, weitergekommen' ist als der dem ,Le Vaillant' verpflichtete, krönt das in diesem Roman immer wieder variierte Spiel ironischer Umkehrung und macht die eigentliche ,Aussage' des Werkes aus."

190 „Die Menschheit hatte immer noch die Macht, sich aus dem Fett, der Ruhe, der Stille heraus dem sehnigsten, hageren, fahrigen Konquistadorentum gegenüber zur Geltung zu bringen. Heinrich Schaumann, genannt Stopfkuchen, hatte dieses mir gegenüber gründlich besorgt." (W. Raabe, Stopfk uchen, S. 204)

$191 \mathrm{Vgl}$. E. Meyer-Krentler, Bürger als Freund, S. 274.

192 D agegen schätzt U. Eisele den Ich-Erzähler als realistische Beglaubigungsfunktion ein, wenn auch nicht im vollen Sinn, so doch noch als ein nahezu gestisches Vorzeigen der realistischen Verfahrensweise: Siehe ders., D er D ichter und sein D etek tiv, S. 39, Fn. 1.

193 F. Martini, D eutsche L iteratur im bürgerlichen Realismus, S. 703.

194 E. Meyer-Krentler, D er Bürger als Freund, S. 273.

195 Ebd., S. 272.

196 Ebd., S. 273.

197 F. Martini, W eltleid und W eltversöhnung. W ilhelm Raabe in seinem Jahrhundert, in: JbdRG 1985, S. 7-26, hier S. 9.

198 Vgl. K. Wirschem, D ie Suche, S. 96: Am Beispiel von Raabes Bildungsroman D er H ungerpastor spricht Wirschem auch von der eine nicht gelebte Realität ersetzenden Bedeutung der Literatur, ihrer Funktion als einer auf eine eigene Weise verstandenen und darauf begründeten Selbstberechtigung. Jedoch im Stopfk uchen, bei Eduard, tritt der Scheincharakter wegen der Erzählstruktur der beiden aufeinander verweisenden Erzähler verschärft auf. 
intimen Charakter seiner Schrift unterstreicht Eduard noch mit seiner Bemerkung dem neugierigen Kapitän gegenüber: „Es würde Sie wenig interessieren, Kapitän. Die reine Privatsache!“, woraufhin er „das Manuskript zu[klappte]".(S. 207)

\section{D er Perspek tivismus ${ }^{199}$ als F ormprinzip}

So liegt in Eduards Schrift der defensive Versuch, seine problematisch gewordene Identität zu retten, während die Erzählsuada Schaumanns „zur Manifestation der aktiven Überwindung und der errungenen Überlegenheit, ja des Triumphes über die Welt" 200 wird.

Die mit dem Schreiben zu rettende Identität, ja das neue Selbstverständnis ist der Sache nach unsicherer, provisorischer ${ }^{201} \mathrm{Art}$, wobei eine nochmalige Wandlung prinzipiell nicht ausgeschlossen ist. Hierin ist die permanente Suche des unruhigen modernen Menschen nach sich selbst angelegt.

Die ewige, endlose Selbstentdeckungsreise ist die eigentliche Geschichte der ,Seegeschichte', die sich symbolischerweise auf den langen Wogen des Atlantischen Ozeans, auf dem „hohe[n] Meer des Lebens“(S. 45), ereignet, während auf dem Schiff selbst eine außergewöhnliche Langeweile, eine symptomatische Ereignislosigkeit, dominiert. So wird vom Kapitän bemerkt:

Wissen Sie wohl, lieber Herr, daß Sie das einzige Merkwürdige sind, was ich auf dieser Fahrt erlebt habe? Etwas von schlechtem Wetter kommt doch immer vor, aber diesmal nicht das geringste; denn den squall von neulich rechnen Sie wohl selber nicht. (S. 206)

Mit der Ankunft des Schiffs in seiner neuen afrikanischen Heimat findet auch der Schreibakt und damit die Selbstsuche ein Ende. „Was rein formal in eine fast absolute Bewegungslosigkeit übersteigert scheint (im Schiffsrumpf zu sitzen und zu schreiben), das entpuppt sich in der Tätigkeit des schreibenden Erzählens als eine stetige Selbstmetamorphose Eduards und damit als permanente innere Bewegung." ${ }^{202}$ Eduard tritt aus dem Schiffsinneren heraus und kommentiert:

Als ich dann auch auf Deck stieg, um mit den anderen den Tafelberg aus dem Meer aufsteigen zu sehen, und als wirklich ein blaues Wölkchen am Horizont vom Schiffsvolk für den berühmten Berg erklärt wurde, mußte ich mich doch an die Stim greifen und fragen: „Eduard, wie ist denn das? Du bist wieder hier?" - - - (S. 207)

Die an sich selbst gerichtete Frage verrät die Erleichterung darüber, daß mit der eben beendeten Niederschrift auch die Selbstmetamorphose erfolgreich abgeschlossen ist. Die Seegeschichte erzählt nicht, sondern ist Ort und Vorwand für die Selbstmetamorphose des spätbürgerlichen Subjekts, für dessen hinfällige Identifikationsversuche mit dem zum Ideal hinaufgelogenen Jugendfreund. Vor diesem Hintergrund ist eine Erzählstruktur gerade einleuchtend, bei der die Erzählsituation sich verkehrt: „Wenn auch Eduard die Geschichte als seine Geschichte präsentiert und erzählt, so wird zunehmend deutlich, daß er vor allem vom Erzählen Stopfkuchens erzählt, dessen Berichten er über die größten Teile des Romans kommentarlos lauscht." ${ }^{203}$ Die wie stenographiert wirkende wörtliche Wiedergabe des Monologs der Heldenfigur ist sowohl die Grundlage für Eduards Verarbeitung der Geschichte als auch die Art und Weise seiner Bearbeitung selbst. Die realistische Aufhebung der Differenz zwischen der Erfahrungsvorlage und der Erfahrungsverarbeitung ist die erzählerische Strategie dieses bedrohten spätbürgerlichen Subjekts und entspricht dessen Bedürfnis nach der Einheit mit und in sich, der in der detailgenauen Vergegenwärtigung der quasi gelungenen Selbstsetzung Schaumanns nachzugehen versucht.

Diese assimilierende Selbstmetamorphose als Prinzip und Ergebnis von Eduards Schreibtätigkeit kann im Vergleich mit Schaumanns Subjektivität und deren auktorialer E rzählhaltung noch näher bestimmt werden.

Im Gegensatz zu Schaumann, dem die olympische Ungeniertheit eines seiner Sache sicheren auktorialen E rzählers eigen ist, ist Eduards Schreiben nach innen gewandt, da es als Tagebuchschreiben dem inneren Monolog im Sinne eines einsamen Selbstgesprächs nahesteht. Die subjektive, isolierte, auf das eigene Innenleben gerichtete Perspektive ist hier programmatischer Art in dem Sinne, daß sie die äußere Textform bestimmt. Während Schaumanns Erzählen als kommunikatives Handeln den leiblichen Zuhörer allzu dringend benötigt, obwohl es vordergründig eine einseitige, unkommunikative Alleinherrschaft ausübt, aber gerade darin sich als auf den anderen angewiesen verrät, verbannt Eduards Erzählen nicht nur mit seiner Geste der Intimität des Tagebuchschreibers sein G egenüber, das sich in der Reisegesellschaft auf dem Schiff darstellt.

199 Bei der Verwendung des doch ,besetzten' Perspektivismus orientiere ich mich vor allem an der literaturwissenschaftlichen Neukonzeptualisierung des Begriffs für die Narratologie (M. Pfister; Studien zum W andel der Perspektivenstruktur in elisabethanischen und jak obäischen Komödien. München 1974; A. Nünning, Figurenperspek tive, E rzählerperspek tive und Perspek tivenstruk tur des narrativen Tex tes, in: ders., Grundzüge eines kommuniationstheoretischen Modells der erzählerischen V ermittlung, Trier 1989, S. 64-84) sowie die soziologische, kulturwissenschaftliche Forschung zur Perspektivenübernahme (D. G eulen, Perspek tivenübernahme und soziales H andeln. Frankfurt/ M. 1982).

200 E. Beaucamp, L iteratur als Selbstdarstellung. W ilhelm Raabe und die M öglichk eiten eines deutschen Realismus, Bonn 1968, S. 62.

201 Vgl. W. Zirbs, Strukturen des E rzählens, S. 135.

202 Ebd., S. 130.

203 I. Roebling, Buchfuhrung, S. 95. In diesem Zusammenhang spricht Roebling von der ,Verkehrung der Erzählsituation'. 
Von der Perspektive dieses Ich-E rzählers her, nämlich durch die Art der Gestaltung des der Ich-Erzählung eigentümlichen Spannungsfeldes zwischen Ich als Erzähler und Ich als Figur wird das kommunikative Element minimalisiert: D ie Diskrepanz zwischen erzählendem und erlebendem Ich wird hier nicht als ein produktives Mittel für die epische Gestaltung anerkannt. Z wischen dem Erlebnis und dem Erzählen liegt kein bedeutender Zeitraum, um eine interpretatorisch signalhafte Erzähldistanz einzuschalten. Das erzählende Ich bleibt dem erlebenden Ich gegenüber distanzlos. Dialogizität, sei es zwischen dem Schreiber und dem gegenwärtigen bzw. zukünftigen Leser oder zwischen dem schreibenden erzählenden Ich und dem erlebenden Ich, stellt sich hier nicht ein.

Eduards Monolog ist dem eigenen Innen zugewandt, d.h. er verfügt, anders als Schaumann, nicht über ein kommunikatives G egenüber. Er verfügt auch nicht über eine innersubjektive Stabilität wie Schaumann. Dies läßt sich im folgenden anhand der erzählerischen Tätigkeit Eduards zeigen, an der die Erinnerung einen großen Anteil hat.

Während es sich bei Schaumanns Erzählvorgang um die im epischen Bericht objektivierte Erinnerung an die Vergangenheit handelt, umfaßt Eduards Erinnerung zwei Arten von Erinnerung. Zum einen ist dies die Erinnerung, die, ähnlich wie bei Schaumann, dem Erzählen als mentales Medium dient und daher den Großteil des Erzählens selbst bildet. Zum anderen ist es eine Erinnerung als existenzielle Erfahrung, die er als Besucher nach langjähriger Abwesenheit in seiner alten Heimat, in einer im Grunde außeralltäglichen Situation, durchlebt. Diese Erinnerung kann man als Begegnung mit der Vergangenheit, dem gelebten Leben verstehen. Es ist eine Lebens- und Selbsterfahrung, deren Kulminationspunkt wohl in der Enthüllung des Jugendfreundes als Mörder liegt. Es sind zerstückelte, spontan von jedem zufälligen kleinen oder großen Anlaß hervorgerufene Erinnerungen, deren Bericht strukturell mit dem Bewußtseinsprotokoll im modernenen Bewußtseinsroman verwandt wirkt.

So entsteht am Rand des humoristisch Totalität anstrebenden Erzählmodus die Erzählung des Detektivgeschichtenerzählers Eduards als eine Art Bewußtseinsprotokoll. Dabei werden die Gedanken des erlebenden Ichs als solche deutlich, indem sie formal markiert - häufig in einer variierenden Form eines ,habe gedacht::

Man begegnet oft dieser an die Erzähltechnik des inneren Monologes erinnernden Wiedergabe des Bewußtseinszustandes. Es sind die Stellen, wo sich in die im Präteritum erzählte Geschichte Sätze im Präsens drängen, die sich deutlich auf den Bewußtseinszustand des erzählenden Ichs beziehen. Ein prägnantes Beispiel ist die Passage, wo Eduard vom Bericht über den Heimweg nach dem gemeinsamen Abend mit den alten Freunden zur Schreibgegenwart an Bord überwechselt:

Nun mußte mir aber die Weggenossenschaft gerade dieses Abends näher liegen als alles [...]. Es waren die Leute, mit denen man ging, die einem in der Fremde im Wachen und im Träumen, vorzüglich jedoch im Halbwachen und im Halbtraume, plötzlich vorübergleiten oder sich in den Weg stellen! Die, an welche man lange Jahre nicht gedacht und an die man dann um so intensiver zu denken hat: I, der und der! Ob der gute alte Kerl wohl noch lebt und es ihm nach Verdienst wohl ergeht?...Und nun - da - guck den Stänker - den hämischen Schulbankpetzer! Wie kommt mir der Bursche in seinen zu kurzen Hosen und Rockärmeln grade jetzt, hier an dieser Straßenecke am Hafen, in den Sinn, hier unter den Palmen und Sykomoren und andern Mohren und bei der äquatorialen Hitze? [...]. (S. 10)

Im Präsens geschrieben sind auch die häufig auftretenden ,man'- Sätze, ${ }^{204}$ mit denen der Ich-Bezug, sei es der zum erlebenden oder zum erzählenden Ich, durch das unpersönliche Pronomen ,man' verdrängt wird. Der Bewußtseins- und Handlungsträger ist hier eine unbestimmte, eigenschaftslose Person. D a zwischen ,Ich' und ,man' häufig gewechselt wird, wird der einheitliche Ich-Bezug des Erzählens durch Segmente ohne eindeutigen Bezug auf die Kategorie ,Person' gebrochen. In dieser Brechung des einheitlichen Personen-Bezugs läßt sich die auch dem inneren Monolog zugrunde liegende Tendenz der Auflösung einer fest umrissenen Selbstidentität wieder erkennen, über die Musil folgendes sagt: „Es steht nicht mehr ein ganzer Mensch einer ganzen Welt gegenüber, sondem ein menschliches Etwas bewegt sich in einer allgemeinen Nährflüssigkeit." 205

Sowohl bei der den Aspekt des inneren Monologs vorwegnehmenden Wiedergabe des Bewußtseins als auch bei dem ,Man'-Satz ist die Ablösung von der Ich-Person der vermittelnden Instanz, des Ich-Erzählers, festzuhalten. Jedoch schlägt Raabe den Weg des Bewußtseinsstroms und des inneren Monologs hier, wie auch später in dem Romanfragment A ltershausen, nicht ohne weiteres ein. In diesem Zusammenhang scheint von Bedeutung zu sein, Überlegungen darüber anzustellen, inwieweit die genannten erzählformellen Erscheinungen als Ausdruck eben der Tendenzen des modemen Bewußtseinsromans auszuwerten wären. In diesem Genre erscheint einerseits die Darstellung der Welt als Reflex des Bewußtseins, und damit wird ein geschlossener Weltentwurf aufgegeben. Andererseits wird damit auch die G eschlossenheit des Subjekts selbst, die Identität des Individuums, problematisiert.

In der Form des ,inneren Monologs' im modemen Roman erscheint die Polarität von Welt und Ich in der Weise, daß dort die klare Gegenüberstellung von Erkennendem und Erkanntem zerfließt und Erkenntnissubjekt und -objekt sich vermischen und gegenseitig durchdringen.

204 Näher zum ,man' bei Raabe im Zusammenhang mit der Thematik des Spießbürgers und zu der M. Heideggers Sein und Zeit (den Paragraphen D as alltägliche Selbstsein und das M an) vorwegnehmenden Aktualität siehe D. Arendt, Raabe und der romantische Schlachtruf: „Krieg den Philistern!", S. 75f.

205 R. Musil, D er M ann ohne E igenschatten, in:ders., G esammelte W erk e in E inzelausgaben. Hrsg. v. Adolf Frisé. Bd. 1, Hamburg 1952, S. 224. 
In der Präsentationsform des inneren Monologs wird die vom individuellen Ich losgelöste Innerlichkeit zur unpersönlichen Seelensubstanz, und sie zerfließt, ohne daß feste Konturen zurückbleiben würden. Dementsprechend zerfällt auch die Außenwelt in zusammenhanglose und anonyme Dinge. Die gegenseitige Durchdringung und Vermischung von Seele und Dingwelt ist charakteristisch für den inneren Monolog. ${ }^{206}$ Entgegenständlichung der Außenwelt und Verdinglichung der Innenwelt können exemplarisch beim inneren Monolog aufgezeigt werden.207 Eine ähnliche moderne psychische Erfahrung und ihre Bearbeitung kann man bei Eduards Traumpartie beobachten, bei der es sich um die Erfahrung der Entfremdung handelt, der Überschreitung der Selbstgrenzen bzw. der Versetzung des Selbst in den Anderen.

So wahrscheinlich bald nach Mitternacht hatte ich mich ganz in des Dicken Stelle, das heißt seine Haut versetzt, das heißt war in dieselbe hineinversetzt worden. Ich war zu seinem Leibesumfang angeschwollen und hatte mich auf die Höhe seiner behaglichen Weltverachtung erhoben [...]. (S. 197)

Der Unterschied zur im inneren Monolog eingefangenen verdinglichten Innerlichkeit, die zur Vermengung mit der personifizierten D ingwelt führt, liegt darin, daß das Fremde, Andere, in das sich die Innerlichkeit des Subjekts hineindrängt, hier der idealisierte Jugendfreund, eine Instanz von humaner Größe ist. Diese Eingrenzung der Erfahrung des Eindringens ins Innere des Anderen auf eine interpersonale Sphäre wird hier als Vorphase dessen begreifbar, was sich nachher im inneren Monolog niederschlägt.

Ich stimme Th. Buck völlig zu, wenn er angesichts dessen, daß auch in A ltershausen Raabes Antizipation des modernen Bewußtseinsromans noch inkonsequent bleibt, Raabes Traditiongebundenheit diagnostiziert.208

So bewegt sich Eduards Bewußtseinsbeschreibung nur am „Rande des inneren Monologs", jenem Protokoll einer eindringenden Erfahrung des Abgrundes des Individuums, die Bruch- und Leerstelle innerhalb der "an ihr Ende gekommene[n] epische[n] Linearität".209

$\mathrm{D} a ß$ diese Erfahrung des Abgrundes bei Eduard durch die eilige Flucht zum neuen Kontinent, der neuen Heimat, und durch die die alte Gemeinschaft der Familie fort- und zugleich ersetzende neue Möglichkeit einer Mischehe ausbalanciert wird, verdeutlicht die Bedeutung der (bürgerlichen) Familie als Produkt und gleichzeitig Stabilisator der bürgerlichen Gesellschaft. Die bürgerliche Familie ist hier die Gemeinschaft, die, angesichts der modernen Zersplitterung aller Gemeinschaftsformen in Individuen, nicht als bloße Reaktion auf diesen Verlust des Zusammenhalts ${ }^{210} \mathrm{zu}$ verstehen ist, sondem als Ausgangspunkt und Erhalt des modemen, aus einem Ganzen herausgetretenen Individuums. Stellt das Beharren der Hauptfigur Schaumann auf ihr absolutes Selbstsein den Idealfall des bürgerlichen Individuums dar, der zugunsten der reinen Idealität sogar die Familie erübrigt, sie jedoch keineswegs prinzipiell verneint, so steht Eduard für den Normalfall des spätbürgerlichen Individuums, der dem Augenblick des Erkennens seiner gefährdeten Selbstidentität mit Hilfe der traditionellen familiären Bindung und der illusionären Identifikation mit dem vermeintlichen Ideal des Jugendfreundes gerade aus dem Wege geht. Von einem unversehrten Status als Individuum bleibt dem spätbürgerlichen Individuum Eduard im G runde nicht mehr als nur ein Reflex, die Verschriftlichung, E rinnerung und Konservierung des Idealfalls Schaumann. Es ist in diesem Sinne eine gelungene 0 peration, bei der paradoxerweise die Selbsterfahrung der Entleerung bei Eduard in die alte Parole der Eigentümlichkeit des Ichs einmündet:

Da überlegte ich mir in dieser Nacht, [...]. Und so, wenn Kienbaum nicht Kienbaum, wenn Störzer nicht Störzer, wenn Stopfkuchen nicht Stopfkuchen und Tinchen nicht Tinchen gewesen wären, so wäre auch ich nicht ich gewesen [...]. (S. 197f.)

Der erzählerische Apparat, mit dessen Hilfe Eduard sich in die intakte Subjektivität Schaumanns hineinretten konnte, ist der Perspektivismus. Seine bewegliche Perspektive ist als die erzählerische Physiognomie des in eine unendliche Bewegung gesetzten modernen Subjekts begreifbar, und stellt insofern die allgemeine Entwicklungstendenz des modernen Romans dar. Es bedeutet einen Prozeß, in dem Geschichten wie Schaumanns D etektivgeschichte, die als Geschichte der Privat-Autonomie aber zugleich öffentlichen Charakters ist, zu Privatgeschichten wie Eduards intimem Tagebuch schrumpfen.

Es geht immer mehr Erzählern wie Eduard, für dessen Erzählen die „Inkompatibilität zwischen der sozialen und der egozentrischen Zielsetzung“, die "in der Figur Stopfkuchens aufgehoben und harmonisiert wird“,211 wesensbestimmend ist. Schaumanns Detektivgeschichte und Eduards Tagebuch - diese Gegenüberstellung von literarischen Formen dient m.E. als eine Art phylogenetische Veranschaulichung und zugleich eine Zuspitzung

206 Siehe J. Schramke, Zur T heorie des modernen Romans. München 1974, S. $76 f$.

$207 \mathrm{Vgl}$. ebd., S. 78.

208 Th. Buck, A m Rande des inneren M onologs - Zur E rzählk onstruk tion von Raabes „A ltershausen“, in: JbdRG 1987, S. 24-45, hier S. 43: „Raabe wollte sich nicht einlassen auf Identitätsbrüche, Entfremdungen und Rollenproblematik. Deshalb ließ er beides antagonistisch (wohlgemerkt: nicht harmonisierend!) nebeneinander stehen. Er spürte die nicht zu behebende innere Unruhe, aber er versuchte krampfhaft, sich zu halten an historisch gewachsene Traditionen tragfähiger menschlicher Beziehungen. Einer fragil gewordenen Identitätsauffassung setzte er das Vertrauen in eine unzerstörbare humane Substanz entgegen. So ersparte er sich modernes Krisenbewußtsein."

209 Ebd., S. 44.

210 Als Beispiel für solche Reaktionen sind Nationalismus und Fundamentalismus zu nennen.

211 W. Zirbs, Struk turen des E rzählens, S. 190. 
dessen, was mit dem bürgerlichen modernen Roman seit dem 18. Jahrhundert in Wirklichkeit geschehen ist. D er für den 'Schreibroman' charakteristische Perspektivismus läßt sich hier in den sozialgeschichtlichen und psychologischen Zusammenhang zurückbinden als Erzählperspektive des Weltwanderers, des "Schnellfüße[rs]" und schließlich des Kolonialherm, der Eduard doch ist. Wie er, perspektivistisch sich verwandelnd, in das Innere des Anderen, des idealisierten Freundes eindringt und sich damit am Ende über seine eigenen Unzulänglichkeiten hinüberrettet, mag für ihn eine praktikable Weise gewesen sein, auch dem Anderen in der Ferne, jenseits des Kontinents, entgegenzutreten - auch wenn der Roman sich darüber ausschweigt. Jedoch enthüllt der Roman schweigend die Spannweite des Sinnzusammenhangs des Kolonialismus ${ }^{212}$ in einer Weise, die in ihrer Radikalität für die Zeit eher unüblich ist. Der Perspektivismus als Erzählhabitus eines beweglichen, rastlosen und heimatlosen Weltwanderers hängt denn am Ende mit dem Eskapismus des ruhelosen Mörders zusammen, der sich von seinem Fernweh nur in einer immerwährenden Pendelbewegung als fleißiger Subbeamter der Reichspost umtreiben lassen muß.213

212 Eine intensive literatursoziologische Auseinandersetzung mit diesem zeitkritischen Problemkomplex des Kolonialismus wird von Philip J. Brewster (0 nk el Ketschwayo in N euteutoburg. Z eitgeschichtliche A nspielungen in Raabes Stopfk uchen, in: JbdRG 1983, S. 96f.) vorgelegt. 213 Die literarische Opposition von Schaumann und Eduard spiegelt nicht zuletzt das Rivalitätsverhältnis auf dem zeitgenössischen literarischen Markt wider, das sich zwischen der Abenteuerliteratur, besonders dem Kolonialroman, und der ,hohen' Literatur abspielt. Wenn Schaumann seine dominante Erzählerschaft immer mehr gegenüber dem zum passiven Zuhörer herabgesetzten Eduard durchsetzt, geht es nicht zuletzt auch um die plakative Werbung um ein Publikum, und zwar unter dem Motto, wer mehr aus seinem Leben zu berichten habe, der "Hinhocker" oder der "Weltwanderer" (W. Raabe, Stopfk uchen, S. 61). In einer solchen Bemerkung wie „Wenn es dich langweilt, Eduard, sag es ja! Wir beide von der Roten Schanze können jeden Augenblick mit unsern Dummheiten auf"hören und dich von deinen erzählen lassen" (S. 130) wird immer wieder der Wettbewerb auf dem Markt angedeutet, bei dem sich ein Eduard als „Weltwanderer und Abenteurer" (S. 145) gewöhnlich mehr G ehör verschafft als ein ,Hinhocker-Erzähler'. 



\section{ZWEITER TEIL: Th. Fontanes Frau Jenny Treibel oder ,Wo sich Herz zum Herzen find't' $(1892)^{1}$}

\section{Problemstellung}

Die heutige Geschichtsschreibung sieht den gesellschaftlichen Umbruch im Deutschland des 19. Jahrhunderts entweder im Zusammenhang mit Napoleon ${ }^{2}$ oder mit der gescheiterten Revolution von $1848^{3}$ oder mit der in den fünfziger und sechziger Jahren einsetzenden Industriellen Revolution ${ }^{4}$ oder mit Bismarck. ${ }^{5}$ Fontane selbst setzt das Jahr 1870 und die Gründerepoche an den Anfang einer Neugestaltung des gesellschaftlichen, politischen und kulturellen Lebens. ${ }^{6}$ Die Überbewertung der siebziger Jahre nimmt den Blickwinkel vorweg, von dem aus Fontane die deutsche G esellschaft beurteilt und darstellt, nämlich vor dem Hintergrund der Veränderungen im Bewußtsein des Bürgertums und in seiner Lebensform als Folge der sozialen und wirtschaftlichen Einflüsse der Reichsgründung und der drei Einigungskriege. Mit dieser Perspektive rückt Fontane gerade das ins Zentrum seines künstlerischen Interesses, was später Norbert Elias mit seiner soziologischen Untersuchung zum ,nationalen Habitus der D eutschen ${ }^{77}$ genauer umreißen wird. Dabei behandelt Fontane den Prozeß, anders als Elias, mit der (wohl adäquaten) Perspektive eines zeitgenössischen, d.h. von der E poche selbst betroffenen Künstlers, und zwar frei von der Belastung durch die reale geschichtliche Konsequenz des Nationalsozialismus, die bei Elias den Ausgangspunkt seiner Überlegung bildet. Was waren nun die unverkennbaren Veränderungen im bürgerlichen Leben, die mit jenem gesamtgesellschaftlichen, ja gesamtnationalen Ereignis der Einheit einhergingen und die, im Sinne von Elias, von gravierender Bedeutung für die nachfolgende G eschichte sein sollten? D eutschland wurde 1871 vereint durch drei Kriege, und zwar unter der militärischen Initiative der Adligen: Die deutsche Einheit, das Hauptprogramm des Bürgertums in seinem Machtkampf gegen die aristokratische Herrschaft, ging paradoxerweise, ja zur unverkennbaren, wenn auch unausgesprochenen Frustration des Bürgertums in einer unbürgerlichen Weise in Erfüllung. Im Machtgefälle des vereinten deutschen Staates bildete das Bürgertum eher eine zweite Klasse, die nur mitherrschen durfte. Der Sieg der deutschen Heere über Frankreich bedeutete zugleich einen Sieg des deutschen Adels über das deutsche Bürgertum. ${ }^{8}$ In seiner Reaktion auf den quasi-modernen Staat mit einer verstärkten feudalen Machtstruktur war das Bürgertum zerspalten. Die Spaltung innerhalb des Bürgertums hing ihrerseits mit der bürgertumsinternen Verschiebung der Gewichte zwischen den verschiedenen Gruppierungen des Bürgertums selbst, als Folge der fortschreitenden Industrialisierung in der zweiten Hälfte des 19. Jahrhunderts, zusammen. Prägte bis dahin das Bildungsbürgertum Bild und Selbstbild des deutschen Bürgertums, so waren es nun Unternehmer und Wirtschaftsbürger, die sowohl zahlenmäßig als auch hinsichtlich ihrer ökonomischen Macht an G ewicht innerhalb des Bürgertums zunahmen. Zum anderen ist darauf hinzuweisen, daß am Ende des 19. Jahrhunderts in bezug auf Besitz und Bildung durchaus nicht mehr von zwei komplementären Sphären gesprochen werden konnte wie noch im 18. Jahrhundert, als die Koppelung von Besitz und Bildung eine seltene Ausnahme in D eutschland war, die nur in den reichen Hansestädten wie in Hamburg vorkam. ${ }^{9}$ Die Verbindung von Besitz und Bildung wurde durch die bei einer langen Ausbildung entstehenden Kosten, die man in der Regel selbst tragen mußte, bedingt. Insofern wurde Bildung die spezifische Verwertungsform von Besitz, die wiederum ein bestimmtes ökonomisches Resultat erbrachte. Auch für die Besitzenden wurde der Erwerb von akademischer Bildung eine zentrale Bedingung für den sozialen Aufstieg oder die Behauptung einer bestimmten gesellschaftlichen Position. Mit dieser existentiellen Einheit von Bildung und Besitz scheint nunmehr zugleich die ehemals festgeschriebene Assoziation von Besitzbürgertum mit materiellen und Bildungsbürgertum mit ideellen Interessen dahinzuschwinden. Anders ausgedrückt: D ie Führungsmacht, die bisher im geistigen und kulturellen Leben dem Bildungsbürgertum zufiel, verlor an Einfluß auf das gesamte Bürgertum. ,Besitz und Bildung', die beiden Zugehörigkeitskriterien des Bürgertums seit dem ausgehenden 18. Jahrhundert, gelangten nun zu einer neuen Dimension in ihrer Konstellation zueinander. Während sich die humanistisch orientierte bildungsbürgerliche Sektion

\footnotetext{
1 D er Roman wird nach der Hanser-Ausgabe zitiert: Th. Fontane, W erke, Schriften und Briefe. Hrsg. v. W. Keitel/ H. Nürnberger. München $1962 f f$. A bt. I: Romane, E rzählungen, G edidhte (I, 1-7); A bt. II: W anderungen durch die M ark Brandenburg. (II, 1-3); A bt. III: E rinnerungen, ausgewählte Schriften und Kritik en (III, 1-5); A bt. IV : Briefe. (IV , 1-4). Die römische Ziffer bezeichnet die Abteilung, die arabische den Band. Die Zitate aus dem Roman (I, 4. Bd.) werden im Text in runden Klammern nur mit Seitenzahl angegeben.

2 Vgl. Th. Nipperdey, D eutsche G eschichte 1800 -1866. Bürgerredht und stark er Staat. I. Der große Umbruch. „Am Anfang war Napoleon“. München 1983, S. 11f.

3 Vgl. Th. Schieder, Staatensystem als V ormacht der W elt 1848 - 1918. Frankfurt/ M.; Berlin; Wien 1982, S. 12.

4 Vgl. W. Conze, V om Pöbel zum Proletariat. Sozialgeschichtliche V oraussetzungen für den Sozialismus in D eutschland, in: V iertejahresschrift für Sozial- und W irtschaftsgeschichte. 41, (1954), S. 334f.

5 Vgl. G. A. Craig, D eutsche G eschichte 1866 - 1945. V om N orddeutschen Bund bis zum E nde des D ritten Reichs. München 1980, S. 13: „Ist es ein Fehler, bei Bismarck anzufangen? [...] Die Einigung D eutschlands hätte wahrscheinlich auch stattgefunden, wenn er nie an die Spitze preußischer Politik getreten wäre, sicher aber nicht zum selben Zeitpunkt und nicht auf ganz demselben Wege."

6 Vgl. J. Ettlinger (Hrsg.), A us dem N adhlaß v. Th. Fontanes,Berlin 1908, S. $269 f$.

7 Es liegt Elias daran, „die Entwicklungen des nationalen Habitus der D eutschen herauszuarbeiten, die den Entzivilisierungsschub der Hitler-Epoche ermöglicht haben, und sie mit dem langfristigen deutschen Staatsbildungsprozeß in Zusammenhang zu bringen." (N. Elias, Studien über die D eutschen. M adhtk ämpfe und H abitusentwidk lung im 19. und 20. Jahrhundert. Hrsg. v. M. Schröter. Frankfurt/ M. 1992, S. 7.)

8 Vgl. ebd., S. 23.

9 Siehe dazu, J. Kocka, Bürgertum und Bürgerlichk eit als Problem der deutschen G eschichte vom späten 18. zum frühen 20. Jahrhundert, in: J. Kocka (Hrsg.), Bürger und Bürgerlichk eit im 19. Jahrhundert. Göttingen 1987, S. 21-63, hier S. 27.
} 
weiterhin vom Staat fernhielt und politisch abstinent blieb, griff das Bürgertum mit seiner anwachsenden wirtschaftlichen Macht, sprich das G roßbürgertum, in die Politik ein, in der es sich als Vertreter einer zweitrangigen Klasse der Herrenschicht des Adels anpaßte. So wurden beim Bildungsbürgertum die humanistischen moralischen Ideale der Frühzeit ihres sozialen Aufstiegs weiter im Begriff der ,Kultur' gepflegt. D emgegenüber wurde beim Großbürgertum auf seiner Wertskala deutlich einem Idealbild des Staates und der Nation eine Priorität eingeräumt, dies oft mit einer Haltung des Triumphes gegenüber den humanistischen und moralischen Idealen aus der Aufstiegsperiode der Mittelklassen, deren Falschheit nunmehr entlarvt schien. ${ }^{10}$ An die Stelle des vermeintlich falschen Bürgerlich-Humanistischen trat als Selbstbild für den bürgerlichen Juniorpartner des Reiches die Lebensform der politisch und militärisch erfolgreichen Herrenschicht. Die bürgerliche Oberschicht machte sich Denkformen, Verhaltensweisen und den materiellen Lebensstil des Adels zu eigen, ein Phänomen, das man als ,Feudalisierung' oder ,Aristokratisierung' des Bürgertums ${ }^{11}$ zu bezeichnen pflegt. Die ,Aristokratisierung' ist so gesehen als Effekt oder Ausdruck der angewachsenen Macht des Bürgertums einzuordnen. D er Sinn dieser Übernahme von Adelsmodellen liegt in der Instrumentalisierung von kulturellen Ressourcen, um neu verteilten Führungsfunktionen gewachsen zu sein. Dies stellt insofern einen Lernprozeß dar, der mit der paradoxen Erfahrung der Selbstverleugnung, der G ebrochenheit im Verhältnis zu sich selbst und zur eigenen Vergangenheit verbunden war. Die innere Distanzierung von früheren Idealen geht mit einem Prozeß von deren Veräußerung einher. Die bürgerliche Welt- und Lebensanschauung büßte ihren eigentlichen Entwicklungsbezug ein, wurde zum statischen Bildungsgut sterilisiert. So waren die ,Aristokratisierung' und die Konservierung der frühbürgerlichen Ideale die kulturelle Adresse des Bürgertums im deutschen Kaiserreich.

Vor diesem sozialen und kulturellen Hintergrund ist Fontanes Bürgertumsstudie anzusiedeln, die er in der Reihe seiner Zeitromane entfaltet, an deren Anfang das unausgeführte Romanprojekt A llerle G lück steht. A llerlei G lüdk soll nach einer Briefstelle ein Z eitroman über Berlin und seine G esellschaft, besonders über die Mittelklassen in der Mitte der siebziger Jahre, sein, in der Z eit also, die Fontane - wie viele andere seiner Zeitgenossen auch - als Einschnitt in die umfassende neue Epoche des Bürgertums vorkam. Der Rückgang der bildungsbürgerlichen kulturellen Integrationskraft ist der geschichtliche Hintergrund dessen, was sich hier als Pluralität der bürgerlichen G esellschaft am Ende der G ründerzeit in der intendierten Vielzahl der Lebenskreise, ihrer Konflikte und ihrer menschlichen Schicksale kundtat. ${ }^{12} \mathrm{~F}$ rau Jenny Treibel sollte, so die Einschätzung der Forschung über die Bedeutung dieses Spätwerkes innerhalb der künstlerischen Entwicklung Fontanes, diesen Ansatz des Z eitromans rund fünfzehn Jahre später verwirklichen, allerdings im kleineren Maßstab. ${ }^{13}$ In F rau Jenny T reibel wird die oben erwähnte qualitative und quantitative Verschiebung innerhalb des Bürgertums als soziale und kulturelle Wirklichkeit geradewegs in die Mitte der Romanhandlung gerückt. So nimmt der Gegensatz von Besitz und Bildung vordergründig die zentrale Perspektive ein. ${ }^{14}$ D ie weitgehende Übereinstimmung innerhalb der Forschung hinsichtlich des gesellschaftskritischen Aussagegehalts des Romans bleibt auf eine briefliche Äußerung des Autors festgelegt. Frau Jenny Treibel soll Fontane zufolge geschrieben worden sein, um „das Hohle, Phrasenhafte, Lügnerische, Hochmütige, Hartherzige des Bourgeoisstandpunkts zu zeigen, der von Schiller spricht und Gerson meint". ${ }^{15}$ Gerade der die Figur Jenny konstituierende Widerspruch, ja deren Antithese ist gemeint, wenn Fontane den Roman ursprünglich „Frau Commerzien-räthin oder Wo sich Herz zum Herzen find't" betiteln wollte. ${ }^{16}$ Jedoch besteht die Antithese nicht allein in dem Gegensatz von Ideologie und Realität bei der von Jenny vertretenen Sozialklasse der Bourgeoisie. Die psychographische Gestaltung des bourgeoisen Bürgers, und zwar im Bereich seiner, um mit Hobsbawm zu sprechen, ,Quintessenz', 17 der Familie, macht erst Fontanes Kritik an dieser Klasse aus. Mit dem Aufstieg des Bürgertums entstanden und von seinem Selbstbewußtsein geprägt, ist die bürgerliche Familie „die rätselhafteste Institution der E poche". ${ }^{18}$ So sucht Fontane in Frau Jenny Treibel das Rätsel der bürgerlichen Psyche selbst in den familialen Beziehungsgebilden der Familie zu lösen. Dies betrifft das Rätsel der Psyche sowohl im Sinne des gegebenen, aber verborgenen Zusammenhanges des Inneren mit der Außenwelt als auch im Sinne der ihr unbekannten, erst zu entwerfenden Subjektivitätsform. So öffnet sich, gegenüber der zeit- und schichttypischen Bedeutung des Familienlebens bei den Treibels, im Familienleben bei den Schmidts eine Perspektive, die in die Zukunft weist, in der das Rollenspielen als Gestaltungsprinzip der Psyche aufgehoben wird. Die ,psychographische Kritik' Fontanes wird damit zur Kritik an dem Ursprung der Psychographie, nämlich der bürgerlichen Familie.

10 Vgl. N. Elias, Studien über die D eutschen, S. 173.

11 Vgl. L. Beutin, D as Bürgertum als G esellschaftsstand im 19. Jahrhundert (1953), in: ders., G esammelte Schriften zur W irtschafts- und Sozialgeschichte. hg. v. H. Kellenbenz, Köln 1963, S. 284-319, hier: S. 313; H.-U. Wehler, D as D eutsche Kaiserreich 1871-1918. Göttingen 1973, S. 54.

12 Vgl. J. Worthmann, D ie ,besprochene' Z eit - Th. Fontanes "Jenny Treibe“", in: J. Worthmann, Probleme des Zeitromans. Heidelberg 1974, S. 144-158, hier S. 146.

13 Vgl. H.-F. Rosenfeld, Z ur E ntstehung F ontanescher Romane. Groningen; Den Haag 1926, S. 36; J. Wortmann, D ie ,besprochene' Z eit, S. 145.

14 Vgl. W. Müller-Seidel, Besitz und Bildung. 1. Frau Jenny Treibel, in: ders., Theodor Fontane. Soziale Romankunst in D eutschland. Stuttgart 1975, S. 300-

319; D. Kafitz, D ie Kritik am Bildungsbürgertum in Fontanes Roman ,Frau Jenny Treibel', in: ZfdP Jg. 92 (1973), Sonderheft Theodor Fontane, S. 74-101; H.H. Reuter, Fontane 2. Bde. München 1968. Bd. 2, S. 690 - 695.

15 Fontane an seinen Sohn Theo, 9. 5. 1888, in: ders., W erke, Schritten und Briefe. Hrsg. v. W. Keitel/ H. Nürnberger. A bt. IV : Briefe. 3. Bd. 1879-1889 (1980), S. 601.

16 Ebd., S. 601.

17 D arauf komme ich später nochmals zurück.

18 E. J. Hobsbawm, D ie Blütez eit des Kapitals. E ine Kulturgeschichte der Jahre 1848-1875, München 1977, S. 293. 


\section{A. Modalität der Familie}

\section{Eine Parvenü-Physiognomie}

Das für das Großbürgertum der Zeit Charakteristische drückt sich bei den Treibels als aristokratische Salonkultur mit eingebauter Intimität aus. ${ }^{19} \mathrm{D}$ ie Anstrengung, die alten Ideale und Werte des Bürgerlichen mit dem neu erworbenen, jedoch noch lange nicht stabilen Selbstbewußtsein zu verbinden, ist eine der ganzen Familie gemeinsame psychische Disposition, die von der jeweils betroffenen Figur unterschiedlich gelebt und gestaltet wird. Auf der Seite Jennys, der kleinbürgerlichen Aufsteigerin, geraten der Anspruch auf Repräsentativität und Macht und der Anspruch auf kleinfamiliale Intimität in besonders krassen Gegensatz.

\section{Intimität der bürgerlichen Familie}

D ie Antithese von Kapital und Gefühl, wie sie von Jenny verkörpert wird, bedient sich der Grundlagen der bürgerlichen Familie, d.h. der ihr eigenen psychischen und ökonomischen Funktionen und der damit verbundenen Geschlechterrollen. Von den Familienformen der vorbürgerlichen Z eit unterscheidet sich der neue Typ der bürgerlichen Familie durch deren Charakterisierung als Privatsphäre, deren Entstehung mit einer Trennung von Arbeits- und Wohnstätte im Zuge der Industrialisierung einherging. Die Ausgestaltung der Privatsphäre und die durch eine relative materielle Sicherheit ermöglichte Konzentration auf Gefühl und Empfindung in ihr prägen die G eschichte der bürgerlichen Familie und ihres Selbstbildes. Der kleinfamiliäre intime Binnenraum ist „der Ort einer psychologischen Emanzipation, die der politisch-ökonomischen entspricht." ${ }^{20}$ D er Inhalt der psychologischen Emanzipation, der absoluten Befreiung „eines nach eigenen Gesetzen sich vollziehenden Inneren vom äußeren Zweck jeder Art“ artikuliert sich in der Idee der bürgerlichen Familie, einer Idee von „Freiwilligkeit", „Liebesgemeinschaft" und „Bildung" 21 der Persönlichkeit. So definiert sich die bürgerliche Familie über die auf das 18. Jahrhundert zurückgehende G efühlskultur.

Z war versteht sich die bürgerliche Familie ihrer Idee nach und mit ihrer relativen materiellen Sicherheit als unabhängig von äußeren Z wängen, jedoch spielt sie in Wirklichkeit „ihre genau umschriebene Rolle im Verwertungsprozeß des Kapitals“. Es ist die „Aufgabe jener schwierigen Vermittlung, die beim Schein der Freiheit die strenge Einhaltung der gesellschaftlich notwendigen Forderungen dennoch herstellt", ${ }^{22}$ die der bürgerlichen Familie als Institution der bürgerlichen Gesellschaft von Anfang an gestellt wurde.

Die Ausführung dieser Vermittlungsrolle, die der Ehefrau als Hauptträgerin der bürgerlichen Familie zufiel, wird bei Jenny mit äußerster Unvermitteltheit praktiziert; Jenny gibt vor und glaubt auch selbst, an zeitlosen Idealen orientiert zu sein, kann aber jederzeit „plötzlich aus dem sentimental Schwärmerischen in den Ton ausgesprochenster Wirklichkeit"(S. 411) verfallen. Dieser krasse Gegensatz zwischen vermeintlichem ,Ideal' und der Praxis der bourgeoisen Gesinnung enthüllt sich im Lauf der Handlung als ein Vorgang, dessen Ausgang von der ironischen Perspektive Schmidts vorausgesagt wird.

Auf der Ebene der Erzählersprache findet man den gleichen zweideutigen ironischen Ton, mit dem die Beschreibung der Treibelschen Villa allegorisch zu werden scheint: Als Statussymbol des ,G ründer-Parvenüs' spiegelt die Villa nun das Z errbild der Ideen und Leitbilder wider, die sich die bürgerliche Familie von sich selbst machte. Die „modische Villa mit kleinem Vorder- und parkartigem Hintergarten“ liegt „auf einem großen G rundstück, das, in der bedeutenden Tiefe, von der Köpnikker Straße bis an die Spree reichte." (S. 306, 307) Der Bau ist „ein Hochparterrebau mit aufgesetztem ersten Stock, welcher letztere jedoch, um seiner niedrigen Fenster willen, eher den Eindruck eines Mezzanin als einer Beletage machte." (S. 307). D er erste Stock wirkt also nicht wie ein richtiges O bergeschoß, sondern eher wie ein niedriges Z wischen- oder Halbgeschoß. Man sieht, daß hier in gewissem Sinne mit der Vorstellungsordnung operiert wird, die dem Klassenbewußtsein des aufgestiegenen Bürgertums naheliegt. Sie ist für die mentale Beschaffenheit von Jenny und ihr Umfeld symptomatisch: groß, tief und hoch - aber: aufgesetzt. Das Aufgesetzte erreicht nicht die Höhe, die man sich wünschte, sondern es bleibt halbhoch. Mit all diesem wird „sowohl der größere gesellschaftliche Anspruch der Bewohner als auch der gequälte Versuch, weiter auf der sozialen Stufenleiter emporzuklimmen" ${ }^{23}$ angedeutet. Die frühbürgerliche Maxime: ,Mehr sein als scheinen!' verkehrt sich hier in ihr G egenteil. ${ }^{24}$ Als Allegorie zum Innenleben der Gartenbesitzerin findet man in ihrem $\mathrm{G}$ arten den Springbrunnen und den Kakadu „mit dem bekannten Auge voll Tiefsinn“ (S. 314). Als moderne bzw. exotische Requisiten verweisen beide auf die bürgerliche Tugend des Strebens nach Höherem und auf die Gefühlstiefe, die in den gewandelten ökonomischen und geisti-

19 Vgl. G. N. Izenberg, D ie ,A ristok ratisierung' der bürgerlichen Kultur im 19. Jahrhundert, in: P. U. Hohendahl / P.M. Lützeler (Hrsg.), L egitimationsk risen des deutschen A dels 1200-1900, Stuttgart 1979, S. 233-244.

20 J. Habermas, Struk turwandel, S. 110.

21 Ebd., S. 111.

22 Ebd., S. 111.

23 G. Wedereit, L eitmotivische W iederholung. Beobachtungen zu Technik und E thos in Fontanes ,Frau Jenny Treibel', in: Acta Germanica 7 (1972), S. 117-125, hier S. 119.

24 Vgl. H. Rosenbaum, Formen der Familie. U ntersuchungen zum Z usammenhang von Familienverhältnissen, Sozialstruk tur und sozialem W andel in der deutschen G esellschaft des 19. Jahrhunderts. Frankfurt/ M. 1990, S. 311. 
gen Verhältnissen des Bürgertums eine Pervertierung erfährt. Jenny selbst, ihr Sprachgebaren, ist als „Allegorie des Individuums" 25 zu deuten, bei der es um das Phänomen geht, daß die Idee des individuellen Sprechens, des sich sprachlich manifestierenden Individuellen, ausgehöhlt und gebrochen wird. Besonders wird dies an der Stelle deutlich, wo Jenny ihre Sentimentalität mit dem Wort ,unentwegt' in einer modischen Weise ,auf Ewigkeit' beschwört; „Mit uns, lieber Professor, bleibt es beim alten, unentwegt" (S. 305). Schmidt erkennt in Jennys modischem Sprachstil noch einmal die totale Vereinnahmung durch den Sozialcharakter der Bourgeoise:

U nentweegt [...] H errliches M odewort, und nun auch schon bis in die Villa Treibel gedrungen... E igentlich ist meine F reundin Jenny noch geradeso wie vor vierzig Jahren, wo sie die kastanienbraunen Locken schüttelte. D as Sentimentale liebte sie schon damals, aber doch immer unter Bevorzugung von Courmachen und Schlagsahne [...] Nun ist das Püppchen eine Kommerzienrätin und kann sich alles gönnen, auch das Ideale, und sogar ,unentwegt'. E in M usterstüdk von einer Bourgeoise. (S. 305; Hervorhebung von J.-H. B.)

Im Salon bei den Treibels hört man bei jedem Diner ein Lied, von der Gastgeberin Jenny selbst vorgetragen, und zwar Jennys Lieblingslied, mit dem vormals ihr jugendlicher Verehrer Schmidt sie angedichtet und das er ihr gewidmet hat.

Glück, von deinen tausend Losen

Eines nur erwähl ich mir,

Was soll Gold? Ich liebe Rosen

Und der Blumen schlichte Zier.

Und ich höre Waldesrauschen,

Und ich seh' ein flatternd Band -

Aug' in Auge Blicke tauschen,

Und ein Kuß auf deine Hand.

Geben nehmen, nehmen geben,

Und dein Haar umspielt der Wind,

Ach, nur das, nur das ist Leben,

Wo sich H erz zum Herzen find't. (S. 338)

Es ist ein Liebesbekenntnis, eine Liebeswerbung und zugleich eine potentielle Heiratswerbung, der aber die Umworbene ihrerseits nicht nachgekommen war. Jenny bewunderte das Poetische der Heiratswerbung, heiratete aber in eine prosaische Bourgeoisie-Familie ein. Ihren trotzdem weiter bestehenden unbedingten Anspruch auf das Poetische, das Ideale und Höhere tut Jenny seitdem mit dem Vortrag des Liedes zur Klavierbegleitung ununterbrochen kund.

So handelt es sich bei Jennys Lied um eine willkürliche Vereinnahmung des Textes. Sie löste von Anfang an das Gedicht vom konkreten zwischenmenschlichen Entstehungskontext, nämlich Schmidts G efühl, ab. Letzterer erinnert sich:

[...] als ich eines Tages mein berühmtes Gedicht gedichtet hatte [...] das Unglücksding, das sie seitdem immer singt und vielleicht auch heute wieder gesungen hat, da warf sie sich mir an die Brust und sagte: ,Wilibald, einziger, das kommt von G ott.' Ich sagte halb verlegen etwas von meinem $G$ efühl und meiner Liebe, sie blieb aber dabei, es sei von G ott [...].(S. 369)

Jennys sentimentalisierender Vereinnahmung des Gedichtes steht Schmidts Abwertung desselben gegenüber. Schmidt bezeichnet Jennys „Herzenslied" nun als „poetische Jugendsünde“ (S. 369). „Wo sich Herz zum Herzen find't", so der Schluß des Liedes, wird von ihm als „himmlische Trivialität" (S. 369) empfunden und beschämt ihn. Ihm mag zugestimmt werden: Die Eingangsstrophe steht im Zeichen einer Liebes- und Lebenssentscheidung - von dem lyrischen Ich wird nicht das „Gold“, sondern werden die „Rosen“ und „der Blumen schlichte Zier" erwählt -, die sprachlich etwas blaß, formelhaft und übersteigert ausfällt. ${ }^{26}$

Wirklich problematisch wird aber das G edicht, wenn es am Ende des Romans, im allerletzten Handlungsabschnitt, auf einmal als „echte Lyrik“ aufgewertet wird, und zwar von dem Schmäher selbst: Denn als Jennys Lied von ihrem SängerFreund vorgetragen worden ist, „weint" Schmidt „vor sich hin“ (S. 477) und sagt:

Treibel, unsere Jenny hat doch recht. Es ist was damit, es ist was drin; ich weiß nicht genau was, aber das ist es eben - es ist ein wirkliches Lied. Alle echte Lyrik hat was G eheimnisvolles. Ich hätte doch am Ende dabei bleiben sollen...(S. 477)

Mit diesem überraschenden Bekenntnis zur geheimnisvollen, poetischen Wirkung des G edichtes stellt sich Schmidt in ein ambivalentes Verhältnis zu dem Lied, was von jeher ein Interpretationsproblem für die Forschung dargestellt hat.

Die Erklärungsversuche für diesen Widerspruch divergieren stark. Bei den älteren Forschungsansätzen führte die D iskussion oft zu Fontanes eigenem Verhältnis zur Sentimentalität, zur mangelnden oder verborgenen, deswegen interpretationsbedürftigen künstlerischen Stringenz des Autors in der Behandlung des Gefühls.27 Dabei schwang unausweichlich

25 A. Poltermann, „F rau Jenny Treibel“ oder D ie Profanierung der hohen Poesie, in: Text + Kritik Sonderband Th. Fontane. Hrsg. v. H. L. Arnold, München 1989, S. 131-147, hier S. 139.

26 Vgl. N. Mecklenburg, E insidhten und Blindheiten, in: Text + Kritik Sonderband Th. Fontane. Hrsg.v. H. L. Arnold, München 1989, S. 148-162, hier S. 150. $27 \mathrm{Zu}$ dem ersten, soziopolitisch und ideologisch orientierten Erklärungsansatz, der in dem zweideutigen Schluß das persönliche künstlerische Versagen des Autors sieht, gehören: G. Lukács, D er alte F ontane, in: D ie G rablegung des alten D eutschland. E ssays zur deutschen L iteratur des 19. Jahrhunderts. Ausgewählte Schriften I. Reinbek bei Hamburg 1967; D. Kafitz, D ie Kritik am Bildungsbürgertum; H.-H. Reuter, Fontane. Zur anderen Erklärungsvariante, die 
die normative, nicht reflektierte Unterscheidung von sogenannter echter Poesie und Kitsch als Argumentation mit. ${ }^{28}$ Hier ist darauf zu verweisen, daß Kitsch, der D efinition nach, in keinem totalen Gegensatz zu der ihm als Vorbild dienenden hohen Poesie steht.29

Neuere Interpretationsansätze fassen deswegen die Neuentdeckung des Gedichtes durch Schmidt nicht als Um- bzw. Aufwertung der künstlerischen Qualität desselben auf. Anstatt die Frage zur Entweder-O der-Situation von Poesie und Kitsch zu führen, stellt man jetzt die Frage nach ihrem Funktionswert in den Mittelpunkt.30

Ich versuche im folgenden, zunächst den Funktionswert des Liedes bei Jenny im spezifischen Kontext der bürgerlichen Ehebeziehung zu bestimmen, um dann zu seinen weiteren Funktionszuschreibungen überzugehen. Das Gedicht ist sowohl trivial - von dem satirischen Kontext und den unbestreitbar trivialen Elementen besonders in der ersten Strophe her - als auch klassisch zu verstehen. Inhaltlich sieht es so aus, daß das Lied, wie Mecklenburg zu Recht bemerkt hat, zwischen der G egenwart erfüllter Augenblicke und dem Wunschbild einer arkadischen Liebesharmonie jenseits der Wirklichkeit schwebt. ${ }^{31}$ Dieses an sich zwischen G egenwart und Zukunft ausgewogene, die zwei Zeitebenen überbrückende Gedicht wird von Jenny voller Tränen in den Augen, nämlich im Sinne einer per definitionem unerfüllbaren, wirklichkeitsentfernten und vergangenen Liebesharmonie gesungen. Jenny liest das an sich noch zu Entscheidende als etwas bereits Entschiedenes zuungunsten des „Herzen'. Sie schließt halbbewußt jegliche Verwirklichungschance des ,höchsten Liebesglücks' aus, um ihm umso intensiver nachtrauern zu können. D as drückt sie aus in ihrem: „das kommt von Gott.“

D as Gedicht selbst schlägt noch eine Brücke zwischen dem romantischen und dem sittlichen Liebeskonzept, die als G rundspannung die bürgerlichen Ehe- und Liebesaufassung orientieren. D as Konzept der von der Aufklärung beeinflußten vernünftigen ehelichen Liebe verbindet das wirtschaftliche Kalkül, das für die bürgerliche Ehe wie bei jeder Eheschließung eine notwendige Rolle spielt, mit der Liebe. Das ist die bürgerlich vernünftige Liebe, die auf dem Erkennen der Tugend des geliebten Menschen, der geistigen $\mathrm{Gemeinschaft,} \mathrm{dem} \mathrm{Interesse} \mathrm{füreinander} \mathrm{und} \mathrm{dem} \mathrm{Austausch} \mathrm{gemachter} \mathrm{Erfahrungen} \mathrm{be-}$ steht. Die vernünftige Liebe kontrastiert mit jener romantischen, wirtschaftlich nicht kalkulierten Liebe, bei der Liebende „über die Augen oder die Haare des geliebten Menschen ins Schwärmen [geraten].. 32 In Jennys Lied wird in G estalt der Augen und der Haare diese romantische Liebe präsent, die aber keineswegs in Widerspruch zu dem bürgerlichen Eheideal der vernünftigen sittlichen Liebe zu geraten braucht. Die verhalten romantische bzw. romantisierte erotische Annäherung geht so am Ende des G edichtes ungestört in die sittliche Forderung „Wo sich Herz zum Herzen find't“, diese „abgegriffene, an die Heiratsmoral von Schillers ,Glocke' bewußt angelehnte Formel“33 über. Das G edicht scheint eine stille Versöhnung der zwei Liebeskonzepte darzustellen. Diese im Lied erstrebte zerbrechliche Einheit wird aber verneint, überhört, wenn Jenny diese zwei Arten der Liebe, wie ihr melancholisch-nachtrauernder G esang nahelegt, als unvereinbar interpretiert. Am Ende ergibt sich so eine Spaltung in die romantische, vergeistigte und echte Liebe und die reale, unechte Ehe-Liebe. Dementsprechend ist Jennys selbstbestimmte Rolle die der unverstandenen ,geistigen' Frau, deren ideale Träume in der Ehe mit dem prosaischen Kommerzienrat leider nicht in Erfüllung gehen können; „es fehlt", meint sie, „jene hohe Freude der Unterordnung, die doch unser schönstes Glück ausmacht und so recht gleichbedeutend ist mit echter Liebe" (S. 410).

Mit dieser "Sublimierung der Liebe zu einem überaus hohen Anspruch an sich selbst“34 instrumentalisiert Jenny die von ihr gewollt unverwirklichte Jugendliebe, um die anstrengende Praxis der geschlechtsspezifischen Rolle der Frau als Hort des G efühls, der Sentimentalität, zu beherrschen.

Um den Sublimierungszwang und die gewollt restlose Unterwerfung Jennys unter diesen Zwang weiß der Jugendfreund Schmidt: In dem Moment, als Jenny in ihrem prosaischen Gegenwartsleben als Frau Kommerzienrätin um die poetische Vergangenheit von ,Rosen' und ,der Blumen schlichte Zier' trauert, greift er zu dem erprobten „Rettungsmittel“ und spricht mit „verschleierter" (S. 410) Stimme, um seine Anteilnahme zu bekunden, von den Kindern. Er weiß wohl: Das Weibliche im bürgerlichen Sinne ist etwas, dem die G egenwart, die Wirklichkeit abhanden gekommen ist. D as Idealbild des Weiblichen wird dementsprechend schon von Schiller, dem Dichter der bürgerlichen Weiblichkeit, „, an die Ränder, an die fernen Horizonte der Geschichte verlegt: Ursprungsmythos und Vollendungsutopie“ sind "vergoldete Vergangenheit und weitentrückte Zukunft", aus denen „das Weibliche seine Größe und seinen Zauber schöpfen" ${ }^{35}$ soll.

Nach einer Landpartie kehrt Jenny nach Hause zurück. Während ihr Mann zur Parteiversammlung gefahren ist, um draußen in der Politik zu handeln, schließt sie sich in ihrem eigenen Zimmer, dem O rt der kultivierten Vereinsamung, der In-

mehr auf die Sinngeschlossenheit eines Kunstwerkes hinausläuft, gehören: C. Wandrey, Theodor Fontane, München 1919; H. Reinhardt, D ie W ahrheit des Sentimentalen. Bemerk ungen zu zwei Romanschlüssen bei Theodor Fontane, in: W irk endes W ort 29 (1979), H. 5, S. 318-326; H. Aust, A nstößige V ersöhnung? Zum Be griff der V ersöhnung in F ontanes „F rau Jenny T reibel“, in: ZfdP 92 (1973), Sonderheft, S. 101-126.

$28 \mathrm{Vgl}$. besonders die divergierenden Interpretationen des Romanschlusses bei H. Aust und H. Reinhardt in ihren jeweils oben genannten Aufsätzen.

29 Vgl. G. Ueding, Rhetorik des Kitsches, in: J. Schulte-Sasse, L iterarischer Kitsch. Tex te zu seiner Theorie, G eschichte und E inzelinterpretation. Tübingen 1979, S. 65-88.

30 D azu gehören die bereits von mir zitierten Interpretationen von N. Mecklenburg und A. Poltermann.

31 Vgl. N. Mecklenburg, E insichten, S. 151.

32 Vgl. M. Gaus, D as Idealbild der Familie in den moralischen W ochenschritten und seine A uswirk ungen auf die deutsche L iteratur des 18. Jahrhunderts. Rostock 1936, S. 32, Angabe nach: H. Rosenbaum, Formen der Familie, S. 264.

33 N. Mecklenburg, E insichten, S. 151.

34 R. Sieder, Sozialgeschichte, S. 143.

35 S. Bovenschen, D ie imaginierte W eiblichk eit. E x emplarische U ntersuchungen zu kulturgeschichtlichen und literarischen Präsentationsformen des W eiblichen. Frankfurt ${ }^{2}$ 1980, S. 242. (Zitiert nach H. Blinn, D ie D isk ussion um den Status der F rau vom 18. Jahrhundert bis zur G egenwart, in: H. Blinn (Hrsg.), E manzipation und L iteratur. Frankfurt 1984, S. 11-108, hier S. 38.) 
nerlichkeit, ein. Als unverstandene ,geistige' Frau weiß sie die Einsamkeit und seelische Isolation im eigenen Lebenskreis zu schätzen: Sie „war froh, ein paar Stunden allein sein zu können." (S. 429). In dem Moment scheint ihr die außerfamiliäre sentimentale Beziehung zu Schmidt umso wertvoller. Sie gibt ihr das fehlende G efühl des gegenseitigen Verstehens. Ein Gefühl, das von ihr, weil es mit Schmidt zu tun hat, wiederum mit dem Höheren schlechthin gleichgesetzt wird. So heißt es in der Form der erlebten Rede, in der sich nicht der Standpunkt des auktorialen Erzählers, sondern Jennys Standpunkt ausspricht: „D ie G ewißheit, sich verstanden zu sehen, - es war doch eigentlich das Höhere“ (S. 429).

In dem darauf folgenden inneren Monolog entpuppt sich aber Jennys D rang zum Höheren als ungesättigter Wille zum sozialen Aufstieg und dessen Übertragung auf Kunst und Wissenschaft:

Kommerzienrätin und immer wieder Kommerzienrätin. Es geht nun schon in das zehnte Jahr, und er rückt nicht höher hinauf, trotz aller Anstregungen. Und wenn es so bleibt, und es wird so bleiben, so weiß ich wirklich nicht, ob nicht das andere, das auf Kunst und Wissenschaft deutet, doch einen feineren Klang hat. Ja, den hat es...(S. 429)

Frustration, Langeweile, Lebensmüdigkeit und Wirklichkeitsflucht treten sukzessive auf, lose assoziativ verknüpft.

[...] mitunter flieht mich der Schlaf, der des Lebens Bestes ist, weil er uns das Leben vergessen läßt...Und auch die Kinder wären anders [...] Mit $\mathrm{O}$ tto ist nicht viel, und mit Leopold ist gar nichts. (S. 429f)

E twas Bemerkenswertes geschieht im nächsten Augenblick. Durch das Fenster öffnet sich vor den Augen Jennys langsam die Außenwelt:"Jenny, während sie sich in süße Selbsttäuschungen wie diese versenkte, trat ans Fenster und sah abwechselnd auf den Vorgarten und die Straße." (S. 430). Mit dem Fenster erschließt sich auch die Tiefendimension von Jennys Bewußtsein. D as Bild der Außenwelt wird für die G edankenwelt der Betrachtenden zu einem symbolischen und kontrastiven Hintergrund. Jenny erblickt so die Außenwelt wie ein Bild ${ }^{36}$ oder wie eine Szenerie, die sich ihr bühnenähnlich auftut, wie jemandem, der vor einer G uckkastenbühne sitzt: „D rüben, im Hause gegenüber, hoch oben in der offenen Mansarde, stand, wie ein Schattenriß in hellem Licht, eine Plätterin, die mit sicherer Hand über das Plättbrett hinfuhr - " (S. 430). Es ist dies die soziale Umwelt, deren unmittelbare räumliche Nähe sonst von Jenny in ihrem hohen Statusbewußtsein als unangenehm empfunden wird. ${ }^{37}$ Jetzt empfindet sie jene Welt anders. Das Fenster wirkt wie ein Bilderrahmen, und dementsprechend verliert die Aussicht, die soziale Wirklichkeit der Plätterin, wie ein eingerahmtes Bild an Realitätsgehalt. So ins Genrebild gebannt, wird der Anblick dieser Welt ihr angenehm. Es handelt sich um die ihrer Aktualität, ja ihrer Bedrohung für die bürgerliche häusliche Ordnung entkleidete, proletarische Arbeitswelt. Somit wäre die Passage „als kritische Replik auf solche G enrebilder" $38 \mathrm{zu}$ verstehen. In dieser ästhetischen D istanz gibt sich Jenny ungestört einer ästhetischen Identifizierung mit der Arbeiterin hin. So rückt die ganze Szene beinah in die Nähe zu einem symbolistischen Bühnenbild.

Dieser Identifizierung liegt eine Art Angstlust auf das Unbekannte, sogar das Verdrängte, zugrunde. Diese Angstlust beschwört das Verdrängte bisweilen in Form von Neid herauf. Neid auf das, wirkliche Leben', das in der gefürchteten und gemiedenen Härte jener Welt vielleicht verborgen sein möchte. In ihrer Angstlust glaubt Jenny die Plätterin in ihrem ,Glück' gut zu verstehen, so daß „es [...] ihr [war], als höre sie das Mädchen singen.“ (S. 430) So wird die befleckende Unterwelt gefiltert und kann nun, nach ihrer ästhetischen Verarbeitung, mit der Innerlichkeit des bürgerlichen Familienlebens in Berührung gebracht werden. Die prosaische Wirklichkeit der nächtlichen Arbeit wird durch den zusätzlich imaginierten Gesang im Idyll aufgelöst. 39

Jennys selbsttäuschende Identifizierung mit der Plätterin bildet ein Pendant zu ihrer Genugtuung über die Freundschaft mit Schmidt. Wie sie bei Schmidt an die „G ewißheit, sich verstanden zu sehen“, glaubt, glaubt sie wiederum, auch die Plätterin gut zu verstehen. Denn „ [d]ie G ewißheit, sich verstanden zu sehen“ und sich andere verstehen zu sehen, „es war doch eigentlich das Höhere" (S. 429) - so die Struktur ihrer „Verstehensseligkeit“. ${ }^{0}$

Daß Jennys ,Verstehensseligkeit' eine fensterrahmensichere Distanz zur Außenwelt voraussetzt, wird im nächsten Moment unmißverständlich deutlich. Jenny, deren „Auge [...] von dem anmutigen Bilde nicht lassen [mochte]“, wird durch einen Zwischenfall in ihren „sentimentalen Anwandlungen“ (S. 430) erschüttert. Ihr Sohn Leopold kündigt nämlich sein Vorhaben an, Corinna, mit der er sich eben verlobt hat, zu heiraten. Erschrocken angesichts dieses drohenden Verlustes des Familienvermögens an die arme Tochter eines Professors fährt die Kommerzienrätin, die sich gerade noch verstehensselig in eine anmutige Arbeiterin hineinversetzt hat, zurück. Es wirkt geradezu symbolisch in bezug auf die bisher beleuchtete Spannung zwischen dem Raum diesseits und dem jenseits des Fensters, wenn der Erzähler kommentiert: „[U]nd ein Glück war es, daß das Fenster, an dem sie stand, ihr eine Lehne gab." (S. 431)

36 Zum Fenstermotiv bei Fontane vgl. R. Brinkmann, D er angehaltene M oment. Requisiten - G enre - Tableau bei Fontane, in: Dvjs 53. 1979, S. 429-462, hier: 439f; W. Jung, Bildergespräche. Z ur F unktion von Kunst und Kultur in Theodor F ontanes „L'A dultera“. Stuttgart 1991, S. 122-127.

$37 \mathrm{Da}$ die Villa keinen Nebeneingang für die Bediensteten hat, „marschiert“ während der Vorbereitungszeit für ein Diner, zum Verdruß der Gastgeberin, „jeder Küchenjunge durch den Vorgarten, gerade auf unser Haus zu, wie wenn er miteingeladen wäre." (Frau Jenny Treibel, S. 307). Zu dem Aspekt der Abschottung der bürgerlichen Familie von der sozialen Außenwelt sowohl in ihrem Leitbild als auch in der historischen Entwicklung siehe H. Rosenbaum, Formen der Familie, S. 262, S. 274f., S. 301f.

38 A. Poltermann, „F rau Jenny T reibel“, Anmerkung 42.

39 Vgl. C. Kahrmann, Idyll im Roman: Theodor Fontane. München 1973, S. 36.

40 A. Poltermann, „F rau Jenny T reibel“, S. 147. 
Bei der Gestaltung der Figur von Jenny Treibels Ehemann schwankt der Erzähler eigentümlicherweise zwischen Sympathie und Antipathie bzw. Ironie. Daraus folgt, daß der Widerspruch zwischen Bourgeois und Privatmann in Treibel je nach Forschungsinteresse unterschiedlich betont werden kann. Die Grunddissonanz seines Wesens besteht für manche Interpreten in einer sympathisch berührenden Unvoreingenommenheit und einem fast widerwärtigen Opportunismus, der stärker ist als jener positive Zug und diesen zu einem bloßen Schein herabdrückt. ${ }^{41}$ Für andere Interpreten illustriert die unverkennbare Liebenswürdigkeit Treibels eher die charakteristische Bemühung Fontanes, seine Kunst darauf zu richten, das Reflexionsniveau seiner Figuren über das Plakativ-Reduzierende eines eindeutig falschen Bewußtseins oder eines sonst mangelhaften Selbstverständnisses zu erheben. ${ }^{42}$

Die vielbeschworene Dissonanz zwischen dem D asein als Bourgeois und dem Dasein als Privatmensch, wie sie von Treibel verkörpert wird, ist nur eine scheinbare D iskrepanz. So gilt es, auf das Ineinandergreifen der beiden Existenzformen als einem kunstvollen G estaltungsprinzip Fontanes einzugehen, anstatt von der Unvermitteltheit bzw. Unvermittelbarkeit zwischen sozialem Dasein und Privatheit zu reden. Wie Eric Hobsbawms Beschreibung des Wesens und der Bedeutung der Familie des Bürgers in der Blütezeit des Kapitals in der zweiten Hälfte des 19. Jahrhunderts nahelegt, ${ }^{43}$ ist der Zusammenhang zwischen den Existenzformen von Bourgeois und Privatmensch an sich komplexerer Natur. So hängt auch Treibels Selbstdarstellung, die er als Privatmann zu geben hat, mit seiner sozialen Existenz als Bourgeois tiefer zusammen, als es den Anschein haben mag, und läßt sich nicht nur als einen auf seine Individualität zurückzuführenden Widerspruch deuten. Die Einsicht, daß dem Begriff Bourgeois neben der schmähenden Konnotation eine positive, auf den Fortschritt verweisende Bedeutung zukommt, teilte Fontane mit seinen Zeitgenossen. Für viele verkörperte der Unternehmer in dieser Zeit den ,bürgerlichen' fortschrittlichen $\mathrm{G}$ eist am reinsten, der in Risikobereitschaft, Konkurrenz, Unternehmungsgeist, Erfolgsstreben und Leistungsbewußtsein bestand. ${ }^{44}$ Diese positive Funktion der Bourgeoisie und deren Anerkennung als solche ist der eigentliche Grund für die teilweise sympathische Erscheinung Treibels. In diesem Sinne ist ohne Schwierigkeit nachvollziehbar, daß die Frau, Jenny Teibel, der der Glanz der Produktivität, die akzeptable Existenzlegitimation der Bourgeoisie in der fortschreitenden Geschichte aus geschlechtsspezifischen G ründen versagt bleibt, als Vertreterin für das geächtete ,Bourgeoisentum' auftritt. Die unternehmerische Rationalität, Ein- und Umsichtigkeit sind Charakterzüge, die der Autor durch den bildungsbürgerlichen Schmidt als Klarheit und Offenheit Treibels (vgl. S. 476) lobt. Treibel ist, so der Erzähler, „sehr der Mann der Betrachtungen aller Dinge von zwei Seiten her", die es ihm ermöglicht, Dinge und Menschen „auch mal von der Kehrseite her anzusehen.“ (S. 438)

Der Erfindungsgeist und die Risikobereitschaft, die die wirtschaftliche Aktivität der Bourgeoisie durchaus kennzeichneten, zeigen sich im Alltag als G roßzügigkeit und Vorurteilsfreiheit, und darin unterscheidet sich Treibel von seiner Frau. Der Zusammenhang zwischen dem wirtschaftlichen D asein und dem privatmenschlichen bei Treibel ist in diesem Sinne nicht als G egensatz von Schein und Sein eines Individuums zu bewerten. Der im Bereich der Ö konomie erfolgreiche und privat, d.h. im Familienleben, tadellose Bourgeois, Hausvater und Ehemann ist das Ideal und mitunter die Wirklichkeit des Bürgers.

$\mathrm{Zu}$ diesem Ideal gesellt sich der Mißerfolg auf politischem Gebiet als Bedingung und Konsequenz hinzu, weil „in Deutschland der Kult der Familie stets Ausdruck der politischen Schwäche oder Resignation des Bürgertums gewesen ist." 45 Treibel ist, wie der Erzähler ausdrücklich bestätigt, „ein guter und auch ganz kluger Kerl“", kann aber, sobald er sich in den Tätigkeits- bzw. Seinsbereich der Politik begibt, nicht mehr Entsprechendes bewirken. Er liest gern die gemäßigt demokratische „Nationalzeitung" und das „Berliner Tageblatt" mit der beliebten satirischen D onnerstagsbeilage, dem „Ulk” (S. 308). Als Angehöriger der Honoratiorenschicht, die Besitz und Bildung mit politischer Tätigkeit vereint, ist Treibel auch liberal gesinnt. So gedenkt er aktiv in die Politik einzugreifen. Im gesteigerten Selbst- und Machtbewußtsein findet er im „Kommerzienrat" "ein[en] Titel von fragmentarischem Charakter", „der doch natürlich seiner Vervollständigung entgegensieht"(S. 322). So wie er sich die Villa baute, weil er sein altes Wohnhaus, "trotzdem es von Gontard, ja nach einigen sogar von Knobelsdorff herrühren sollte, [...] nicht mehr zeit- und standesgemäß" (S. 306f.) fand, will er seine gesellschaftliche Rolle zur repräsentativen Funktion, möglicherweise zum Titel eines „G eneralkonsuls" (S. 315), ausbauen.

Seine politischen Tendenzen bezeichnet Treibel offen als Resultat eines reinen Zweckdenkens ökonomischer Berechnung:

„[...] Sie wissen, unsereins rechnet und rechnet und kommt aus der Regular-de-tri gar nicht mehr heraus, aus dem alten Ansatze: ,wenn das und das soviel bringt, wieviel bringt das und das.' [...] nach demselben Ansatz hab' ich mir auch den Fortschritt und den Konservatismus berechnet und bin dahinter gekommen, daß mir der Konservatismus [...] besser zu mir paßt, mir besser kleidet." (S. 322)

41 Vgl. R. Schäfer, Theodor F ontane. U nterm Birnbaum / Frau Jenny Treibel. Eine Reihe: Interpretationen zum D eutschunterricht. Hrsg. v. R. Hirschenauer / A. Weber. München 1974, S. 147.

42 Vgl. M. A. Lehrer, Intellek tuelle A porie und literarische Originalität. W issenschaftsgeschichtliche Studien zum deutschen Realismus: Keller, Raabe und Fontane. Califonia 1986, S. 179.

43 „Die Q uintessenz seiner Welt war dem Bourgeois sein Zuhause, denn hier und nur hier ließen sich die Probleme und Widersprüche der bürgerlichen G esellschaft vergessen oder künstlich beseitigen. Hier und nur hier konnte die bürgerliche und mehr noch die kleinbürgerliche Familie die Illusion harmonischen, hierarchischen Glücks zum Ausdruck bringen und es zugleich erst ermöglichen." (E. J. Hobsbawm, D ie Blütez eit des Kapitals, S. 284f.) 44 Vgl. G. A. Ritter/ J. Kocka (Hrsg.), D eutsche Sozialgeschichte, Bd. 2: 1870-1914. München 1974, S. 63.

45 H. Rosenbaum, F ormen der Familie, S. 314. 
Die G esellschaftsdame warnt darauf den Bürgerlichen, vom Standpunkt politischer Professionalität aus, vor einer Verirrung in die Politik: „Überhaupt, Kommerzienrat, warum verirren Sie sich in die Politik? [...] Was wollen Sie mit Politik?“ (S. 321). Sie gibt ihm desweiteren eine Lektion über den eigentlich fortschrittlichen gesellschaftlichen Auftrag des Bürgertums:

„[...] was wollen Sie mit Konservatismus? Sie sind ein Industrieller [...] Jeder Lebensstellung entsprechen auch bestimmte politische G rundsätze. Rittergutsbesitzer sind agrarisch, Professoren sind nationale Mittelpartei und Industrielle sind fortschrittlich. Seien Sie doch Fortschrittler. Was wollen Sie mit dem Kronenorden? Ich, wenn ich an Ihrer Stelle wäre, lancierte mich ins Städtische hinein und ränge nach der Bürgerkrone." (S. 321)

Dieser geschichtlich progressiven Version seiner politischen Bedeutung stellt Treibel eine um ihr geschichtliches Fortschrittsbewußtsein gekürzte Klassikrezeption gegenüber, die bekanntlich für das bürgerliche Lager der G ründerzeit steht. D as Harmonische gehe dem Fortschrittlichen vor, schließe es letztlich gar aus, heißt es bei ihm:

„[...] ich erkenne die Lebensaufgabe des Weisen vor allen Dingen in Herstellung des sogenannten Harmonischen, und dies Harmonische, wie die Dinge nun mal liegen, oder [...] wie die Zeichen nun mal sprechen, schließt in meinem Spezialfalle die fortschrittliche Bürgerkrone so gut wie aus." (S. 322)

Die ,Harmonielehre' entfaltet sich weiter zu einer politischen Anschauung, die einen karikierten Symbolismus nahelegt. Treibel schwärmt von einer symbolisch-ästhetischen Einheit zwischen seiner ökonomischen Tätigkeit und seiner politischen ,Colour'. Die blaue „Kornblume“, welche die Lieblingsblume Königin Luises und Zeichen der preußischen Monarchisten war, dient hier als der Symbolträger, mit dessen Hilfe sich der Machtanspruch des Bürgerlichen an die reale Machtstruktur ästhetizistisch anpaßt:

„Ja, meine Gnädigste. Fabriken im allgemeinen neigen der Bürgerkrone zu, Fabriken im besonderen aber - und dahin gehört ausgesprochenermaßen die meine - konstatieren den Ausnahmefall [...] können Sie sich einen Handelsgärtner denken, der [...] Kornblumen im großen zieht, Kornblumen, dies Symbol königlich preußischer G esinnung, und der zugleich Petroleur und Dynamitarde ist? [...] was sind alle Komblumen der Welt gegen eine Berlinerblaufabrik? Im Berlinerblau haben Sie das symbolisch Preußische sozusagen in höchster Potenz, und je sicherer und unanfechtbarer das ist, desto unerläßlicher ist auch mein Verbleiben auf dem Boden des Konservatismus. D er Ausbau des Kommerzienrätlichen bedeutet in meinem Spezialfalle das natürlich Gegebene... jedenfalls mehr als die Bürgerkrone." (S. 322f.)

In Treibels Politikverständnis findet man die damals verbreitete irrationale „Vorstellung von Politik“ wieder, „die sich in der ,rechten Gesinnung', im ,Eintreten für das Vaterland', in der ,Verehrung von Kaiser und Reich' erschöpfte. "46 So wählt Treibel als Präsidenten seines Wahlkomitees, als "agent provokateur" (S. 308), einen fanatischen „Prinzipienreiter" (S. 396), den Lieutnant A. D. Vogelsang. Alt und steif, in der Erscheinung von einer "Mephistophelesschaft" gestreift, hat Vogelsang aber „den Glauben an sich selbst" (S. 309), was Treibel in seiner qualvollen endlosen ,Regular-de-tri' tief beeindruckt. Vogelsangs politische Idee nennt sich „Royaldemokratie“ (S. 329), ein reaktionäres Programm, das nur zwei großen Mächten dienen will: „Volkstum und Königtum“ (S. 328). Auf den Anachronismus dieser komisch-grotesken Figur verweist die Gesellschaftsdame. Sie nennt Vogelsang ein "Gespenst", einen „Vorachtundvierziger", eine "Karikatur durch und durch" (S. 320), der "doch nur als Warnungsschatten vor den Prinzipien stehen [kann], die das Unglück haben, von ihm vertreten zu werden." (S. 321)

Wie schon gesagt, muß dieser O pportunismus auf dem Feld der Politik das Bild des Kommerzienrats als eines besonnenen kritischen Menschens nicht unbedingt trüben. Treffender wäre wohl: Je blinder und unselbständiger im Öffentlichen, desto intensiver, durchdringender und beherrschender richtet sich der kritische Blick Treibels auf sein Privatleben. ${ }^{47}$ Er scheint zeitweise die Selbstironie - den „denkbar höchsten Standpunkt" (S. 347) im Sinne von Schmidt, dem Erzähler und dem Autor selbst - zu erreichen. Aus seiner Ironie zieht er aber keine Konsequenz. Die ironisch-kritische Haltung gegenüber seiner Umgebung im Privatleben erschöpft sich in einer Art „Sprechanismus" (S. 308), einer Beredsamkeit, die danach strebt, sich restlos auszusprechen. Sein ,Verbal-Aktivismus' wird von seiner Frau durchschaut und ausgenutzt. Die Streitszene zwischen Treibel und Jenny über die mögliche Einheiratung Corinnas in die Familie Treibels zeigt dies deutlich. Anstatt Jennys Erregung zu teilen, gerät er seinerseits in Wut über ihren Hochmut. Sogleich äußert er eine gründliche und umfassende Kritik an ihr. Im Verlauf von „Treibels Philippika“ wird aber Jenny „merkwürdig ruhig“ (S. 438). Denn:

Sie wußte, daß er in einem überhohen Grade das Bedürfnis und die Gewohnheit des Sichaussprechens hatte und daß sich mit ihm erst wieder reden ließ, wenn gewisse Gefühle von seiner Seele heruntergeredet waren. Es war ihr schließlich ganz recht, daß dieser Akt innerlicher Selbstbefreiung so rasch und so gründlich begonnen hatte; was jetzt gesagt worden war, brauchte morgen nicht mehr gesagt zu werden, war abgetan und gestattete den Ausblick auf friedlichere Verhandlungen. (S. 438)

Wie sein Wahlkampf, der trotz der gut bestandenen „Beredsamkeitsprobe neulich bei Buggenhagen“ (S. 308) erfolglos endet, bleibt auch seine Wut, so scharfsinnig seine Kritik an Jenny auch sein mag, ohne Konsequenz. Es erweist sich, daß die Entscheidungsmacht über die Interessenpolitik innerhalb der Familie nicht in seiner Hand liegt, sondern in der Hand seiner Frau. Sobald der Redeakt als Aggressionsabfuhr vollzogen ist, kehrt der alte Friede zurück, in dem nicht "gewisse G efühle seiner Seele", sondern Jennys Hochmut und Kalkül die Lage beherrschen. Schon am Ende der Szene, als er in sein Zimmer hinübergeht, steht es mit ihm so. Er ist schon halb willig zu „friedlichere[n] Verhandlungen“: „Als er sich in den Fauteuil 
warf, brummte er vor sich hin: ,Wenn sie am Ende doch recht hätte!"“ (S. 439).

Seinem Sprachgebaren können allerdings zwei verschiedene Bedeutungen beigemessen werden, die für die geschichtliche Wirklichkeit der Mediendiskurse wichtig sind. Sicherlich gibt sein Sprachgebaren den Stil der Zeit wieder, das Bemühen, das literarische und historische Gebildetsein des Sprechers durch das Zitieren der ,Klassiker'- aus dem ,Sprach- und Bilderschatz deutscher Nation' - zu dokumentieren. Parallel zur kulturhistorischen Übersättigung der sprachlichen Bedeutung läuft die Durchdringung und Entgrenzung von verschiedenen, historisch gleichzeitigen Sprechstilen, um so in Richtung einer Aushöhlung der sprachlichen Bedeutung zusammenzuwirken. Treibels Stil48 durchläuft alle Sprachebenen, verfügt mühelos über die ganze Skala vom derben Berliner Ausdruck bis hinauf zur geistreichen Formulierung, wobei er das Wechseln der Ebenen kaschiert durch ein Einbeziehen des ,Redensartlichen' aus dem „Schatzkästlein deutscher Nation“ (S. 475). Diesem sich das historische und soziale Andere aneignenden Sprachstil Treibels ähnlich ist der von Jenny. Während bei Jenny die Aushöhlung des sich sprachlich manifestierenden Individuellen über die Sentimentalisierung erfolgt, vermittelt bei Treibel ein zum Redensartlichen geronnener klassizistischer Anspruch zwischen den auseinanderfallenden Sprachebenen.

\section{A ushöhlung des bürgerlichen E rziehungsprogramms}

An Jennys unverheiratetem zweiten Sohn Leopold wird eine der wesentlichen Leitideen der bürgerlichen Familie, nämlich ihr Erziehungsprogramm, ad absurdum geführt. Die Charakterschwäche trifft nicht allein Leopold, sondern sie gilt tendenziell auch für den ersten Sohn O tto, seine Frau Helene und ihre Tochter Lizzi, also für die ganze Nachwuchsgeneration der Treibels. Dies signalisiert das Versagen der Familie Treibel als Erziehung- und Sozialisationsinstitution.

In seiner nächsten Umgebung gilt Leopold als „ein Kind“ (S. 412), als der „Schläfrige[]“, „Temperamentlose“ und als „beinah eine Suse“ (S. 375) oder als „gar nichts" (S. 430). So stellt Leopold genau das Gegenteil dessen dar, was man unter dem ,innengeleiteten Individuum' als Ziel der Erziehungspraktiken der bürgerlichen Familie verstanden hat.

Angesichts des Umstandes, daß die Grundlage des bürgerlichen Selbstbewußtseins im Vertrauen auf die eigene Leistungsfähigkeit liegt, ist diese Verfassung Leopolds als ein aussagekräftiges Symptom zu betrachten. Der Leistungsfähigkeit des Menschen, dem wichtigsten Sozialcharakter des bürgerlichen Menschen, geht eine Ich-starke Persönlichkeit voraus, die dem bürgerlichen Individuum, dem innengeleiteten Menschen, ${ }^{49}$ entspricht.

Die von dem unmittelbaren materiellen Z weck befreite persönlichkeitsbildende Erziehung, die im bürgerlichen häuslichen Raum stattfinden soll, nimmt eigentlich die Bedeutung eines „Instrument[s] des politischen Kampfes gegen den Adel [an], dessen angeborenen Privilegien es [das Bürgertum; J.-H. B.] die Leistungsfähigkeit seiner Kinder entgegenhalten wollte ${ }^{\prime .} .0$ D ort, wo nicht der politische Kampf gegen den Adel, sondern die Assimilation an ihn angestrebt wird, fehlt jener als ideelle Bewaffnung verstandenen Erziehung die eigentliche Triebfeder.

So sucht die Kommerzienrätin den Grund für die gescheiterte Persönlichkeitsbildung ihres Kindes in der suspekten „Herkunft' und ,Geburt': „Ich weiß nicht, wo beide Jungen diese Milchsuppenschaft herhaben. [...]. Sie haben doch beide was Schläfriges, und ich weiß wirklich nicht, Treibel, auf wen ich es schieben soll..." (S. 375) Zwar wird von Jenny resignierend eingestanden, „daß sich solche Charaktere nicht ändern lassen“ (S. 375), jedoch weiß sie durch ihre Rolle als Trägerin der bürgerlichen Erziehungsmission auch, „daß man die Pflicht hat, da zu helfen, wo noch geholfen werden kann." (S. 375) So wünschen sie und ihr Mann ihrem Leopold einen Liebesskandal, der dem fehlerhaften, vermutlich angeborenen Charakter nachhelfen kann, denn „[z]um Menschen gehört Leidenschaft“ (S. 376); und die Leidenschaft erscheint für sie am reinsten in der geschlechtlichen Liebe. Aber wie die Vorstellungen der Eltern, die Leidenschaft als zu etwas ,rein Menschlichem' sentimentalisiert verstehen, ist auch die betonte Leidenschaftslosigkeit Leopolds im Grunde nichts anderes als Ausdruck eines bedrohten und entleerten bürgerlichen Selbstbewußtseins, das, wie oben gezeigt, mit der Feudalisierung des Bürgertums in Zusammenhang steht.

Ein Hinweis auf diese versteckte Bedeutung der ,Leidenschaftlosigkeit' bei Leopold - als Ausdruck für die mangelnde Leistungsfähigkeit und insofern als fehlendes Selbstbewußtsein des Bürgerlichen - ist, daß jedesmal, wenn von Leopold gesprochen wird, wie formelhaft „gut aber leidenschaftslos" eingefügt wird: Eine phrasenhafte Wendung, in der die Spannung zwischen dem Wert der modernen Epoche und der Z eit zuvor präsent ist. D as Gute und das Nützliche, Praktische und Fähige fallen weit auseinander. Während die Leidenschaft, die für die Ich-starke Persönlichkeit und damit für das leistungsfähige Individuum vorausgesetzt wird, den Status des ,rein Menschlichen' beansprucht, wird das Gute eher "eine[r] Suse" zugeschrieben: „, [E]inen besseren Menschen als unseren Leopold gibt es eigentlich überhaupt nicht; er ist schon beinah eine Suse..." (S. 375). Die Erziehung, die zur Ausbildung eines „inneren Kreiselkompa[sses]“ ${ }^{51}$ zu dienen hat, trägt bei Leopold den Charakter einer D ressur. Der Vorgang des Erlemens von Selbstkontrolle und des Aufschubs von Bedürfnisbefriedigung wird eher zur ,Bevormundung' verkürzt. So verbietet Jenny Leopold die zweite Tasse Kaffee am Morgen:

Ich kann nicht sagen, daß mein Sohn ein passionierter Mensch ist, er ist ein guter Mensch, ein lieber Mensch... [...] aber er hat die Kaffeepassion. Und das ist immer das Schlimme, daß die Menschen gerade die Passion haben, die sie nicht haben sol-

48 Vgl. R. Schäfer, Theodor F ontane, S. 149f., bes. S. 152, 153, und 154.

49 Vgl. D. Riesmann, D ie einsame M asse. Reinbeck 1962, S. 32 f.

50 R. Sieder, Sozialgeschichte, S. 136.

51 Ebd. S. 136. 
len. Also, Mützell, eine Tasse mag gehen, aber nicht zwei. (S. 386f.)

Unter dem gleichen Stern wie seine ,Kaffeepassion' steht Leopolds Liebesgeschichte. Wie seine Eltern als Gegenbeweis für die offenbare Charakterschwäche ihres Kindes eine Liebesaffäre herbeiwünschen, hegt er selbst eine heimliche Hoffnung auf eine geschlechtliche Liebe und darauf, daß er mit Hilfe seiner Liebe zu Corinna aus seinem „elenden Zustand" (S. 388) herausgerettet werden kann: „[...] wenn es wahr ist, daß einem die Liebe Mut und Entschlossenheit gibt, so muß doch alles gut werden.“ (S. 388) Der, wenn man will, aus Not Verliebte erwartet, daß die Liebe mehr als „bloß gut“ ausgehen wird: „es muß mir auch leicht werden und mich geradezu zwingen und drängen, den Kampf aufzunehmen und ihnen allen zu zeigen, und der Mama voran, daß sie mich denn doch verkannt und unterschätzt haben." (Ebd.)

Die Verlobung zwischen Leopold und Corinna erfährt heftigen Widerstand seitens der Mutter Jenny, für die die geplante Heirat eine Gefährdung des Interesses der Familie als Kapitalgemeinschaft und daher ,Unsinn' und ,Unvernunft' bedeutet. Leopold hält zwar an seiner entschlossenen Haltung fest, ist aber zu schwach, um sich tatkräftig, über seine täglichen Briefchen hinaus, gegen die Mutter durchzusetzen: Es bleibt nur die Folgenlosigkeit der Entschlossenheit eines nicht, innengeleiteten' Menschen.

Eine andere Selbsthilfe-Aktion stellt sein tägliches Reiten dar. Leopold, der „wegen zu flacher Brust“ bei den Gardedragonern nicht angenommen worden war, , , [hatte] zur Auswetzung der Scharte wenigstens Reitstunde genommen [...]." (S. 383) Die flache Brust spielt dabei bildlich auf den Mangel „an einer Instanz in der eigenen Brust", 52 nämlich das Selbstbewußtsein, an. D ie Disziplin gibt ihm aber nur „eine ganz leidliche Figur" (S. 383), denn „das Heroische läßt sich nicht lernen." (S. 389)

Nach der Nachbesserungsstunde für die zu flache Brust tritt er in seine Berufswelt ein, ins Kontor, wo er sich als Nachwuchs der Bourgeoisie zum disziplinierten Akkumulierer zu bilden hat, der früh an Triebverzicht gewöhnt wird, um Höheres zu genießen, der sich ,draußen' im Beruf auf die härteste Weise schlägt.53

Trotz aller Kompensationsmaßnahmen bleibt der Nachwuchs der Treibels charakterschwach, weit entfernt von dem Erziehungsideal des innengeleiteten, selbstverantwortlichen und disziplinierten Menschen. Am Ende der Geschichte gar rutscht das Bild von Leopold leicht in die Nähe eines Anormalen, Asozialen. Während alle sich im Festsaal von Corinnas Hochzeit befinden, reitet Leopold im Wald herum. Denn bei Fontane dürfen „nur die Ratlosen, Irrenden und Abwegigen [...] in problematischer Einsamkeit in Garten oder Park ihren trüben G edanken nachhängen“. .54

Bei der kleinen Tochter von Jennys erstem Sohn Otto wird die bürgerliche Mädchenerziehung in ihrer hamburgisch übertriebenen viktorianischen Variante aufgezeigt. D as Bild Lizzis und der „Mustererziehung“ (S. 377), die das Kind erfährt, kann sowohl im Sinne einer Frühstation der Kinderzeit als auch im Sinne von weiblicher Sozialisation im bürgerlichen Kreis der Zeit als E rgänzung zum Fall Leopold gelesen werden. D as spezifisch Bürgerliche in der Beziehung zum Kind ist die Vorstellung vom Kind als erziehbarem Wesen. In der Vision einer gesellschaftlichen G ruppe, die auf die ,Bildbarkeit' der Persönlichkeit setzte, wurde das kleine Kind zum ,unbeschriebenen Blatt', dem mit Sorgfalt und Nachdruck die Spuren der Erziehung eingeschrieben werden sollten. ${ }^{55}$

\section{Utopie der defizitären Familie}

Der geschlossenen und vollständigen Familie Treibel - Frau, Mann und Kind - steht die Familie Schmidt gegenüber, die aus dem Witwer Schmidt, seiner Tochter Corinna und der ebenfalls verwitweten Haushälterin Schmolke besteht. Im erweiterten Sinne der Familie gehört auch Marcell, der Sohn der verstorbenen Schwester Schmidts, der sein zukünftiger Schwiegersohn sein soll, dazu. Während die Treibels, dem Charakteristikum der bürgerlichen Familie entsprechend, eine von ihrer sozialen Umwelt abgeschlossene Einheit bilden, zeigt sich die Familie Schmidt schon wegen ihres formalen D efizits als vom idealisierten Familienleben relativ entfernt.

Um einen ausgesprochenen Gegenentwurf der bürgerlichen Familie, eine Utopie im emphatischen Sinne, handelt es sich bei den Schmidts freilich nicht. Jedoch weicht die Familie Schmidt von dem tradierten Leitbild der Familie, das bei den Treibels in charakteristischer Starrheit und Übertreibung praktiziert wird, nicht nur äußerlich ab. Mit dem signifikantvorausweisenden Fehlen der Ehefrau und Mutter als Integrator der intimen Beziehungen der Familie fällt der psychologische Mechanismus, dem z.B. die Treibels unterworfen sind, aus. Anstelle des festen Rollenspiels etabliert sich bei Schmidt und seiner Tochter Corinna ein gewisser Freiraum, bewußt Rollen auszuwählen und zu gestalten. Diese geistige Beweglichkeit und intellektuelle Distanz zur gegebenen rollenhaften Existenz wird in der Forschung ausreichend gewürdigt, jedoch ausschließlich im Sinne einer indiviuellen geistigen Leistung der Figuren. Dadurch wird der soziogene Z usammenhang, daß die weltanschauliche Opposition der Familie Schmidt zu ihrer Umgebung gerade in ihrer defizienten Familialität bedingt bzw. vorprogrammiert ist, ${ }^{56}$ gänzlich außer acht gelassen.

52 H. Rosenbaum, Formen der Familie, S. 282.

53 Vgl. R. Sieder, Sozialgeschichte, S. 144.

54 P. D emetz, F ormen des Realismus: Theodor F ontane. Kritische U ntersuchungen. München 1964, S. 103.

$55 \mathrm{Vgl}$. Th. Sieder, Sozialgeschichte, S. 136.

56 Vgl. M. A. Lehrer, Intellek tuelle A porie, S. 176: Lehrers Hinweis auf „das Spielen von Rollen als Mittel zur Befreiung von vorgeschriebenen Verhaltensnormen" als „Regel“ des Romans, in dem nur die Titelgestalt Jenny eine Ausnahme sein soll, ist mit gutem Recht auf die zwei Figuren Schmidt 
In ihrem formalen D efizit, der fehlenden Geschlossenheit, ist die Familie Schmidt strukturell offen gegenüber der Umwelt, die stets in Veränderung begriffen ist. Diese horizontale Breite durch die stetige Berührung mit der Außenwelt läßt die Intimität und die Sentimentalisierung der Beziehungen nicht zu. In die Familien spielen Probleme und Perspektiven der Gesellschaft hinein. So lebt man als Schmidtsches Familienmitglied weniger mit innigstem Identitätsgefühl. Eher wird die bürgerliche Häuslichkeit in die D imension einer gesellschaftlichen Integration der Familie überführt.

\section{Bildungsbürgerliche Intellek tualisierung der $E$ rfahrung der M oderne}

Die bei dem Ehepaar Treibel ausgeprägte Spaltung in geschlechtsspezifische Lebensbereiche wird bei Schmidt in seinem Witwerdasein aufgehoben. Schmidt tritt in seiner bewußten, ironisch gespielten Rolle als Gegenspieler seiner früheren Freundin Jenny, also als G egenpol zur Privatsphäre der bourgeoisen Familie auf.

$\mathrm{Zu}$ ihrem Ehemann Treibel, dem Mitbürger, verhält er sich viel weniger kontrastiv, zumal jener im Privaten als guter Ehemann und guter Hausvater fungiert. In der Schlußpartie nennt Schmidt Treibel gar ,Bruder' und redet ihn mit ,D $u^{\prime}$ an. In der zur Beschreibung der Figuren benutzten Wettermetaphorik ist die zunehmende G ewichtverschiebung zwischen Bildungsbürgern und Besitzbürgern abzulesen. D er Bildungsbürger Schmidt erscheint in „Dampfwolken" (S. 468), während der Unternehmer Treibel immer ein „klares und offenes Gesicht" (S. 476) hat. Im Unterschied zu Treibel, der nicht in seinem glanzvollen Berufsleben, sondern ausschließlich als Privatmann auftritt, wird Schmidt mehr in seinem Professorentum, als Professor für antike und deutsche Literatur, dargestellt. In seinem Kreis der "Sieben Waisen aus G riechenland" von halb beruflichem, halb privatem Charakter herrscht Geselligkeit. Es ist eine der Honoratiorenkultur eigene Geselligkeit, die sich jetzt im unaufhaltbaren Niedergang befindet. D er vor der Folie seiner homophonen Variante doppeldeutige, ironische Name der "Sieben Waisen (Weisen) aus Griechenland" spielt auf die entwurzelte Situation des neuhumanistischen Bildungsbürgertums an, das, anders als der antike Kreis griechischer Philosophen und Politiker gleichlautenden Namens, über keinerlei nennenswerten gesamtgesellschaftlichen Rückhalt mehr verfügt und damit gleichsam, verwaist' ist. So ist ihre Geselligkeit von der drohenden G efahr des inneren Zerfalls getrübt. „O ffenheit und Ehrlichkeit im Verkehr mit- und untereinander war keineswegs ein hervorstechender Zug der ,sieben Waisen', eher das Gegenteil“ (S. 348). Fehlendes G emeinschaftsgefühl, „Selbsterhaltungstrieb“ und „Saumseligkeit" (S. 348) kennzeichnen das „Kränzchen“ (S. 346). Schmidt, „die Seele des Kränzchens“, sagt: „Ich werde Pessimist." (S. 348)

In den Gesprächen innerhalb des Kreises formuliert sich die Krise als allgemeine, inhaltliche Aushöhlung der Bildungsidee, jenes Begriffs für das (bildungs-)bürgerliche Selbst- und Weltverständnis. Denn der akademische Professionalisierungs- und Spezialisierungsprozeß und die zunehmende Bedeutung der Technik und Naturwissenschaft führten da$\mathrm{zu}$, daß sich neben dem alten neuhumanistisch orientierten Bildungsbürgertum verschiedene Positionen und zahlreiche Disziplinen behaupteten, die einen jeweils unterschiedlichen Bildungsbegriff für sich in Anspruch nahmen. Distelkamp klagt über das beobachtbare Hinschwinden der Autorität, des - in Anknüpfung an eine Kantische Formulierung - „kategorischen Imperativ[s]“ (S. 351): „D enn wie kein Heerwesen ohne Disziplin, so kein Schulwesen ohne Autorität.“ (S. 352) Mit der Autorität sei es „wie mit dem Glauben“.(Ebd.) D eswegen heißt es: „[D ]as Entscheidende bleibt doch immer der Charakter, nicht der eitle, wohl aber der gute, ehrliche Glauben an uns selbst.“ (Ebd.) Es sei nicht „nötig, daß das Richtige geglaubt [werde], aber daß überhaupt geglaubt [werde], darauf [komme] es an. In jedem Glauben stecken geheimnisvolle Kräfte und ebenso in der Autorität.“ (S. 352) D arauf erwidert Schmidt: „[M]it der geschwollenen Wichtigtuerei, mit der Pomposität ist es heutezutage nicht mehr getan." (S. 353). Das Ansehen - nicht die Autorität - komme nicht von dem Charakter, sondern von der „reelle[n] Macht des wirklichen Wissens und Könnens“ (S. 353). „Es ist vorbei mit den alten Formen, und auch unsere Wissenschaftlichkeit wird davon keine Ausnahme machen" (S. 352). Als Beispiel für die Wissenschaft der neuen Zeit nennt Schmidt die Archäologie, konkret Heinrich Schliemanns Ausgrabungen zu Mykene. D em von Distelkamp beschworenen Glauben an sich selbst setzt Schmidt Schliemanns durch genaue Lektüre der antiken Schriftsteller geweckten Glauben an historische Sachen, historische Wirklichkeit und Wahrheit entgegen. ${ }^{57}$

Schmidts Bewußtseinslage läßt sich mit seiner selbständig erworbenen, dem Zeitwandel angepaßten Vorstellung von Wissen und Wissenschaft umschreiben, die sich vor allem durch eine ironische Distanz zu der von der klassischen neuhumanistischen Bildung beeinflußten Umwelt auszeichnet.

Den Gegenpol zu seiner Ironie bildet Distelkamps selbstgefällige Haltung, die in der „ewigen Kritik, eventuell auch Selbstkritik“ (S. 352) eine G efahr für die Selbsterhaltung sieht, denn: „[0]hne Glauben an uns und unsere Sache keine rechte Lust und Freudigkeit, und auch kein Segen, am wenigsten Autorität." (S. 352) Die Schmidtsche Selbstironie läßt sich deshalb nicht auf den vermeintlichen G egensatz zwischen Besitz- und Bildungsbürgertum zurückführen. Sie bestreitet auch die Stichhaltigkeit der praktisch überholten, nur noch im Bildungsgut konservierten und zur bloßen Formel erstarrten Welt- und Menschenvorstellung. In Schmidt spiegelt sich eine gewagte D enkens- und Verhaltensweise, die aktiv die Schatten des Vergangenen zu überwinden und dem Neuen gegenüber offen bleiben will.

und Corinna einzuschränken. Sie allein sind es, die ihre Rolle, aus den vorgeschriebenen Verhaltensnormen heraustretend, mit neuem Inhalt zu füllen versuchen, was die Bedeutung einer Befreiung ausmacht. Darauf werde ich noch näher eingehen.

57 Vgl. R. Schäfer, Theodor F ontane, S. 143. 
Wie genau sieht jenes neue Verständnis der Welt aus? Läßt sich Schmidts Versuch der Überwindung der veralteten Weltvorstellung bzw. Vorstellungswelt in einer positiven Formulierung fassen?

Beim Abendessen der „Sieben Waisen Griechenlands“ serviert man den Gästen Oderbruchkrebse. Das Tischgespräch der Gelehrten geht von der Herkunft der Oderkrebse über zur Literaturgeschichte. Dabei kommt es zu einer Auseinandersetzung zwischen den zwei Formen des Geschichtsbewußtseins, wie sie jeweils von Schmidt und Distelkamp vertreten werden. Schmidts Position, die sein Gegner und Freund Distelkamp als „Schmidtiana“ bezeichnet, liegt in der Hervorhebung des „Anekdotische[n]“, des „G enrehafte[n]“, während für Distelkamp „in der G eschichte nur das G roße, nicht das Kleine, das Nebensächliche [gilt]" (S. 360).

Unter dem ,Anekdotischen', ,Genrehaften' versteht Schmidt aber nicht - wie Distelkamp, der es zu einem Gegensatz zwischen $\mathrm{G}$ roß und Klein quantifiziert - etwas vom Eigentlichen, Wichtigen Abweichendes, sondern etwas, in dem sich das Eigentliche verbirgt. So formuliert Schmidt: „D as Nebensächliche, soviel ist richtig, gilt nichts, wenn es bloß nebensächlich ist, wenn nichts drin steckt. Steckt aber was drin, dann ist es die Hauptsache, denn es gibt einem dann immer das eigentlich Menschliche." (S. 360)

D as anekdotische Verfahren, wie Schmidt es versteht, bedeutet, im Nebensächlichen das eigentlich Menschliche zu finden. G emeint ist damit die Verfahrensweise der Induktion, nämlich das Aufsteigen vom Besonderen zum Allgemeinen.

Schmidts Vorliebe für das Anekdotische in der G eschichte spiegelt Fontanes Neigung zur Induktion. Z war steht Fontane, wie die meisten seiner Zeitgenossen, unter dem allgemeinen Einfluß des Historismus, jedoch gilt für ihn die Hauptthese des Historismus von der Singularität historischer Prozesse und Strukturen ${ }^{58}$ kaum. Dieser Sachverhalt ließe sich mit dem Hinweis auf die Differenz von Historie und Literatur erklären. Wiewohl Fontane für seine Kunst die Methode des Historismus, kulturelle Erscheinungen primär unter dem Aspekt ihrer historischen Gewordenheit zu betrachten, übernimmt, ist er als Schriftsteller unausweichlich und immer wieder an dem interessiert, was zwar in dem historisch gewordenen Individuellen erscheint, aber nicht ganz darin aufgeht. Dies kann man, wenn man will, als das allgemein Anthropologische bezeichnen, was von Schmidt selbst dann noch als „das eigentlich Menschliche“(S. 360) bezeichnet wird, wenn es sich lediglich um die Aktualisierbarkeit und Modellhaftigkeit historischer Einzelerscheinungen handelt. In dem Sinne, daß es die Poesie, die Literatur ist, der es auf dieses historisch Anthropologische ankommt, gibt Distelkamp Schmidt recht: „Poetisch magst du recht haben." (S. 360) Mit dieser einräumenden Billigung Distelkamps, die an den dem Historismus eignenden, aus der isolierenden Betrachtung entstehenden Wertrelativismus im ethischen Bereich erinnert, gibt sich Schmidt nicht zufrieden. Er stellt das Poetische als das verbindliche Prinzip über das historistisch verstandene Historische: „Das Poetische [...] , das Poetische hat immer recht; es wächst weit über das Historische hinaus..."(S. 360)

Die Differenz zwischen diesen beiden Welt- und G eschichtsauffassungen geht über die Differenz zwischen dem Historischen und dem Poetischen, zwischen dem historistischen und dem anekdotischen Verfahren weit hinaus. Eine wichtige Deutungsfigur, mit der das Verhältnis des neuen D enkens zum alten D enken veranschaulicht wird, liegt in Schmidts Verteidigung von Krebsen. Geschickt knüpft Schmidt an die durch die Ankunft von Corinna und Marcell unterbrochene Debatte an, indem er Marcell die Frage stellt, was er vorziehe, Hummer oder Krebs. D er Selbstverständlichkeit, mit der Marcell den allgemein vorgezogenen Hummer nennt, widerspricht Schmidt. Er erkennt zwar dem Hummer seine unbestreitbare Überlegenheit zu, aber in einer einschränkenden Weise:

Natürlich, wenn solch ein Hummer aufgeschnitten vor einem liegt, und der wundervolle rote Rogen, ein Bild des Segens und der Fruchtbarkeit, einem zu allem anderen auch noch die Gewißheit gibt, es wird immer Hummer geben', auch nach Äonen noch, gerade so wie heute [...] Also einem die G ewißheit gibt, auch nach Äonen noch werden Menschenkinder sich mit dieser Himmelsgabe freuen - ja, Freunde, wenn man sich mit diesem G efühl des Unendlichen durchdringt, so kommt das darin liegende Humanitäre dem Hummer und unserer Stellung zu ihm unzweifelhaft zugute. D enn jede philanthropische Regung, weshalb man die Philanthropie schon aus Selbstsucht kultivieren sollte, bedeutet die Mehrung eines gesunden und zugleich verfeinerten Appetits. Alles Gute hat seinen Lohn in sich, so viel ist unbestreitbar. (S. 362)

Die absolute Überlegenheit des Hummers gegenüber dem Krebs, das Humanitäre des Hummers und schließlich das Philanthropische sind also nach Schmidt erst im „Gefühl des Unendlichen“ möglich, in dem Weltgefühl der Kontinuität. „Aber", so wendet sich Schmidt von der „Philanthropie“ des Hummers ab und der Naturordnung zu:

Aber es ist trotzdem dafür gesorgt, auch hier, daß die Bäume nicht in den Himmel wachsen, und neben dem Großen hat das Kleine nicht bloß seine Berechtigung, sondern auch seine Vorzüge [...] auch er darf sagen: ich habe nicht umsonst gelebt [...] so hat er Momente wirklicher Überlegenheit, vor allem auch darin, daß sein Bestes nicht eigentlich gegessen, sondern geschlürft, gesogen wird [...] das [...] ist das natürlich Gegebene. Wir haben da in erster Reihe den Säugling, für den saugen zugleich leben heißt. (S. 362)

Wiewohl Schmidts Sprache auch eine gelungene Parodie auf die scheinheilige Ernsthaftigkeit von Jennys Dinerkonversation - im direkt vorangegangenen Kapitel - darstellt, wird die Ironie und das darin reflektierte Bewußtsein des Sprechers nicht ganz verstanden. So bleibt noch für die jüngere Forschung Schmidts ,Hummer oder Krebs' im Bannkreis der bildungsbürgerlichen „Hypertrophierung der sprachlichen Form“ .59

Im G egensatz zu einer solchen abwertenden Lektüre des Vergleichs von „Hummer und Krebs' unterstelle ich dem Ver-

58 Vgl. G. Loster-Schneider, D er E rzähler Fontane. Seine politischen Positionen in den Jahren 1864-1898 und ihre ästhetischeV ermittlung. Tübingen 1986, S. 87. 59 So D. Kafitz, ,Frau Jenny Treibel', S. 81. 
gleich die Bedeutung einer sich selbst ausdrückenden Erfahrung der Moderne, die die ganze humanistische Geschichtsvorstellung in Z weifel zieht.

Die tiefere Bedeutung der Alternative „Hummer oder Krebs“ als Ausdruck eines neuen Geschichtsbewußtseins von Schmidt wird im weiteren Verlauf des G esprächs deutlich. D enn wenn Distelkamp das G espräch „aus dem allgemein Kulinarischen auf einzelne berühmte kulinarische Persönlichkeiten überlenkte" (S. 363), wird offensichlich, daß es hier immer noch um den Methodenstreit zwischen Schmidt und Distelkamp geht. Der Kern der Erfahrung der Moderne bei Schmidt liegt im Sprachlichen selbst ausgedrückt vor, nämlich in der Rhetorik seines Diskurses über die Geschichte. D as heißt, daß Schmidt die G eschichte nicht als Handlungsraum von großen Individuen, also als Welt der Autoritäten, sondern vielmehr als Welt des kulinarischen, sinnlichen Genusses deklariert. Was manifestiert sich in dieser Perspektivenverschiebung? Oder anders gesagt, was wird hier in Anlehnung an das Kulinarische faßbar gemacht?

Schmidts philosophische Leidenschaft für das „Kochbuchliche[]“, für „reine Menufragen“ (S. 363), richtet sich nach meinem D afürhalten auf den diesem Sinnenbereich des Menschen eigenen Pluralismus und Relativismus. Die moderne Welt wird nicht reaktionär und ex negativo aufgefaßt als en $\mathrm{N}$ icht-M ehr der guten alten Zeit, sondern sie wird analog zu einem eigentlich Menschlichen, also dem Sinnlich-Kulinarischen, verstanden und darin bejaht.

So gesehen schließen die anekdotische Betrachtung der Geschichte und die Erfahrung der Moderne einander ein. Mit dem Saugen, der allerelementarsten, primären Tätigkeit des Menschen, wird eine Erfahrungsform, eine Wahrnehmungsweise der modernen Welt benannt. Diese über die sprachliche Virtuosität eines Gebildeten hinausreichende neue Richtung liegt noch im Dunkeln, sowohl für seinen eigenen K reis als auch für den Leser. Die Intellektualisierung der Erfahrung der Moderne läuft dann jedoch bei Schmidt G efahr, in das belanglose, witzige Sprachspiel des Gebildeten zurückzufallen.

\section{D ie moderne Stopfk unst: D as neue Subjek tsmodell}

Die Modeme wird bei Schmidt, indem er seine wissenschaftliche Tätigkeit reflektiert, als D enken im Sinne eines nachvollziehenden Verstehens von Welt und Selbst vorbereitet. Wie das ,Bourgeoisentum' von Jenny verkörpert wird, so wird das Utopische der neuen Zeit von dem weiblichen Teil des über die Zukunft theoretisch reflektierenden Bildungsbürgertums getragen. Sucht man nach dem Utopischen im Roman, nach dem Utopischen in dem Sinn, daß hier nach der Überwindungsmöglichkeit der erstarrten neuhumanistischen Kulturform gesucht wird, so findet sich dies als Keim in der Figur der Corinna angelegt. Die neue Zeit konkretisiert sich bei Corinna als eine Frage der Praxis unter den konkreten Lebensbedingungen. Es handelt sich bei dieser Art von Antizipation, dem ,Traum nach vorwärts' seitens Corinnas, um einen weiblichen Lebensentwurf unter der gesellschaftlichen Bedingung des Bürgertums. Bei näherer Betrachtung stellt sich heraus, daß das neue weibliche Selbstbild und Handlungsmodell, das mit Corinna erprobt wird, eine gewisse Differenz zu dem jeweils von Marcell und Schmidt vertretenen Idealen des Neuen enthält. Die Spannung zwischen Corinna und Marcell wird allerdings durch den Verlauf der Geschichte äußerlich beseitigt. Die Spannung zwischen Corinna und ihrem Vater ist milder, weil durch die väterlich besorgte, verständnisvolle Perspektive Schmidts bereits entschärft. Und doch bleibt eine Differenz vorhanden. Das Utopische bei Corinna scheint diese Differenz auszumachen. Worin besteht ihre eigene Stimme? Der Hauptunterschied zwischen Corinna zu den anderen Figuren liegt darin, daß sie sich offen zur Modeme bekennt, während die anderen die moderne Lebensform als oberflächlichen Materialismus nur von sich weisen wollen. Corinna gesteht demgegenüber, daß „ein Hang nach Wohlleben, der jetzt alle Welt beherrscht, [...] mich auch in der G ewalt [hat], ganz so wie alle anderen“.(S. 344) Sie weiß um die Macht des materiellen Besitzes und sieht ihn als Grundlage eines Lebens voll Freiheit und Unabhängigkeit an. Corinnas illusionsloser Anerkennung der materiellen Vormacht steht das idealistische, sentimentale ,Herzensprinzip' gegenüber. Die Vertreter des „Herzensprinzips' sind Marcell und Jenny, allerdings mit unterschiedlicher innerer Beteiligung. Während Jenny plakativ den Idealismus verkündet, nimmt Marcell, aus einer „, beinah schon christlich[en]“ (S. 467), humanistischen Perspektive, das Ideale, das Herz über alles andere ,ernst'.60 Auf dem Weg nach Hause vom Treibelschen Diner von ihrem Vetter Marcell zur Rede gestellt, legt Corinna ihre Absicht offen, den Treibelschen Sohn Leopold zu heiraten. Corinna, für die Bildung und Besitz keine konkurrierenden, einander ausschließende Prinzipien sind, betrachtet diese Dinge nicht als wesenseigen und unveränderlich. Die Tatsache, daß sie Leopold heiraten will, hat dementsprechend für sie nur "den Status kontingenter Sinnsetzung" 61 :

[...] das, wozu der liebe $\mathrm{G}$ ott mich so recht eigentlich schuf, das hat nichts zu tun mit einem Treibelschen Fabrikgeschäft, oder mit einem Holzhof und vielleicht am wenigsten mit einer Hamburger Schwägerin. Aber ein Hang nach Wohlleben, der jetzt alle Welt beherrscht, hat mich auch in der Gewalt, ganz so wie alle anderen. [...]. (S. 344)

Die Heirat mit Leopold bedeutet für Corinna nicht das Ziel ihres Handelns selbst, sondern ein Mittel, ja einen „Rettungsanker" (S. 345) zum erhofften Leben in materieller Sicherheit. Corinna sieht die Notwendigkeit, wenn man so will, die Schicksalshaftigkeit ihres Handelns, nicht in der Bedeutung des Individuellen - wie bei der Familie Treibel - begründet, son-

60 R. Brinkmann spricht von einer allgemeinen Tendenz bei Fontane, „das Christentum weitgehend auf den Bereich seiner Ethik einzuschränken und auf allgemeine, formale sittliche Maximen zurückzudrängen.“ (Kap. W eltfrömmigk eit und Säkularisation. D ie historische Balanœ im Bereich der Religion, in: R. B., Theodor F ontane. Ü ber die V erbindlichk eit des U nverbindlichen. Tübingen 1977², S. 175) Mit dieser Einschränkung hängt gewiß zusammen, so Brinkmann, daß bei Fontane, wenn „Religiöses ernst und distanzlos zur Sprache kommt oder ,in actu' dargestellt wird, [es] prekär in die Nähe des Peinlichen, ja des Kitsches [zu] geraten“(ebd., S. 179) droht, wie dies auch für Marcell zutrifft.

61 A. Poltermann, „F rau Jenny Treibel“, S. 141. 
dern in der sozialen und geschichtlichen Bestimmtheit ihrer eigenen Existenz wie auch der unzähliger anderer Menschen. Die Treibels stellen für sie also nicht das Ziel selbst dar, wie für Jenny, die aus Selbstüberschätzung stets alles auf ihre Familie bezogen denkt. Das Individuelle der Treibels spielt dabei nur eine zufällige Rolle. Demgemäß legt Corinna auf ihre eigene Individualität auch keinen besonders großen Wert. Sie zeigt neben dem hochgradigen Selbstbewußtsein auch ein Rollenbewußtsein, das die traditionellen Forderungen der Weiblichkeit nahelegt. Ihre Äußerungen verweisen daher auf eine gewisse Distanzierung von der radikalen Form der Frauenemanzipation, ${ }^{62}$ eine Distanzierung, wie sie in bürgerlichen Kreisen der Zeit im allgemeinen der Fall war.

So sichert Corinna sich und den anderen ihre Traditionsgebundenheit, welche aber bei ihr von jeglicher emphatischen Identifizierung mit dem eigenen Ich entfernt ist:

Ich erfreue mich, dank meiner Erziehung, eines guten Teils von Freiheit, einige werden vielleicht sagen von Emanzipation, aber trotzdem bin ich durchaus kein emanzipiertes Frauenzimmer. Im G egenteil, ich habe gar keine Lust, das alte Herkommen umzustoßen, alte, gute Sätze, zu denen auch der gehört: ein Mädchen wirbt nicht, um ein Mädchen wird geworben. (S. 343)

E inerseits über die Grenzen traditioneller Weiblichkeit hinausweisend, sich andererseits auf das alte herkömmliche weibliche Rollenbewußtsein berufend, greift Corinna ganz aktiv in den Prozeß der Partnerwahl ein, die bisher ausschließlich zu den Vorrechten des Mannes gehörte. Sie vermengt das indirekte Mittel der Manipulation, das Mittel, das die passive Frau in patriarchalischen G esellschaften seit eh und je benutzt hat, mit dem G eist und der Vernunft, die bisher nur dem männlichen G eschlecht zugerechnet wurden.

$\mathrm{Zu}$ beachten ist hier, daß Corinna ihrem geistigen Vermögen keinen emphatischen emanzipatorischen Selbstwert zuzumessen scheint, und zwar im großen Unterschied zu den emanzipierten Frauen, für die der G eist, das Bewußtsein und die Subjektivität einen Selbstzweck, genauer gesagt, sowohl Prozeß als auch Ziel, darstellen. Da sie sich wenig mit ihrem wachen Bewußtsein identifiziert, klingt auch eine distanzierte Stimme gegenüber dem neuen G eist der Frauenemanzipation an, wenn sie sich auf die weibliche Tugend der Passivität beruft. Schon in ihrer Wahl der guten alten Sätze ist ihre nicht ganz naive, ja gewiß ironische Haltung zu diesem Sachverhalt spürbar. D ie beschworene Traditionstreue hat daher bei ihr einen eher strategischen Stellenwert, wobei es ihr als Handelnder gar nicht um die strikte Erhaltung der Tradition um ihrer selbst willen geht.

Bei Corinna geht es in Wirklichkeit um das möglichst höchste Glück des Individuums, welches es mit möglichst wenigen Risiken innerhalb seiner Möglichkeiten zu erringen gilt, wobei das Glück weder einseitig als geistiges noch als materielles erscheint. Darin, daß sie ihren Geist und ihren Witz ganz aktiv einsetzt, um die erwünschte Werbung herbeizuführen, spiegelt sich die energische, zielstrebige Mentalität des Bürgertums wieder.

Es ist nicht schwer zu verstehen, daß ein solcher Glücksbegriff jegliche emphatische Absolutsetzung eines Teils des Selbst, sei es die emanzipatorische oder die traditionelle Selbstbestimmung, geradezu ausschließt. Eine solche offene IchBestimmung führt dazu, das eigene Dasein als Rollenspiel mit einem bestimmten, zur Verfügung stehenden Repertoire von Verhaltensweisen zu betrachten. Ein solches Ich- und Lebensgefühl verweist auf die Erfahrung der historischen Kontingenz: Corinna historisiert einerseits die von vielen ihrer Geschlechtsgenossinnen als schicksalhafte Selbstbestimmung erfahrene Weiblichkeit als ,Tradition'. Andererseits bezeichnet sie ihre sie am meisten von anderen Frauen in ihrer Umgebung unterscheidende Individualität, ihre Geisteshaltung und schließlich ihre Erziehung als ,zufällige Bescherung'. Es fehlt bei ihr der blinde Emst, die fatale Eingenommenheit dem gegenüber, was die menschliche individuelle Existenz bestimmt: die geschichtliche Bedingtheit und die Besonderheit der eigenen Lage. Anstatt darin eine Notwendigkeit zu sehen, betrachtet sie sie als zufällig, als relativ.

Im Zeichen dieser Kontingenz steht ihr gesamter Heiratsplan, und zwar in der Weise, daß der Verlauf der Handlung eine Entwicklung passiver und zufälliger Natur annimmt. Andererseits wird dieser Vorgang aber von einem hohen Grad an Reflexion begleitet, der für Blindheit kaum Raum läßt. So besteht der eigentliche Konflikt, den Corinna für die Romanwelt herbeiführt, in einem aus „reiflicher Überlegung“ (S. 342) gesteckten „Ziel“.(Ebd.) „Alles ist Berechnung“ (S. 367), was sich dort ereignet. Wie der Ausbruch des Konfliktes ist auch sein Ausgang das Ergebnis von Reflexion. D er Konflikt wird dann weniger gelöst als unterbrochen, indem die handelnde Figur es aufgibt, weiter zu handeln, sobald sie die zuvor nicht erkannte Wirklichkeit neu erfährt. Corinna sieht, daß sie sich „in Überschätzung Ihrer [Jennys; J.-H. B.] freundlichen G efühle" (S. 448) verirrt hat, daß sie Jennys „Lyrik und obligate[ ] Träne“(S. 464) mit der Wirklichkeit verwechselt hat. Schmidt sagt dazu, daß Corinna "den Fehler gemacht [habe], sich einzubilden, ,das ginge so “'(S. 465), d.h. „mit zwei Familienporträts und einer väterlichen Bibliothek in eine reiche Familie hineinheiraten"(S. 445) und so Bildung und Besitz in Einklang bringen zu wollen. Mit der Einsicht in Jennys verlogenen Charakter erkennt Corinna eine ganz andere und von ihr erst spät verstandene Dimension des Heiratsplanes, daß nämlich ihr angestrebtes Ziel, die „Befriedigung“ des Sinns für Äußerlichkeiten, unter Umständen „doch zu teuer erkauft werden“ kann:

[...] diese Mama, diese furchtbare Frau! G ewiß, Besitz und Geld haben einen Zauber, wär es nicht so, so wäre mir meine Verirrung erspart geblieben; aber wenn Geld alles ist und Herz und Sinn verengt und zum Überfluß Hand in Hand geht mit Sentimentalität und Tränen - dann empört sich's hier, und das hinzunehmen wäre mir hart angekommen. (S. 471)

Aus dieser neuen Erkenntnis heraus behandelt sie, so der Erzählerbericht, die Sache „nach ihrer Art" , d.h. „so wenig tra-

62 So spricht H. Mittelmann bei Corinna von einem gewissen Paradoxcharakter, von einer „paradoxen Vermengung von Konzepten“ der Emanzipation.(Dies., D ie U topie des weiblichen G lüdks in den Romanen Theodor F ontanes. Frankfurt/ M. 1980, S. 85) 
gisch wie möglich“ (S. 470). Vor „der ganzen Niederlage, die sich in Leopolds selbstgewolltem Rückzuge aussprechen würde“, falls „Jenny, trotz Lyrik und obligater Träne, sich ihrem Jungen gegenüber doch mächtiger erweist als Corinna“, wählt sie "die halbe Niederlage, indem sie von sich aus Leopold abschreibt." (S. 464)

Ihr Vater und ihr künftiger Ehemann sehen, dabei für sich das Gute herauslesend, den Sinn der ganzen G eschichte, „einer kurzen" aber lehrreichen „Abirrung" (S. 465), darin, daß sich die Überlegenheit der bildungsbürgerlichen Tradition bestätigt hat. Schmidt sagt: „Was vordem halb Berechnung, halb Übermut war, das sieht sie jetzt in einem andern Licht und ist ihr G esinnungssache geworden.“ (S. 466) Daraufhin resümiert Marcell: „Corinna hat nun wohl für immer mit der Modernität und dem krankhaften Gewichtlegen aufs Äußerliche gebrochen, und hat statt dessen die von ihr verspotteten Lebensformen wieder anerkennen gelernt, in denen sie großgeworden ist."(S. 466)

Was die G esinnung und Lebensform angeht, läßt sich bei der betroffenen Figur selbst kaum eine Änderung erkennen, wenn Corinna sagt: „II]ch habe von früh an den Sinn für Äußerlichkeiten gehabt und hab' ihn vielleicht noch.“(S. 471)

In der Tat gibt es bei Corinna kein Zeichen einer inneren Entwicklung. Der Vorfall ihres gescheiterten Heiratsplans ist grundsätzlich weit entfernt davon, eine Persönlichkeitsentwicklung auszulösen. Allerdings wird die junge Frau von ihrer Umgebung nun immer als erwachsene Person angesehen, so daß Schmolke sagt: „D u bist ja nun eine große, forsche Person und hast die Kinderschuhe längst ausgetreten und könntest schon sechs Jahre verheiratet sein."(S. 426) Corinna korrigiert nur einen eigenen Fehler, der aber nicht darin besteht, daß sie etwa fälschlicherweise auf Besitz und Geld Wert gelegt hätte, sondern darin, daß sie den verlogenen Charakter Jennys nicht durchschaut hat. Wohl deswegen spricht sie höchstens von „Verirrung"(S. 471) und wählt damit eine Bezeichnung, die keinen moralischen, persönlichkeitsbezogenen Beigeschmack hat wie die vom Vater und Vetter gewählte Bezeichnung „Abirrung“, sondern eher auf einen Sinnes- und Wahmehmungsirrtum verweist.

Ganz im Sinne ihres schon erwähnten flexiblen Selbstbildes setzt sie auch Marcell eine andere Vorstellung von Liebe und Glück entgegen. Als Antwort auf seine Frage, ob sie emsthaft Leopold geliebt hätte, malt sie sich ein mögliches Glück mit Leopold aus, das nicht auf einer innigen Z weierbeziehung im bürgerlich idealisierten Intimbereich basiert, sondern durch die Weite der Erfahrungswelt bereitet wird:

[...] ich glaube auch nicht, daß ich sehr unglücklich geworden wäre, das liegt nicht in mir, freilich wohl nicht sehr glücklich. Aber wer ist glücklich? Kennst du wen? Ich nicht. Ich hätte Malstunden genommen und vielleicht auch Reitunterricht, und hätte mich an der Riviera mit ein paar englischen Familien angefreundet, [...]. Leopold ist etwas schläfrig. Ja, so hätt' ich gelebt. (S. 471)

Als Konsequenz eines solchen relativen Glücksbegriffs hält sie die von Marcell so sehr angezweifelte Liebe zu Leopold auch für möglich: „Sieh, das mit dem Leopold, das wäre vielleicht gegangen, warum am Ende nicht? Einen schwachen, guten, unbedeutenden Menschen zur Seite zu haben kann sogar angenehm sein, kann einen Vorzug bedeuten." (S. 471) D enn für sie war es „ja doch möglich [...] diesen lieben und guten Menschen [...] aufrichtig und von Herzen“ (S. 455) zu lieben.

Es sei hier an Schmidts G espräch über ,Hummer oder Krebs' erinnert. Ähnlich wie ihr Vater die Vielfältigkeit als Prinzip in der Welt des $\mathrm{G}$ enusses ansieht und damit dem Krebs auch Momente einer wahren Überlegenheit gegenüber dem Hummer zuspricht, bestreitet sie das eine Glück: es gibt vielerei Glück.

Die immanent-eschatologische Auffassung, die vor allem beim bildungsbürgerlich-neuhumanistischen, christlichen Marcell immer noch als glaubhaftes D enk- und Wertesystem fungiert, wird mit Corinna kritisiert. Am Abend des Diners bei den Treibels präsentiert Corinna ihre Kunststopferei, die sie im Lette-Verein, der Schule für weibliche Handarbeit, erlernt hat. Als Kunststopferin mit zwei Medaillen will sie das Loch, das sie jetzt in Leopolds Rock mit einer Zigarre brennen werde, in einem Tag so perfekt genäht haben, daß es nicht möglich sein werde, die Stelle zu finden. Worin Corinna sich als Meisterin beweisen will, ist die Kunst der spurenlosen Wiedergutmachung, die Kunst, das Vergangene für das Kommende unverbindlich, unverantwortlich zu machen, Dinge von ihren Kausalitäts- und Beziehungsgeflechten freizumachen. Als Metapher für die neue Selbstkonstitution, wonach Erfahrungen nicht mehr den zukunftsbestimmenden Stellenwert haben, spielt Corinnas Kunst ironisch auf die eschatologische Bildungs- und Persönlichkeitsidee an, bei der nichts ohne Spuren bleibt und bleiben soll. So nimmt sie den Ausgang ihres eigenen Heiratsplans mit Leopold und dessen Wirkung vorweg, wenn sie bei ihrem Experiment das Loch am Rock Leopolds symbolisch gerade dort, „wo sein Herz sitzt”, verortet. D ie Prophezeiung erfüllt sich insofern, als nach dem Scheitern der Liebesgeschichte ihr, wie auch Leopold, das G lück nicht fembleibt. Wie in dem von ihr vorgestellten Experiment der Kunststopferei bleibt kein Herz gebrochen. Dies gilt für sie, wenn sie versichert, „daß [sie] froh [sei], aus dem allen heraus zu sein“ (S. 471) und wenn sie von ihrer Entscheidung, Leopold abzuschreiben, denkt, daß „[a]m Ende [...] er [Leopold; J.-H. B.] auch ganz froh [ist]".(S. 470)

Die bevorstehende Glückserfüllung wird dadurch betont, daß Schmidt und Schmolke Corinna als „Glückskind“ (S. 469) bezeichnen. D as Glück, die schließlich doch zustande gekommene Endogamie mit Marcell, ist aber mehr Resignation und Resultat eines Sich-Fügens in das Unvermeidliche, also ein Kompromiß. Es ist eine ironische Anpassung an die willkürlichen Bestimmungen, die zwischen den beiden Extremen von Unterwerfung und Ablehnung liegt.63

63 Vgl. M. A. Lehrer, Intellek tuelle A porie, S. 183. 


\section{Sentimentalität und der Z erfall der F amilie}

Der Einbruch der Moderne in die bürgerliche Gesellschaft, dem man bei Schmidt auf der Ebene der G esinnung, bei Corinna auf der Ebene der Intellektualisierung begegnet, stellt sich in einer weiteren Figur des Hauses, der Wirtschafterin Schmolke, als ein Problem der Familie dar. Die bürgerliche Familie, die Essenz der bürgerlichen Lebensform überhaupt, ist, wie schon bei Jenny beobachtet wurde, gekennzeichnet vor allem durch eine G efühlskultur, für die die Ehefrau als Hauptträgerin bestimmt ist. D as familiäre G efühlsleben tritt im Haus des Witwers Schmidt natürlicherweise in den Hintergrund. O der besser gesagt, es wird in einer modifizierten Weise geführt. Schmolke, ihrerseits Witwe eines Sittenpolizisten, verleiht dem Haus etwas ,Herzliches', wie Corinna der mütterlichen Haushälterin bescheinigt. So fehlt es auch im Hause Schmidt an der - wenn man so will - Sentimentalität nicht ganz. Wie Fontane selbstkritisch bemerkt, bestand die Sentimentalität in dem sich auf die ganze Bevölkerung, ja sogar auf ihn selbst sich ausbreitenden ,Bourgeoisiegefühl'.64

Aber Sentimentalität ist nicht immer gleich Sentimentalität. Affin und kontrastiv zugleich hinsichtlich dieses Aspektes verhält sich Schmolke zu Jenny. Schmolke stammt, wie Jenny, die geborene Bürstenbinderstochter, aus dem kleinbürgerlichen Milieu. Schmolke bleibt aber, im Gegensatz zu Jenny, weiter dem Kleinbürgertum zugehörig, was sozialhistorisch eher die Regel war. In Schmolke wird die Familienlosigkeit im doppelten Sinne figuriert. Sie ist so einerseits kinderlose Witwe, andererseits dient sie, wenn sie sich bei jeder Gelegenheit auf ihren verstorbenen Ehemann beruft, als Indikator für bestimmte soziale Zustände, die besonders die Familien der unteren sozialen Schichten betreffen. D urch die Erinnerung an ihren Mann, der bei der Abteilung der Polizei arbeitete, „die für den Anstand und die gute Sitte zu sorgen hat"S. 423), wird der weitere soziale Kontext der Romanwelt, die eingefriedete bürgerliche Lebenssphäre, angedeutet. Die Prostitution als eine spezifische Form der Familienlosigkeit der modernen G roßstadt ist der Berufsalltag des Sittenpolizisten Schmolke. Mit gutem Grund erfreut ihn seine eigene Familie, wenn er von der Arbeit nach Hause kommt. Seine eifersüchtige, um die Treue des Mannes ängstliche Frau, weiß der Sittenpolizist zu beruhigen. Er sei, so tröstet er sie, „über all das Elend und all den Jammer“ traurig und habe Mitleid für „das arme Wurm“ und dessen „Eltern zu Hause“, „möchte rausgehn und weinen, und ein paarmal hab” ich's auch, alter Kerl, der ich bin, [getan]", denn "man hat ein Herz im Leibe“.(S. 425)

Die Witwe lebt gedanklich und gefühlsmäßig mit ihrem verstorbenen Mann weiter, womit sie die durch den Tod des Partners aufgehobene Ehe bis in die Gegenwart hinein verlängert. Wie ihr Mann bei den Prostituierten das allgemeinmenschliche Elend der Familienlosigkeit empfindet und um die zerfallende Familie trauert, so ist auch sie der eigenen Familie und zugleich der Familie als gesellschaftlicher menschlicher O rdnung treu ergeben. So hängt die Sentimentalität bei Schmolke mit der Erfahrung des Verlusts der kleinen Familie zusammen, der im doppelten Sinne, als natürlich und als auch als gesellschaftlich bedingter Zerfall der Familie gemeint ist. In diesem Erfahrungs- und Lebenszusammenhang hebt sich wohl Schmolkes Sentimentalität von der Jennys ab, für die die Sentimentalität jene klassenspezifische kulturelle Dimension von Klassikrezeption und Bildungsprache angenommen hat. Während es hier um Sentimentalität als künstlich gepflegtem $\mathrm{Ge}$ fühlsleben im Sinne von nachgeahmter Empfindsamkeit geht, handelt es sich dort um die authentische Empfindung als Folge des menschlichen Elends des Verlustes der familiären Nähe durch Tod oder Armut. Als echtes authentisches G efühl entbehrt Schmolkes ,Herzliches' dann jeder bloßen und großen Formel. Während die mutterlose Corinna, für die Schmolke in gewissem Sinne die Ersatzrolle der gefühlvollen Mutter spielt, dies betont, wenn sie sagt: „Sie haben ja immer so was Herzliches...", weist Schmolke eine solche E mphase von sich: „Ach, rede doch nich, Corinna. Wovon soll ich denn was Herzliches haben?" (S. 421)

D ie Witwe weiß aber gleichzeitig allzu gut, daß das Herzliche ein Allgemein-Menschliches ist, das mit der halbbewußten Verschönerung durch Bildungssprache weniger zu tun hat, als die Z eitgenossen sich dies einbilden. Keiner, gebildet oder nicht gebildet, darf und kann sich von dem Herzlichen freisprechen. Etwa in diesem Sinne fügt sie noch hinzu: „Oder eigentlich, wovon soll ich denn was Herzliches nich haben." (S. 421) Schmolke bezweifelt die Alleininanspruchnahme des Herzens, sie bestreitet einen solchen absoluten Anspruch auf das Herzliche überhaupt. In ihrer Anspruchslosigkeit hinsichtlich jenes erhabenen ,Herzens' ist die treuherzige Schmolke der ,herz-untreuen' Kommerzienrätin mit ihrem Selbstanspruch auf „ein Herz für das Poetische“ (S. 300) wesensfremd. So gesteht Schmolke Corinna: „[...] die Kommerzienrätin, ja höre, da kann ich mir nich helfen, die Rätin, die hat so was, was mir nicht recht paßt".(S. 427)

64 „D as Bourgeoisiegefühl ist das zur Z eit bei uns maßgebende, und ich selber, der ich es gräßlich finde, bin bis zu einem gewissen Grade davon beherrscht. Die Strömung reißt einen mit fort." (Fontane an seine Tochter, vom 25. August 1891, in: Th. F., W erke, Schriften und Briefe. Hrsg. v. W. Keitel / H. Nürnberger. A bt. IV : Briefe. 3. Bd. 1879-1889 (1980), S. 148.) 


\section{B. Die erzählte Komödie ${ }^{65}$}

\section{Die ironische Funktion des Theatralischen}

Wie entfaltet sich die weltanschauliche Auseinandersetzung mit der alten Weltordnung der Tradition auf der Ebene der Romanform? Wie sieht die relative innere Freiheit, die das Welt- und Selbstverständnis bei Schmidt und Corinna anvisiert, auf der Ebene des formalästhetischen Selbstverständnisses des Romans aus?

Hierbei wäre hinzuweisen auf die Ironie, weniger im Sinne eines sprachlichen Ausdrucks der Überlegenheit als einer Verhaltens- und D enkform, die gegen das erstarrte alte O rdnungskonzept ankämpft, um sich der Macht des Gegebenen zu entziehen. Genau diesen Sachverhalt meint R. Musil, wenn er über seinen später als M ann ohne E igenschaften betitelten Romanentwurf sagt, daß "mir Ironie nicht eine G este der Überlegenheit ist, sondern eine Form des Kampfes“. 66

Als ,Form des Kampfes' gegen die alte Weltauffassung verstanden vollzieht sich die Ironie bei Schmidt und seiner Tochter darin, daß sie die ihnen vorgeschriebene Rolle bewußt umgehen, und zwar ohne dabei die Situation selbst zum Schlachtfeld verwandeln zu müssen. Was sie und mit ihnen der Autor auch vorführen, ist somit ein leiser, intellektueller und langwieriger, eben ,formal' gehaltener Kampf.

E in solcher Kampf kann eigentlich nur einen Kampf der Form bedeuten, wobei anstelle des lebendigen Menschen die Form in den Kampf zieht. D aß in der Ironie, der ,Form des Kampfes', nur der ,Kampf der Form' vorgesehen ist, liegt nahe, wenn Schmidt und Corinna ihr Rollenbewußtsein mit ausgesprochen spielerisch-theatralischer Geste unterstreichen. D as Theatralische wird so als Signal für ihre bewußt-ironische Haltung, als Ausdruck für ihre geistige Fähigkeit eingesetzt, den mangelnden Sinn der Wirklichkeit zu durchschauen.

Diese Funktion des Theatralischen als Signal des Ironischen, der ironischen D istanz, beschränkt sich nicht auf die Figuren innerhalb der Romanwelt. Das Formverständnis, auf das der Roman zielt, drückt sich ebenso in der Annäherung der Romanstruktur an die theatralische Form aus. Es ist dieser Aspekt, auf den in der Forschung schon früh und oft aufmerksam gemacht worden ist: Man spricht von „leichtem Lustspielton“, 67 „erzählerischer Komödienform“, 68 „erzählter Komödie“ 69 und „versöhnlich gestimmter Komödie“ ${ }^{70}$ Läßt man zunächst die auf die versöhnliche Art einer Konfliktlösung bezogene Bestimmung der ,Komödie' beiseite, so handelt es sich hier um eine auffällige Vorherrschaft des Szenischen, wobei die bürgerliche Welt, auf zwei Häuser mit jeweils dazugehörigem Personenkreis verteilt, abwechselnd gezeigt wird. Die analogen Szenen in den beiden Häusern werden parallel geführt (D iner bei Treibels / Abendessen bei Schmidts; häuslicher Alltag bei Treibels / häuslicher Alltag bei Schmidts). Dann folgen jeweils szenische Engführungen der beiden Häuser (Verlobung bei der Landpartie, Streitszene und Hochzeit). So erweckt dieses szenische Arrangement den Eindruck, daß es sich hier um eine „paradigmatische Reihung vorgegebener theatralischer Muster"71 handele. Ein Analogon zum theatralischen Gestus der Figuren - zugunsten einer inneren Distanz zu den eigenen Rollen und dem mit den Rollen verbundenen zwischenmenschlichen Beziehungsgeflecht - stellt sich auf der Ebene des Formbewußtseins des Autors her: Die erstrebte und gewollte Nähe zum Theatralischen bedeutet nichts anderes als eine ebenso inszenierte Distanznahme im formalästhetischen Bewußtsein des Textes zur vorgegebenen Romanform. Nicht um des Theatralischen an sich oder als eines letzten Ziels willen wird hier theatralisiert, sondern das Theatralische ist die vorläufige alternative Form für das Romanhafte, wie es zeit- und landläufig verstanden wurde. Deswegen kommt dem Theatralischen ein in gewissem Sinn provisorischer Stellenwert für die ästhetischen Fragen zu, vor deren Hintergrund Jenny T reibel gesehen werden muß und zu denen sich der Roman polemisch verhält. So gesehen ist das Theatralische als Fluchtort zu charakterisieren, mit Hilfe dessen gleichsam die alternative Form des Romans sich zunächst vorläufig seiner alten Form, ja seiner alten Haut entledigen kann, um als Kunstform des Übergangs für die neue Zeit eigene Möglichkeiten zu erproben und zu artikulieren.

Die Theatralisierung auf der Formebene zielt vor allem auf die Abwendung, auf die Entfernung vom Romanhaften, das mit der gewählten Gattung des Romans formfest (vor-) gegeben ist. Welche ästhetischen, poetologischen Elemente sind es, die der kanonisierten Romanform zugrunde liegen, und wovon wird hier mit der die Ironie konstituierenden kämpferischen

65 Die „erzählte Komödie“ ist ein in der Forschung gelegentlich gebrauchter Begriff für die Gattung von Frau Jenny Treibel, allerdings mit einer Akzentverschiebung. So spricht in der älteren Forschung G. K ricker von dem „leichten Lustspielton“ (ders., Th. Fontane. V on seiner A rt und epischen Technik. Berlin 1912, S. 80), während F. Martini von einer „erzählerischen Komödienform“(ders., D eutsche L iteratur im bürgerlichen Realismus, S. 788) und I. Mittenzwei von einer „Sprachkomödie“(dies., D ie Sprache als Thema. Untersuchungen zu Fontanes G esellschaftsromanen. Bad Homburg; Berlin; Zürich 1970, S. 47) spricht. W. Müller-Seidel verleiht dem Komischen in Frau Jenny Treibel eine weitere Dimension in G estalt der englischen humoristischen Lebensform (ders., Besitz und Bildung. 1. Frau Jenny T reibel, S. 316f.). Eine Strukturanalogie zu Shakespeare sieht Schäfer. (W ie endet eine Komödie, in: ders., Theodor F ontane, S. 166-170.)

66 R. Musil, Interview mit O skar M aurus Fontana: W as arbeiten Sie? (1926), zitiert nach Hartmut Steinecke (Hrsg.), Theorie und Technik des Romans im 20. Jahrhundert. Tübingen 1979, S. 37.

67 G. Kricker, Th. Fontane, S. 80.

68 F. Martini, D eutsche L iteratur im bürgerlichen Realismus, S. 788.

69 R. Schäfer, Theodor F ontane, S. 118.

70 P. D emetz, F ormen des Realismus, S. 108.

71 A. Poltermann, „F rau Jenny Treibel“, S. 142. 
Theatralisierung versucht, auf Distanz zu gehen? Es wird zu zeigen sein, daß es dieselben Merkmale sind, die mit dem Begriff des Schreibromans zusammenhängen: Geschlossenheit, die D ramatisierung und die Schlüsselfunktion des Symbols. Die Auseinandersetzung mit dem Schreibroman, die Liquidierung von dessen hartem Kern der Geschlossenheit, der Dramatisierung und der Symbolisierung, bildet nicht nur die Formsituation dieses Romans, sondern sie stellt auch den Prozeßcharakter des Romanganzen dar. Am Ende des Romans hat man so mit etwas zu tun, das einen völlig anderen formalästhetischen Charakter aufweist: etwas wesentlich Neues, das nur als ,Wirkung', ,Resultat' und ,Konsequenz' der bis zum Ende durchgehaltenen ironischen Distanzierung von der Schreibromanform sinnvoll zu verstehen ist. Dieses ästhetisch Neue bezieht sich auf die allerletzte, verblüffende Szene des Romans. In der Szene wird nichts anderes manifest als die wahrnehmungs- und erkenntnisbezogene Übergangserfahrung Schmidts. Daß bei diesem Übergang das romanpoetologische Formbewußtsein mitwirkt, ist der $\mathrm{G}$ rund dafür, warum viele Interpretationsversuche, die einseitig von den Fiktionsebenen ausgehen, dieser Szene nicht gerecht werden können.

\section{Abschied vom Formprinzip der organischen Geschlossenheit}

Hinter dem Romanhaften, von dem sich Jenny Treibe durch die Theatralisierung zu distanzieren trachtet, steht der deutsche Roman seit Wieland und G oethe.72 Es ist dies eine Romanwelt, deren G esinnung - seitdem Schlegel G oethes W ilhelm M eister als das ewige Vorbild des modernen nachromantischen Romans von dem romantischen Roman D on Q uijote Cervantes abgesetzt hat ${ }^{73}$ - gemäß dem Charakter der Deutschen im Emst und Tiefsinn liegt. Dieser ,ernste Sinn' wird dann beim späteren Goethe im Sinne der ,Entsagung' angelegt: Die Integration der äußeren Geschehnisse in einen Kosmos, der als vernünftig präjudiziert wird, läßt sich nur noch mit Mühe als Ergebnis von Wechselwirkungen zwischen einer Welt und einem Individuum ausgeben. Die Weltentsagung erfährt in der Zeitstimmung nach 1848 eine dramatisch-tragische Steigerung, die sich romantheoretisch mit Gustav Freytag artikulierte. Dabei war Freytags Romantheorie D okument für die große Ähnlichkeit von Roman und Drama, was offensichtlich mit dem G eschmack fürs Theatralische der Z eit zusammenhängt.

Unter dem Einfluß von G. Freytags Romantheorie sah auch Fontane (1855) in einem dramatisch-tragischen Aufbau das formal gewährleistet, dessen seiner Meinung nach der Roman, ja „der Realismus unserer Zeit bedarf", nämlich eine „ideelle Durchdringung" ${ }^{74}$ Bekanntlich haben die deutschen Realisten für jene ,ideelle Durchdringung' den Begriff der Verklärung funktionalisiert.

Jedoch im Werk selbst ging es Fontane immer auch um etwas anderes als in seinen romantheoretischen Äußerungen, in denen er, neben einer „rezeptive[n] Ideal-Identifikation“ mit Freytags Romanpoetologie das Programm „eines naiven Fiktionalismus" 75 vertrat. Seine künstlerische Entferung von der G attung des ,verklärenden' Romans war kontinuierlich bis zu einer neuen Darstellungsweise fortgeschritten,76 in der die neue Herangehensweise an die Wirklichkeit, an die moderne Wirklichkeit, zum Ausdruck kommt. Bei dieser D arstellungsweise steht der Anspruch im Zentrum, die mit der etablierten Romanform sich ins Werk setzende hohe ideelle O rdnung - die aber in der dargestellten, empirischen gesellschaftlichen O rdnung nirgendwo spürbar ist, weswegen umso fester an ihre Existenz geglaubt wird - als ästhetische Lüge, als Mythos zu entlarven.

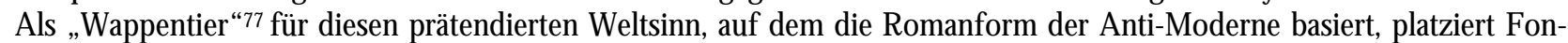
tane im Garten der bourgeoisen Muse Jenny den grauen Kakadu „mit dem bekannten Auge voll Tiefsinn“ (S. 314). Der Kakadu sitzt aber nicht nur "ernst", sondern zugleich „verstimmt", „weil sich keiner um ihn kümmert." (S. 335) Wie der Kakadu als allegorische Figur für den Tiefsinn im modernen Garten Jennys anwesend ist, so sind die Prinzipien der epischen Gestaltung als formstruktureller Ausdruck jenes höheren Weltsinnes in der Welt der Moderne vorhanden. Diese sind aber nicht wie der Kakadu: anwesend und vergessen zugleich, sondern sie üben durch ihre Anwesenheit im Roman eine Macht aus, die feindlich gegen die Moderne gerichtet ist, weil sie bei ihrer „Idee des schönen G anzen, dessen Formvollendung an der unvollkommenen Moderne nur den Sinnverlust hervorkehren."78

Fontane nimmt so die wichtige Erkenntnis vorweg, die man später bei Hoffmannstahl, Rehm und Staiger finden wird, die Erkenntnis, daß die innere G eschlossenheit des Romans als Bemühung des Romanschöpfers um eine Sinndeutung erlebter Wirklichkeit zu verstehen ist. ${ }^{79}$ Hat Fontane einst mit der Verklärungsästhetik die Romanform einer inneren Geschlossenheit als erstrebenswertes künstlerisches Resultat einer gelungenen Sinndeutung proklamiert, so greift er hier eben diese Roman-

\footnotetext{
72 Zum klassischen und traditionellen Romanbegriff siehe W. Kayser, D ie A nfänge des modernen Romans im 18. Jahrhundert und seine heutige Krise, in: D V js 28, 1954, S. 417-446.

73 Vgl. F. Schlegel, Ü ber G oethes M eister; V ersuch über den Styl in G oethes früheren und späteren W erk en, in: Kritische Friedrich-Schlegel-A usgabe. Abt. I. Bd. 2. Charakteristiken und Kritiken I (1796-1801). Hrsg. u. eingel. v. H. Eichner. D armstadt 1967, S. 126-146 und S. 334-351.

74 Th. Fontane, Sämtliche W erk e. H ist.- Krit. A usgabe. Hrsg. v. K. Schreinert. Bd. XXI/ I. München 1963, S. 214.

75 B. Hillebrand, Theorie des Romans. Erweiterte und überarbeitete Aufl. München 1980, S. 237; Näher zu Fontanes beiden Freytag-Rezensionen über Soll und $\mathrm{H}$ aben (1855) und D ie A hnen (1875), in denen schon Fontanes anfängliches klares Zugeständnis an Freytag in eine subtile Distanz übergeht, vgl. ebd., S. $236 f$.

76 Zu dieser Problemgeschichte vgl. A. Poltermann, „F rau Jenny Treibel“, S. 131-138.

77 Ebd., S. 140.

78 Ebd., S. 138.

79 H. Mayer, D er deutsche Roman im 19. Jahrhundert, in: ders., V on L essing bis Thomas M ann. Pfullingen 1959, S. 297-316, hier S. 312.
} 
form als Ursache, als Hindernis für die Schaffung eines positiven Verständnisses der Moderne an, die ja gerade jeden Begriff von $\mathrm{G}$ eschlossenheit sprengt.

\section{D ie A uflösung der $\mathrm{H}$ andlungseinheit}

Zunächst soll die Aufmerksamkeit auf die mit dem 19. Jahrhundert besonders in ihrer Bedeutung angewachsene Handlung gelenkt werden. D er ,Mythoscharakter', den die Handlung als feste Ordnungskategorie in der Romanpoetologie gewann, wurde zeitweise so weit getrieben, daß sie sich im dramatischen Roman Freytags schematistisch festgelegt findet.

In Frau Jenny T reibel distanziert sich Fontane von dem „modischen unmittelbaren D rauflosgehen aufs Ziel“ ${ }^{40}$ wie man es besonders bei dem dramatischen Roman ausgeprägt findet. Das dramatische Schema des zu einer Lösung hin sich entwickelnden Konfliktes wird gerade vermieden. Hier hat man es mit einer Variation von jenem Phänomen zu tun, welches in unmittelbarem Z usammenhang mit der beim späteren Fontane in vollem Umfang auftretenden Auflösung der Handlung steht. In Frau Jenny Treibel zeigt sich die Vorstufe dieses typischen ,Fontanisierens'.81 Das Eigentümliche von F rau Jenny Treibel im Vergleich etwa zur vollzogenen Handlungsauflösung im Stedhlin liegt in der Übernahme der Komödienform, die einer romanhaften Handlung tragischen Charakters von Grund auf widerspricht. Frau Jenny Treibel stellt deswegen eine Art Kompromiß des Romanciers dar, für den „was neben dem Weg liegt", „meist hübscher als der direkte Weg" 82 geworden ist, dem es aber noch nicht geheuer ist, ganz auf das traditionelle Erzählen zu verzichten. In diesem Sinne ist es nicht ganz zutreffend, daß Fontane schon in F rau Jenny T reibel auf alles Romanesk e verzichtet.83

Hat Freytag in Soll und Haben auf seine Weise „die Handlung der Romane zu künstlerischer Durchbildung“ gebracht, d.h. nach dem dramatisch-tragischen Vorbild in „Einleitung, Aufsteigen, Höhepunkt, Umkehr und Katastrophe“" 84 schematisiert, benutzt Fontane die Theatralisierung als schlichte szenische Darstellung, die auf eine dramatische Dynamik der Entwicklung der Geschichte gerade hemmend wirkt. Fontanes Theatralisierung ist der Freytagschen dramaturgisch gestützten Wirklichkeitsverfälschung entgegengesetzt. Sie will nämlich gerade entdramatisieren. So erscheint in Frau Jenny Treibel die Handlung nicht als „nach dem Prinzip kausaler Verknüpfung organisierte und syntagmatisch entfaltete Handlung“. Selbst in den eigentlichen Handlungsszenen wirkt sie „als Resultat der Bereitstellung paradigmatischer Verknüpfungs- und Verwicklungsfiguren“. D adurch entsteht die "für die Komödie typische[] Struktur". 85

Betrachtet man den Fontaneschen anti-dramatischen Umgang mit der Handlung genauer, dann entdeckt man, daß es hier um eine besondere Form von Handlung geht, die zwei Arten von Konflikt in sich trägt. Die zwei Konflikte sind zwar miteinander verschränkt, aber dennoch als zweisträngig, jeweils für sich entfaltet, zu betrachten. Diese ,D oppeldimensionalität der Handlung' wird zwar in der Forschung registriert, ist aber bis jetzt $\mathrm{m}$. E. in ihrer weiterreichenden Konsequenz oder in ihren weiter zurückreichenden Bedingungen nicht beachtet worden.

Die zwei Handlungsstränge lassen sich nach ihrer Bedeutung für das Romanganze anordnen. Corinnas gescheiterter Heiratsplan mit Leopold, der Plot des Romans, besteht als „anderweitige Handlung“. ${ }^{\circ 6}$ D ie eigentliche Handlung, für die die erwähnte „anderweitige Handlung“ auslösende Funktion hat, ist das Auseinandertreten zwischen Anspruch und Realität bei der sentimentalen Titelfigur Jenny Treibel. D ies stellt nicht die Entstehung, Entwicklung und Lösung einer Konfliktlage dar, sondem eine allmähliche Enthüllung von etwas G egebenem, die wiederholte Selbstbehauptung eines verlogenen Charakters und dessen Entlarvung. D arin liegt die unveränderbare Wirklichkeit, der status quo und ein Zustand der bürgerlichen G esellschaft der Gründerzeit. Die ,echte Handlung', Corinnas Geschichte, fungiert daher wie ein „Experiment", „das herausbringt, was wirklich ist" ${ }^{87} \mathrm{Zu}$ dem ,Experiment', Corinnas Heiratsplan, verhält sich die eigentliche G eschichte wie die Widerstand leistende Außenwelt, die Realität, die dem handelnden Subjekt die Erfüllung seines intendierten Handlungszieles versagt. Der Plot des Romans erweist sich somit als eine zum ,Experiment' degradierte epische Handlung, in der es nicht angelegt ist, in der Form des Konfliktes - wie die epische Handlung von Hegel proklamiert wird - die Figur und ihre Erfahrungswirklichkeit in einen neuen Z ustand höherer Einheit zu versetzen. ${ }^{88}$ Statt der Handlungsraum zu sein, wo das Subjekt und die Welt sich begegnen, um beiderseits Veränderung zu erfahren, ist die Handlung eine bloße Bestätigung des bereits Bekannten bzw. löst das richtige Erkennen des Vorhandenen aus, stellt also einen Korrekturvorgang des subjektiv Wahrgenommenen dar.

Zusammenfassend läßt sich sagen: Die Handlung wird aus ihrem traditionellen Funktions- und Sinnzusammenhang heraus, sie wird in ihrem realitätskonstitutiven Wirklichkeitswert entwertet. Die Handlung zeigt sich in ihrer D oppeldimension als symptomatisch für die Entwicklung der epischen Welt: hier die harte, von jeglichem Eingriff unabhängig sich behauptende

80 Th. Fontane, W erke X X I/ 1, L iterarische E ssays und Studien, S. 273f., in: Th. F., Sämtliche W erke. 36 Bde. Hrsg. v. E. Groß / K. Schreinert u.a. München 1959-1975.

$81 \mathrm{~J}$. Worthmann, D ie ,besprochene' Z ieit, S. 144-158.

82 Th. Fontane, W erkeX X I/ 1, S. 273.

83 Vgl. J. Worthmann, D ie ,besprochene' Z eit, S. 145.

84 G. Freytag, G esammelte W erk e. 22 Bde. 2. Aufl. Leipzig 1896-1898, Bd. I. S. 179f.

85 A. Poltermann, „F rau Jenny Treibel“, S. 142.

86 H. O hl, Bild und W irk lichk eit, Studien zur Romank unst Raabes und F ontanes. Heidelberg 1968, S. 195.

87 Ebd., S. 195.

88 Vgl. G. W. F. Hegel, V orlesungen über die Ä sthetik I. S. 234, 268, in: ders., W erke in 20. Bdn. Hrsg.v. E. Moldenhauer / K. M. Michel. Bd. 13. Frankfurt/ M. 1986. 
äußere Wirklichkeit, dort das bloße subjektive Interesse.

So ist der Romanstruktur ein leicht parodistischer Bezug auf die ,Geschichte der Personen' des traditionellen Romans immanent. Denn die Geschichte, der Konflikt, ist in dem traditionellen Roman nicht bloß im Sinne zufälliger Lebensereignisse zu verstehen, sondern sie wird als typischer Ablauf konstituiert. ${ }^{89}$

Anders als durch eine alles durchdringende Motivation bei dem ,Herzenskonflikt' - nach der mit Hegel formelhaft gewordenen Bestimmung des Romans als Ort des ,Konfliktes zwischen der Poesie des Herzens und der entgegenstehenden Prosa der Verhältnisse' - ist der Konflikt durch ein von Corinna mit „reiflicher Überlegung“ (S. 342) gestecktes „Ziel“ (ebd.) ausgebrochen. Der Konflikt wird also aus rein subjektiver Sinnsetzung und ohne ,objektive Gültigkeit' motiviert. Die Subjektivität des Konfliktes, dem von vornherein ,Wechselwirkung' mit der ihrerseits einseitigen objektiven Welt abgesprochen wird, wird noch gesteigert, ihr partieller kontingenter Charakter wird noch erhöht, indem Corinnas Plan von den beteiligten Figuren perspektivisch entwertet wird. Der Heiratsplan wird als „Unsinn“ (Jenny; S. 433 / Schmidt; S. 367) und „Komödie“ (Marcell; S. 342 / Jenny; S. 447) gedeutet, weil er mit ihren jeweils eigenen Interessen nicht zur Deckung gebracht werden kann oder weil er sich auf den „unbedeutenden Menschen“ Leopold (S. 344) und nicht auf ein „eigentliches Lebensglück“ (S. 344), auf „Herz" (S. 339) und "E rnst' bezieht. Nicht zuletzt sind die Heiratspläne („Visionen“ Schmidt; S. 367), „Phantasterei“(Marcell; S. 344), weil ihre Verwirklichung nicht wahrscheinlich ist. Bei einer derart moralisch und pragmatisch unterminierten Handlung bleibt eine lebendige Wechselwirkung zwischen Figur und der Wirklichkeit der Gesellschaft von Anfang an ausgeklammert. Seitdem sich die geschichtliche und psychische Wirklichkeit dahingehend gewandelt hat, daß die historisch entstandenen Verhältnisse den Individuen als von ihnen unabhängig gegenübertreten, ist in der Romanwelt ein Konflikt im traditionellen Sinne - das sich entwickelnde Spannungsverhältnis zwischen einer handelnden Person und ihrer Umgebung - unmöglich geworden. Formal und strukturell rückt dann der Konflikt ins Uneigentliche, so wie Corinnas Geschichte für den ganzen Roman. Die Wirklichkeit ist den Individuen gegenüber unabhängig, nicht weil diese das geschichtliche Leben als ein ihnen Überlegendes erfahren, sondern weil die von den Individuen durchlebte Geschichte etwas ganz Äußerliches, Zufälliges ist.90 Die Geschichte und damit die Romanhandlung erscheint schließlich als Ansammlung unbedeutender Anekdoten und Episoden. Dieser Zusammenhang zwischen der Auflösung der Handlungseinheit und der Äußerlichkeit und Abstraktheit der Wirklichkeit ist allerdings als bereits etabliertes Forschungsergebnis im Fall des Stechlin anzusehen. Im Alterswerk Stechlin, als Endstation der künstlerischen Entwicklung der Handlungsauflösung, ist die für Fontanes Romankunst charakteristische D ominanz des Dialogs gegenüber dem Geschehnis am weitesten fortgeschritten. Diese Handlungsarmut wird $u$. a. von Lukács und den von ihm inspirierten Marxisten aus der Perspektive des klassischen Romans als Formzerfall kritisiert. Demgegenüber stellt man bei der Handlungsauflösung - mit einer romantheoretisch weiter gefaßten Perspektive, die davon ausgeht, daß der Strukturwandel des Romans gerade eine Notwendigkeit der ästhetischen und geschichtlichen Aufgabe seiner Gattung sei den Übergang zum modemen Roman fest. Die G esprächsstruktur im Stechlin wird so als „eine neue, umfassende Sinnbildlichkeit" ${ }^{\text {91 }}$ einer abstrakt gewordenen Wirklichkeit verstanden.

Die Bedeutung und Funktion der Handlung im modernen Roman ist eine mythische Einheit in weltlicher Prägung. In ihr wird der Mythos zur Geschichte und zur Bildung. Diese Entsprechung zum Mythos, diese stillschweigende gegenwärtige Erinnerung an den Mythos - die freilich den direkten Bezug zu mythischen G ehalten und Göttergeschichten gekappt hat, wenngleich diese in den formalen Gesetzen der Dichtung noch implizit enthalten sind -, bezeichnet Lugowski als mythisches Analogon..$^{92}$ Als schöpferisch bewußtes Prinzip drückt sich das Analogon-Verhältnis zum Mythos am klarsten in der G runderfahrung des klassischen Goethe aus. Nach dem Untergang aller normativen Systeme müsse man, so Goethe, nun eben selbst bilden, also formen, um vom Chaos zur Form zu gelangen. ${ }^{93}$ Dieser der künstlerischen Form eignenden Mythos-Erfahrung Goethes ist die Entwicklung des Romans im 19. Jahrhundert nicht gefolgt. Zunehmend auf individuelles Erleben eingeengt und damit verinnerlicht, konnte die Handlung nicht mehr die noch bei G oethe erreichte mythische Einheit des Einzelnen mit dem Allgemeinen ${ }^{94}$ heraufbeschwören. Die Diskrepanz zwischen subjektivem Erleben des Geschehens und allgemeiner Erfahrung ist der Weg und zugleich das Problem der Romanhandlung geworden. ${ }^{95}$ Als Folge und Ausdruck einer abstrakten Wirklichkeit verstanden steht die zum ,Erlebnis' verinnerlichte Handlung der allegorischen Darstellung nahe. Anders als das Symbol, bei dem die Verweisungsfähigkeit auf die Natur einer Sache zurückführbar ist, erhält die Allegorie ihre Verweisungskraft erst durch die soziale und sprachliche Konvention. ${ }^{96}$ Als Ergebnis der Konventionalisierung sind bei Allegorien die Bedeutungen allen Schwankungen, allen Neu- und Uminterpretationen der sozialen Umgebung ausgesetzt. Sie sind geradezu

89 Vgl. H. Mayer, D er deutsche Roman im 19. Jahrhundert, S. 302.

90 Vgl. A. Poltermann, „Frau Jenny Treibel“, S. 143.

91 H. Turk, Realismus in F ontanes G esellschaftsroman. Z ur Romantheorie und zur epischen Integration, in: Jahrbuch der Wittheit zu Bremen 9 (1965), S. 407-456, hier S. 415.

92 Vgl. H. Schlaffer, E inleitung. Clemens L ugowsk is Beitrag zur D isziplin der L iteraturwissenschaft, in: C. Lugowski, D ie Form der Individualität im Roman. Frankfurt/ M. 1976, S. VI-XXIV, hier: S. XII. Im Sinne von Lugowskis ,mythischem Analogon', d.h. der Entsprechung zwischen der späteren literarischen Form und dem Mythos, geht H. Schlaffer der Handlung als formaler Verwirklichung von vorgegebenen Weltbildern nach, und zwar bei Fontane mit der zunehmenden Auflösungstendenz der Handlung. (ders., D as Schidksalsmodell in Fontanes Romanwerk. Konstanz und A uflösung, in: GermanischRomanische Monatsschrift. Neue Folge. 16 (1966), S. 393-409).

93 Vgl. D . Brüggemann, F ontanes A llegorien, in: ders., Neue Rundschau LXXXII (1971), S. 290-310 (I) u. 486-505 (II), hier S. 308.

94 Vgl. ebd., S. 306, 307 und 308.

95 Zum Gegensatz von Erfahrung und Erlebnis im 19. Jahrhundert vgl. A. Poltermann, G enreszene in der Stadt. Fremderfahrung am Beispiel einer D idk ensÜ bersetzung, in: Jahrbuch für Internationale G ermanistik. Jg. XXII / Heft 1. S. 56-97, hier S. 63.

96 Siehe zur D efinition von Allegorie und Symbol D. Brüggemann, F ontanes A llegorien (I), S. 300-308. 
schillernd. In ihrem Perspektivismus, ihrer mangelnden Ganzheit, ist die Allegorie die Sprache der Welt nach dem Zerfall einer mythischen All-Verbundenheit. Wo die Dinge ihren Sinn als etwas durch Erfahrung zu Bewältigendes verloren haben und der Zusammenhang zwischen Mensch und Ding nur noch etwas über die Innenwelt des Betrachters besagt, dort wird Sprache allegorisch. Als „dinglich erstarrte[] ,Sprache des Erlebens ${ }^{\text {"“ } 97}$ offenbart die Allegorie die gesellschaftliche Erfahrung des Waren-Fetischismus; Gegenstände erscheinen, von ihrem G ebrauchszusammenhang abgelöst, als an sich ,bedeutend', verselbständigen sich zu einer eigenen Macht, der man sich, im Hungern nach einem Sinnganzen, unterwirft. Die Handlung macht in ihrer Vernetztheit durch allegorische Verweisungen die Sinneinheit der Welt zu einer Eindeutigkeit der Z eitfolge, und damit zu einem irreversiblen Prozeß.

Vor diesem Hintergrund ist die Auflösung der Handlung bei Fontane als Kritik an der mit der Allegorie einhergehenden Fetischisierung begreifbar. Den Fetischen seitens des Erlebenden entsprechend ist der irrationale Fatalismus oder der rationale Fatalismus, der Sozial-D eterminismus seitens des Erkennenden bzw. Handelnden. Die Auflösung der Handlung zielt bei Fontane letztendlich gegen die Zwangsläufigkeit und Konsequenzhaftigkeit des G eschehens, der man restlos unterworfen ist, der man nicht entrinnen kann. ${ }^{98}$

Im F rau Jenny Treibel ist die Handlungseinheit in der Weise negiert, daß der Konflikt keine Konsequenz für die Romanwelt und ihre Figuren hinterläßt, weder hinsichtlich ihrer äußerlichen noch ihrer innerlichen Umwelt. So nimmt die Titelfigur das G eschehene leicht, indem sie sich entschlossen hat, „den ganzen Vorfall als eine Kinderei zu nehmen und dadurch das schon hier und da laut gewordene Gerede der Menschen auf die leichteste Weise totzumachen." Auch die Figuren nehmen alles auf die leichte Schulter: „Man wollte vergeben und vergessen, hüben und drüben." (S. 473f)

Die Auflösung der Handlung findet hier statt im Sinne einer Entwertung der Handlung als eines konsequenten und irreversiblen Geschehens. Die Bedeutung der Handlung ist nicht nur ,uneindeutig' und dadurch für viele D eutungen offen. Darüber hinaus bedeutet die Handlung bzw. das Geschehen hier in ihrer Folgenlosigkeit nichts, sie ist also nicht bedeutend. Was mit dieser Entwertung der Handlung abgelehnt wird, ist das Moment der Fixierung des Lebens auf Bedeutungen, welches der literarischen Form wie auch allen konventionalisierten Verhaltens- und Wortklischees eigen ist. Es ist der D rang zur Sprengung der durch die Romantradition konstatierten Funktion der Formstruktur der Handlung. Mit der Auflösung der Bindung zwischen allegorischem Signifikanten (Handlung) und allegorischem Signifikat (die Sinnhafigkeit der Handlung und schließlich der erzählten Welt) wird auch die Aufhebung der der Allegorie immanenten Distanz von äußerem Geschehnis und dessen Sinn intendiert.

In dem Maße, wie die Geschichte der Personen als „der für die Romanform charakteristische typische Ablauf“ an Wirklichkeitskonstituierendem und -veränderndem an Gewicht verloren hat, mangelt es bei dem Charakter der Person an jener handlungantreibenden ,Innerlichkeit'. Anders ausgedrückt: In dem Maße, in dem die Handlung den Ernst eines folgenreichen Ereignisses verliert, büßen die Personen ihre innere Tiefe ein. Alle Figuren sind in ihrer inneren persönlichen Motivation durchsichtig gemacht. Entweder durch Figurenaussagen oder durch den Erzählerbericht oder durch andere Figuren kennt man als Leser das eigentliche Motiv des oder der Handelnden. Von Jennys verschleiertem Interesse nur an dem „Pondable[n]" (S. 370) bis hin zu Schmidts Wunsch nach Endogamie, von Corinnas Abwägung zwischen geistigem und materiellem Glück bis hin zu Leopolds Liebes-Projekt als Selbstrettungsaktion eines innerlich schwachen Menschen sind alle Motivationen klar und handgreiflich, seien sie den Betroffenen selbst nun bewußt oder nur halb bewußt oder gar verstellt. Fontane weiß, daß der Mensch in seiner Zeit bis in sein Innerstes sozial und historisch zu sehr bedingt ist, um als ein von einer in sich verborgenen Vorsehung geleitetes Wesen dargestellt zu werden.

Hierbei scheint Marcell eine Ausnahme darzustellen, die aber bei genauerem Hinsehen als eine modifizierte Form jener sozialen und geschichtlichen Bedingtheit zu verstehen ist, in der die Motivationen der anderen Figuren unmittelbar plaziert sind. Marcells Handlung bezieht sich auf das Praktizieren von christlicher Liebe, was der Figur nicht zufällig eine gutmütige, aber etwas steife Erscheinung verleiht. Von Marcell, der, als Ausnahme, emsthaft an dem ,Herzensprinzip' festhält, wird das „Herz' als Religiosität, und zwar als überlieferte und institutionalisierte Handlungsorientierung ohne jegliches mythische Moment, vertreten. So enthält sein Inneres auch nicht das G eheimnisvolle, das sich halb verbirgt und halb öffnet und dadurch imstande ist, auf eine noch nicht manifeste mögliche Qualität des Menschseins hinzuweisen.

D ergestalt empirisch fixiert, so daß zwischen subjektivem Interesse und Weltobjektivität keine Vermittlung und daher kein Konflikt, also keine Handlung in ihrem eigentlichen Sinne möglich ist, ist dies der Dauerzustand der modemen Welt. Zu diesem Weltzustand gehört der Verlust an einem Schicksalsglauben, an Weltobjektivität als dessen Bestandteil. Die Desillusionierung ist in der Tat der erzählten Geschichte vorausgesetzt, indem sich die gleiche Konstellation zwischen Schmidt, Jenny und Treibel bereits in ihren früheren Jahren abgespielt hat. Die vergangene Geschichte von Schmidt und Jenny spielt nämlich als „Präzedenzfall für das Kommende“ 99 in die Verlobungsgeschichte Corinnas hinein. Anders als der traditionelle deutsche

97 A. Poltermann, G enreszene, S. 95.

$98 \mathrm{H}$. Schlaffer versucht die fortschreitende Auflösung des mythischen deterministischen Weltmodells und damit der Handlung bei Fontane zu zeigen. Nicht zwischen den frühen Schicksalsnovellen und den späteren Gesellschaftsromanen soll, wie üblich angenommen, der Einschnitt in Fontanes epischem Werk liegen, weil, so H. Schlaffer: „hinter dem Wechsel in der Materie [...] die ideelle und formale Struktur weiter[lebe]. Die eigentliche Wandlung erfolgt erst später, in den Poggenpuhls und im Stechlin, ihre Anzeichen sind im Gesellschaftsroman nur als Negation des Prinzips spürbar, das an seiner Grenze auch seine Beschränktheit verrät." (ders., Schick salsmodell, S. 401). Der Endpunkt dieser Entwicklung, "die wirkliche neue Welt des Alterswerks [der Stechlin; J. -H. B.]”, drückt sich in „Handlungs- und Ziellosigkeit, Leben, Breite, Schicksalslosigkeit“ (S. 409) aus: Elemente, die in Frau Jenny Treibel auch bereits vorhanden sind.

99 G. Wedereit, „Frau Jenny T reibel“, S. 118. 
Roman, der mit der D esillusionierung des Subjektes endet, fängt Fontanes Roman mitten in der Geschichte an, die dann die weitere Geschichte ,danach' erzählt, wobei die Geschichte ,davor' für das Kommende als Spiegel dient.

Mußte der alte Roman mit der desillusionierenden Lebenserfahrung enden, da das innere Leben der Figuren nicht anders möglich ist als in Resignation, muß eine G eschichte, die jene Erfahrung als bereits Gegebenes strukturell vorausschickt, der Resignation ihren Status als letztes Wort bestreiten wollen. Solch eine G eschichte mußte wohl über das übliche Ende der Entsagung hinausgehen wollen. Weit entfernt davon, sich der Resignation preiszugeben, lebt Schmidt weiter, und zwar heiter und offen trotz des Vorangegangenen. Die Vorgeschichte mit Jenny nimmt bei Schmidt den Stellenwert einer bereits erreichten intellektuellen Wirklichkeitserkenntnis ein. Sie erschöpft sich also nicht in einer reinen Herzensangelegenheit. Seine Selbstrettung aus der gescheiterten Liebesgeschichte gründet so gesehen auf der Menschen- und Wirklichkeitserkenntnis eines Soziologen, ja, wenn man so will, eines Romanciers, der die soziale Bedingtheit der menschlichen Existenz hervorhebt. Die Erfahrung der D esillusionierung, die im Fall Schmidt durch die (An-)erkennung des weiteren Kontextes und der Kontingenz des persönlichen Seins erfolgt, befreit ihn zum großen Teil von seiner persönlichen Betroffenheit. Die geschichtlichgesellschaftliche Absenz des Sinnes ist die allgemeine Situation, also die Ausgangssituation, die Schmidts Ironie immer wieder anspricht. Im Bewußtsein der herrschenden Macht dieser Wirklichkeit sagt Schmidt den Verlauf und Ausgang der Verlobungshandlung voraus. Er weiß um die hauptsächlich nicht-personelle Dimension der Verlobungsgeschichte, nicht-personell deswegen, weil in dieser Geschichte eine Figur - also Jenny - in einer großen Selbstvergessenheit die fixierte empirische Macht des ökonomischen Denkens vertritt und sich damit durchsetzt. So spricht Schmidt, bezüglich des voraussehbaren Sieges von Jenny in der Verlobungsgeschichte, von „einer ruhigen historischen Entwicklung“ (S. 448). Jennys Wille stellt eine überpersönliche Dignität und eine eigenständige historische Entwicklung dar. Es wird in ihm eine geschichtliche Situation manifest, in der man von der Vorstellung der Freiheit als einer absoluten Z wanglosigkeit weit entfernt ist; der Akzent bei dem Begriff der Freiheit verschiebt sich; die Grenze zwischen dem zu Befreienden und dessen Fesseln ist fließend geworden, und die Frage nach einem erfültten Dasein wird mehr rhetorisch als inhaltlich verstanden. Die Freiheit hat bereits etwas von der Kraft ihres pathetisch-emanzipatorischen $G$ estus verloren. Für die Kunst bedeutet dies alles eine ethische Frage: Inwiefern können literarische Figuren unter den prägenden Einflüssen ihrer soziohistorischen Bedingungen frei handeln? Worin liegt die Chance für das Individuum, das - nach dem wissenschaftlichen Menschenverständnis der Zeit - ein psychisch restlos fremdbestimmtes Wesen ist, trotz allem frei zu handeln? Fontane zieht seine Konsequenzen aus dieser Einsicht, wenn er die feste Kategorie von Handlung und Charakter auflöst und teilweise neu gestaltet.

\section{Simultaneität und 0 ffenheit zur $V$ ergangenheit}

Die ,klassische' G estalteinheit eines Romans beruht oft auf einer Wechselwirkung von Raum und Zeit. Diese verleiht nämlich dem Dargestellten den Schein einer natürlichen Ordnung, eines organischen G ewachsenseins. Mit der szenischen theatralischen Bauweise wird in F rau Jenny Treibel dem Raum die Bedeutung des dominierenden 0 rdnungsprinzips beigemessen. ${ }^{100} \mathrm{Die}$ klassische Wechselwirkung, die eine natürliche Formschönheit erzeugt, wird hier aber eigentlich zerstört.101 Als vorherrschende Form der Zeiterfahrung sind, in der D ominanz des Raums, die Simultanität der Begebenheiten und die extreme Kürze der Zeiterstreckung des gesamten Ereignisses festzustellen. Die G eschichte fängt mit Jennys Besuch bei Schmidt an einem der letzten Maitage an, endet mit Corinnas Hochzeit am 28. Juli. Häufig werden verschiedene, gleichzeitig ablaufende Vorgänge von einem den Standort wechselnden Erzähler zusammengefaßt. ,Natürlich` wirkt dieses erzählerische Verfahren nicht, das im Nacheinander, im Fortschreiten der Zeit, das Simultane vermittelt.

Was den natürlichen Schein angeht, ist er nur insofern vorhanden, als im großen und ganzen die natürlich-chronologische Aufeinanderfolge gewahrt wird. Praktisch verliert die O rdnung des Lokals selbst an höherer Bedeutung als ,Symbol der Weltordnung'. Die O rdnung des Lokals ist in diesem Fall auf die häusliche Ordnung der Familie reduziert. Zudem stellt sie sich jetzt mehr als ,Symbol der Menschenordnung'102 dar, die alles andere als eine von den Figuren unabhängige, unveränderbar bestehende Welt bzw. Weltordnung ist. Schon der Romananfang kündigt an, wie sehr man es in diesem Roman mit der Menschenordnung zu tun haben wird. Der Roman beginnt mit einem auktorialen Erzählerbericht über die Ansicht des Schmidtschen Hauses. Die realistische Erzählhaltung, die den G egenstand um jeden Preis ,realitätsnah' zu beschreiben sucht, wird bei dem Erzähler am Ende mehr ironisch zitiert als authentisch erzeugt, denn die genannten deskriptiven Details widersetzen sich aufgrund ihrer Heterogenität einem abschließenden ästhetischen Gesamturteil: Über Schmidts Besitz heißt es, es sei ein „trotz seiner Front von nur fünf Fenstern, ziemlich ansehnliche[s], im übrigen altmodische[s] Haus[], dem ein neuer, gelbbrauner Ö lfarbenanstrich wohl etwas mehr Sauberkeit, aber keine Spur von gesteigerter Schönheit gegeben hatte, beinahe das G egenteil"

100 W. Kayser (ders., D ie A nfänge des modernen Romans, S. 434f.) unterscheidet zwischen drei Hauptformen des modernen Romans seit dem 18. Jahrhundert, je nachdem, durch welche strukturtragende Schicht der einzelne Roman seine Geschlossenheit gewinnt, sei es durch Handlung, den Raum (d.h. eine Vielzahl von Räumlichkeiten) oder eine Figur: Er bezeichnet sie jeweils als Handlungsroman, Raumroman und Figurenroman.

$101 \mathrm{Da}$ in jeder der von Kayser genannten drei Romanformen eine nur unterschiedlich akzentuierte Wechselwirkung von Handlung, Raum und Figur vorausgesetzt wird, kann hier bei der räumlichen Akzentuiertheit in Frau Jenny Treibel von einem „Raumroman“ im Sinne Kaysers nicht die Rede sein. Wie die ,Verselbständigung des Raums' bei Fontane eine andere neue Möglichkeit des Romans als die klassische Romanform bedeuten kann, versucht H. Turk anhand des Alterswerks Stechlin zu zeigen. (D ers., Realismus in F ontanes G esellschaftsroman.)

102 „Menschenordnung...nicht die Weltordnung, von der wir gar nichts wissen“. (Fontane an seine Tochter Martha, am 24.8.1893, in: ders., W erke, Schriften und Briefe. Hrsg. v. W. Keitel / H. Nürnberger. A bt. IV : Briefe. 4. Bd. 1890-1898 (1982), S. 283.) 
(S. 297). Die Beschreibung wirkt eher wie ein ,Stilexperiment', als daß sie ein eindeutiges, klares und rundes Gesamtbild von dem G eschilderten vermitteln würde. ${ }^{103}$ D er Erzähler scheint mit den unterschiedlichen G esichtspunkten unentschieden umzugehen, anstatt die Eigenart des Hauses als ,An-sich-Seiendes' heraustreten lassen zu können. Hier wird nicht der mythische Status der ewigen, unantastbaren Naturordnung angestrebt, sondern die verschiedenen, sich relativierenden Gesichtspunkte wie ,altmodisch', ,ansehnlich', ,Sauberkeit' und ,Schönheit' signalisieren die Kontingenz der Menschenordnung, der menschlichen Existenz selbst.

Neben dem erwähnten Primat des Räumlichen als O rdungssymbol gegenüber der Z eit läßt sich ein weiteres Moment des Verhältnisses zwischen Raum und Zeit in dem Roman feststellen: D em gewollt realistischen Anfang widersprechend ist die zeitliche $\mathrm{O}$ ffenheit zur Vergangenheit hin. Zeit, nach dem Vorstellungsmuster der Zeit, wie es auch der realistischen Zeitgestaltung zugrunde liegt, erscheint wie ein Fließen. Etwas zieht vorbei, kommt von irgendwoher, aber nie zurück, und verschwindet irgendwohin, und zwar in einer Bewegung, deren Richtung irreversibel ist. Anstatt im Sinne eines solchen Zeitverständnisses den Ablauf geradlinig und teleologisch zu gestalten, setzt der Roman, um die Skizzierung einer traditionell sinnhaften Ausgangskonstellation unbekümmert, scheinbar wahllos mitten in einer Geschichte ein. So wird die Vorstellung von einem Anfang aufgegeben, welcher die Sinnhaftigkeit und die Notwendigkeit des folgenden G eschehens motivieren könnte.

Anstatt die Einmaligkeit und Einzigartigkeit der zu erzählenden Geschichte und damit den Sinn des Erzählens zu behaupten, zeigt der Roman das Durchschnittliche, das Nicht-Besondere der erzählten Geschichte. Dabei ist die Wiederholung die Wiederkehr des Gleichen - die Wirklichkeit: Was mit der Jugendliebe zwischen den Eltern war, fungiert als ,Präzedenzfall für das Kommende' bei ihren Kindern. Sowenig der Erzähler schon beim Romaneingang seine persönliche und unverwechselbare Stimme hören läßt, sich eher stets zwischen Diskursen schwankend zeigt, sowenig ist seine Erzählung selbst die Geschichte eines persönlichen und individuellen Lebens. Die für den Roman spezifische Verschränkung von Erzählerschaft und Geschichte, die darin besteht, daß das Erzählen durch einen persönlichen Erzähler und die Einbeziehung des persönlichen Lebens sowie die Begrenzung des Erzählens auf ein individuelles Leben und eine persönliche Geschichte innerlichst zusammengehören, ${ }^{104}$ bestätigt sich hier in negativer Form.

\section{Die Form der kontingenten Welt der Modeme}

\section{D er Romanschluß und der W irk lichk eitsbegriff im W andel}

Symptomatisch und symbolisch für seinen romanpoetologischen Anti-O rganismus endet der Roman mit einer Szene, die das bisher G ültige auf einmal in Frage stellen will. Nachdem Jenny den Festsaal bei der Hochzeit von Corinna und Marcell verlassen hat, bittet der Gastgeber Schmidt Krola, den Sänger und Millionär, Jenny Treibels Lieblingslied zu singen. Auf den Vortrag des Künstlers Krola hin macht der anscheinend betrunkene Schmidt ein recht rätselhaftes Eingeständnis. Jetzt plötzlich entdeckt Schmidt das Gedicht als "wirkliches Lied“ (S. 477), und es rührt ihn zu Tränen. Indem Schmidt seiner Freundin Recht gibt, ja kurzerhand die behauptete G egensätzlichkeit zwischen ihm und ihr zurücknimmt, zerbricht die Bezogenheit und Beziehbarkeit der perspektivischen Aspekte aufeinander abrupt. Dem gesamten Sinngefüge wird somit der feste Boden entzogen.

Diese der Sinneinheit drohende G efahr wird übersehen, wenn man sich auf Fontane selbst, ja auf seine ,Versöhnungsästhetik' beruft. So verweist H. Reinhardt, von der klassischen Schönheitskonzeption Fontanes ausgehend, auf die „unglückliche Gewichtung" des Romans, die durch die pointierte Sentimentalisierung und die kompositorisch allzu akzentuierte bildungsbürgerliche Satire entstanden sei. Diesen Strukturmangel versuche Fontane, nach Reinhardt, „ein wenig zurechtzurücken“, indem „er seinen Schmidt am Ende in jener derangierten, sentimental eingefärbten Verfassung [präsentiere], die dem Leser Rätsel" ${ }^{105}$ aufgebe. Für ihn liegt der Sinn der Schlußpartie lediglich in der nachträglichen Ausbalancierung der Figurenperspektiven zugunsten der angeblich dem Kunstsinn Fontanes entsprechenden „Unbestimmtheit für den Erzählzusammenhang“. Sie bedeute daher nur eine Art Gag, eine Irritation des Lesers und ein „Rätsel“, damit „eine der Romanform nicht günstige Offenkundigkeit" 106 vermieden werde. D emgegenüber operiert H. Aust mit dem inhaltlich bzw. gehaltlich erfüllten ,Versöhnungsbegriff'. Wenn die Versöhnung innerhalb der Handlung mit dem Hochzeitsfest stattfindet, dann scheint sie sich symbolisch als spontane Übernahme des Treibelschen Rituals zu vollziehen, welches mit Jennys Lied das Fest beschließt. Diese Versöhnung bediene sich jedoch einer besonderen Verfahrensweise des übernommenen Rituals, die darin bestehe, „das Herzenslied“ Jennys in gewissem Sinne „zu profanieren“. Nach Austs Argument bedeutet Schmidts Profanierung des Liedes, daß er dem von Jenny mißverstandenen Lied durch doppelte Verneinung den ursprünglichen positiven Sinn der poetischen Gegenwelt zurückgebe. Schmidts Profanierung sei eine Rettungsaktion für den durch Jenny ehemals profanierten Wahrheitswert des Liedes, und die Neuentdeckung dieses Liedes bedeute dadurch den endgültigen Triumph der wahren Poesie. Für Aust handelt es sich hier dann um eine standesgemäß typisierte Verhaltensform der Kunstrezeption, die damit eine andere Wirkungs-

103 Vgl. A. Poltermann, „F rau Jenny Treibel“, S. $138 f$.

104 Vgl. W. Kayser, D ie A nfänge des modernen Romans, S. 435.

105 H. Reinhardt, W ahrheit, S. 321.

106 Ebd., S. 321. 
möglichkeit der Kunst als bei Jenny bedeutet. Die mit Schmidt präsentierte wahre Wirkungsmöglichkeit der Kunst ist nach Aust, der sich bei diesem Kunstverständnis auf Fontane beruft, eine Loslösung vom Ich, eine Selbstbefreiung. Während bei der Bourgeoisie das Poetische als verlogene, egoistische, selbstgenüßliche Sentimentalität gebraucht wird, werde das in dem Bildungsbewußtsein potentiell bewahrte richtige Verhältnis zur Kunst durch Schmidt verwirklicht. So legt Aust den letzten Monolog Schmidts als eine neue E inschätzung seiner selbst und seiner Umwelt aus:

Für mich persönlich steht es fest, Natur ist Sittlichkeit und überhaupt die Hauptsache. Geld ist Unsinn, Wissenschaft ist Unsinn, alles ist Unsinn. Professor auch. Wer es bestreitet, ist ein pecus. Nicht wahr, Kuh...Kommen Sie, meine Herren, komm, Krola...Wir wollen nach Hause gehen. (S. 477f.)

Im Gegensatz zu den oben skizzierten Interpretationen spreche ich der letzten Szene jegliche Gültigkeit einer solchen Sinn-, Welt- und Textdeutung ab, die von einem organisch Ineinandergefügten ausgeht bzw. dies simuliert. Es handelt sich hier gerade um die inszenierte oder performative Ad-absurdum-Führung einer solchen Sinnerwartung. Signalisiert wird damit die Unterbrechung, ja die plötzliche Veränderung des Wirklichkeitserlebnisses, der Schmidt unter dem Eindruck des Liedes erliegt. Seine Begeisterung ist von der Art, daß er das Lied erlebt, und weil dieses Erlebnis ein Wirklichkeitserlebnis ist, nennt er es ein ,wirkliches Lied'. Für Schmidt eröffnet das G edicht eine spontane und intuitive Einsicht, die als ein ,wirkliches' zwar fühlbar, aber nicht rational faßbar wird, zumal sie sich seinen subjektiven Auffassungen, die im Verlauf des Romans entwickelt worden sind, strikt widersetzt. Dieses Moment legt das nahe, was von Blumenberg als Erfahrung der „Realität als das dem Subjekt nicht Gefügige" bezeichnet wird.

Für Schmidts Bewußtsein bis zu diesem Moment ist das dominierend gewesen, was von Blumenberg als Wirklichkeitsbegriff „eines in sich einstimmigen Kontextes“ bezeichnet und als für den modernen Roman konstitutiv erklärt wird. Dieses nimmt „Realität als Resultat einer Realisierung, als sukzessiv sich konstituierende Verläßlichkeit, als niemals endgültig und absolut zugestandene Konsistenz, die immer noch auf jede Zukunft angewiesen ist, in der Elemente auftreten können, die die bisherige Konsistenz zersprengen und das bis dahin als wirklich Anerkannte in die Irrealität verweisen könnten. ${ }^{107}$ Es ist der Perspektivismus, nämlich die Konkurrenz bzw. Intersubjektivität, in der jede kontextuell realisierte Wirklichkeit mit den möglichen anderen Wirklichkeiten steht. Jede Wirklichkeit hat den Stellenwert „einer perspektivischen Position, eines topologisch zuordnungsfähigen Aspektes von Realität", weswegen für diesen Wirklichkeitsbegriff "die Verbindung des Possessivpronomens mit dem Ausdruck Wirklichkeit" "charakteristisch“108 ist. So korrespondiert diese Realität „mit dem demiurgischen Vermögen möglichkeitsgesättigter Subjektivität“. ${ }^{109}$ Es ist als Wirklichkeit des Möglichen die Wirklichkeit des Romanciers, deren Dignität als Wirklichkeit nicht mehr auf „eine[r] den gegebenen Dingen gleichsam anhaftende[n] Qualität“ beruhen kann, sondern die „des einstimmigen Sichdurchhaltens einer Syntax von E lementen “110 bedarf. Wie schon einmal erwähnt, ist Schmidts Wirklichkeitsbegriff mit dem des Romanautors verwandt, welcher über die avancierte Menschenkenntnis der Zeit verfügt bzw. diese anstrebt. Schmidts Realität weist sich aus als eine in sich einstimmige Kontextualität, die besonders mit jener Art von Wissen korrespondiert, die die Menschheit seit dem vom Empirismus begeisterten vergangenen Jahrhundert über sich selbst als gesellschaftliches, geschichtliches Wesen erreicht hat. Repräsentativ für den den modernen Roman fundierenden Wirklichkeitsbegriff der immanenten Konsistenz ist Schmidts Position nicht nur hinsichtlich dieses Punktes. Was bei Schmidt als Ironie hervortritt, hängt mit der Problematik des modernen Romans zusammen, daß er nämlich als ein in sich endlicher Text auf die Unendlichkeit als Voraussetzung für die eigene Realisierung zu verweisen hat.

Es ist das „Dilemma, als endlicher Text die Vorstellung eines unendlichen Kontextes zu evozieren“,111 das der Roman als Formganzes immer wieder thematisiert hat und noch thematisiert, und zwar darauf hinauslaufend, daß gerade dadurch der Roman sich, entgegen der ihn seit seinem Aufstieg begleitenden Prophezeiung seiner Krise, weiterentwickelt hat. D as künstlerische $\mathrm{G}$ elingen des modernen Romans scheint davon abhängig zu sein, wie man mit diesem ihm wesenseigenen Widerspruch umgeht, ja ihn als zwingendes Moment zur neuen dichterischen Formung ausschöpft.

Die Spannung zwischen der imaginären Kontextrealität und dem Wirklichkeitscharakter der gegebenen und unerreichbaren Welt wird von der Ironie eingefangen, indem „Ironie zur authentischen Reflexionsweise des ästhetischen Anspruchs im modemen Roman geworden“ ist, „und zwar so, daß dieser gerade in seinem Realitätsbezug ironisch wird, den er weder aufgeben noch einlösen kann." 112

Bekanntlich hat Th. Mann die Ironie als Prinzip seiner Erzählkunst herausgestellt. Die Schein-Genauigkeit der epischen Sprache, die sich der wissenschaftlichen Schreibweise bedient, ist "pure Ironie“, „denn [sie ist] das Wissenschaftliche, angewandt auf das ganz Unwissenschaftliche und Märchenhafte". ${ }^{113}$

Schmidts Ironie, die in seinem bewußten Rollenspiel zum Ausdruck kommt, korrespondiert mit der Ironie des Romanciers. Wie ein Romancier, wie Th. Mann, der sich zwar des Schein- und Spielcharakters des Romanschreibens voll bewußt ist, jedoch den Illusionscharakter des Kunstwerkes noch bewahrt, bewahrt Schmidt, indem er seine Rolle theatralisch aufführt, den Rahmen der gesellschaftlichen Verhaltens- und Seinsform, ja des Lebens, außerhalb dessen er zugleich steht. In der Tat

107 H. Blumenberg, W irklichk eitsbegriff, S. 12f.

108 Ebd., S. 13.

109 M. Makropoulos, Konstellation und Synthese. Kracauer, L azarsfeld und die Konstruktion soziologischer W irklichk eit um 1930, in: Jahrbuch fur Soziologiegeschichte 1992, O pladen 1994, S. 147-159, hier S. 147.

110 H. Blumenberg, W irk lichk eitsbegriff, S. 21.

111 Ebd., S. 22.

112 Ebd., S. 25.

113 Th. Mann, Joseph und seine Brüder. E in V ortrag, in: ders., G esammelte W erke. 12 Bde. Oldenburg 1960. Bd X I. Reden und A ufsätze 3. S. 656. 
nähert sich Schmidts Position der der Mannschen Ironie, bei der man von einer doppelten Funktion sprechen kann: „Sie verwandelt das ins Werk eingewanderte Wirkliche in Fiktion und bewahrt damit den Kunstcharakter des Romans. Andererseits entlarvt sie aber auch die Fiktion des Wirklichen als Fiktion und hebt sie damit auf."

Jedoch anders als bei Th. Mann bleibt bei der Schmidtschen Ironie diese Balance nicht bis zum letzten erhalten. Die zwei Momente der Ironie, die einander die Waage halten, um innerhalb des traditionellen Illusionismus das Realitätsbewußtsein in Frage zu stellen, geraten auf einmal in ein Mißverhältnis, so daß das bis dahin aufgebaute ästhetische Gebilde des Romans zersprengt wird. Es ist die von mir bereits akzentuierte Schlußpartie, in der Schmidt aus seiner ausgewogenen D istanziertheit herausfällt. D adurch wird die Realität als Kontextualität, die sich reflexiv absichert, indem sie in ihrem Realitätsbezug ironisch wird, endgültig preisgegeben. Hier tritt gerade der Blumenbergsche vierte Wirklichkeitsbegriff auf, der „das Wirklichkeitsbewußtsein vom Denken trennt und in die Sphäre der unverfügbaren Erfahrungen des Subjekts mit sich selbst verlegt." 115 Im Zeichen dieses vom Denken getrennten Wirklichkeitsbewußtseins erfährt Schmidt mit sich selbst etwas ihm Unbekanntes, welches er von sich selbst am wenigsten erwartet hätte. Er weint über das von ihm selbst geschriebene und die ganze Z eit über verleugnete Gedicht. Die Ironie als die höhere - weil selbstreflexive - Form jenes Wirklichkeitsbegriffs des Kontextes stellt sich ein, und zwar anhand der von ihm bisher ironisch verzerrten Wirklichkeit bzw. Wahrheit des Gedichtes. Bei Schmidt ist die Preisgabe der Realität als Kontext an die Realität des dem Subjekt nicht G efügigen nicht unmittelbar mit Widerstand in einem eigentlichen, aktiven Sinn verbunden. Sie ereignet sich nicht dramatisch, d.h. sie wird nicht direkt von äußeren G eschehnissen veranlaßst. O hne über unerwartete Umstände zu stolpern oder gar daran zu scheitern, gleitet Schmidt auf einmal in die unverfügbare Wirklichkeit ab. Deren intellektueller Charakter, der darin besteht, daß sie ausschließlich in Form eines inneren Ereignisses motiviert und vollzogen wird, macht Schmidts Erfahrung des sich am Widerstand konstituierenden Wirklichkeitsbegriffs aus. So sehr dies eine erschütternde Selbsterfahrung bedeuten mag, entspringt dieser Umschlag in die widerstehende Wirklichkeit doch dem Effekt, der die Wirklichkeit als Kontext herbeiführt. Denn insofern einstimmige Kontextualität nur in Abgrenzung zu anderen Kontexten zu haben ist, konkurriert jede kontextuell realisierte Wirklichkeit mit möglichen anderen Wirklichkeiten. Daher ist es nicht abwegig, in der dem Subjekt widerstehenden, ganz und gar unverfügbaren Wirklichkeit einen Effekt der Realisierung einstimmiger Kontexte zu sehen.116

Aufgrund des bisher Gesagten ist Jennys Lied als Ort und zugleich als Spur der Erfahrung der Widerstand leistenden Wirklichkeit zu betrachten. G emäß der sich verändernden Sinn- und Wirklichkeitsvorstellung wandelt sich das Lied in seinem Zeichencharakter, ja in seiner Funktion.

Jennys Lied hat bis zu dem Moment des überraschenden Sich-Bekennens Schmidts zu selbigem für die Romanwelt den Status eines Symbols: Für Jenny ist das G edicht Symbol des Poetischen, Garant für die Sinnhaftigkeit der Welt. Schmidts Abwendung von dem Lied richtet sich gegen das von dem G edicht symbolisierte Poetische, das vermeintlich über der sinndefizitären Wirklichkeit steht. Sie richtet sich jedoch nicht gegen den Symbol-Status des Gedichtes an sich. Schmidts Abwertung des Liedes setzt gerade voraus, daß er die gleiche Art der Übereinstimmung von Zeichen und Bezeichnetem bei dem Lied annimmt wie auch Jenny. Die sich widersprechenden Standpunkte zwischen Schmidt und Jenny, die besonders in ihrem unterschiedlichen Verhältnis zu dem Lied deutlich werden sollen, teilen insofern eine gemeinsame Sprache, nämlich dasselbe Zeichensystem; ein Umstand, der ihre G egensätzlichkeit als nur partielle und passive Negation des jeweils anderen Standpunktes entlarvt.

Das Symbol hängt mit dem Begriff der Wirklichkeit als Kontext eng zusammen: Unter dem Eindruck der KontextWirklichkeit entwickelt sich die Romanform der linearen Konsistenz in einem Raum-Zeit-System. ${ }^{117}$ D as Symbol sorgt für die O bjektivität und die Notwendigkeit der Weltordnung, wie sie sich textuell realisiert. Es erfüllt die Aufgabe, die material nicht erfahrbare Sinnhaftigkeit der Romanwelt, ja deren Notwendigkeit als So-Seiende dem Roman immanent zu machen.

Es ist einleuchtend, daß dort, wo der Wirklichkeitsbegriff der Konsistenz als brüchig erscheint, auch die Funktionsbasis des Symbols unterhöhlt wird. Schmidts E rfahrung der Widerstand leistenden Wirklichkeit verlangt deswegen seine Neuentdeckung des Liedes, die nichts anderes als eine Sprengung bzw. Zersprengung des Symbolcharakters des Liedes ist. Somit wandelt sich der Status von Jennys Lied vom Symbol zu etwas, in dem die Unmöglichkeit der Seinsweise des Liedes als Symbol vorgeführt wird.

Die Besonderheit dieses nun mit Vorbehalt - weil nur bis zu einem gewissen Zeitpunkt der Lektüre gültigen - als Symbol zu bezeichnenden Liedes besteht darin, die Unmöglichkeit, an einem So-Sein (im Verhältnis von Zeichen und Bezeichnetem) festzuhalten. Jennys Lied will und kann nicht mehr das sein, was es bisher war, nämlich das Symbol einer Weltordnung, sei es als Weltordnung im Sinne des heuchlerischen Glaubens (Jenny) oder im Sinne der ironischen Kritik und des Zweifels an der Wahrheit dieses G eglaubten (Schmidt). Preisgegeben wird durch Schmidts Neuentdeckung jenes Korrespondenzverhältnis, in dem das Lied - für Jenny als etwas „von Gott" und für Schmidt als "Jugendsünde“ - eine unabdingbare semantische 0 pposition ihrer Welten garantierte.

114 W. Emrich, D ie E rzählk unst des 20. Jahrhunderts und ihr geschichtlicher Sinn, in: ders., Protest und V erheißung. Frankfurt/ M.; Bonn 1960, S. 176-192, hier S. $178 \mathrm{f}$.

115 H. Blumenberg, W irklichk eitsbegriff, S. 14.

116 Vgl. M. Makropoulos, Konstellation, S. 148. Für Blumenberg ist der Zusammenhang zwischen der Kontext-Wirklichkeit und der WiderstandWirklichkeit lose. D och immerhin spricht er davon, daß „der Wirklichkeitsbegriff des intersubjektiven Kontextes hinüberführen kann in einen Wirklichkeitsbegriff der erfahrenen Widerständigkeit des G egebenen“. (H. Blumenberg, W irk lichk eitsbegriff, S. 24)

117 Vgl. H. Blumenberg, W irk lichk eitsbegriff, S. 23. 
Schmidts Konzession an Jennys Lied ist schließlich nichts anderes als eine begründete und damit bewußte „D urchbrechung der formalen Konsistenz, eine Durchbrechung“, die nicht „in einem Versagen oder einem Sicherschöpfen der produktiven Potenz gründet, sondern im G egenteil als Äußerung einer Anstrengung gefaßt sein will, die sich die bewußte Mißachtung des immer noch als quasi-objektiv empfundenen Prinzips der formalen Konsistenz leisten kann.."118

Als vollends, ja kategorisch überwunden erachtet werden kann das alte, von Jenny besungene Wirklichkeitsverständnis erst in dem Moment, wo ihr Gegner nicht einmal mehr die Gegenposition zu Jenny mittels seiner Ironie in Anspruch nimmt, sondern bewußt die Enge der Antithese und die Spielregeln dieser Wirklichkeit überhaupt durchbricht.119

D araus kann man schließen, daß das plötzliche Aufgeben seiner Gegnerschaft die Form einer aktiven Negation darstellt, die aber eine passive Negation nicht ausschließen muß.

O hne die grundsätzliche Infragestellung der symbolischen Weltdeutung durch Schmidt als Textereignis zu erkennen, sucht die Forschung vergebens, aus ihr eine organische symbolische Welt- und Sinneinheit abzuleiten. Wenn Jennys Lied aufhört, Symbol zu sein, heißt dies nicht nur, daß es nicht mehr das Sinngefüge zu repräsentieren hat, sondern auch, daß es dadurch in der Lage ist, gerade jenen Zusammenhang des Sinns radikal aufzustören. Diese performative Ambivalenz zielt letztendlich auf eine Entblößung des artifiziellen Charakters jeden Sinns. Sobald Schmidt, der gerade mit seiner Kritik der Kronzeuge für den unleugbaren Symbolcharakter des Liedes für bestimmte Weltauffassungen war, seinen Standpunkt anzweifelt, verblaßt die Macht des Liedes als Symbol. Mit der Macht des Symbols wird der Macht des Schicksals ein Ende bereitet, denn das Weiterleben symbolischer Bezüge wird erst durch das Weiterleben der Schicksalsmacht möglich, deren verschleierte, aber wirksame Existenz die 0 mina, die Verknüpfungen und Verweise bestätigen. ${ }^{120}$ Die inszenierte Nähe Schmidts zu Jenny ist, so kann man resümieren, die „Technik theatralischer Überführung des vermeintlich zeitlos Idealen und innerlich Notwendigen in geschichtlich kontingente Sinnsetzung".121

\section{A mbivalenz der Kontingenz}

Ich habe bereits den programmatischen Charakter der Kontingenz im Roman hervorgehoben. Von Kontingenz wurde einerseits bei Corinna gesprochen, und zwar als mehr oder weniger reflektiertem Seinsgefühl. Andererseits wurde Kontingenz im künstlerischen Formbewußtsein, negativ ausgedrückt: im absichtlichen Abweichen von traditionellen organistischen Gestaltungsmitteln, gesehen.

Mit der Feststellung, daß es in der Schlußpartie des Romans eigentlich um nichts anderes als um die geistige Bewegung vom Weltverständnis der Sinnhaftigkeit hin zu dem der Kontingenz geht, bietet sich nun eine Möglichkeit, Schmidts Monolog unter dem spezifischen Aspekt der Kontingenz zu verstehen. Seinem Z ugeständnis an das gesungene Lied fügt Schmidt etwas hinzu, was man als Beteuerung seiner unverhofften Begeisterung verstehen könnte: „Ich hätte doch am Ende dabei bleiben sollen..." (S. 477)

Vor dem Hintergrund der Kontingenz-Erfahrung, der Begegnung mit dem kategorisch neuen Wirklichkeitsbegriff betrachtet, läßt sich diese Aussage leicht aufwerten als Indiz für eben diese Erfahrung. Um dies klarer herauszustellen, verweise ich auf die Art des Selbstverständnisses wie auch des Weltverständnisses von Schmidt, das bereits einmal mit der Perspektive eines gesellschaftlich und geschichtlich orientierten Romanciers verglichen wurde. Es ist dem distanzierend objektivierenden und empirisch begründenden D enkprinzip unterworfen, bei dem die Wirklichkeit immer mit der Vorstellung der ,Notwendigkeit' verbunden ist. Das unaufhaltbar sich aufdrängende aktuelle Seinsgefühl legt aber nahe, daß er doch anders hätte leben sollen, d.h. auch, daß er anders hätte leben können. Nicht zufällig taucht hier der Konjunktiv auf, eben der Modus des Möglichen. Der ,Konjunkiv-G edanke', die Idee des Anders-Sein-Könnens, beschränkt sich schließlich nicht auf die Vergangenheit, was dem das Leben selbst und die Wirklichkeit überhaupt als solche umfassenden Erfahrungscharakter der Kontingenz entsprechend ist. Er setzt sich fort und gelangt zur unmittelbaren Gegenwart, der Geschichte Corinnas.

Im G egensatz zu seiner sonstigen Sichtweise, nach der Corinnas Heiratsgeschichte einen notwendigen und daher voraussehbaren Ausgang hat und insofern weder ,Scheitern' noch Resignation noch eine Liebestragödie bedeutet, verleiht Schmidt plötzlich der ganzen $\mathrm{G}$ eschichte einen quasi tragischen Charakter :

(...) die arme Corinna! Jetzt ist sie bei Trebbin, erste E tappe zu Julias G rab...Julia Capulet, wie das klingt. Es soll übrigens eine ägyptische Sargkiste sein, was eigentlich noch interessanter ist... (S. 477)

In einer disponibel gewordenen Welt ist Corinnas Heirat mit Marcell nicht notwendig, so wie ihre Heirat mit Leopold nicht unmöglich ist. Daß es aber in dieser kontingenten, ontologisch unterdeterminierten Welt etwas gibt, das sich so absolut und unbedingt durchsetzt wie Jennys Wirklichkeitssinn, resultiert in einer ambivalenten Wirklichkeitserfahrung, die im Vergleich Corinnas mit Julia zum Tragen kommt. Diese Perspektive läßt sich weiter führen, wenn Schmidt sinniert:

[...] ich weiß nicht, ob es recht ist, die Nacht so durchzufahren; früher war das nicht Brauch, früher war man natürlicher, ich möchte sagen sittlicher. [...] Für mich persönlich steht es fest, Natur ist Sittlichkeit und überhaupt die Hauptsache. (S. 477)

Die Kontingenzfrage dehnt sich hier aus auf ihre allgemeine und primäre Dimension als Effekt des Zivilisationsprozes-

118 Ebd., S. 26.

119 Vgl. ebd., S. 26.

120 V gl. H. Schlaffer, Schidk salsmodell, S. 398.

121 A. Poltermann, „F rau Jenny Treibel“, S. 141. 
ses, und zwar im Sinne einer Erweiterung des Bereiches des Menschenmöglichen und einer Verringerung des Bereichs des Naturnotwendigen.

In einer auf diese Weise verallgemeinerten Bedeutung nähert sich die Kontingenz dem existentialistischen Lebensgefühl, d.h. dem gleichsam seinsmäßigen Schwebezustand des Wirklichen, der als Abwesenheit aller Notwendigkeit und aller substantiellen Fundierung des Wirklichen erfahren wird. ${ }^{122}$

In diesem Sinn ist die manchmal als nihilistisch gelesene Schlußmeditation Schmidts eher existentialistisch zu verstehen: „G eld ist Unsinn, Wissenschaft ist Unsinn, alles ist Unsinn. Professor auch. Wer es bestreitet, ist ein pecus“. (S. 477f.).

Schmidt gebraucht hier das Wort ,Unsinn' in einer anderen Perspektivierung als er es einmal bezüglich Corinnas Heiratsplan benutzt hat. Er nannte den Heiratsplan ,Unsinn', weil er seinem Interesse an einer Endogamie mit Marcell nicht entsprach, ein Interesse, das sich unschwer als Einsicht in die objektive Wirklichkeit ausgeben konnte. In Unsinn verkehrt sich aber jetzt, inmitten der augenblicklich eindringenden Erfahrung der Wirklichkeit als das dem Subjekt Unverfügbare, alles, was als die sogenannte objektive Wirklichkeit den seriösen Status einer Q uelle des weltimmanenten Sinns genossen hatte.

Entblößt wird damit „die männliche reife Einsicht, daß der Sinn die Wirklichkeit niemals ganz zu durchdringen vermag, daß aber diese ohne ihn ins Nichts der Wesenlosigkeit zerfallen würde“. D ies ist schließlich "die O bjektivität des Romans“. ${ }^{223}$ $\mathrm{D}$ aß die Objektivität des Romans als Objektivität der konstanten Romanform im Frau Jenny Treibel ausdrücklich negiert wird, bekommt hier seine Bestätigung seitens Schmidts, der Figur von männlicher reifer Einsicht im wahrsten Sinne.

Mit dem zivilisationskritischen und existentialistischen Ton allein endet jedoch Schmidts Rede nicht. Ein durchaus nüchterner Ton rundet das G anze ab. Das allerletzte Wort des Monologs und zugleich des Romans ist ein Vorschlag, der in seinem routinemäßig unauffälligen Alltagscharakter nur scheinbar unbedeutend ist: „Kommen Sie, meine Herren, komm, Krola...- Wir wollen nach Hause gehen." (S. 478)

Es scheint hier noch einmal zu gelten, daß, wie so oft bei Fontane, vom ernsthaften, höheren Sinn in Causerie oder im Entscheidungsmonolog gesprochen wird. ${ }^{124} \mathrm{O}$ hnehin ist das ,Nach Hause gehen' ein programmatisches Motiv der modernen Dichtung: Lukács weist darauf hin, daß die metaphysische Situation des problematischen Individuums, seine sich permanent steigernde "transzendentale[] O bdachlosigkeit" 225 in der kontingenten, modernen Welt, 126 im modernen Roman adäquat gespiegelt wird. Fontane, der das Motiv des ,Nach Hause gehens' in die betonte Position am Ende seines Romans rückt, streicht diese ,O bdachlosigkeit' noch heraus.

Mindestens seit dem Frühromantiker Novalis, der einprägsam formulierte: „Wo gehen wir denn hin? Immer nach Hau$\mathrm{se}^{\prime \prime}, 127$ ist das ,nach Hause gehen' eine Antwort auf die metaphysische Situation der Neuzeit geworden. Darin offenbart sich der ebenso unerfüllbare wie unstillbare Wunsch, das metaphysische ,Zuhausesein' und die einstige Geschlossenheit der Gesamtkultur der seligen Z eiten (wieder-)herzustellen. ${ }^{228}$

Jedoch klingt es hier bei Schmidt, im Kontext der nachromantischen spätrealistischen Literatur, nicht ganz wie das philosophische Heimweh, mit Novalis gesagt, nach dem „Trieb, überall zu Hause zu sein“. ${ }^{229} \mathrm{O}$ hne auf die romantische Urbedeutung verzichten zu müssen, verschiebt sich aber der Akzent der Formel ,nach Hause gehen'. Wenn Schmidt sich und die anderen Gäste auffordert, nach Hause zu gehen, handelt es sich hier vordergründig nicht um eine metaphysische Rückkehr. Diese unverkennbare A-Metaphysik der ,nach Hause gehen'-Phrase ruft einen berechtigten Verdacht hervor, ob sie nämlich nicht den ohnehin den bürgerlichen Realismus prägenden resignierten Privatismus ausdrückt, ${ }^{130}$ dem die kritische Sprengkraft der romantischen Formel wesensfremd ist. Schmidts ,nach Hause gehen' korrespondiert aber m.E. wiederum so wenig mit dem bürgerlich realistischen Rückzug in die Privatsphäre als letzten O rt von ontologischer Bindung wie es auch nur bedingt mit der romantischen Reaktion auf die "transzendentale Obdachlosigkeit" korrespondiert. Eher handelt es sich bei Schmidt um die Verkündung einer lebensnotwendigen Rückkehr. Es ist die Rückkehr von der geistigen Erfahrung der Realität, der in ihrem Wesen kontingenten Welt, zur alltäglichen, in ihrer empirischen G egebenheit sich weiter kontextualisierenden Erfahrung der Realität. D aß diese empirische Realität die Familie in ihrer sowohl regressiven als auch progressiven Bedeutung als Repräsentanten der bürgerlichen G esellschaft in den Vordergrund rückt, ist für Fontanes bürgerlichen Realismus charakteristisch. Familie ist jedoch für Schmidt wie für Fontane keine Vorstellung von Vollkommenheit, von Substantialität. Sie lebt zwar vor allem durch die Sehnsucht nach Substantialität und Notwendigkeit weiter, aber sie selbst ist keine Substanz, sondern Handlungs- und Gestaltungsraum. Als solcher setzt sie per definitionem Kontingenz voraus.

Die mit dem ,nach Hause gehen' bekundete Rückkehr zur kontextuellen Realität impliziert zugleich Diskontinuität, d.h. das erhöhte Bewußtsein um den Fiktionscharakter der kontextuellen Wirklichkeit des Alltags. Daraus erwächst die Potenzie-

122 Vgl. M. Makropoulos, M odernität als ontologischer A usnahmezustand? Studien zur Theorie der M oderne in den Schriften W alter Benjamins. Göttingen 1989 , S. 27. 123 G. Lukács, D ie Theorie des Romans. Darmstadt; Neuwied 1972 (1920), S. 77.

124 V gl. A. Poltermann, „F rau Jenny T reibel", S. 132.

125 G. Lukács, D ie Theorie des Romans, S. 32.

126 Lukács hat das zentrale Problem der Moderne auf eine Formel gebracht, indem er „[k]ontingente Welt und problematisches Individuum“ als „einander wechselseitig bedingende Wirklichkeiten" in der europäischen Neuzeit charakterisiert hat. (Ebd., S. 67).

127 Novalis, W erke, T agebücher und Briefe F riedrich von H ardenbergs. Hrsg. v. H. J. Mähl / R. Samuel. 2 Bde. mit einem Kommentar-Bd. München 1978f. Bd. I. S. 373.

128 Siehe dazu die Anfangspassage des I. Kapitels von Lukács T heorie des Romans: Die Formen der großen Epik in ihrer Beziehung zur Geschlossenheit oder Problematik der G esamtkultur. (Ebd., S. 21).

129 Novalis, W erke, Bd. I. S. 373.

130 Vgl. R. Schäfer, Theodor Fontane, S. 170. 
rung des Moments einer subjektiven Entscheidung.

Kontingenz ist für Schmidt wie für Fontane nicht gleichzusetzen mit der Haltlosigkeit in einer bedrohenden G efahr, die man zu beseitigen hat. Sie ist vielmehr in ihrer Ambivalenz erfaßt, nämlich sowohl in ihrer psychischen und mentalen Wirkung als Unsicherheit und deshalb als einer Sehnsucht nach einem vermeintlich naturnahen Leben der früheren Kulturstadien als auch in ihrem emanzipatorischen Wert, nämlich in der Loslösung von einer einzigen Seinsform mit der Konsequenz einer permanenten Suche nach einer anderen Seinsform.

Während der erste Aspekt der Kontingenz in dem nostalgischen, allgemein zivilisationskritischen Ton ausgedrückt wird, scheint der zweite Aspekt eine unmittelbare Aussageform zu verweigern. Er erscheint eher als Vorahnung, als Hoffnung, daß die Zukunft trotz - eigentlich mit dem Preis - der Melancholie und des Verlustgefühls des natürlichen Lebens mehr Freiheit und damit mehr Glück bringen kann.

Schmidts Appell, ,nach Hause zu gehen', ist, in seiner bisher beobachteten Mehrdeutigkeit der Ausdruck eines Paradoxons, d.h. des Widerstreits zweier an sich gleichbegründeter Sinngehalte, deren Parallelführung die Kontingenz hervorruft. So möchte ich diese Aufforderung hier als Gipfelpunkt und Finale der widerspruchsvollen Kontingenz-Erfahrung Schmidts bewerten. D enn hier wird die Familie, der unter allen menschlichen Handlungs- und Lebensbereichen am meisten die Natur, die Natürlichkeit zugeschrieben wird, als Stellvertreter für das dem Kontingenz-Paradox ausgesetzte menschliche Leben eingesetzt.

Sein Zuhause ist jetzt, mit der Heirat der einzigen Tochter, von der bürgerlichen kleinen Familie einen Schritt weiter entfernt. Im eigentlichen, d.h. bürgerlich engen Sinne ist sein gegenwärtiger Z ustand ,familienlos'. Andererseits befestigt die defizitäre Familie Schmidts durch die Endogamie ihren Charakter als Solidargemeinschaft. Eine solche Solidargemeinschaft bildet die Familie vorher auch, weil die verwitwete kinderlose und zur unteren sozialen Schicht gehörende Schmolke mehr als eine Haushälterin ist. Die Perspektive der Schmidts ist wohl, daß sie eine vierköpfige Familie werden, eine vielleicht die Enge der Kleinfamilie überwindende Lebensgemeinschaft, die, anders als jene, ihre Bedeutung als G egenstruktur zur Gesellschaft nicht mit dem Preis der Abkapselung, der Isolierung von weiteren sozialen Sphären bezahlen muß.

In Frau Jenny T reibel ist Fontane gelungen, der Modernität gegenüber überraschend viel Einsicht zu gewinnen. Die Moderne wird von ihm in ihrer Komplexität als ein Zusammenhang von bizarren, einander widersprüchlichen Phänomenen wahrgenommen, für die Begriffe wie ,Paradox' und ,Ambivalenz der Kontingenz ${ }^{\prime 131}$ zu gebrauchen wären. Einerseits wird die Stichhaltigkeit eines dramatisch-tragischen Weltentwurfs bezweifelt, nach dem alles auf Konzepten der Zweckhaftigkeit beruht, auf unerforschlichen, letzten Zwecken' des Schöpfers, die man auch als ,tieferen Sinn' zu bezeichnen pflegt. Andererseits wird die Hoffnung auf eine offene Zukunft von der Traurigkeit über den fortschreitenden Verlust evidenter substantieller Grundlagen des Wirklichen begleitet. In der Zweideutigkeit der Kontingenz aufgefaßt, ist die moderne Welt ambivalent, in dieser Welt endet dann auch eine Komödie mit Tränen.132

$131 \mathrm{Zu}$ dem Thema ,Modernität als Kontingenz' werden innerhalb des kulturkritischen Diskurses der 20er Jahre in Deutschland unterschiedliche Positionen angeboten. Bei vielen Positionen blieb es bei einer Metaphysik des Kontingenten. Näher dazu: M. Makropoulos, T endenzen der Z wanziger Jahre. Z um D isk urs der Klassischen M oderne in D eutschland, in: DZfPh 39, 1991, H. 6, S. 675-687.

132 Vgl. R. Schäfer, Theodor F ontane, S. 166. 


\section{DRITTER TEIL: G. Kellers Martin Salander (1886) ${ }^{1}$}

\section{Problemstellung}

Kellers Alterswerk und einziger Zeitroman Martin Salander behandelt die Gründerzeit der Schweiz. Die Besonderheiten der schweizerischen $\mathrm{G}$ ründerepoche können, etwa im Vergleich zu der deutschen, mit dem Hinweis auf die politische Entwicklung des Landes nach der erfolgreichen 48er Revolution beschrieben werden. Mit der Einführung einer neuen, repräsentativdemokratischen Bundesverfassung konstituierte sich die Schweiz als der einzige liberale Nationalstaat auf dem europäischen Kontinent. Dabei war sie sogar in einem Punkt, dem Recht der Verfassungsinitiative für eine Gesamtrevision der Bundesverfassung, über die repräsentative Demokratie im Sinne des alten Liberalismus hinausgegangen: Der Prozeß der Erweiterung der Volksrechte brachte im Kanton Zürich 1869 eine Totalrevision der Verfassung.

Nach jener ,trockenen Revolution' von 1868/69, auf die ein wirtschaftlicher Aufschwung folgte, war die schweizerische Gesellschaft mit einer ähnlichen sozialökonomischen Entwicklung konfrontiert wie die deutsche der Gründerepoche. Keller begegnete der D emokratisierungsbewegung mit dem altliberalen Bedenken, daß das Volk der Selbstregierung noch nicht gewachsen sei. Im Zusammenspiel der ökonomischen Entwicklung mit dem demokratischen System glaubte er die gefürchteten Folgen der Demokratisierung zu erkennen. Rückschläge und Krisen des ökonomischen Aufschwungs, die in unzähligen Korruptionsaffären im öffentlichen Personenkreis um Politiker und Beamte zum Ausdruck kamen, wurden von Keller als Verfall des sittlichen $\mathrm{G}$ efühls verurteilt. Dieser moralische Verfall war für ihn die Folge eines allzu großen Spielraums, den die neue Verfassung jedem einzelnen Glied des Volkes gegeben hatte. Die schweizerische Gründerepoche wurde so von Keller in ambivalenter Weise, nämlich gleichzeitig als politischer Sieg und als Bedrohung des schweizerischen Liberalismus, betrachtet. Er trifft damit genau jenen Widerspruch des Liberalismus, der in anderen Ländern wie Deutschland zum Bündnis zwischen Bürgertum und Aristokratie und schließlich zu den Sozialistengesetzen führte. Genau in diesem Spannungsfeld des sich selbst unterhöhlenden Liberalismus entsteht Kellers Versuch des Martin Salander, nämlich um „ein politisches Spiegelbild der öffentlichen Zustände in meiner engeren Heimat zu entwerfen". ${ }^{2} \mathrm{Zu}$ der Form des Zeitromans genötigt fühlte sich Keller in seinem sich selbst gestellten Anspruch, sich mit der eigenen Zeit und Heimat auseinanderzusetzen, und zwar ähnlich wie die Autoren in Frankreich, Deutschland, Rußland usw. ${ }^{3}$ Dieser Versuch ist aber nach der vorherrschenden Forschungsmeinung nur eingeschränkt gelungen.

D ie Kritik der Forschung richtet sich hauptsächlich gegen die moralisierende Tendenz des Romans: Die kranke Zeit werde anhand der vermeintlichen Q uelle ihrer Krankheit, d.h. der moralisch defizitären Persönlichkeit, dargestellt, und so werde gerade der Gestaltung der immanenten Konflikte der Gesellschaft, also der eigentlichen Leistung der Gattung des Z eitromans, ausgewichen. Diese moralisierende Methode hat bei Keller zwei Gründe. Erstens zeigt Martin Salander in der Tat die zeitgenössische Wirklichkeit hauptsächlich als eine politische Misere. Ausdrücklich spricht Keller davon, „ein politisches Spiegelbild der öffentlichen Zustände" zu zeigen. Bekanntlich hat Keller mit seiner künstlerischen Tätigkeit versucht, auf den Bereich des politischen Selbstverständnisses des Bürgertums pädagogisch einzuwirken, wobei es sich um die bürgerliche Existenzform, die mit dem Begriff des citoyen zu fassen wäre, handelt. Im Falle Kellers muß die generelle These E. Lämmerts relativiert werden, daß das Thema des citoyen in der deutschsprachigen Literatur des 19. Jahrhunderts allenfalls im Austragen von scharfer Adelskritik sichtbar werde. ${ }^{4} \mathrm{Da}$ in der Schweiz die Feudalaristokratie relativ unterentwickelt blieb und daher das Bürgertum gegen sie ohne große Mühe seinen Machtanspruch durchsetzen konnte, hat es Kellers atoyen nicht nötig, die Adelskritik als Vergleichsfolie zu benutzen, um das eigene politische Bewußtsein zu präsentieren und zu objektivieren. Vielmehr handelt es sich beim bürgerlichen Selbstbewußtsein des àtoyen für den Schweizer Keller darum, ein Modell aufzustellen, das imstande ist, aktuelle Probleme der Gesellschaft zu erkennen und zu lösen: „Nicht in der revolutionären, vielmehr in der reformatorischen Einsetzung des dritten Standes als Nation verkörpert sich für Keller das Citoyen-Ideal." ${ }^{5}$ Kellers schriftstellerische Bestandsaufnahme läßt sich am treffendsten als Versuch einer „Phänomenologie des Citoyens“6 beschreiben. Im Martin Salander, der letzten Station seiner Bemühung um das Citoyenideal, wird die Problematik unter den zeitgenössischen politischen Bedingungen der Demokratisierung reflektiert. Mit der betonten Vorrangigkeit der Citoyenthematik wird die Zeit nicht so gestaltet, wie es der Realismus europäischer Ausprägung, also der sozialgeschichtlich orientierte Realismus, leistet. Zahlreiche wirkliche Geschehnisse und öffentliche Skandale der damaligen Zeit sind in die Romanwelt eingeflossen, und zwar mit dem Ziel, die der bürgerlichen Schicht noch gebliebenen Möglichkeiten zu erkunden, sich mitten in der sich etablierenden bürgerlichen G esellschaft patriotisch für die Nation einzusetzen.

1 Martin Salander wird nach der Ausgabe: G. Keller, Sämtliche W erke. A uf G rund des N achlasses besorgte und mit einem wissenschaftlichen A nhang versehene A usgabe. Hrsg. v. J. Fränkel / C. Helbling. 22 Bde. Bern; Leipzig 1931-1948. Bd. 12, 1943, zitiert. Im folgenden werden die Textstellen mit Seitenzahl hinter den Zitaten in Klammern angegeben.

2 K. Jeziorkowski (Hrsg.), G ottfried Keller. München 1969, S. 529.

3 Vgl. ebd., S. 529.

4 E. Lämmert, Bürgerlichk eit als literarhistorische Kategorie, in: J. Kocka (Hrsg.), Bürger und Bürgerlichk eit im 19. Jahrhundert, Göttingen 1987, S. 196-219, hier S.

213. Lämmert nennt hierbei die Figur Kreislers in E. T. A. Hoffmanns Kater M urr.

5 G. Kaiser, G. Keller. D as gedichtete L eben. Frankfurt/ M. 1981, S. 427.

6 Ebd., S. 425. 
Der zweite Grund für die moralische Verfahrensweise des Romans hängt mit der Tradition des deutschen Zeitromans zusammen. Worthmann weist diesbezüglich auf die auch im Martin Salander spürbare Tradition des deutschen Zeitromans seit der Spätromantik hin. Diese drücke sich darin aus, „der Zeit-Analyse eine konkrete Zeit-Therapie gegenüberzustellen, die „Diagnose, selbst sozusagen als ,Heilprozeß' zu gestalten“. . D iese weltimmanente Zukunftsperspektive, eine „Heilsgeschichte' in säkularisierter Form also, ist auch im Roman Martin Salander angelegt. Sie erfüllt sich jedoch nicht, was in Kellers Erwägung einer Fortsetzung mit dem Titel A rnold Salander ${ }^{8}$ als Lösung des ungelösten Problems zum Ausdruck kommt. Allerdings wird die Lösung jener Aufgabe einer Zeit-Diagnose des Zeitroman-Romanciers nicht in der Form des Fortsetzungsromans - dazu kam es nie - versucht, sondern der Roman selbst unternimmt diese ansatzweise. Die Konsequenz war, „daß die Tendenz zur verklärenden Versöhnung über die Bereitschaft zu pragmatisch realistischer Wirklichkeitsschilderung dominierte". 9

So geht es, wie der Autor an Paul Heyse schreibt, im M artin Salander um „eine politisch oder sozial moralische Entwicklung aus der aktuellen Misère heraus in versöhnliche [...] Perspektiven“.10 Keller betrachtete die an sich widersprüchliche, komplizierte Z eit-Wirklichkeit mit einem grundsätzlichen Weltvertrauen. „Für ihn bleibt die Wirklichkeit ein objektives ,D a“",11 zu dem sich der Einzelne durch seine falsche Subjektivität in eine verzerrende perspektivische Position bringen kann. So begreift Keller im Gegensatz zu Raabe und Fontane die Subjekt-Objekt-Problematik nicht auch als das Problem einer an sich schon vielschichtigen und spannungsreichen Welt, sondern er gestaltet sie als ein Versagen des Individuums, als moralische Verfehlung. ${ }^{12}$ O bwohl der Humor - jene Instanz mit dem Zweck, den mangelnden objektiven Sinn der Wirklichkeit subjektiv zu ergänzen - hier längst ausgeklungen ist, wird im M artin Salander zwar still und leise, aber immer noch unverbrüchlich an dem Glauben an eine in sich ruhende Realität festgehalten. Das Weltvertrauen des Humoristen rettet sich jetzt in die pessimistischere Skepsis eines "Galgenhumors" ${ }^{13} \mathrm{O}$ hne den Glauben an die Objektivität der Wirklichkeit völlig aufzugeben, kündigt Keller einen leisen, aber ununterdrückbaren Zweifel an der Haltbarkeit dieses Weltbildes an: So fügt er der oben zitierten Briefstelle über „eine politisch oder sozial moralische Entwicklung [...] in versöhnliche [...] Perspektiven“ den einschränkenden Nebensatz „wenn ich's herausbringe“14 hinzu. Der Zweifel, hier als Zweifel am eigenen künstlerischen Können ausgedrückt, hat sich insofern als gerechtfertigt erwiesen, als im Roman selbst, wider die erklärte Erzählintention der Harmonie, eine pessimistische, apokalyptische Stimmung unüberhörbar wird. Im Zeichen dieses Widerspruchs zwischen einem objektivistischen und in diesem Sinne optimistischen Wirklichkeitsverständnis und einem pessimistischen Weltgefühl und einer negativen Welterfahrung steht der Hoffnungsträger Arnold in seiner eigentümlichen Starrheit und Farblosigkeit. Besonders bei dieser Figur, mit der die G egenwartskrise, wenn nicht in eine völlig neue Dimension überführt, so doch zumindest perspektivisch überwunden werden soll, zeigt sich die ästhetische Grenze des Romans, und zwar fokussiert in der Schwierigkeit der Figurengestaltung. Darin wird das Ende eines Menschen- und Gemeinschaftsbildes, das das Grundmotiv Kellerscher Erzählkunst ausmacht, greifbar, ein Bild, dem nämlich inzwischen die gesellschaftliche Entwicklung den einstigen festen Boden einer anschaulichen Realisation unwiederbringlich entzogen hat. D er Eigenwert dieses Z eitromans resultiert aus diesem brüchig gewordenen Menschenbild und erschöpft sich damit nicht etwa mit der sozialgeschichtlich nur zu bestätigenden O bjektivität des Stoffes.

Somit tritt nun der moralische Ton, in dem Kellers Kritik an der Zeit zu wurzeln scheint, in vermehrter Differenziertheit auf. Er erschöpft sich nicht in der moralischen Verurteilung der geistigen Begrenztheit eines Kleinbürgerlichen gegenüber der neuen Entwicklung. Hier scheint Adornos Hinweis angebracht, daß es zu leicht wäre, die Befangenheit von Gottfried Kellers letztem Roman darzutun und der Konzeption des M artin Salander vorzuwerfen, daß das auftrumpfende So-schlecht-sind-heutedie-Menschen kleinbürgerliche Unkenntnis der ökonomischen Gründe der Krisen, der gesellschaftlichen Voraussetzungen der G ründerjahre verrate und das Wesentliche verfehle. ${ }^{15}$

Es liegt auf der Hand, daß die Zeit in diesem Werk nicht so begriffen wird, wie es vom Realismus europäischer Ausprägung gefordert wird. Anders als im sozialgeschichtlichen Realismus als dominantem Strom der europäischen Literatur der Zeit richtet sich der Realismus Kellers im Martin Salander deswegen nicht auf die zeitgeschichtliche Entwicklung selbst, sondem auf das spezifisch Menschliche als Ausdruck und Bedingung eben dieser Entwicklung. Dementsprechend läßt die Baustruktur der Romanwelt die G egenwart als ein Nebeneinander von zwei G rößen bzw. Welten erscheinen. Die eine Welt, die im Zentrum des G eschehens steht, repräsentieren der bürgerliche Kaufmannn Martin Salander und seine Kleinfamilie. Um die Salanders herum und in ihrem wechselvollen Schicksal kommt die andere Welt zur Anschauung. Es ist die Welt des ,Volkes', das im Zeichen der sich wandelnden Zeit, der Veränderungen in der Schweiz der G ründerzeit steht. Sie bildet das Gegenüber der Familie Salander, die sich, in sich geschlossen, vor der rastlos vom Strom der Bewegung mitgerissenen Umwelt inselhaft bewahrt. Die zwei Welten sind als getrennt - im Sinne einer Wesens- und Prinzipienverschiedenheit - dargestellt. Sie sind als Verkörperung zweier Epochen der bürgerlichen $\mathrm{G}$ esellschaft konzipiert.

7 J. Worthmann, G ottfried Keller, ,M artin Salander', in: ders., Probleme des Z eitromans. Heidelberg 1974, S. 117-129, hier S. 121.

8 Vgl. G. Keller, Bd. 12, Anhang, Entstehungsgeschichte, S. $424 \mathrm{f}$

9 J. Worthmann, ,M artin Salander', S. 121.

10G. Keller, G esammelte Briefe. 4 Bde. Hrsg. v. C. Helbling. Bern 1950-1954, Bd. III 1., S. 70.

$11 \mathrm{~J}$. Worthmann, ,M artin Salander', S. 119.

12 Vgl. ebd.

13 A. Muschg, G. Keller: ,M artin Salander', in: H. Steinecke (Hrsg.), Interpretationen zu G ottfried Keller. Stuttgart 1984, S. 158-166, hier S. 158.

14 G. Keller, G esammelte Briefe. Bd.III. 1., S. 70.

15 Th. W. Adorno, Ü ber epische N aivität, in: ders. N oten zur L iteratur I. Frankfurt 1963, S. 54. 


\section{A. Holistische Diktion der Modeme}

\section{Die organistische Harmonie der bürgenlichen O rdnung}

Martin Salander und seine Familie stellen die vergangene Epoche der bürgerlichen G esellschaft dar, in der sich die bürgerliche Welt als natürlicher Weltzustand verstehen konnte. D er natürlichere Weltzustand der bürgerlichen Welt beruht, vereinfachend formuliert, auf einem harmonischen Verhältnis zwischen dem Einzelmenschen und seiner Umwelt. Im Schoß der Familie Salander ist der Demokratismus noch als politische Hoffnung und als Glaube an ein sinnerfülltes gemeinschaftliches Leben bewahrt. Nicht als praktiziertes soziales und ökonomisches Leben, sondern in einer noch ganzheitlichen, unbeschädigten Form des Patriotismus - frei von dem Schatten irgendeines Verwirklichungsversuches - begegnet man bei den Salanders der demokratischen Idee. So ist auch Kellers Verständnis der Demokratie: Es beruht weniger auf einer Einsicht in die realen G egebenheiten der industrialisierten Massen- und Klassengesellschaft seiner Zeit als auf der mehr poetischen Vorstellung von der ,Einheit des Mannigfaltigen', die es gerade in Zeiten fortschreitender Unifikation zu erhalten gelte. ${ }^{16}$

Bei näherer Betrachtung zeigt sich jedoch, daß der konkrete materielle Hintergrund der Entstehung der Kaufmannsfamilie Salander in einem Demokratismus besteht, der über diesen ideologisch-moralischen Anspruch hinausgeht. Die Lebensforderung, die das Familienoberhaupt sich zu eigen macht, indem er, aus dem Schulmeisterstand hervorgegangen, mit Hilfe des Gutes seiner Frau Unternehmer wird, ist denn nichts anderes als die mit Emst verfolgte Forderung des demokratischen Zeitalters, nämlich ,unabhängig zu sein'. Insofern ist Martin Salanders Glaubensbekenntnis zur Demokratie eigentlich die andere Seite bzw. Konsequenz seiner sozialökonomischen Existenz. Auf diese Einheit zwischen der sozioökonomischen und politischen D aseinsform in der G estalt Martin Salanders weist man zu Recht hin. Dabei sei es gerade als für Martin Salanders Charakter typisch hervorzuheben, wenn er das gleiche Recht für alle, ,unabhängig' (und das heißt auch: vermögend) zu werden, wahrgenommen habe und die demokratische Basis dieses Postulats nicht einfach auf sich beruhen lasse, sondern fortfahre, dafür politisch zu wirken. ${ }^{17}$ Martin Salander ist, um es anders auszudrücken, „nicht als patriotisches Muster" wie man ihn und sein Schicksal oft einschätzt, intendiert. Er ist vielmehr „als sozialer Typus des Aufsteigers“, „als Repräsentant" 18 einer wirtschaftlich und politisch demokratischen 0 rdnung konzipiert.

Keller hat aus diesem G rund den Zeitroman anfangs mit $\mathrm{E}$ x calsior betitelt, ${ }^{19}$ der die für die Zeit repräsentative Bedeutung der Hauptfigur noch deutlicher zeigt. Z war folgt er jener in der Epoche üblichen Individualisierung mit der Umbenennung im M artin Salander, aber es liegt Keller nicht daran, bei dem spezifisch Bedeutsamen der Figur zwischen seiner Individualität und seiner Sozietät zu oszillieren. Diesen Sachverhalt, bei dem es um einen allgemeinen und so selbstverständlich gebrauchten Begriff wie ,Individuum ' und ,Individualität' geht, kann man vielleicht unter Z uhilfenahme der analytischen Trennung, die Louis Dumont bei dem Begriff ,Individuum' vornimmt, weiter verdeutlichen. Dumont unterscheidet, um die kulturell relative Bedeutung des Wortes ,Individuum' faßbar zu machen, zwei Aspekte dieses im abendländischen modernen Denken so grundlegenden Begriffes: „EE ]inerseits das empirische, sprechende, denkende und wollende Subjekt, d.h. das einzelne Exemplar der menschlichen Gattung, wie man es in allen Gesellschaften findet, andererseits das unabhängige, autonome und infolgedessen wesentlich nicht-soziale moralische Wesen, Träger unserer höchsten Werte, das vor allem in unserer modernen Ideologie von Mensch und Gesellschaft präsent ist." ${ }^{20}$ Hier muß auf die allgemein bei Keller geltende Tatsache hingewiesen werden, daß er, wenn er der Individualität den höchsten Wert zuspricht, dies nicht im Sinne des Selbstzwecks einer konturierten Individualität des Einzelmenschen versteht. So betont M. Merkel-Nipperdey, daß der Mensch im Martin Salander nicht als isoliertes Wesen behandelt, sondem immer mit der Gemeinschaft verbunden werde. ${ }^{21} \mathrm{G}$ emeint ist damit die ,holistische Anschauung', die auch von der späteren Kellerforschung mehrfach festgestellt wurde.22 Entsprechend der holistischen Anschauung tritt bei Keller das Individuum in Dumonts zweitem Sinne, nämlich im Sinne der Individualiät als des höchsten Wertes, in den Hintergrund.

Dieses Menschen- und Individuumsverständnis, welches das Individuum nur in der Einheit mit der Gemeinschaft erkennt und anerkennt, verliert in der Zeit, in der der Elan der einzigartigen politischen Emeuerung verblaßte, seine einstige ontische Basis. Die Konsequenz aus dieser bedrohten und zerrütteten Bedingtheit des Einzelmenschen als eines vor allem gemeinschaftlichen Wesens ist, daß die Konturen des Einzelmenschen, des Individuums in der ersten Bedeutung im Dumontschen Sinne, dementsprechend unschärfer werden. Man kann die Gestaltungsschwierigkeit im Kellerschen Altersroman gewiß als Ausdruck der in das Wertesystem des Individualismus einbrechenden Krise und deren Konsequenz auf der anthropologischen Ebene des Individuums deuten.

16 Vgl. C. Winter, Gottfried Keller. Z eit - G eschichte - D ichtung. Bonn 1971, S. 389.

17 Vgl. A. Muschg, ,M artin Salander', S. 159.

18 Ebd., S. 159.

19 Vgl. G. Keller, Bd. 12., Anhang, Entstehungsgeschichte, S. $413 f$.

20 L. D umont, Individualismus. Z ur Ideologie der M oderne. Frankfurt/ M. 1991, S. 35.

21 Vgl. H. Boeschenstein, G ottfried Keller. Stuttgart 1969, S. $105 f$.

22 Vgl. unter anderem M. Merkel-Nipperdey, Gottfried Kellers ,M artin Salander'. Untersuchungen zur Struktur des Zeitromans. Göttingen 1959; A. Ehrensperger, Individuum und öffentliche G emeinschaft bei G ottfried Keller, Zürich 1972; U. Schweizer, F eier des F estes. D as F est in der D ichtung G ottfried Kellers. Diss. Zürich 1973. 
Bedeutet Individualität die zeitlose Wesensbestimmtheit des zeithaften Lebens, so ist es bei der Hauptfigur persönlichkeitsund biographiekonstitutiv sowie Zeichen seiner unverkennbaren Individualität, daß er aus Wohlwollen die schlechte Realität nicht wahmimmt: Leichtgläubig übernimmt Salander die Bürgschaftsleistung für seinen Jugendfreund Louis Wohlwend: „In fünfzehn Minuten hatte ich als solidarischer Bürge und Selbstzahler die erste Unterschrift auf ein in Wohlwends Hause bereitliegendes D okument gesetzt und ging gleich darauf schlafen." (S. 20)

Louis Wohlwend erweist sich als zahlungsunfähig. Der Konkurs beansprucht die Summe der Bürgschaftsleistung Martin Salanders, worauf er die Heimat verlassen muß. Ähnlich verliert er zum zweiten Mal sein ganzes, im Ausland erworbenes Vermögen und entzieht sich und der Familie erneut den festen Boden der Existenz: Aus Leichtgläubigkeit zahlt er alles Erworbene auf eine einzige Bank ein, hinter der Wohlwend, wieder zahlungsunfähig, steht.

Man kann sagen, daß Keller die unverwechselbare Individualität Martin Salanders, seine Wesenheit, gerade in Richtung seiner anti-individualistischen Eigenschaften übertreibt. Das Hauptmerkmal dieser Figur ist denn nichts anderes als der Mangel an Widerstandskraft, sich gegen die feindliche Umwelt zu schützen. Er steht paradoxerweise in seiner einmaligen, unverwechselbaren Gutmütigkeit für das in seiner Selbstbewahrung gefährdete Individuum des demokratischen Massenzeitalters. So dient die Individualität Martin Salanders schließlich zur Karikatur eines D enkmodells, nämlich des demokratischen Dogmatismus, ja zur Kritik der selbstgefälligen Bereitschaft des fortschrittsblinden Bürgertums, „sich und andere falsch einzuschätzen, an die schrankenlose Verbesserungsfähigkeit des Volkes zu glauben etc. "23

D ie Hauptfigur zeigt keine ausgeprägte Individualität. Dies gilt auch für zwei weitere wichtige Figuren, Marie und Arnold. Eher können diese Figuren erst in wechselseitiger, sich ergänzender Abhängigkeit, in ihrer Zugehörigkeit zu der Gemeinschaft der Familie, sinnvoll gedeutet werden. Im Mittelpunkt dieser sinngebenden, sinnproduzierenden Instanz der Familie steht Marie, die nicht einmal in ihrer Individualität, sondern als „ein Muster edler Weiblichkeit“ (S. 198) auftritt. Dank Maries innerer Festigkeit und ihres feinen Spürsinns für das Unechte geht die durch die Charakterschwäche des Familienoberhauptes zweimal, beinah dreimal, um ihre Existenz gebrachte Familie nicht zugrunde. ${ }^{24}$ Mit der Figur der Marie besteht die Familie als entwicklungs- und handlungsfähiges Subjekt, das allein als Garant für das Individuum zu sehen ist, fort. Nicht das Individuum als E inzelmensch, sondern die Gemeinschaft der Familie ist als widerstands- und überlebensfähige Integrations-, Rettungs- und Produktionsinstanz des (Lebens-)Sinnes bedeutsam. D ie Familie ist somit als Sozialisationsagentur jeder öffentlichen Institution vorzuziehen. Trotz dieser erklärtermaßen vorrangig moralischen Bedeutung wird aber die Salander-Familie in erster Linie als wirtschaftliches Kraftzentrum und in ihrer Funktion für das bürgerliche Wirtschaftssystem dargestellt.25

So wird die ökonomische Tüchtigkeit der Ehefrau vorgeführt, und zwar in der Weise, daß in ihr gerade das Musterhafte des kaufmännischen frühbürgerlichen Wirtschaftsethos zur vollen Geltung kommt:

Aber es stellte sich heraus, daß die wackere Frau nicht so leicht auf alles einging, sondern bereits so gut ihre G rundsätze besaß, wie ein altbewährtes Handelshaus. Sie wollte sich mit nicht vielen aber als gut bekannten Waren begnügen, für welche sie eine sichere K undschaft wußte; diese vermehrte sich unausgesetzt, aber gemächlich und ohne Gedränge, so daß sie nie genötigt war, den Bedarf in ungeordneter Weise zu decken; kurz, ihr Geschäft war eines von denen, welche man ein stilles Goldgrüblein zu nennen pflegt. (S. 98)

In auffälligem G egensatz zu dieser Ausführlichkeit im ökonomischen Bereich wird Marie als Mittelpunkt der Familie als der wichtigsten Sozialisationsinstanz der bürgerlichen O rdnung kaum bzw. mangelhaft in ihrer erzieherischen Rolle dargestellt. Ihre Bedeutung wird gar in dieser Rolle als ,beeinträchtigt' geschildert, wenn ihre Töchter ihr ihre Beziehung zu den WeidelichSöhnen vorenthalten und sie sich darüber gekränkt zeigt. Sie sagt ihrem Mann, daß sie ihm gegenüber lange von der Sache geschwiegen habe, „weil ich mich schämte, mich von den eigenen Kindern so beiseite gesetzt zu sehen!" (S. 120)

Man könnte angesichts dieses Widerspruchs zwischen der beschworenen und der dargestellten Bedeutung der Familie von einem gewissen $\mathrm{G}$ estaltungsmangel sprechen. Ferner läßt sich dieser letztich als Beweis dafür annehmen, daß sich in den Roman, abseits von Kellers Intention, die zeitgenössische Wirklichkeit der bürgerlichen Familie drängt und in dieser Weise den Roman noch auf andere Weise zu einem ,Z eitroman' werden läßt. Ähnliches läßt sich beobachten, wenn der Heimgekehrte, anstatt sofort seine Familie, von der er seit sieben Jahren getrennt war, aufzusuchen, erst im Wirthaus verbleibt, um sich über den Wirtschaftsverkehr des O rtes zu informieren. Martin Salanders Mängel als Kunstfigur machen sich von den Intentionen des Autors unabhängig, denn: „Die ,Schwäche' des Helden offenbart das objektive G ewicht, ja die Priorität des geschäftlichen vor dem menschlichen Verkehr. ${ }^{26}$

23 A. Muschg, G. Keller: ,M artin Salander', S. 159.

$24 \mathrm{Vgl}$. A. Ehrensperger, Individuum, S. 128.

25 Vgl. B. Neumann, Gottfried Keller. E ine E inführung in sein W erk. Königstein/ Ts. 1982, S. 274.

26 A. Muschg, ,M artin Salander', S. 160. 


\section{Die Auflösung der O rdnung und ihre anthropologischen Ausdnucksformen}

Der Demokratismus und der Finanzkapitalismus sind die neuen Organisationsprinzipien seit den Gründerjahren. Bei der D arstellung und Kritik der Zeit ist es, wie schon erwähnt, für Kellers G rundposition bestimmend, die Zeit nicht als objektive Größe, d.h. sozialhistorisch, sondern anthropologisch, d.h. in der Wert- und Denkkategorie des menschlichen Subjekts einzufangen. Die gesellschaftlichen Verhältnisse werden weniger objektiv konstatiert und protokollarisch wiedergegeben. Eher finden sie in der D arstellung der Personen ihren Ausdruck. ${ }^{27}$

Die Individualität, die Einzelmenschlichkeit ist die spezifische Form des menschlichen Daseins, deren Selbstverständlichkeit und Evidenz Keller im Angesicht des gesellschaftlichen Wandels beeinträchtigt sah; also versuchte er, ihre politische und sozioökonomische Erscheinung in dieser anthropologisch problematisierten Gestaltung auszudrücken. D abei ist bei Keller die Individualität nicht im emphatisch-überhöhten Sinne des Individualismus zu verstehen. Die Individualität wird daher eher auf die menschliche Seinsweise als $\mathrm{G}$ attung bezogen thematisiert. Die so problematisierte Individualität symbolisiert nichts anderes als die gefährdete Seinsweise des Menschen als Gattung, deren umfassende Problematik sich auch im apokalyptischen Ton des Romans niedergeschlagen hat.

D ie Bedrohung der neuen Zeit steht gänzlich unter dem Zeichen von einer problematisch gewordenen Individualiät, die in zwei Spielarten auftritt. Einerseits wird sie mit den beiden Töchtern Salanders, Setti und Netti, in der Gestalt der Gefahr der Verdoppelung, der Vermassung, für die Familie aktuell: Die Weidelich-Zwillinge, die durch die Heirat mit diesen beiden Töchtern die Familie Salander in ihre Kreise ziehen, sind eine doppelte Erscheinung, also bereits in ihrem Wesen die Verneinung von Individualiät. Andererseits wird die G efährdung der Individualität in der G estalt der beständigen Verwandlung, der Unmöglichkeit der Durchschaubarkeit eines inneren Wesens, in Wohlwend verkörpert. Von einem Menschen als von etwas fest Bestimmtem und mehr oder weniger bleibend Gedachtem läßt sich bei Wohlwend schwer sprechen. Die WeidelichZwillinge und Wohlwend beziehen sich negativ auf jeweils zwei Aspekte von Individualität: Der Einzelmensch soll zum einen ein identifizierbarer Mensch sein, und zum anderen ist für die Einzelmenschlichkeit die Identität des Subjektes unabdingbar.

Auf welche Art und Weise reflektiert nun die negative Individualität, in der Wohlwend und die Z willinge auftreten, die gesellschaftlichen Phänomene? Es scheint beim Herangehen an diese Frage ratsam, die Figuren als Träger und zugleich als Opfer der gesellschaftlichen Entwicklungstendenzen zu verstehen und sie als Bezugszentren zu interpretieren, in denen verschiedene Probleme des gesellschaftlichen Lebens zusammentreffen und in deren Mitte sich der Demokratismus und der Finanzkapitalismus befinden.

\section{D er M assenmensch des D emok ratismus}

Es ist der Geist einer demokratischen Ära, den der - nach 7jährigem Aufenthalt in Brasilien - heimkehrende Martin Salander in seiner Heimat vorfindet. Das Desorientiertsein in einer veränderten sozialen Umwelt ist bereits in der Situation des Romaneingangs vorweggenommen:

Ein noch nicht bejahrter Mann, [...] ging [...] sofort in einer bestimmten Richtung nach einem Punkte der Umgegend, gleich einem, der am Orte bekannt und seiner Sache sicher ist. Dennoch mußte er bald anhalten, sich besser umzusehen, da diese Straßenanlagen schon nicht mehr die frühern neuen Straßen waren, die er einst gegangen [..... (S.1)

Nachdem er mühsam und doch vergebens mit Hilfe der Erinnerung seine D esorientierung als Folge der Straßen- und Ortsveränderung zu bekämpfen versuchte, befindet sich der Heimkehrer mehr zufällig in der ländlichen bäuerlichen alten Lokalität, dem Zeisig, wieder, den er " mit warmem Heimatsgefühl“(S.2) begrüßt. Sein ,Heimatsgefühl' ist patriotisch bestimmt. Bei der Entdeckung des abgesägten Flintenlaufes, durch den, statt aus einer eisernen Brunnenröhre, das klare Bergwasser sprudelt, spricht Martin Salander für sich:

Sei mir gegrüßt, ehrwürdiges Zeichen friedlicher Wehrkraft! [...] dies Rohr, das einst Feuer gesprüht, spendet das lautere Q uellwasser für Mensch und Tier! Aber schon hängt in jedem Hause, wie ich vernehme, das gezogene Gewehr und harrt der ernsten Prüfung; möge sie der Heimat lange erspart bleiben! (S. 2 f.)

Die ernste Prüfung für die Heimat besteht in Wirklichkeit schon lange nicht mehr in der Abwehr der äußeren Feinde. Die Gegenwart der Heimat wird durch eine Gruppe sich neckender Kinder, „kleines Volk von zwei bis sechs Jahren“ (S. 3), reflektiert. Die Weidelich-Zwillinge verlachen den kleinen Arnold Salander, weil Arnold nur ,Mutter' statt ,Mama' sagt. Die Mutter der Z willinge meint diesbezüglich: „für meine Kinder bin ich die Mama, damit sie sich nicht vor dem Herrenvolk zu schämen brauchen und einst aufrechten Hauptes durch die Welt gehen dürfen!“ (S. 6) Im Unterschied zur geographischen, kraft der Erinnerung langsam überwundenen Desorientierung stellt sich das soziale Verhalten der Menschen Salanders Absicht, im

27 Vgl. K. Szemkus, D er gesellschaftliche Bedeutungswandel Seldwylas. Untersuchungen zur D ichtung G ottfried Kellers. Reihe: Germanistische Abhandlungen 26. Stuttgart 1969, S. 101; Szemkus führt diese fruchtbare Untersuchungsperspektive auf Wohlwend beschränkt durch. Im Anschluß an B. Neumann, der den Z willingen wie auch Wohlwend eine Charaktermasken-Funktion zuschreibt, verfolge ich diese Richtung weiter, um die fragwürdige Individualität Wohlwends und der Weidelich-Z willinge näher zu charakterisieren. 
erinnernden Wiedererkennen seine Orientierung zu finden, ${ }^{28}$ erinnerungsfeindlich in den Weg. In diesem Kontext der Darstellung des veränderten sozialen Verhaltens bezeichnet der E rzähler Martin Salander signifikanterweise als: den "Fremde[n]“, „der nicht recht weiß, wo er sich im Augenblicke befindet". (S. 9) Das Volk ist in Folge der D emokratisierung selbstentfremdet und in sich zersplittert.

Die Gärtnerfamilie Weidelich steht als Beispiel für das Volk der demokratischen Ordnung. Das Prinzip der freien Wirtschaft und dementsprechend des sozialen Aufstiegs ist das, was die Mutter der Z willinge unter der neuen Zeit versteht. „Wir sind hier nicht Volk, wir sind Leute, die alle das gleiche Recht haben, emporzukommen! Und alle sind gleich vornehm!" (S. 6) Unter dem gleichen Zeitgeist soll die Aufgabe der Familie nach ihrem Verständnis ausdrücklich darin bestehen, in den Kindern das Bewußtsein von Sozialprestige zu wecken. So sagt sie: „Jede rechte Mutter hat die Pflicht, dafür zu sorgen, weil es Zeit ist!" (S. 6)

So „fuhren“ die Kinder des demokratischen Aufstiegsgeistes „fort, kräftig emporzuwachsen und leiblich zu gedeihen“ (S. 114). Die Z willingsbrüder treten als Tanzpartner, als geheime Liebhaber und als Verlobte der Töchter in den privaten Kreis Salanders ein. Dem politischen Glauben Martins, dessen voreilige Heimkehr von seinem zweiten Aufenthalt in Brasilien zum Ziel hatte, das Volk „in seinen glorreichen Anfängen noch sehen und mitgenießen“ zu können, „als unabhängiger Mann“ der Republik mit ihrer neuen Verfassung „zu helfen und zu nutzen“ (S. 81f.), wird nun mit Hohn beantwortet, wenn die Z willinge als betrügerische Politiker auftreten.

Die Doppelliebschaft der Töchter mit den Weidelich-Zwillingen läßt sich aber als die private, feminine Variation des väterlichen volkserzieherischen Fanatismus entlarven. Die Töchter zeigen in ihrem Verhältnis zu ihren Liebhabern mehr dem Idealismus ihres Vaters ähnliche „Wahngebilde“ (S. 136) als eine Liebesleidenschaft; „sie meinen, aus ihnen zu machen, was sie wollen und was gut sei!“ (S. 137) Nach ihrer Meinung bedürfen nämlich die Brüder „nicht nur liebevoller, sondern auch mit einem mütterlichen Sinne begabter Frauen, die sie wohltätig zu lenken verstehen!" (S. 134) Sie wollen die Zwillinge erziehen, also nachholen, was deren eigene Mutter an ihnen versäumt hat, denn diese, so meinen die Töchter, "hat nicht diejenigen Eigenschaften, welche zur Bezähmung so kecker Burschen erforderlich waren“. Sie hätten aber „schon einen veredelnden Einfluß über sie gewonnen, sie hören auf uns und lassen sich gefallen, was wir ihnen sagen." Die Töchter glauben an die eigenen pädagogischen Fähigkeiten: „[S]ie sind schon viel manierlicher, selbst gesitteter, als da wir sie kennenlemten!“ (S. 134)

Zwar hegen die Töchter auch Vertrauen zu "der nie ganz versiegende[n] Güte der Mutter", verlassen sich bezeichnenderweise „hauptsächlich aber auf den freieren Sinn des Vaters!“ (S. 126)

D er freie Sinn ihres Vaters ist, wie Mutter Marie durchschaut, Schwärmerei „für die freien Töchter des Hauses und für die freien Hausfrauen, welche nicht der Dienstbarkeit zu verfallen brauchen" (S. 117f.), um "den Ärmeren das Brot vor dem Munde [...] weg[zu]nehmen" (S. 117). So schwärmt eine der beiden Töchter für einen gewiß anti-emanzipatorischen freien Sinn, nämlich den patriarchalischen Humanismus im Sinne ihres Vaters. Sie beruft sich in ihrem Zugeständnis an den freieren Sinn des Vaters auf „ein gewiß wahres Wort", das sie neulich gelesen habe, „daß nur ein Mann im vollen Sinne des Wortes human sein könne, human in allen Lagen des Lebens!" (S. 126) Sie hat dies nicht nur gelesen, sondern sie ist auch überzeugt von ihrer eigenen Unzulänglichkeit: „Ich fühle wenigstens, ich als Weib bin es nicht imstande, ich will nichts weiter sagen!“ (S. 126) Die Mutter sieht nun die tiefere Ursache für die unglückliche D oppelliebschaft eben darin und bereut, daß sie und ihr Mann die Mädchen "nirgends in die Welt geschickt haben und auch nichts erlernen ließen, was einem Berufe ähnlich war" (S. 117). D enn „hätten die Mädchen nicht über eine so vollkommene Muße und Freiheit verfügt, so hätten sie schwerlich das widerwärtige Abenteuer zusammen ausspintisiert!" (S. 118)

Die Zwillinge sind, wie Wohlwend, von dem noch die Rede sein wird, als typische Persönlichkeiten der neuen Zeit konzipiert, als Charaktermodell, mit Hilfe dessen der Autor das ,Böse' der Z eit als anthropologische Erscheinung einzufangen versucht.

Sie sind die neue Physiognomie des Volkes, das sich von einem Gemeinschaftswesen in eine amorphe Masse aufzulösen droht. Sie stellen, anders gesagt, den sogenannten Massenmenschen, das leibhaftige Exemplar aus einer rasenden Menge, die die Brotläden stürmt oder an einem politischen Demonstrationszug teilnimmt, dar. ,D er Mensch' als Produkt jener historischen Erfahrung der politischen Umwälzung faßt sich gerade in einem Maximum von Allgemeinheit auf29 und nicht in einer Bestimmbarkeit des Einzelmenschen als identifizierbarem Menschen. D er moderne reale Mensch geht denn auch nicht darin auf, Einzelmensch zu sein: „[D ]er Einzelmensch ist nicht der reale Mensch der heutigen G egenwart, sondern ist in diesem nur enthalten". 30

Martin Salander findet die Zwillinge „doch unbequem und vexierlich“, weil er „diese wenigstens gar nicht voneinander unterscheiden" (S. 113) kann. In der Streitszene wird die Doppelhaftigkeit und die darin begründete Notwendigkeit der mühsamen Identifizierung als ein mit dem Ernst der Situation unverträglicher komischer Umstand bloßgestellt: „D as beliebte G reifen nach dem O hrläppchen war durch den Ernst des Augenblicks unmöglich geworden" (S. 129).

In der Doppelhaftigkeit wird den Zwillingen die Individualität, aber auch damit zusammenhängend der Emst und der Tiefsinn, kurz, jeder moralische Wert abgesprochen. So brechen sie das begonnene Studium ab, als „das Leben und Lernen ihnen täglich ernster und tiefsinniger wurde", und gehen mit ihrer kalligraphischen Kunst in eine Notariatskanzlei, wo sie

28 Vgl. K. Szemkus, Bedeutungswandel, S. 93.

29 Vgl. C. Lugowski, D ie F orm der Individualität im Roman. Frankfurt/ M. 1976, S. 18.

30 Ebd., S. 18. 
„beinahe spielend“ (S. 114) vorwärts kommen. ,Individualität' bedeutet für die Zwillinge weder Daseinsform noch Wert, sondern sie gerät bei ihnen in die bloße Funktion eines besseren Fortkommens und ist nur ein nützliches Hilfsmittel im Kampf um das größere gesellschaftliche Prestige. ${ }^{31}$ Denn „, $\left.u\right] \mathrm{m}$ auf der nunmehrigen Laufbahn nicht mehr verwechselt zu werden, hatten sie auch das Äußere so ungleich als möglich gemacht, Julian das üppige Haar kurz gestutzt und ein zartes Schnurrbärtchen gepflanzt, Isidor das Haar mit Pomade glatt gestrichen und gescheitelt; dazu trug jener einen schwarzen Filzhut, breit wie ein Wagenrad, dieser ein Hütlein wie ein Suppenteller." (S. 157f.) So spiegeln sie Individualität lediglich in der Ausübung ihrer Ämter vor, legen also in ihrer gesellschaftlichen Rolle das an den Tag, was ihnen privat und damit, eigentlich' abgeht.32 Im Privaten, selbst für die Geliebten und Ehefrauen, sind die Z willinge nur an der Form des einen Ohres zu unterscheiden. Das winzige Identifizierungsabzeichen ist dabei nicht einmal menschlich und persönlich, sondern es kommt einer dinghaften, tierhaften Signatur nahe.

Die Töchter Salander gehen mit einer illusionären Hoffnung und einem falschen Pflichtbewußtsein die Ehe mit den Weidelich-Brüdem ein. Sie wollen für die Ehemänner "mit einem mütterlichen Sinne begabte Frauen" (S. 134) sein, so wie sich ihr Vater, unausgesetzt „auf den unverlierbaren guten Ackergrund des Volkes vertrauend“ (S. 100), einbildet, Volkserzieher zu sein. Mit mehr Einblick in die tatsächliche Sachlage verweist Marie ihrem leichtgläubigen Mann gegenüber auf die Umkehrung des Macht- bzw. Einflußverhältnisses zwischen den Erziehern (ihren Töchtern) und den zu Erziehenden (WeidelichZ willingen): „[A ]ber du sprichst ganz verkehrt und närrisch! D as G egenteil ist wahr, die Bengel üben ja die unglückliche Gewalt über die Kinder!" (S. 136)

Das umgekehrte Verhältnis zwischen dem Erzieher und dem zu Erziehenden trifft insofem genau auf Martin Salander selbst zu, als auch er von seinem Erziehungsobjekt, d.h. dem Volk im demokratischen Zeitgeist, gesteuert wird, und nicht umgekehrt.

\section{D er ,Proteus' des Finanzk apitalismus}

Ein weiteres gesellschaftliches Phänomen, das mit dem Verlust der Individualität einhergehend aufgefaßt wird, findet sich in Martin Salanders ehemaligem Kollegen im Lehrerseminar, Louis Wohlwend, verkörpert. Keller versucht auf eigentümliche Art und Weise, die Individualität Wohlwends und die neue wirtschaftliche Ära zu verflechten. Die neue wirtschaftliche Ära wurde von Keller wie von den meisten seiner Zeitgenossen als unerklärbar, unbeherrschbar und absolut neu und fremd erlebt. Bei der D arstellung von Salanders G eschäft, dem von Keller bevorzugten Bereich des Handelns, fällt die merkwürdige Isoliertheit und Eigengesetzlichkeit der wirtschaftlicher Vorgänge ins Auge.33 Dem zugrunde liegt der Gemeinplatz der bürgerlichen Ideologie seit A. Smith, die in Anlehnung an die Naturwissenschaft und die Philosophie Newtons die ökonomische Sphäre als Bereich eines harmonischen Zusammenspiels unter freien Individuen interpretierte. Heißt bei Newton das Weltall das göttliche Urwerk, so erscheint A. Smith und anderen nach ihm auch der freie Wirtschaftsprozeß als ein naturgesetzlicher Ablauf, harmonisch strukturiert wie das Weltall: Das ökonomische All dreht sich in selbsttätiger, menschlichen Eingriffen sich entwindender Harmonie. ${ }^{34}$ Diesem bloßen Glauben zuwider lief aber die realgeschichtliche Entwicklung und Erfahrung.

So kommt die schwerste und folgenreichste Krisenerscheinung des 19. Jahrhunderts einem Keller als etwas vor, das nicht als Resultat realer historischer Bedingtheiten, sondern als Fehlentwicklung eben jenes Harmonischen, Moralischen zu verstehen ist, dem auch die Wirtschaft unterworfen sein sollte. An einer Stelle im Roman wird in jenem liberalen Glauben an die frühbürgerliche Wirtschaftsform die ihr entgegenstehende, aber für die G ründerzeit spezifische Haltung bezüglich der Spekulation kritisiert. Und zwar wird Salanders Glück auf dem Markt als in seiner Treue gegenüber der alten wirtschaftlichen Handlungsform begründet interpretiert: Martin Salander wird als jemand aufgefaßt, „dessen Hauptverkehr ohne besondere Anstrengung fortwährend ordentlich blühte, vielleicht gerade weil er nicht künstelte und spekulierte" (S. 115).

D em traditionellen, liberal-bürgerlichen Wirtschaften eines Salander, der mit konkreten Waren, auf überschaubare Weise und mit altfränkisch-solider kaufmännischer Ethik handelt,35 wird mit Wohlwend ein Ende gesetzt. In diesem Gegenspieler Salanders personfiziert sich der bedrohliche, schwindelerregende Zug der ,Gründerjahre'.36 Es ist dies die neue Entwicklungsphase des modernen Finanzkapitalismus, dessen ersten großen Durchbruch auch die Gründerjahre markierten. Als „Ausdruck von Kellers MiStrauen gegenüber dem Geld- und Kreditwesen der Gründerepoche“ ${ }^{37}$ steht Wohlwend unter dem Z eichen des Verlustes der für Kellers Menschenverständnis unabdingbaren menschlichen Qualität, der Individualität. Im folgenden soll gezeigt werden, wie in der Darstellung der Figur Wohlwends das Wesen und die Wirkungsweise der neuen Wirtschaftsform in Teilperspektiven thematisiert wird.

31 Vgl. B. Neumann, G ottfried Keller, S. 283.

32 Vgl. ebd., S. 283.

33 R. v. Passavant, Z eitdarstellung und Z eitk ritk in G . Kellers ,Martin Salander'. Berlin 1978, S. 38.

34 Vgl. G. Sautermeister, Gottfried Keller - Kritik und A pologie des Privateigentums. Möglichk eiten und Schrank en liberaler Intelligenz, in: G. Mattenklott / K.

Scherpe (Hrsg.), L iteratur im historischen Prozeß. 2 Bde., Kronberg/ Ts. 1973, Bd. 2, S. 80.

35 Vgl. B. Neumann, G ottfried Keller, S. 278.

36 Vgl. ebd., S. 279.

37 R. v. Passavant, Z eitdarstellung und Z eitk ritik in G . Kellers ,M artin Salander'. Berlin 1978. S. 53. 
Die "Person' Wohlwends ist "charakterologisch schon gar nicht mehr beschreibbar" und „zutiefst zweideutig und schattenhaft" ${ }^{\prime \prime}$ Wohlwends Individualität zeigt sich gerade in der eigentümlichen Abwesenheit eines beständigen Wesens. So entzieht seine Individualität sich jeder festen, positiven Bestimmung. Wohlwend entspricht weniger der Vorstellung von einem Menschen, der als bestimmt und mehr oder weniger kohärent gedacht wird. Bezeichnend dafür ist schon seine „Bastelei am eigenen Namen". 39

Im Mangel an charakteristischen Merkmalen und Eigenschaften hat sich Wohlwend aber eine Verhaltensweise angeeignet, um sich unterschiedlichen Situationen anpassen und sie zu seinem Vorteil wenden zu können. Diese Eigenart zieht sich wie ein roter Faden durch sein gesamtes Leben. D ie ,Person' Wohlwends, der ausdrücklich die Individualität als etwas einem Menschen Eigenes, Substanzielles versagt wird, geht daher völlig in ihrem Schicksal auf, das vor allem im Wechsel ihres ökonomischen Glücks besteht. Darin scheint Wohlwend den sich durchsetzenden ökonomischen Wandel der G esellschaft zu demonstrieren. „Er besitzt keine fest umrissenen Vorstellungen von dem, was sein Leben leiten und wertmäßig ausrichten könnte, außer der Sorge, überleben und seine materielle Sicherheit finden zu können. ${ }^{40} \mathrm{D}$ ie Bedeutung seiner Existenz als Individuum wird auf das ,Überleben' und das ,Anpassen' reduziert, was nicht mit einer festen Identität zu vereinbaren ist, sondern nur etwas mit dem Übernehmen und Spielen von verschiedenen Rollen zu tun hat.

Repräsentiert die feste Identität Salanders und seine zeitlose Wesensbestimmtheit die Form der Individualität in der Ära des liberalen Handels, ${ }^{41}$ so steht wohl Wohlwends ,entleerte' Persönlichkeit für die deformierte Form der Subjektivität im Zeitalter des modernen Finanzkapitalismus. In der Epoche des Finanzkapitalismus geht es nicht um eine konkrete Ware, sondern um Zahlen und Zeichen. Während Salander ein ausgeglichenes Verhältnis zu seinem Geschäft hat, bewegt sich Wohlwend zwischen zwei Extremen, die seine Entfremdung signalisieren: In der Szene der Unterredung mit Salander identifiziert sich Wohlwend völlig mit seinem Geschäft. Auf Salanders Bemerkung: „Es ist so ziemlich, was ich in sieben Jahren aufgebracht habe! Aber es wäre mir lieb, wenn du nachschlagen wolltest!“ (S. 54), reagiert Wohlwend mit: „D as kann ich augenblicklich nicht, guter Martin! Du mußt wissen, daß wir uns in einer unversehens hereingebrochenen Krise befinden, welche hoffentlich vorübergehend ist!“ (Ebd.) Schließlich fragt Martin Salander: „Wer sind denn die Wir!“ (ebd.), worauf Wohlwend antwortet: „Nun, die Firma und ich, deren Inhaber!" (Ebd.)

Intentional ist Wohlwends G ebrauch des Wortes „Wir", da er sich so in die Anonymität der Firma zurückziehen kann und die persönliche Verantwortung dem kollektiven Wir der Firma anlasten kann.42 Dieser Ausspruch ist symptomatisch für die eigentümliche Verschmelzung von Sache und Person, der Versachlichung des Menschlichen und der Vermenschlichung des Sachlichen. Zugleich erfolgt ein „Umschlag der Individualzwecke in eine unkontrollierbare Macht über den Individuen",43 indem das Wir einer überpersonalen Institution, hier der Firma, zwischen die persönliche Ich-D u-Beziehung tritt, und zwar so, daß Wohlwend das Wir in eigener Sache benutzt.44

Wohlwend ist aber in der Lage, sich im nächsten Augenblick in ein gerade entgegengesetztes Verhältnis seinem Geschäft gegenüber zu versetzen. Er versteht es nämlich, seinen wirtschaftlichen Mißerfolg von seiner Person fast gänzlich fernzuhalten und über einer recht flüchtigen Beschäftigung mit Wissenschaft und Kunst - dies sogar als „Mäzen[]" - den Mißerfolg des „Kaufherren" (S. 55) zu vergessen. Wohlwend bemerkt zu Salander, der sich über die eigentümliche Unberührtheit und Teilnahmslosigkeit verwundert, die jener gegenüber seinem emeuten Unglück zeigt:

Lieber alter Freund! Mach es wie ich, behalte den Kopf oben! Sieh her, in meiner unfreiwilligen Muße bin ich nicht müßig, grüble nicht über Unabwendbares; ich werfe mich auf Wissenschaft und Kunst. Hier treibe ich Heraldik, mit Einbeziehung der bürgerlichen Hauszeichen, der Handwerksinsignien und verwandter Dinge! (S. 55)

Solch eine "proteusartige Verwandlung im Interesse des jeweiligen Geschäftes“45 enträt einer personalen Integration, wie sie dem rationalen Menschenbild zugrunde liegt. Wohlwends „unverbrüchlich kalte, schweigsame Haltung, die er stets der Anweisung gegenüber einnahm, ohne sich je mit einem Worte in Verlegenheit zu setzen", veranlaßt seinen Anwalt zu einem „etwas ungewöhnliche[n] Experiment" mit ihm, der „ein interessantes Subjekt, juristisch genommen“ (S. 92), ist. Aber selbst ein erfahrener Irrenarzt kann Wohlwend nicht „zur gesunden Vernunft" (ebd.) zurückbringen. Nach der Diagnose des Arztes ist Wohlwend eine „merkwürdige Abart" eines Menschentyps, zu dem „Menschen, welche die Macht haben, ein unbequemes Faktum sozusagen in ihrem Bewußtsein so gut aus dem Wege zu räumen, daß sie nicht einmal im Schlafe, geschweige im Wachen davon sprechen, wenn sie nicht wollen" (S. 93), gehören. Diese ungewöhnliche Macht über das eigene Verhalten wird unverzüglich im Sinne des rationalistischen Menschenverständnisses auf die Schwäche der Kontrollinstanz des Bewußtseins zurückgeführt: „Und es seien das durchaus nicht geistig starke Leute, vielmehr solche, denen jedes Bedürfnis mangle, sich mit sich selbst auseinanderzusetzen". (Ebd.) Die Auseinandersetzung mit der eigenen Person heißt, jene dem Menschen als Gattungswesen gegebene, eigene Vernunft zu verwenden, um sich selbst und die Wirklichkeit zu erhellen. Während für seine Frau Marie Wohlwend "nichts Besseres" als ein „Sträfling[] in den Zuchthäusern“ (S. 72) ist, glaubt Martin in Wohlwend vielmehr, entsprechend seinem Geist der Aufklärung, einem Versagen der Vernunft zu begegnen. Ähnlich wie die anderen

38 K. Szemkus, Bedeutungswandel, S. 98.

39 B. Neumann, G ottfried Keller, S. 279.

40 K. Szemkus, Bedeutungswandel, S. 98.

41 B. Neumann, G ottfried Keller, S. 282.

42 Vgl. K. Szemkus, Bedeutungswandel, S. 97.

43 V gl. G. Sautermeister, G ottfried Keller, S. 72f., 80.

44 Vgl. K. Szemkus, Bedeutungswandel, S. 97.

45 B. Neumann, G ottfried Keller, S. 279. 
männlichen Träger der Gesellschaft und ihrer O rdnungsvorstellungen - wie z.B. der Anwalt oder der Arzt - , die in Wohlwend das von der rationalistischen Menschenvorstellung Abweichende sehen, hält Martin Salander bei seiner Beurteilung Wohlwends am aufklärerischen Menschenbild fest. Typisch für ihn, für seinen unerschütterlichen Glauben an das Gute im Menschen, ist aber, daß das rationalistische Menschenverständis im Falle von Wohlwend eine Alibi-Funktion für dessen moralische Unzulänglichkeit einnimmt: „Ich weiß nicht, ich schwanke doch zuweilen, ob er nicht eher ein Narr sei, als ein schlechter Mensch: freilich ein gefährlicher Narr!"(S. 72)

Um jedoch als Narr angesehen zu werden, beherrscht Wohlwend allzusehr die Kunst, die Funktionsweise und die Lücken des alten und des neuen Wirtschaftssystems und des juristischen Systems auszunutzen. Dem Narren ist es gelungen, in geschickten Überschreibungen und Transaktionen dem rechtmäßigen Besitzer, der ihn als Narr bezeichnet, sein Vermögen erneut zu entziehen. Salanders Aussage verrät also nichts anderes als die Begrenztheit seines Urteils, die zugleich die Begrenztheit des herrschenden Diskurses einer Epoche ist.

Bei der Gestaltung Wohlwends in ihren verschiedenen Deutungsversuchen durch andere Figuren (Marie, Martin Salander, Anwalt und Irrenarzt) liegt dem Autor daran, die Subjektivität der Figur in verschiedenen Richtungen, d.h. moralisch, juristisch und psychologisch, als fraglich, ja sie als $\mathrm{G}$ renzfall für das herkömmliche Menschenverständnis darzustellen, ein $\mathrm{G}$ renzfall, der als „Übergangsfigur ins Modeme" 46 gelesen werden kann.

In Wohlwend wird nicht nur die neue unmoralische Wirtschaftsform personifiziert. Bei näherem Hinsehen zeigt sich Wohlwend auch von weiteren, altbekannten geistigen Haltungen geprägt, die sich durchaus mit den neuen Zeiterscheinungen verbinden lassen. Keller sucht in Wohlwend das Irrationale, das Anti-Kulturelle der anbrechenden finanzkapitalistischen Epoche mit den früheren anti-aufklärerischen Bewegungen zu verflechten. Nur so, im Gewand des alten Feindes des Humanismus, scheint Keller das bedrohlich Neue als konkrete Realität voll erkennen und es als den beschrittenen Weg einer Fehlentwicklung des menschlichen Subjektes künstlerisch- sinnlich formulieren zu können.

Im folgenden soll Wohlwends antagonistische Beziehung zu Salander detaillierter analysiert werden. Sie geht über den Widerspruch zwischen traditionellem Handelskapitalismus und Finanzkapitalismus hinaus und läßt sich in vielfältige (kultur-) geschichtlich nuancierte Gegensätze auffächern.

Wie von einem harmonischen Naturbild regiert, steht Martin Salanders ökonomische Tätigkeit mit seiner staatsbürgerlichen Existenz im Einklang. D em „mehr von seinen bürgerlichen Liebhabereien oder Pflichtleistungen eingenommen[en]“ Kaufmann als Abgeordnetem im Großrat „blühte“ sein „Hauptverkehr ohne besondere Anstrengung fortwährend ordentlich“.(S. 115f.) Die Kluft zwischen Egoismus und Gemeinwohl wird bei ihm nicht spürbar. ${ }^{47}$ Währenddessen zeigt der finanzkapitalistische Bourgeois Wohlwend stets die Kehrseite, und zwar auf die Weise, daß dabei der unversöhnte krasse Widerspruch in seinem Dasein zum Vorschein kommt. Der Bourgeois führt nebenbei die Lebensform eines "Mäzens', ,Sektengründers' und ,Insektensammlers'. Er widmet sich solchen Liebhabereien, dem „edeln Idealismus“ (S. 70), wie er es selbst nennt, dann, wenn er finanziell ruiniert ist, also sich in einer „unfreiwilligen Muße“ (S. 55) befindet. So gerät er zwangsweise in eine Welt der Idealität. Der (selbstbe)-trügerische, politisch-gemeinschaftliche Charakter von Wohlwends Idealismus steht nicht nur Salanders demokratischem Idealismus entgegen. Mit seinem Hobby als Heraldiker legt Wohlwend noch von einem überspannt-nostalgischen Verständnis von der kulturellen Größe von Volk und dem Volkstümlichen Zeugnis ab, wenn er die „bäuerlichen Hauszeichen“ und „Handwerksinsignien“ (S. 55) usw. in sein Interessengebiet der Heraldik miteinbezieht: „Hier lassen sich alte Fäden politischer und kultureller Entwicklung offen legen und neue anknüpfen im Sinne einer neuen Verteilung der Volksehren" (S. 55). So scheint seine ethnosymbolische Auslegung der Heraldik das Volkstümliche als eine universale, geschichtliche Kraft zu verherrlichen. Der Ton legt einen Hang zur idealisierenden Verfälschung der Vergangenheit mit der Aufforderung zur Volkstümlichkeit um der Volkstümlichkeit willen nahe. Einer solchen Auffassung vom Volk als vordergründig kultureller Größe steht Keller, bei dem dieses die Bedeutung eines politisch-gesellschaftlichen Subjekts hat, fern. 48

Wohlwend ist hinsichtlich seiner Beziehung zur Natur und - damit verbunden - zur Gemeinschaft Salanders Antipode, bei welchem der Widerspruch zwischen privatem und gemeinschaftlichem Dasein in der Natur in einem harmonischen Naturbild aufgehoben wird. Dies läßt sich anhand der Spaziergangsszene verdeutlichen: Salander geht mit seiner Familie durch eine „Staats- und G enossenschaftswaldung“ und klärt sie auf über den Unterschied zwischen den „Forsten der alten Welt, wo der Wald gebaut und gepflegt würde fast wie ein Hausgarten“ und „den Urwäldern des Westens, wo nur Kampf und Ausrottung herrsche“. Inmitten dieses „Kulturgehölzes“ (S. 66), des Sinnbildes für die erreichte Harmonie zwischen Natur und Kultur und folglich zwischen Individuum und Gemeinschaft, finden die Salanders Wohlwend, der nach Fischen und Krebsen jagt. Wohlwends Beziehung zur Natur tritt in diesem Augenblick als von zwei Richtungen der Naturauffassung geprägt hervor,

46 K. Szemkus, Bedeutungswandel, S. 100. Wohlwends ,Proteus-Charakter' legt die Möglichkeit nahe, ihn als eine allegorische Figur für die Moderne zu betrachten. Zum Proteus als Zentralgestalt der literarischen Moderne vgl. Glauco Cambon, D er Kampf mit Proteus. Untersuchungen über Sprache und Sein in der modernen L iteratur. München 1970.

47 Sie wird in der liberalen Ideologie entweder in der Vorstellung des Weltalls als göttlicher, prästabilierter Harmonie aufgelöst oder, wie bei Kant (Idee zu einer allgemeinen $\mathrm{G}$ eschichte in weltbürgerlicher A bsicht [1784]), anthropologisch als ,ungesellige G eselligkeit' des Menschen gelöst. Hierzu vgl. H. Plessner, U ngesellige G eselligk eit. A nmerk ungen zu einem Kantischen Begriff (1966), in: H. Plessner, G esammelte Schriften. 10 Bde. Hrsg. v. G. D ux. Frankfurt/ M. 1980-85, Bd. V III. Conditio humana, S. 294-306.

48 In dem Sinne verstanden ist ,Volk' bei Keller immer „ein idealischer Begriff“, der aber nicht „ohne konkreten Gehalt" ist, sondern von realgeschichtlicher Substanz und aus der Perspektive des politischen Liberalismus benutzt wird; vgl. dazu im Gegensatz die Auffassung von C. Winter, Gottfried Keller, S. 87. 
wobei die eine dem 18. Jahrhundert und die andere dem 19. Jahrhundert eignet. Erstere zeichnet das Bild einer idyllischen, friedlichen Natur und letztere das eines Wirtschafts-Urwaldes, eines anarchischen D schungels, in dem alle als einander feindlich gesinnt dargestellt werden. Sowohl der ersteren als auch der letzteren liegt die naturale $\mathrm{N}$ atur ${ }^{49}$ fern, wie sie bei Keller und seinem Helden Salander auftritt. Die ihrerseits miteinander im Widerspruch stehenden Vorstellungen der Natur als Antithese der Gesellschaft und als Spiegelung der Konkurrenzgesellschaft verschmilzt Wohlwend ohne Bedenken miteinander, um seiner bizarren Existenz Ausdruck zu verleihen. Während einerseits die darwinistisch verstandene Natur als Ort des „Kampfes ums Dasein" (S. 70) zur Rechtfertigung seines anarchischen wirtschaftlichen Egoismus als etwas Natürlichem, Selbstverständlichem dient, so sucht der im Überlebenskampf Verlorene seinen Trost nirgendwo anders als eben in der jetzt idyllisierten Natur: „[W]o sollte ich am heutigen Tage mich hinflüchten, als an den Busen der Mutter Natur? Es ist gewissermaßen mein Ehrentag, an dem ich das Martyrium unsers Jahrhunderts antrete als O pfer des Verkehrs, des Kampfes ums Dasein!" (S. 69f.)

In jenem mit Sentimentalitäten und Reminiszenzen an klassische Bildung versetzten Satz Wohlwends wird die Anspielung auf den durch Rousseau ${ }^{50}$ geprägten Aufruf ,Zurück zur Natur' unüberhörbar, von dem sich Keller ebenso wie vom D arwinismus distanzierte.

\section{Die Zukunftsordnung}

Von der Familie Salander geht zuweilen „eine Bewegung der Ruhe“" ${ }^{11}$ aus, die von einer Zukunftsutopie weit entfernt ist und auch mit der Fortschrittslehre wenig zu tun hat. Der Sohn Amold kündigt den Einzug des neuen Zeitgeistes an, der die unwiderruflich in Mißkredit geratene Bürgertugend des Vaters ablösen soll. Im Spannungsverhältnis zwischen Vater und Sohn Salander, das sich aus den verschiedenen Verhaltensmustern in ihrer bürgerlichen Lebenspraxis ergibt, eröffnet sich die Tiefendimension der Problematik der bürgerlichen Tugend als die Problematik der bürgerlichen Rationalität im Wandel ihrer geschichtlichen Praxis. Diese Spannung läßt sich als die der Bürgerlichkeit eigene D ynamik verstehen, eine Dynamik, welche im Lauf der Geschichte die bürgerlichen Ideale und Werte von sich weisen.

Eva Graef zeigt in ihrer Studie Martin Salander. Politik und Poesie in Gottfried Kellers G ründerzeitroman, daß Kellers Position hinsichtlich dieser Problematik in die Nähe der Dialektiker der Aufklärung, Adorno und Horkheimer, gerückt werden kann. ${ }^{52}$ Des weiteren deutet Graef die Figur Arnolds als „Komplementärgestalt" zu dem selbst Fortschrittsgedanken zum Opfer gefallenen Martin Salander. Wie die Denkfigur zur Rettung der Aufklärung von Adorno und Horkheimer als „Aufklärung der Aufklärung" bestimmt wird, ist Arnold „wie eine lebendige Kritik vor ihm [Martin Salander; J.H. B.] und wirkt[e] augenblicklich auf seine gute Natur" (S. 385). D as im Bewußtsein des Fortschrittlers Salander ausgesparte Vermögen der Kritik wird in Arnold inkarniert, inkarniert auch in dem Sinne, daß etwas Verlorengegangenes wieder zurückkehrt. In diesem Sinne hat auch die ältere Forschung, z.B. Werner Kohlschmidt, in Arnold den Rückgriff auf „zwei Werte“ der aufklärerischen Tradition, auf die "tragenden Ideen des 18. Jahrhunderts", gesehen, nämlich „Nüchternheit und - echte - Bildung“.53 Darin lege die Welt Kellers, so Kohlschmidt, nicht die Gotthelfs nahe, deren Wirkung auf und deren repräsentative Bedeutung für die schweizerische Geistesgeschichte in mehreren Hinsichten mit der von Keller vergleichbar sei. Wenn es auch scheint, daß sich Keller im Martin Salander mit der Gotthelfschen Position eng, und zwar im Negativen, berührt, ${ }^{54}$ ist bei Keller keine Spur von jenem Irrationalismus zu finden, welcher bei Gotthelf in seinem Zeitroman in Form der Verteuflung alles politisch Fortschrittlichen einen breiten Raum einnimmt. 55

Die Potenzierung des kritischen Denkens allein ist aber noch lange nicht das, was Arnolds Geisteshaltung ausmacht. Arnolds Position unterscheidet sich, trotz einiger vergleichbarer Punkte, etwa von dem kritischen Denken der Dialektiker der Aufklärung, wie es sich überhaupt bei seiner G eisteshaltung um keine handelt, die als Reaktualisierungsversuch der Aufklärung zu beschreiben wäre.

\section{A molds ,H istorismus'}

Der Historismus ist zunächst eine nähere geistesgeschichtliche Positionsbestimmung von Arnolds kritischem Bewußtsein, wie es sein Gelehrtentum als privater Geschichtswissenschaftler nahelegt. Arnold verfügt über ein differenziertes

\footnotetext{
49 Vgl. G. Kaiser, N atur und G eschichte. Kellers "U rsula“ und der A ufbau der „Züricher N ovellen“, in: G. Kaiser / F. Kittler, Dichtung als Sozialisationsspiel. Studien zu G oethe und Gottfried Keller. Göttingen 1978, S. 135-224, hier S. 218.

50 Näher zu Rousseau-Kritik und -Rezeption bei Keller vgl. G. Kaiser, G. Keller, S. 23f. 213, 249, 256f. 331 und 370 et passim.

51 A. Ehrensperger, Individuum, S. 128.

52 Vgl. E. Graef, M artin Salander. Politik und Poesie in G ottfried Kellers G ründerzeitroman. Würzburg 1992, S. 82. Die Affinität sieht Graef darin, daß Keller „die Salanderschen Ideale und ihre Umsetzung, die den ursprünglichen Absichten gänzlich zuwiderläuft, als synchrones Korrespondenzverhältnis" gefaßt hat. „Mit dieser zeitgleichen Ineinssetzung“, so Graef, beschreibe Keller genau „den Mechanismus, den Horkheimer und Adorno für die von ihnen analysierte ,rastlose Selbstzerstörung der Aufklärung' verantwortlich machen."

53 W. Kohlschmidt, D er Zeitgeist in G ottfried Kellers, Martin Salander', in: O rbis L itterarum. V 01. X X II. Kopenhagen 1967, S. 93-100, hier S. 99.

54 Vgl. ebd., S. 99.

55 Vgl. W. Kohlschmidt, D er Z eitgeist, S. 94.
} 
Fortschrittsverständnis, das im Sinne des ,Historismus' dem Gebrauch des Fortschrittsbegriffs ebenso eine Absage erteilt wie einem teleologisch verstandenen Geschichtsverlauf. Wo genau kann man aber Amold dann innerhalb der ungewöhnlichen Bandbreite des Historismus, jener zum Teil recht unterschiedliche Standpunkte umfassenden geistigen Entwicklung des 19. Jahrhunderts, verorten? Graef zufolge ist Amold als „eine Art Musterfigur aus der Schule Jacob Burckhardts" 56 zu betrachten. Wie Craig differenzierend, darin sich auf Adolf Muschg berufend, feststellt, teilte Keller als Dichter jedoch nicht die allzu vereinfachende Auffassung von Jacob Burckhardt. 57 Und wie G. Kaiser in seiner Analyse der Züricher Novellen gezeigt hat, besaß Keller eine eigene G eschichtstheorie, die am Gedanken der Reform und der Emeuerung orientiert war. Nach Kaiser präsentiert die Geschichte für Keller „eine Folge gelingender Brückenschläge zwischen den Zeiten, in denen das Alte erneuert, das Neue an das Alte angeknüpft wird“".58 Man könnte meinen, daß sich diese Geschichtsanschauung Kellers einem sich auf die G eistes- und Kunstgeschichte kaprizierenden Historismus wie dem Burkhardts nähere..$^{59}$

Jedoch sprengt Arnold die Rahmenbedingung des historistischen Denkens in der Spielart Burckhardts. Und zwar in dem Sinne, daß sein Verhältnis zur G eschichte die neben der Entwicklung und dem Fortschritt andere wichtige Denkkategorie des Historismus, nämlich die Individualität, in Frage stellt. Die Thematisierung der Individualität durch A mold kommt freilich nicht so sehr als G egensatz zu Martin Salander zum Tragen, wie dies bezüglich des Fortschrittes der Fall ist. Das Verhältnis von Vater und Sohn im Punkt der Problematik der Individualität scheint gerade deswegen das zu präsentieren, was für Keller die Geschichte als eine „Folge gelingender Brückenschläge zwischen den Zeiten, in denen das Alte erneuert, das Neue an das Alte angeknüpft wird“, bedeutet. Als „Dialektik der Kulturbewegung“ formuliert, hat Keller diesen Gedanken ins Zentrum seines G eschichtsverständnisses gestellt: daß nämlich das Vergangene stets Gegenwart ist. Nicht zufällig heißt es, daß Vater und Sohn Salander „so grundverschieden und doch wieder so grundähnlich“ (S. 394) sind. Die folgende Analyse konzentriert sich darauf, bei der Betrachtung der Zukunftsperspektive des Romans diesem Aspekt nachzugehen und dabei über die Rolle und die Bedeutung der, Individualität' und der,Individuation' bei Arnold zu reflektieren.

Die volle Entfaltung des einzelnen, nämlich die Handels- und Handlungsfreiheit des bürgerlichen Wirtschaftssubjekts einerseits und die Hingabe an das Ganze, an die Gemeinschaft als atoyen andererseits, diese Einheit, die der Vater exemplarisch repräsentiert, bewahrt bei dem Sohn noch ihre Glaubwürdigkeit. Dies kann auf die besonderen Bedingungen der geschichtlichen Erfahrung der Schweiz und Zürichs zurückgeführt werden: „In der Glanzzeit“, d.h. „als Geld und Geist einander befruchteten und beförderten, machte man keinen so großen Unterschied zwischen individuellen und gesellschaftlichen Leistungen" ${ }^{60}$ Martin Salander, der beispielhafte Repräsentant des Frühliberalismus, geht seines Anspruches auf Heldentum auf der Bühne der Geschichte erst in dem Moment und insofern verlustig - so Kellers Position -, als dieser von äußeren Mächten gefährdet wird. Mit Amold tritt deswegen die Kritik an diesem immer noch gültigen Ideal als Forderung nach einer partiellen Korrektur, nach einer Ergänzung auf. Das Gebot dieser Kritik ist deswegen keine inhaltliche Kurswendung, sondern verlangt Bescheidung und Einschränkung in den eigenen Ansprüchen, die so mit den voraufgegangenen Ansprüchen identisch bleiben. So steht „ein leidlicher Kaufmann“ (S. 181) in Arnold dem erfolgreichen Kaufmann in seinem Vater entgegen. Arnold ist wirtschaftlich desinteressiert und will das Familienunternehmen lediglich in überschaubaren Grenzen halten. G egenüber der Expansion, jenem G eist der Zeit, dem der Vater mit Maßen zu folgen gedenkt, tritt er skeptisch auf: „Für meine Person, muß ich gestehen, habe ich drüben, jenseits des Wassers in stillen Augenblicken mehr als einmal nachgedacht, wie weit wir denn eigentlich gedeihen wollen in unserem Erwerb?" (S. 391f.)

Angesichts der von dem eigentlichen genetischen Z usammenhang der menschlichen Bedürfnisse abgelösten, als Eigenwert verselbständigten und unhaltbar um sich greifenden Macht des G eldes betont Amold das Paradoxe der Situation: „Wollen wir in der Tat kleine Nabobs werden, die entweder ihr Leben ändern oder den weit über ihre Bedürfnisse reichenden Mammon ängstlich vergraben müssen und in beiden Fällen vor sich selbst lächerlich sind?" (S. 392)

Dem Geld, das in dem von Vater Salander verkörperten Zeitalter des Freihandels als Garant bzw. Bedingung der Individualität mit der individuellen Freiheit schlechtin gleichgesetzt wurde, wird jetzt in der von Keller mit persönlicher Bitterkeit dargestellten Zeit der verschärften wirtschaftlichen Konkurrenz eine andere, neue Bedeutung beigemessen.

Dies mündet bei Arnold dahin, daß er dem Geld seine ursprüngliche, sinnliche Dimension zurückgeben soll. In diesem Sinne ist Arnolds Spielen „mit dem Muster einer neuen Goldwage [sic!], die man auf des Vaters Tisch gestellt hatte“ (S. 391), während des $\mathrm{G}$ esprächs über die Zukunft ihres G eschäftes zu verstehen.

Während seine Schwestern sich zu dem rationalistischen Ideal des Vaters bekennen, nennt der Sohn die Mutter „eine Spezialität meines Herzens" (S. 180) und steht unter dem Einfluß seiner religiösen und zuweilen mystischen ${ }^{61}$ Mutter Marie.

In derselben Bescheidung betrachtet Arnold sich als ,Staatsbürger'. Für sein gesellschaftliches Selbstverständnis charakteristisch ist seine Weigerung, sich von seinem Vater in politische $\mathrm{G}$ remien einführen zu lassen, um die G esellschaft aktiv mitzugestalten: „D as sogenannte Mitwirken wolle er an sich kommen lassen, wenn es einst sein müsse“ (S. 401). So stellt sich der Sohn als "Geschichtsfreund" und "Jurist" dem "Politiker" und „Volksmann" (S. 392) im Vater entgegen. Er sieht seine Bürgerpflicht vor allem und zuerst in einer passiven und beschaulichen Beobachterrolle. Was hier zum Ausdruck kommt, ist

56 E. Graef, M artin Salander, S. 98.

57 Vgl. G. A. Craig, G eld und G eist. Zürich im Z eitalter des L iberalismus 1830-1869. München 1988, S. 256.

58 G. Kaiser, G. Keller, S. 424.

59 Vgl. G. Kaiser, N atur und G eschichte, S. 220f.; E. Graef, M artin Salander, S. $98 f$

$60 \mathrm{G}$. A. Craig, G eld und G eist, S. 283.

61 Auf die damit zusammenhängende Problematik der poetisch-magischen Marie gehe ich im Kapitel „Maries Märchen“ näher ein. 
eine veränderte Einstellung zur G eschichte. Aus der G eschichte des menschlichen Handelns ist eine Geschichte der Erkenntnis der Vergangenheit geworden: „Der poeta doctus überholt den poeta politicus“ .62 Im Sinne von Burckhardts „archimedische[m] Punkt außerhalb der Vorgänge“63 ist es zu verstehen, wenn es über Arnold heißt: „D ie hergebrachten Einflüsse möge er nicht auf sich wirken lassen und gehe deshalb auch nicht hin, wo sie ausgewechselt werden; nur so fühle er sich frei und einst imstande, jedem zu sagen, was er für wahr halte" (S. 401).

$\mathrm{Da}$ es sich nicht um das Handeln, sondern um die Erkenntnis der objektiven Wahrheit handelt, klingt gar ein ,beobachtender' Rigorismus des Politischen an, wenn Amold erklärt, daß er sich vorgenommen habe, „sich auf die Erfüllung aller Bürgerpflichten zu beschränken, wozu, nebenbei gesagt, auch gehöre, niemals an einer Wahl teilzunehmen, wenn er weder den Vorgeschlagenen noch die Vorschlagenden kenne". (Ebd.).

Die in einer solchen politischen Abstinenz lauernde Gefahr wird von Keller bewußt gemacht, wenn er den Vater zu dem G edanken kommen läßt, daß „der Sohn [...] auf den Schulen ein Doktrinär geworden [sei], in welchem vielleicht der Reaktionär nur schlummere." (Ebd.) Mit seinem Protagonisten hegt Keller nämlich „[e]in schmerzliches Mißtrauen“(ebd.) gegenüber der historistischen Richtung, ihrer Lieblosigkeit und "Negativbeziehung zur Gegenwart". ${ }^{64}$ So läßt Keller auch über die Unzulänglichkeit der historistischen Position keinen Zweifel.65

Arnolds historistische Gelehrtheit als notwendige Korrektur des destruktiven Potentials der Fortschrittsbewegung ist gegen das dem Fortschrittsglauben zugrunde liegende Idealisierungsverfahren gerichtet. D er Historismus im 19. Jahrhundert hat das klassische Altertum aus der ideologischen, geschichts-, natur- und einheitsphilosophischen Globaldeutung historischphilologisch gelöst. Wenn Arnold bezüglich Myrrhas hervorhebt, „wie gut sich natürliche Anmut mit Blödsinnigkeit zu vertragen scheine" (S. 399), ist der Historismus als Verfahrensweise präsent, also in seiner heuristischen Bedeutsamkeit bezüglich unserer Kenntnis über das klassische Altertum. In Arnold ist nämlich der Philologe tätig, der das Klassische vom humanistischen Bildungsgehalt im Sinne Winckelmanns, Herders und Humboldts abzutrennen sucht.66 Es scheint mir wichtig, darauf aufmerksam zu machen, daß der Historismus in Amold in erster Linie die historisch-philologische Verfahrensweise meint, mit der das philologische Verstehen, ja das ganze Erkennen auf das Niveau einer historischen Wissenschaft gehoben wurde. ${ }^{67} \mathrm{G}$ enau aus diesem Grund läßt sich Arnolds Position nicht allein auf den Zeitgeist des Historismus zurückführen. Und besonders Burckhardt, dessen Gelehrtentum und Bildungsidee Keller wohl für die G estaltung von Arnold Modell gestanden haben mag, scheint in seiner kulturpessimistisch vereinfachenden Option weniger geeignet zu sein, hier eine über die allgemeine zeit- und geistesgeschichtliche Bedeutung hinausgehende Rolle zu spielen.68

\section{D as Prinzip des, $\mathrm{N}$ ach der $\mathrm{G}$ eschichte ${ }^{69}$}

Im folgenden möchte ich zeigen, daß sich die Geschichtsauffassung Arnolds in ihrem Kernpunkt zu dem Historismus in seiner vorherrschenden nationalstaatlichen Historiographie sogar widersprüchlich verhält. In seiner Fortschrittsskepsis erweist sich der Sohn als grundverschieden von seinem demokratischen Vater und zeigt darin in erster Linie eine Skepsis gegenüber dem Fortschritt der Geschichte als Nationalgeschichte. Arnolds Fortschrittsskepsis richtet sich daher auf den Wandel der emanzipatorischen Bedeutung der Nation in der schweizerischen G eschichte.

Im Rahmen der westeuropäischen Moderne entstand durch die Universalisierung des Volksbegriffs die Nation. In diesem Prozeß wird eine ethnisch-räumliche Identität durch eine politisch-staatsrechtliche neu formuliert. Bekanntlich bieten sich hier zwei Modelle an: das englische und französische 18. Jahrhundert als universalistischer Rationalismus einerseits und das deutsche 19. Jahrhundert als die deutsche Ideologie mit ihrem Hauptinhalt der kulturellen Besonderheiten andererseits. Martin Salanders bzw. Kellers Schweiz steht unter dem Zeichen der Universalisierung nach französischem Muster. D er Elan der schweizerischen Geschichte der 48er Revolution und der ihr folgenden Nationalstaatsbildung und Demokratisierung ist für Martin Salanders Volksbegriff geradezu konstitutiv. Das Volk bedeutet für ihn die politisch aktive, öffentliche Gemeinschaft, die sich mit der Nation und Republik gleichsetzen läßt. So steht er für das Stadium der Universalisierung des Volksbegriffs zur Nation im Sinne eines universalistischen Rationalismus. Bei Martin Salander erscheint die Interpretation jener politischen Erfahrungen und das darauf basierende Selbstbild der Schweiz etwas anders als in Frankreich, wo Nation und Republik die Überlegenheit der universalistischen Kultur und Werte dokumentieren und wo damit das Selbstbild als Nation allgemein-menschliche, moralische Werte einschließt. Wenn die politische Erfahrung dahingehend interpretiert wird, Nation und Republik als eine Besonderheit, als die eigene Überlegenheit gegenüber anderen Völkern anzunehmen, schwingt hier nicht zuletzt die deutsche Variante des modernen Universalismus mit.

62 K. Jeziorkowski, L iterarität und H istorismus. Beobachtungen zu ihrer E rscheinungsform im 19. Jahrhundert am Beispiel G ottfried Kellers. Heidelberg 1979 , S. 124. 63 Zitiert nach E. Graef. M artin Salander, S. 98.

64 K. Jeziorkowski, L iterarität und H istorismus, S. 122.

65 Vgl. E. G raef, M artin Salander, S. 101.

66 H. Turk, V om Klassischen A ltertum zu den Klassikern der Moderne, in: Wilhelm Voßkamp (Hrsg.), Klassik im V ergleich. N ormativität und Historizität europäischer Klassiker (D F G -Symposium 1990). Stuttgart 1993, S. 466 - 492, hier S. $482 f$.

67 Vgl. A. Boeckh, E ncyklopädie und M ethodologie der philologischen W issenschaften. Hrsg. v. Ernst Bratuschek. Leipzig 1877, S. 10, 19.

68 Vgl. Graefs Interpretation , Arnold sei angesiedelt „zwischen Bewahrungswillen, Pragmatismus und Kulturkritik“, S. 88f.

69 So heißt der Titel eines polemischen Aufsatzes von Sloterdijk; P. Sloterdijk, N ach der Geschichte, in: W. Welsch (Hrsg.), W ege aus der Moderne. Schlüsseltex te der Postmoderne D isk ussion. Weinheim 1988, S. 262-273. 
Im folgenden werde ich versuchen, die geschichtsphilosophische Position Amolds als ein $\mathrm{G}$ anzes erscheinen zu lassen, um aus den episodenhaft und fragmentarisch verstreuten Aussagen Arnolds einen in sich relativ geschlossenen Komplex herauszukristallisieren. Dabei gilt, daß das Zusammentreffen der französischen und der deutschen Modeme in der Tat ein wichtiger Bestandteil der schweizerischen Identität ist, sowohl zeitrealitätsbezogen als auch zukunftsbezogen. Denn der Imaginationsraum, in welchem die Zukunft der Nation der Schweiz durch Arnold reflektiert wird, entsteht über eine Art des ,interkulturellen' Dialogs, so daß der französische und der deutsche Nationalismus sich gegenseitig zugunsten eines neuen Verständnisses der Nationen aufheben.

Ein erhellendes Beispiel für die Dialogizität als Prinzip des kritischen D enkens bei Amold liefert ein Sprachspiel: Amold kehrt den Spruch ,C'ést partout omme chez nous' (,Es ist überall wie bei uns') zu ,C'est dhez nous oomme partout' („Es ist bei uns, wie überall") (S. 389) um. Mit dem Spruch ,C'est partout omme chez nous' kann wohl der bekannte Satz ,la civilisation francaise est la avilisation humaine' assoziiert werden - einerseits Ausdruck des französischen Nationalismus und Expansionismus, andererseits Ausdruck des Glaubens an das Allgemein-Menschliche.70 Dieser französische Universalismus wird in Form von Arnolds Sprachspiel in den deutschen Universalismus überführt und damit seines sendungsbewußten Glaubens beraubt: Im Vergleich mit den anderen nichts Besonderes, sie sind ihnen nicht überlegen. Arnolds Entdeckung des Eigenen im Fremden läuft schließlich auf „eine kleine Zurücknahme aller Eigenart" einer Nation hinaus. Es bedeutet eine Eindämmung des Patriotismus des Vaters, der in der Sache der Nation "manches für unvergleichlicher und einziger gehalten hatte, als es war" (S. 389).

D ie Idee, die dem Patriotismus Martin Salanders zugrunde liegt, ist einmal der Holismus, daß „sich nur im Zusammenspiel von personaler und sozialer Selbstverwirklichung eine harmonische Identitätsbildung erreichen läßt" ${ }^{71}$ Die Nation ist für Martin Salander nach innen und außen eine „Patrie à faire", also „eine staatsbürgerliche wie persönliche Aufgabe erster Güte“ .72 Zum anderen erinnert Martin Salanders Betonung der Unvergleichlichkeit und Einzigartigkeit der Nation an einen Gedanken, der auf Johann Gottfried Herder zurückgeht.73 In seiner frühen Schrift A uch eine Philosophie der G eschidte (1774) betrachtet Herder die Kulturen und Nationen als untereinander gleichberechtigt. Die Kulturen bzw. Völker sind bei Herder kollektive Individuen, denen durch die Natur ihres Landes und durch ihr geschichtliches Schicksal mitbedingte, in allen Objektivationen nur sich selbst gleiche genetische Individualität zuzuschreiben ist.74 Herder überträgt nämlich den Individualismus auf die Ebene bisher untergeordneter kollektiver G ebilde, wobei seine Auffassung vom Menschen holistisch ausgerichtet ist, d.h., daß der Mensch bei Herder nicht der abstrakte Wert eines Individuums ist, sondern immer in einem konkreten geschichtlichen und kulturellen Kontext steht. Während Herder von der "ganze[n] E inheit [...] aller Nationen [ ] in alle[r] ihrer M annigfaltigk eit" 75 spricht, hat seine Nachwelt die kollektiven Individuen häufiger hierarchisch mißverstanden. ${ }^{76}$ Nicht der Holismus an sich, sondern der Holismus in dieser spezifischen Umprägung im Sinne von hierarchisierten Kollektivindividualitäten ist die Zielscheibe von Arnolds Kritik: „[E ]s würde vieles erträglicher werden, wenn man weniger selbstzufrieden wäre bei uns und die Vaterlandsliebe nicht immer mit der Selbstbewunderung verwechselte!" (S. 388)

So wie er den französischen einheitlich-universalistischen Spruch zur rhetorischen Entleerung des deutschen individualistischen Universalismus seit Herder einsetzt, verfährt Arnold auch in umgekehrter Richtung. Kritisiert wird von Arnold der Fortschrittsgedanke, der zu politischem Handeln auffordert und gleichzeitig selbiges begründet. Dabei liegt eine gewisse Affinität zu der geschichtsphilosophischen Position Herders nahe: Der Titel A uch eine Philosophie der G eschichte kennzeichnet Herders Schrift als Relikt einer Geschichte der Aufklärung - besonders der Voltaireschen, rationalistischen und damit einheitlichen G eschichtsauffassung. Angesichts der Vielfalt aller untereinander gleichberechtigter Kulturen ist bei Herder die Geschichte gerade nicht linearer Fortschritt: „D as menschliche G efäß ist einmal ke ener V ollkommenheit fähig: muß immer verlassen, indem es weiter rüdkt." ${ }^{77}$ Demnach ist die Geschichte ein Komplex von Bewegungen und eine Folge sich ablösender Blüteperioden, in denen jeweils eine kollektive kulturelle Individualität im Vordergrund steht und sich als jeweils einzigartiger und unersetzlicher Repräsentant der "nichtlinearen, widersprüchlichen, progressiven Entfaltung der Humanität"78 zur Geltung bringt. In diesem Sinne distanziert sich Herder davon, die Humanität, „den Charakter unseres Geschlechts",79 mit den Teilaspekten ihres Inhalts zu identifizieren und diese isolierten Teilaspekte dann zu verabsolutieren. Für ihn schließt das Wort Humanität alles ein,

70 Vgl. N. Elias, E in E xkurs über N ationalismus, in: ders., Studien über die D eutschen. M achtk ämpfe und H abitusentwidk lung im 19. und 20. Jahrhundert. Hrsg. v. M. Schröter. Frankfurt / M. 1992, 176f.

71 H. Scheuer, H istorismus - Positivismus - Realismus. S. 27, in: D eutsche L iteratur. E ine Sozialgeschichte. Bd. 7. V om N achmärz zur G ründerzeit: Realismus 18481880. Hrsg. v. Horst Albert Glaser. Hamburg 1982.

72 A. Muschg, ,M artin Salander', S. 163.

73 Es liegen bei Kaiser (ders., G. Keller.) mehrere Stellen zum Vergleich von Kellers und Herders Geschichtsvorstellung vor, jedoch nicht spezifisch auf Martin Salander bezogen.

74 L. D umont, Individualismus, S. 132

75 J. G. Herder, A uch eine Philosophie der G eschichte, in: ders., W erke 10 Bde. Bd. 4. Schriften zu Philosophie, Literatur, Kunst und A ltertum 1774-1787. Hrsg. v. J. Brummack / M. Bollacher. Frankfurt/ M. 1994, S. 35

76 Vgl. O. Dann, H erder und die deutsche B ewegung, in: G. Sauder (Hrsg.), J. G . H erder 1744-1803. Hamburg 1984, S. 308-340.

77 J. G. Herder, A uch eine Philosophie der G eschichte, S. 29.

78 H. E. Bödeker, M enschheit, H umanität, H umanismus, S. 1093, in: O. Brunner u.a. (Hrsg.), G eschichtliche G rundbegriffe. H istorisches L exik on zur politischsozialen Sprache in D eutschland. Bd. 3.

79 J. G. Herder, Ideen zur Philosophie der G eschichte der M enschheit, in: ders., W erke 10 Bde. Bd. 6. Hrsg.v. M. Bollacher. Frankfurt/ M. 1989. S. 154. 
was ich [Herder; J.H. B.] bisher über des Menschen edle Bildung zur Vernunft und Freiheit, zu feinem Sinnen und Trieben, zur zartesten und stärksten Gesundheit, zur Erfüllung und Beherrschung der Erde gesagt habe: denn der Mensch hat kein edleres Wort für seine Bestimmung als er selbst ist, in dem das Bild des Schöpfers abgedruckt lebet.80

So in säkular-religiösen Kategorien gefaßt ist die Geschichte bei Herder eine in den Bereich der Natur eingefügte Menschheitsgeschichte, eine ,andere' Universalgeschichte, in der sich in eigentümlicher Weise kausale und teleologische Betrachtung vermischen. Jede geschichtliche Bewegung muß demnach organisch-vitalistisch sein.

Bei Arnolds Geschichtsauffassung handelt es sich um einen Gedankenkomplex, in dem mehrere Denkfiguren dahingehend synthetisiert sind, daß die rationale Sinn- und Zielbestimmung der G eschichte aufgelöst wird.

In einem Brief an seinen Vater meldet Arnold während seines Englandaufenthaltes seine Fortschrittsskepsis an, indem er einen „alten Herren“ zitiert:

[...] sei der Fortschritt nur ein blindes Hasten nach dem Ende hin und gleiche einem Laufkäfer, der über eine runde Tischplatte wegrenne und, am Rande angelangt, auf den Boden falle, oder höchstens dem Rande entlang im Kreise herumlaufe, wenn er nicht vorziehe, umzukehren und zurückzurennen, wo er dann auf der entgegengesetzten Seite wieder an den Rand komme. Es sei ein Naturgesetz, daß alles Leben, je rastloser es gelebt werde, um so schneller sich auslebe und ein Ende nehme; daher, schloß er humoristisch, vermöge er es nicht gerade als ein zweckmäßiges Mittel zur Lebensverlängerung anzusehen, wenn ein Volk die letzte Konsequenz, deren Keim in ihm stecke, vor der Zeit zu Tode hetze und damit sich selbst. (S. 182f.)

In diesem Bild wird die Geschichte, die geschichtliche Entwicklung, als ein Phänomen der Natur vorgestellt. Bei genauerem Hinsehen ist zu merken, daß hier zwei Typen bzw. Stufen der Naturvorstellung miteinander verknüpft werden, von denen sich wiederum zwei Geschichtsauffassungen im 19. Jahrhundert ableiten lassen. Zum einen ist es die organischvitalistische Vorstellung, die von der Aufklärung über Herder bis Hegel auf verschiedene Weise mit dem Fortschritts- und Entwicklungsgedanken einhergegangen ist. Das Bild vom Keim und der Frucht oder das der Lebensalter stellt dabei die naturale Entwicklungsmetaphorik bereit, in der man den Weg der Geschichte zu versinnbildlichen suchte. Diese Naturmetaphorik in ihrer organisch-vitalistischen Prägung vermengt sich hier mit einer weiteren Naturmetaphorik, so daß die ihr eigenen fortschrittstheoretischen Ingredienzien zurücktreten. Dieses zweite, eigentlich dominierende Naturbild entspingt der Z eit der explosiven Entwicklung der modernen Naturwissenschaften, in der die Natur ihre metaphysische, ideelle und moralische Bedeutungsdimension einbüßt. Mit der Natur wird auch „die Moral zur Physik“, so „daß Moralisches nicht mehr von der Idee her, sondern physiologisch begründet wird. " ${ }^{81}$ Fortschritt ist nicht als qualitativer Richtungsbegriff zu denken, sondern als animalischer Instinkt, sich zu bewegen, ohne Ziel und Zweck, ja ohne überhaupt „zu wissen, was das Unerhörte eigentlich sein solle" (S. 182).

Liegt dem Fortschrittsoptimismus die Vorstellung der Unendlichkeit der moralischen und politischen Entwicklung zugrunde, so wird in Arnolds Bild der Bewegungsraum der Geschichte als „eine runde Tischplatte“ (ebd.) eingegrenzt gedacht. Die Beschleunigung bedeutet in der Begrenztheit dieses Raumes eine nur ,falsche', selbstzerstörerische Bewegung, die schnell an ihr Ende kommt. Sinnvoll bleibt nur noch das Hinauszögem des Endes, die Verlängerung der Lebenszeit, der Gegenwart: „,G egenwart' ist das Losungswort, es gilt das Hier und Jetzt." ${ }^{2}$ Es ist die „Aversion gegen die Geschichte und den historischen Blick, die dem Versunkenen zugeschlagen werden" ${ }^{\prime}, 3$ die die G eisteshaltung des Naturalismus im Wesentlichen treffen.

So betrachtet geht, wie schon behauptet, Arnolds Position nicht im Historismus auf. Sie nähert sich zum Teil auch der naturalistischen Reaktion gegen den Historismus. D as Naturalistische bei Amold drückt sich als das Allgemeine aus, das er im Fremden wie im Eigenen gefunden hat. Es ist nicht das, was die universalistische, aufklärerische Geschichtsauffassung als das Allgemein-Menschliche deklariert: das Prinzip der Vernunft und Freiheit.

Die Reife der politischen Praxis, also die G eschichte, erweist sich nicht als zielgerichtete Entwicklung, sondern als ziellose Veränderung, mit der die Länder sich immer mehr annähern. Was steht hinter dieser stetigen Veränderung, hinter der Bewegung ohne Ende und Ziel? Es ist die Kraft des Geldes, das in seinem abstrakten allgemeinen Charakter alles Konkrete, jede individuelle Differenz zerstört. Zerstörerisch ist diese K raft für den Wert der Nation und deren progressive Rolle für Demokratie und Freiheit. D er patriotische G rundsatz, in dem Vater und Sohn Salander sich einig sind, ist durchaus zurückhaltend: Diese Nation durfte, obwohl sie sich in der zunehmenden Reife der politischen Praxis andern Vaterländern annähern mochte, mit keinem anderen verwechselt werden. ${ }^{84} \mathrm{D}$ ie einst emphatisch beschworene E inzigartigkeit der Nation wird auf eine minimale Bedingung der Individualität, nämlich die der Nicht-Verwechselbarkeit reduziert. Die Nation wird sich hier von ihrer Vergänglichkeit im Sinne von Vergänglichkeit bewußt. D as Ende der Nationalgeschichte als politischer Entwicklungsgeschichte und kultureller Individuationsgeschichte rückt näher.85

80 Ebd., S. 154.

81 K. Jeziorkowski, L iterarität und H istorismus, S. 112.

82 Ebd., S. 113.

83 Ebd., S. 113.

84 Vgl. A. Muschg, ,M artin Salander', S. 163.

85 Vor diesem Hintergrund kann der historiographische Perspektivenwandel von der Nationalgeschichte zur Sozialgeschichte in England und Frankreich verstanden werden. In D eutschland überlebte der Historismus seine politische G egenwartslosigkeit in der Form der Kulturgeschichte. Eine Ausnahme bedeutet Karl Lamprechts ,Kulturgeschichte', die sich gegen die damals dominante politische Geschichtsschreibung, die auf große Persönlichkeiten im Rahmen ihrer Staatstätigkeiten fixiert war, wandte, die sich aber auch von ,der Kulturgeschichte' der Zeit grundsätzlich abhebt. Mit ,Kultur' meinte Lamprecht nicht den engen, in der Zeit charakteristisch vom Nationalbewußtsein geprägten Kulturbegriff, sondern die „Lebensformen vergesellschafteter Menschen“ (L. Schorn-Schütte, Karl L amprecht. Kulturgeschichtsschreibung zwischen W issenschaft und Politik. Göttingen, 


\section{Bildersprache des, $\mathrm{N}$ ach der $\mathrm{G}$ eschichte'}

Die nachlassende Individualität der Nation zieht ihre Konsequenz auf der Ebene der Darstellung der Figuren nach sich. So zeigt sich bei der Gruppe um Amold eine Konturierungsschwäche in dem Maße, wie ihre Gemeinschaft in der Zeit der sich einander immer ähnlicher werdenden Nationen ihre Kollektivindividualität verliert. So tritt der Zusammenhang zwischen dem Mangel an politischer Aktivität und Gestaltlosigkeit bei Amolds Tafelrunde deutlich hervor. Kellers Charakterisierung jener „ganz vortreffliche[n] Menschen“ (S. 405) ist nichts anderes als "das karge und prosaische Porträt der leidenschaftslosen und pragmatischen „Mannschaft', ,. 86 Die Charakterisierung bleibt sprachlich nur in solchen ,Ex-negativo-Formeln' faßbar wie: „die Abwesenheit aller schlechten Sprechmanier" (S. 403), „nicht ein unfreisinniges Wort“ (ebd.), „keiner tat sich als Lehrer oder Prophet hervor" (S. 404), „es spielt keiner eine Rolle“ (S. 405), „es sind keine Streber“ (ebd.) und „ohne starkes Geräusch“. (Ebd.)

$\mathrm{Daß}$ das geschichtliche Projekt des Nationalstaates substanzlos geworden ist, drückt sich nicht nur in der Unmöglichkeit aus, den politischen Bürger als Individuum zu gestalten. Mit der gleichen Konsequenz ist auch die Zeit, die geschichtliche Zeit, problematisch geworden. Die G eschichte oder die Z eit können nicht mehr wie bisher als Geschichte der Nation, analog zur Lebenszeit einer einzelnen Pflanze, eines Tieres, eines Menschen usw. vorgestellt werden. Die neue Zeit oder die neue Geschichte liegen deswegen jenseits der Lebenszeit, sind also der Tod. Der Tod, das Ende der Geschichte, tritt in etwas gemilderter Form auf. Die Geschichte des Romans schließt so mit dem Ende des Festmahls in Arnolds Freundeskreis. Die Freunde gehen nach Hause, und im Haus Salanders wünscht man sich Gute Nacht. Allein Arnold bleibt wach: „[W]ill ein Stündchen lesen, eh' ich schlafe!" (S. 406)

Erstaunt über Amolds Nüchternheit ruft der Vater aus: „D en Teufel hat er Wasser getrunken!“ und erzählt der Mutter: „Er schluckte so viel Wein, wie jeder andere! Er ist eben dein Sohn, du Hexe!“ (S. 406) Die Szene klingt wie folgt aus: „Alle lachten über den komischen Zorn und gingen zu Bett." (Ebd.)

Nun wird eine Zeit angekündigt, in der allein der "Geschichtsfreund“ zum Lesen wach bleibt, während die anderen sich schlafen legen. Es ist die Zeit des "Nach der Geschichte', zum „Zorn“ des Fortschrittsidealisten Martin Salander. ,Nach der G eschichte' ist aber nichts tragisches, und auch der Zorn ist nur „komisch“.

Auf diese Szene des Schlafengehens folgt unmittelbar die Metapher des Schiffleins. Im folgenden versuche ich die mit Arnold angekündigte Z eit des ,Nach der G eschichte' an diesem allerletzten Bild des Romans weiter zu verfolgen.

Ruhig fuhr nun das Schifflein Martin Salanders zwischen Gegenwart und Zukunft dahin, des Sturmes wie des Friedens gewärtig, aber stets mit guten Hoffnungen beladen. Manches Stück mußte er noch als gefälschte Ware über Bord werfen; allein der Sohn wußte unbemerkt die Lücken so wohl zu verstauen, daß kein Schwanken eintrat und das Fahrzeug widerstandsfähig blieb den bösen Klippen gegenüber, welche bald hie, bald dort am Horizonte auftauchen. (S. 406)

O berflächlich betrachtet wirkt der Übergang vom Schlafengehen zur Schiff-Metaphorik unvermittelt, ja etwas abrupt, in dem Sinne, daß die Ruhe des Schlafes sich in die Bewegung der Schiffahrt verwandelt. Unterhalb dieser O berfläche aber scheint dieser Übergang gerade eine Steigerung und Weiterführung dessen zu sein, was von dem Schlafmotiv angeregt wurde. Nicht zufällig fängt das Bild von der Schiffahrt mit dem Wort ,ruhig' an.

Die Steigerung bzw. Weiterführung erfolgt in der Form einer Verräumlichung: Die Vorstellung des Endes der bewegten Geschichte versinnbildlicht sich hier als Meer - im Bild der Klippen. Als Symbol des ewigen Jetzt, der ewigen Gegenwart, ist das Meer symptomatisch für die Vorstellung von Zeit, bei der die G eschichte nicht mehr über ein klar gegliedertes Zeitbild, ein Zeiten-Kontinuum von Vergangenheit, G egenwart und Zukunft verfügt. Das Meer hat im Gegensatz zum Fluß, der immer weiter fließt - dem oft verwendeten Bild für eine bewegte, zielbestimmte G eschichte - , keine Richtung, keinen Anfang und kein Ende. Auf dem Meer befindet sich alles in einem Nebeneinander. Jedoch bleibt das Meer nicht bewegungslos. Es bewegt sich stets, "des Sturms wie des Friedens gewärtig“, aber in der Weise, daß es sich als G anzes nicht verändert und daß die einzelnen Teile nur zufällig miteinander in Berührung kommen und sich dadurch vermischen. In diesem Meer hat jeder Fluß, der darein mündet - und damit selbst zur Vergangenheit wird - die Funktion, den zurückgelegten Weg zu bespiegeln. Ähnlich ist auch Kellers Perspektive: Wie man aus dem Entwurf zu einem unausgeführten Vorwort zum Martin Salander herauslesen kann, wollte er im Roman eine Zeit deklarieren, „in der alle Nationen, große und kleine, eine Art Romanbekenntnisse ablegen, in denen sie ihre Schäden vergleichen und beklagen, Überhebungen und Verirrungen abbüßen, und ihre Besserungsrecepte austauschen." ${ }^{\text {"87 }}$

D as herrschende K lima in den zwischennationalen Beziehungen im Europa seiner Zeit war in Wirklichkeit alles andere als das, was Keller sich vorstellte. Insofern enthält Kellers Forderung nach einer sich kommunizierenden Völkergemeinschaft ein utopisches Moment. Die Nationen verlängerten ihre Lebenszeit, indem sie räumlich zu expandieren versuchten, indem sie also ganz anders kommunizierten als von Keller gemeint, nämlich durch militärische Machtpolitik. Soll man diesen anscheinend

1984, S. 113), das Produkt allgemein-menschlichen Handelns; deswegen also sowohl das Materielle als auch das Ideelle. Die Geschichtsschreibung soll für Lamprecht, ausgehend von dieser Kulturauffassung, die Wechselwirkungen zwischen der materiellen und der ideellen Kultur zu ihrem Zentrum machen.

86 E. Graef, Martin Salander, S. 103.

87 G. Keller, Bd. 12, Anhang, S. 432. 
krassen Widerspruch als künstlerische Fehlleistung einstufen, als eine illusorische, irrtümliche Wirklichkeitseinschätzung, völlig von der Realität abgelöst und ins Gegenteil verkehrt? Diese Frage muß mit ja' und ,nein' beantwortet werden.

Es ist gerade die überindividuelle, spracheigene Weisheit der Meeresmetaphorik, welche die Schlußszene vor einem totalen Ausblenden der Realgeschichte des Kolonialismus schützt. Trotz Kellers Aktualisierung im Sinne der Stillegung der Geschichte, die mit einer gewissen Sanftmut der Resignation im friedlichen Sich-Austauschen einhergeht, geht die der Bildsprache des Meers eigene Doppelsinnigkeit nicht ganz verloren. Diese Doppelsinnigkeit basiert darauf, daß das Meer in der gerade nicht pazifistischen realen Geschichte zum Medium der Verbindung und damit der Expansion geworden ist. So wird das Meer bei dem Philosophen der bürgerlichen Gesellschaft, Hegel, als das „größte Medium der Verbindung" und „für die Industrie das nach außen sie belebende natürliche Element" 88 bezeichnet. Durch das Meer werden, so Hegel weiter, „entfernte Länder in die Beziehung des Verkehrs, eines den Vertrag einführenden rechtlichen Verhältnisses" gebracht. Das Prinzip ,Meer' ist zugleich als „Element[] der Flüssigkeit, der Gefahr und des Untergangs“ gefaßt: Untergang des „Prinzip[s] des Familienlebens", dessen natürliches Element „die Erde, fester Grund und Boden“ ist.

Die pazifistische Zukunftsvision Kellers vom Meer als Bild für die rege Kommunikation unter den Nationen zugunsten ihres reiferen Selbst- und Geschichtsbewußtseins ist eine spätbürgerliche Version dessen, was Hegel im Zusammenhang mit „dem größten Bildungsmittel“ "alle[r] großen, in sich strebenden Nationen“ gesehen hat. Das Meer ist für Hegel Verkehr, Expansion, Gefahr und Untergang in einem. Bei Keller wird das Meer, d.h. das in ihm geschichtlich verwirklichte Prinzip, weniger als Element der Expansion bewußt gemacht, sondern eher als Vermischungs- und Austauschsmedium entmilitarisiert und entökonomisiert. Abseits von Kellers Intention bleibt aber der realgeschichtliche Zusammenhang von Kommunikation, Austausch und Expansion dem Meerbild verhaftet. D er Untergang des Prinzips des Familienlebens, des „begrenzten Kreisen [sic] des bürgerlichen Lebens", den das Meer-Prinzip in sich einschließt, wird in Kellers Meer ebenso deaktualisiert. Keller widmet dem Untergang ein anderes, märchenhaftes Bild, und zwar Maries Erdmännchen-Märchen. D er Abschied vom Prinzip ,Erde' wird feierlich-wehmütig hingenommen, worauf später noch zurückzukommen sein wird.

Kellers Meer-Bild konkretisiert die von Arnold vertretene Zukunftsperspektive und führt sie zugleich weiter. Expansion und kapitalistisches Wachstum werden in der Übernahme des Imaginationsraums des Meeres als geschichtliches Prinzip grundsätzlich bejaht, wenn auch in gemäßigter Form. Die Gefahr des Verlustes der kulturellen Identität durch die beständige Vermischung von Altem und Neuem wird unterbunden, indem jede Kultur, jede Nation bereits über eine Art rückwärtsgewandtes Selbstverständnis verfügt. Keller entkoppelt somit in seinem Meer die beiden in Hegels Meer ineinander verschränkten Triebkräfte der bürgerlichen gesellschaftlichen Moderne. Oder: Kellers Meer vereint, stillgestellte' kulturelle Wandlungen und das noch heute wohl bewährte Prinzip einer expandierenden Ö konomie.89

\section{B. Märchen als Paratext ${ }^{90}$ des Zeitromans}

Während Keller die Frage der sozioökonomischen und politischen Seinsweise als Gestaltungsprinzip der männlichen Figuren anthropomorphisiert, bettet er die literarästhetische Thematik in die Konstellation der beiden Frauenfiguren, Myrrha und Marie, ein. Daß die Figur Myrrha von allegorischer Bedeutung für Kellers poetologische Selbstreflexion ist, wird in der Forschung immer wieder erwähnt. Nicht genug aufmerksam gemacht wird aber auf Marie in ihrer Bedeutung als poetologischer Gegenspielerin Myrrhas. ${ }^{91}$ Die Geringschätzung der poetologischen Bedeutung Maries liegt wohl in der Romanhandlung begründet, insofern es nicht Marie selbst, sondern ihr Sohn Arnold ist, der mit dem ,Rüstzeug des Historismus' gegen den Scheincharakter der klassischen Schönheit Myrrha agiert. D iesem Umstand gemäß wird die ästhetische Position des Romans im Sinne eines Übergangs von der Poesie zur wissenschaftlichen Nüchternheit, von dem poetischen Realismus zum Historismus aufgefaßt. ${ }^{22}$ D iesen poetologischen Positionswechsel bestreite ich, indem ich bei der Betrachtung der poetologischen Frage den Akzent vom Gegensatz zwischen Myrrha und Amold auf ,Myrrha contra Marie' verschiebe. Z war wird in der Myrrha-Figur der poetische Realismus als klassisch-idealistische Vorstellung von Schönheit widerrufen. Aber dies kommt nicht einer historistischen Nüchternheit zugute. Denn in Marie, genauer in ihrem Märchen, wird die Poesie bewahrt. Es handelt sich keinesfalls um einen neueren Poesiebegriff, vielmehr um einen uralten. Sie ist es, die nun vom Gewicht der idealistischen

88 G. W. F. Hegel, G rundlinie der Philosophie des Rechts. Frankfurt 1986, § 247.

89 Diese Strategie ist, Habermas zufolge, gerade für die deutschen neokonservativen Gesellschaftstheoretiker nach dem 2. Weltkrieg charakteristisch, die Habermas neben den amerikanischen Neokonservativen und den enttäuschten Liberalen in einem Aufsatz analysiert. (ders., D ie Kulturk ritik der N eok onservativen in den USA und in der Bundesrepublik, in: ders., D ie neue Unübersichtlichkeit. Kleine politische Schriften V . Frankfurt/ M. 1985, S. 30f.) „Theoretiker wie Ritter, Forsthoff und Gehlen hatten sich gerade auf der Basis einer stillgestellten kulturellen Moderne mit der gesellschaftlichen Moderne ausgesöhnt." (Ebd., S. 44) In seinem Meer-Bild scheint Keller wohl das vorwegzunehmen, was A. Gehlen mit dem Stichwort ,Kristallisation' ausdrückt. Nach Gehlen ist die moderne Kultur „kristallisiert", weil „die darin angelegten Möglichkeiten in ihren grundsätzlichen Beständen alle entwickelt sind." (Ebd., S. 43)

90 Ich übernehme diese Terminologie von G. Genette (ders., Paratexte. D as Buch vom Beiwerk des Buches. Frankfurt/ M. 1992.).Vgl. hinsichtlich der Modifikationen, die ich für die Interpretation des Romans vornehme, den Eingang von Kapitel III: M aries Märchen dieser Arbeit.

91 G. Kaiser bezeichnet Marie in diesem Sinne als ,Antimuse'. (ders., G . Keller, S. 596.)

92 Vgl. B. Neumann, G ottfried Keller. V II: Jenseits der Poesie - „M artin Salander", bes. S. 292-300. 
Ästhetik entlastet, zugleich aber auch von dem Naturalismus „entfremdeter Realitätsbrocken“93 befreit selbst durch den Historismus nicht mehr einzuholen ist. Die Poesie erscheint im Märchen ursprünglich und elementar.

\section{Mymha: Kritik an der Funktionsgeschichte des Klassischen}

Myrrha gilt für viele Keller-Forscher als späte Distanzierung des Autors von der schönen Poesie im Sinne des poetischen Realismus. Wie in diesem und noch deutlicher in den folgenden Kapiteln zu zeigen ist, hat Keller aber, so meine Hauptthese, den Glauben an die Schönheit als Wesen der Poesie nicht ganz preisgeben wollen. D enn, wie sein eigenes Urteil über Martin Salander: „Es ist nicht schön! Es ist nicht schön! Es ist zu wenig Poesie darin!"94 verrät, konstituiert sich die Poesie für den Autor nach wie vor durch ,Schönheit'.95

In der Myrrha-Episode liegt dennoch ohne Zweifel etwas, was im Sinne einer kritischen Selbstdarstellung des Autors bezüglich des eigenen ästhetischen Ideals zu deuten ist. Es liegt Keller bei Myrrha wohl daran, der Schönheit, der omnipräsenten Machthaberin im Reich der Poesie, den Schleier zu entreißen. Statt die Schönheit in seiner künstlerischen Tätigkeit, im Erzählen, obwalten zu lassen, und damit einmal mehr ihre Gesetzgebung zur vollen Geltung zu bringen, vergegenständlicht er die Schönheit in Myrrha zu einem bloßen Anordnungsprinzip. Statt der Schönheit stillschweigend im Erzählen zu dienen, macht der Autor sie zu einem Erzählgegenstand, der sie degradiert. Darin dürfte die poetologische Bedeutung der Myrrha-Figur liegen. Gleichwohl wäre es verfrüht, die in die Myrrha-E pisode eingebettete Distanz zur Schönheit als eine ,emphatische' Distanz und dramatische Abwendung von der Poesie zu deuten. Zwar wird der Mythos der klassischen Schönheit als solcher vergegenständlicht und in seinem Schein-Charakter entlarvt. Die Schönheit wird jedoch nicht in jedem Sinn aus der Poesie verbannt. D er Status der schönen Poesie ist im Martin Salander recht ambivalent. Auf welches ästhetische D ilemma läßt das zwiespältige Verhältnis zur Schönheit schließen? Dies wird im folgenden geklärt.

\section{Schöner Schein im D ienst des W ahren und des $G$ uten}

Kellers doppeldeutiges Verhältnis zur Schönheit steht vor dem Hintergrund des zeitgenössischen institutionalisierten Schönheitsdiskurses, der sich in der spezifischen Ästhetik-Rezeption des deutschen Idealismus im ausgehenden 19. Jahrhundert ausdrückt. Was Keller in der Myrrha-Gestalt reflektiert, ist die Funktionsgeschichte des klassischen Schönen in seiner Rezeptionsgeschichte. Seine Reflexion richtet sich dabei sowohl auf die konstitutive und sich immer mehr aushöhlende Rolle des Klassischen für den geschichtlichen Fortschritt als auch auf das konkrete gründerzeitliche Phänomen des regressiven Umgangs mit den nationalliterarischen Klassikern. Was die Ästhetik des deutschen Idealismus im Rückgriff auf das klassische Schöne aufgefangen hatte, war nichts weniger als die allgemeine Problematik der Moderne, das widersprüchliche Verhältnis zwischen Besonderheit und Allgemeinheit, Individuum und dem größeren $\mathrm{G}$ anzen. Wie bereits gezeigt, handelt es sich bei Keller niemals um das Individuum an sich. Während bei Rousseau die notwendige Bedingung bzw. die letzte Instanz die soziale Natur des Menschen war, ${ }^{96}$ bildete bei Keller das Individuum den Ausgangs- und Zielpunkt der moralischen Frage. Die individuelle Erscheinung, die konturscharfe Individualität, konnte aber durch die soziale und politische Existenz versehrt werden.

Vor dem Hintergrund der Individualitätsproblematik bei Keller ist Myrrhas Erscheinung als klassische griechische Schönheit zu bewerten. Auffallend ist bei Myrrhas schöner Erscheinung, daß sie anfangs ähnlich wie Weidlichs Z willinge und Salanders Töchter in einer gewissen Duplizität mit ihrer Halbschwester Alexandra, der Ehefrau Wohlwends, auftritt. Von Wohlwend ins Hotel mitgenommen, „sah er [Martin Salander; J.-H. B.] sich in einem Salonzimmer zwei stattlichen Frauen gegenüber, deren Schönheit verschieden, aber gleich fremdartig erschien, ebenso wie ihre Haltung und Reisetracht." (S. 270) Erst beim zweiten Besuch erkennt Martin Salander die Verschiedenartigkeit zwischen den „Wohlwend-Frauen“ genauer. D iesmal stehen Myrrha und Alexandra bezüglich ihrer G röße, ihrer Gesichtszüge, ihrer Geschicklichkeit und ihrer Bekleidung im Kontrast zueinander. Jedoch ist mit dieser Erkenntnis der äußeren Eigentümlichkeit Myrrhas durch den Protagonisten noch nicht die Individualität Myrrhas gewährleistet. Diese Szene ist vielmehr der Anfang eines peinlichen Vorgangs des Verkennens, das die ganze Episode der Begegnung mit Myrrha durchzieht. Durch Wohlwends Hinweis auf Myrrhas Abstammung aufmerksam gemacht, fährt' Martin Salander prompt auf deren griechisches Profil ,ab'.

"Nimm dich in acht!" sagte Louis Wohlwend scherzend, „es fließt wahrscheinlich hellenisches Blut in ihren Adern. Mein seliger Herr Schwiegerpapa hat ihre selige Mama vom Schwarzen Meere herüber geholt und deren Vorfahren sollen aus Thessalien dorthin gekommen sein." Martin blickte die stille Nachbarin von der Seite an, die ihm jetzt ganz nah war. [...] alles wie nach dem Rezept für altgriechische Frauenköpfe. (S. 271f.)

93 G. Kaiser, G. Keller, S. 588.

94 Gottfried Keller im Gespräch mit Adolf Frey über M artin Salander, in: Bd. 12, Anhang, S. 424.

$95 \mathrm{Vgl}$. W. M. Fues, A bbildentstellung? A nmerk ungen zu G ottfried Kellers M artin Salander anhand neuester Literatur, in: IASL. Bd. 9, 1984, S. 152-179, hier S. 152.

96 Vgl. L. D umont, Individualismus. Zur Ideologie der M oderne, S. 131. 
Von diesem Moment an wird Myrrhas individuelle Erscheinung von Martin Salander zur idealen G eltung erhoben. Myrrha führt ein tendenziell vom Sozialgefüge losgelöstes Dasein, was ja im Sinne Kellers kein wahres menschliches Sein ist, weil es einer konturscharfen Individualität enträt. G enau gesehen ist ihre Herkunft rätselhaft im negativen Sinn; sie soll aus Thessalien, dem Hexenland der klassischen Mythologie, kommen. Diese Auskunft ist nicht einmal als glaubwürdige Familiengenealogie gesichert, sondern gilt lediglich dem Familiengerücht nach. Fernerhin wird die soziale Stellung Myrrhas in ihrem etwas unklaren Verwandtschaftsverhältnis zu Wohlwend problematisiert. Da Myrrhas genealogische Beziehung zu Wohlwend die Enge der erstgradigen Familiarität sprengt, impliziert diese indirekt das Soziale, insofern dieses außerhalb des Kreises der Kleinfamilie verortet ist. Für Myrrha bedeutet dieses latent soziale Verhältnis nichts weniger als totale Abhängigkeit und Unterwerfung., zumal sie von Wohlwend als Köder für den „Erbe[n] des bedeutenden Handelsgeschäftes“ (S. 381) Salanders, Arnold, benutzt wird. Es fehlt ihren Äußerungen jede Innenperspektive, die einem Individuum als Subjekt zur Verfügung stehen muß. Vielmehr wird ihre Ich-Identität ausschließlich von der Außenperspektive getragen. Myrrha sagt Arnold in peinlicher O ffenheit: „Bin ich nur schön, aber nicht ganz gescheit, sagte mein Vater seliger, und Herr Volvend-Glavicz sagt, bin ich auf den Kopf gefallen“. (S. 397) Im Sinne jener Außenperspektive soll ihre künftige Lebensführung heißen: „[A]ber Heiraten macht gesund!“ (Ebd.) Ein Lebensplan, den das Subjekt, der eigentliche Handlungsträger, nicht versteht, nicht glaubt, aber hinnimmt, denn Myrrha fügt hinzu: „Versteh ich nicht, aber auch glaube ich nicht, bis ich das sehe!“ (Ebd.) Was hier mit Myrrha gezeigt wird, ist die Unfreiheit, die Unvernunft eines gesellschaftlich nicht fest zu lokalisierenden Individuums. Denkt man daran, daß die Substanz der klassischen Schönheit mit der geschichtsphilosophisch fundierten Harmonielehre von Individuum und Gesellschaft konvergierte, 97 dann bricht bei Myrrha gerade das Wesen des Schönen - „die Einheit desselben [des Begriffs in seiner Allgemeinheit; J.-H. B.] mit der individuellen Erscheinung" 98 - zusammen. D as Schöne tritt nun aus dem Dienst des Wahren und des Guten heraus.

\section{G eschichtliche Referenzlosigk it des Klassischen}

D ie geschichtliche und politische Implikation des klassischen Schönen tritt bei dem Protagonisten in der Weise zutage, daß sich dieser von der Schönheit mutmaßlich griechischer Abstammung inspiriert "glaubte", "das Blühen des Vaterlandes in neuer Jugend zu genießen" (S. 306). D aß seine späte erotische Bezauberung unbedingt zur politischen Aktivität sublimiert werden soll, wird vom E rzähler als „pedantische Liebelei“ (S. 385) verhöhnt. Z weifellos ist das schöngeistige Pendant dieser „pedantische[n] Liebelei“ die in jener Zeit weit verbreitete Form der Klassikrezeption. Sie wird von den Bürgern getragen, denen Martin Salander bei der Ausfahrt mit der Wohlwendsippe begegnet. Ein bekannter Künstler sagt angesichts Myrrhas:

D as sieht man nicht alle Tage! Sapperlot, sehen Sie, welch ein einfacher Rhythmus, ohne allen Aufwand, man weiß kaum, wo es steckt, Form und Bewegung in eines gegossen! Wie edel das fließt, vom Nacken über Schultern und Arme, auf den Rücken und von den Hüften herunter! (S. 298f.)

An dieser nach Winckelmanns berühmter Formel, edle Einfalt und stille G röße' konstruierten Bemerkung schließt sich die Frage nach dem Herkunftsort der zum fassadenhaften G egenstand degradierten Schönen an: „Wo stammt die Dame her?" (S. 299). Salander antwortet: „,Sie kommt mit einer Familie aus Ungarn, ihre Mutter soll aber irgend von altem Griechenboden, aus Thessalien herstammen.“ (Ebd.) Darauf folgt noch ein anzüglicher Kommentar des Künstlers: „Ganz glaublich! Und auch in diesem Fall noch eine Rarität! Viel Vergnügen, Herr Salander!“ (Ebd.) „Welch eine Bestätigung [m]eines Schönheitsgefühles!“ (ebd.), denkt sich der Protagonist. Die Worte des „Künstlers und Kenners" machten „sein Herz klopfen und seine Augen glänzen, während sie zugleich seine Schritte lähmten, daß er sich auf eine im G ehölze befindliche Bank niederlassen mußte." (Ebd.) D abei stellt der Erzählerkommentar den pedantischen Protagonisten in den Vordergrund.

Wie wurde sein dunkler Trieb aufgehellt, noch eine Strecke Weges im Strahle echter Schönheit zu wandeln, und er ahnte nicht, wie echt pedantisch es war, durch Aussagen eines andern, eines Kenners, sich bestärken zu lassen. (Ebd.)

Die Tragweite dieses Vorwurfs von ,pedantischer Liebelei' geht doch recht weit, denn sie visiert den ganzen Projektcharakter der klassischen Ästhetik an. Oft wird diese thematische Dimension auf Kellers K ritik an der Klassik-Rezeption der Gründerzeit verkürzt. Kellers Reflexion über die „Pervertierung des idealistischen Schönheitsideals“ im Ästhetizismus des Jahrhundertendes ${ }^{99}$ erschöpft sich aber nicht in dem konkret gründerzeitlichen Phänomen. Die Konstruktion der MyrrhaEpisode ist wohl dahingehend zu verstehen, daß die Rezeption des klassischen Schönen in ihrem Projektcharakter verdeutlicht werden soll. Das Griechisch-Klassische wird bekanntlich in der Regel nicht um seiner selbst, sondern um des neuzeitlichen Menschen willen benötigt, und zwar, um dessen Fortschritt zu ermöglichen. Bei dem Klassischen geht es um „die Artikulationsmöglichkeit einer Zukunftserwartung, um ein Bild der besseren Zukunft, das mit Hilfe des Verweises auf eine als gelungen akzeptierte Vergangenheit gewonnen werden soll und kann. ${ }^{\prime 100}$ Dort, wo die Geschichte im Zerfall der

97 Auch W. M. Fues verweist auf diese klassizistisch-idealistische „Gewähr freier Individualität durch die Gesellschaft" (ders., A bbildentstellung?, S. 152.)

98 G. W. F. Hegel, V orlesungen über die Ä sthetik I. S. 140, in: ders., W erke in 20. Bdn. Hrsg. v. E. Moldenhauer / K. M. Michel, Bd. 13. Frankfurt/ M. 1986.

99 E. Graef, Martin Salander, S. 114

100 A. Gethmann-Siefert, D as Klassische als das Utopische. Überlegung zu einer Kulturphilosophie der Kunst, in: R. Bockholdt (Hrsg.), Über das Klassische. Frankfurt/ M. 1987, S. 47-76, hier S. 54. 
Zukunftserwartungen als rückläufig gesehen wird, wird das Klassische in seinem Inhalt, in seiner Kulturfunktion, in Frage gestellt. Mit der allgemeinen Entwicklung der Geschichte, dem zunehmenden Abstraktwerden der menschlichen Vergesellschaftungen samt den damit verbundenen Entfremdungsprozessen ist die G esamtheit des Seins, d.i. das Klassische im $G$ riechenverweis, ins Unerreichbare, Unrealisierbare und Unvorstellbare entrückt worden. Infolgedessen wird jede schöne Erscheinung zu einer doppelten Absenz, d.h. zum Relikt der Vergangenheit im doppelten Sinn: Dies ist zum einen die ontische (d.h. auf die klassische Antike bezogene), zum anderen, daraus hervorgehend, die regulative (d.h. auf die klassizistische Ästhetik bezogene) Sinngeladenheit des schönen Scheins. Die Kunst, die sich dazu auserkoren sah, durch die schöne Form das in der Politizität bestehende Humane als allgemeine Nachvollziehbarkeit zu stiften, um damit der geschichtlichen Standortgewinnung zu dienen, ist selbst haltlos, orientierungslos geworden. Mit Myrrha kehrt das Klassische von einer Utopie der besseren Zukunft in die Utopie in der ursprünglichen Bedeutung des Wortes zurück: $\mathrm{Ou}$ topos (= kein Ort, nirgendwo) ist die Ortlosigkeit als geschichtliche Orientierungslosigkeit. Eine Szene symbolisiert diese geschichtliche Lage der schönen Kunst in Myrrha: Der wegen der Begegnung mit Myrrha angeregte Martin Salander findet diese beim Abschied nicht mehr. Er sucht sie nämlich „an der unrechten Stelle" (S. 273), dreht sich um sich selbst und fält beinahe hin, ehe er merkt, daß sie hinter ihm steht. Die klassische Schönheit, einst als „Vehikel geschichtlicher Selbstbewußtseinsgewinnung“101 funktionalisiert, steht jetzt „an der unrechten Stelle". Nicht als Bote der Freiheit, sondern umgekehrt als Hilfesuchende vertraut die klassische Schönheit Myrrha Arnold ihre erbärmliche Situation an, „wie wenn sie da vor die rechte Schmiede gekommen wäre in einer verworrenen und höchst bedenklichen Angelegenheit." (S. 397) Darin zeigt sich ein Paradigmenwechsel im bürgerlichen Selbst- und G eschichtsverständnis von der Poesie zur Geschichtswissenschaft, von der idealistischen Ästhetik zum Historismus, besonders zur Fortschrittsskepsis à la Arnold. Die Idealisierung oder Projektion verkehrt sich hier in den Prädikaten „blödsinnig“ und „in hohem Grad einfältig" (S. 398). Was mit Myrrha gestaltet und widerrufen wird, ist somit der funktionelle Wert des Ideals, welches dazu diente, „die O rientierung des geschichtlichen Handelns auf eine Zukunft hin zu gewährleisten durch den Blick zurück auf eine vollendete vergangene Kultur". ${ }^{102}$ Bekanntlich wurde das Ideal im Nationalstaat vorläufig als realgeschichtlich erfüllt angesehen. Bezeichnend dafür war, daß der Begriff der Weimarer Klassik im Deutschland der achziger und neunziger Jahre des vergangenen Jahrhunderts fest institutionalisiert wurde. Die Figurierung des Klassischen in Myrrha zielt auf Überspitzung und Widerspiegelung dieser Denkweise. Die Sprachlosigkeit, Schweigsamkeit der schönen Myrrha ist symbolisch für die Wirkungslosigkeit und Bezugslosigkeit der Poesie, der jegliche geschichtliche Referenzialität abhanden gekommen ist. Diese komplexe Dimension wird, wie gesagt, oft auf Kellers Kritik an der Klassik-Rezeption, der gründerzeitlichen „Pervertierung des idealistischen Schönheitsideals“, 103 reduziert. Myrrhas trügerischer Scheincharakter wird gern im idealistischen dualistischen Sinne von Schein und Sein angesehen, ein Widerspruch, der seit je für Kellers Schreiben wie ein allgemeiner Rezept gebraucht wird. Der Zerfall der Einheit von Form und Inhalt, wie ihn Keller in Myrrha thematisiert, ist aber nicht eine abstrakte, begriffliche und mechanische Entzweiung, die neben der inhaltlosen Form den formlosen Inhalt hervorbrächte. ${ }^{104}$ Mit dem Zerfall wird die Substanz, der Inhalt selbst, substanzlos. Solche genuin idealistische dualistische Perspektive erschließt nur die Hälfte des Sinnkomplexes der Myrrha-Figur, nämlich, daß Myrrha eine falsche Muse ist. Dem kann jedoch entgegengesetzt werden: die Fälschung der Muse schließt in sich die Falschheit der Musen ein. Die Fragwürdigkeit einer solchen Verfahrensweise wird nur zu deutlich, wenn die Verfahrensweise den Text selbst strapaziert, um den „D ualismus von Form und Inhalt" ${ }^{\prime 105}$ als ein den Text durchziehendes ästhetisches Gestaltungsprinzip zu belegen. In der Konsequenz dieser Sichtweise stellt der andere Teil der zerbrochenen Einheit, nämlich Marie, die moralische Instanz ohne Sinnlichkeit dar. Man kann bei Myrrha vom schönen, inhaltsleeren Schein sprechen. Es scheint aber allzu willkürlich in Marie den formalen Gegensatz dazu, nämlich die moralische Substanz ohne Sinnlichkeit, zu postulieren. Es widerspräche zumindest der Hegelschen Auffassung, daß „die Kunst es" sei, „welche die Wahrheit in Weise sinnlicher G estaltung für das Bewußtseyn hinstellt". ${ }^{106}$ D ie konturschwache Marie deutet nicht auf die Gegensätzlichkeit etwa zwischen Schein und Wesen hin. Wenn man einen Gegensatz von Myrrha und Marie im idealistischen dualistischen Sinne postuliert, wie es Graef tut,107 begeht man den Fehler, einen der wichtigen Charakterzüge dieses realistischen Textes zu übergehen. D enn Maries mangelnder Sinnlichkeit liegt das Darstellungsprinzip des Romans zugrunde. Der Roman überläßt das Äußerliche, nicht nur Maries, sondern fast aller Figuren dem Vorstellungsvermögen des Lesers. Das Aussehen der Figuren wird hier nie um seiner selbst willen angeführt. Nein, es muß einen bestimmten funktionalen Wert, d.h. einen engen Z usammenhang mit dem Handlungsverlauf haben, um über die nötige Beschreibung - wie immer sie geartet sein mag - hinausgehend thematisiert zu werden. Diese Funktionalität, welche die Beschreibung der Figur der Handlung gegenüber zu beweisen hat, kann man allgemein bei realistischen Texten, besonders aber bei Keller, beobachten. Es ist das ökonomische G esetz des Textes, demzufolge die Handlung primäre Bedeutung besitzt.

D as Kontrastverhältnis zwischen Arnold und Myrrha enthält neben dem Paradigmenwechsel innerhalb des bürgerlichen Geschichtsverständnisses ein weiteres Moment, das gerade für Kellers Kunst symptomatisch scheint. Es ist die praktische Unfähigkeit, die Ironie als ästhetisches Prinzip einzugliedern. Hegel und seine Nachfolger könnten hier wegen der

101 Ebd., S. 56.

102 Ebd., S. 65.

103 E. Graef, M artin Salander, S. 114

104 Vgl. ebd., S. 114 ; Graef spricht von einem „Auseinanderklaffen von äußerer Schönheit und moralischer Substanz, von Form und Inhalt". 105 Ebd., S. 114

106 G.W.F. Hegel, V orlesungen über die Ä sthetik I. Bd. 13. S. 140.

$107 \mathrm{Vgl}$. E. Graef, M artin Salander, S. 114. 
Ausschließung der Negativität der Ironie zugunsten eines einheitlichen, versöhnenden Denksystems angeklagt werden. Gibt es bei Schiller eine Selbsteinschränkung der Vernunft, so sollte die Ironie - als methodisches Korrektiv gegen den Klassizismus, ja gegen das der Aufklärung immanente Diktat des D enkens - auch in Kellers idealistische Ästhetik gehören. Keller formuliert denn auch die Aufgabe der Kunst 1860 noch im O ptimismus der allgemeinen Blüte der Jahrhundertmitte wie folgt:

[D jie Pflicht eines Poeten, nicht nur das Vergangene zu verklären, sondern das G egenwärtige, die Keime der Zukunft so weit zu verstärken und zu verschönern, daß die Leute noch glauben können, ja, so seien sie und so gehe es zu! Tut man dies mit einiger wohlwollenden Ironie, die dem Z euge das falsche Pathos nimmt, so glaube ich, daß das Volk das, was es sich gutmütig einbildet zu sein und der innerlichen Anlage nach auch schon ist, zuletzt in der Tat und auch äußerlich wird. Kurz, man muß, wie man schwangeren Frauen etwa schöne Bildwerke vorhält, dem allzeit trächtigen Nationalgrundstock stets etwas Besseres zeigen, als er schon ist. 108

Ob Keller diese wohlwollende Ironie als ästhetische Form und gestaltendes Prinzip zu verwirklichen wußte? In der deutschen Mentalitätgeschichte wurde die Ironie, Hand in Hand mit dem Siegeszug des Humors im 19. Jahrhundert, eher verdrängt. Allgemein findet sich ein wachsender E rnst im deutschsprachigen literarischen und philosophischen Feld. So leidet Kellers Sprache im Martin Salander unter dem Mangel an sublimer Ironie. Keller, der Autor des Humors, versagt sich die auktoriale Ironie. Es ist zwar Ironie, was sich in Arnold meldet, wenn er das ,falsche Pathos' seines Vaters umfassend konterkariert, indem er nicht nur die blöde Dummheit des verschleiernden Schweigens von Myrrha entlarvt, sondern auch auf den peinlichen Wurstgeruch im Atem der Schönen hinweist. Arnold ist, bezogen auf Myrrha, jedoch weit entfernt von dem Subjekt im Sinne der romantischen Ironie, einem Subjekt, das im gesetzlosen, subjektiven "Streben[] nach unendlicher Realität" 109 "die Spaltung zwischen seinem Ich und der Welt auf der Ebene des Scheins aufzuheben"110 sucht. Es scheint, daß Keller die ausbleibende Sprache der künstlerischen Ironie durch einen eher handfesten, derben Spott, eine volkstümliche Form der Ironie ersetzt. Dabei verknüpft Keller in Amold die Ironie zugleich mit dem Geschichtsbewußtsein der liberalen, nachmetaphysischen Gesellschaft, dem Historismus. Kellers Version der Ironie geht insofern in der subjektiven Bewußtseinsform des (Geschichts-)Wissenschaftlers auf. D amit schließt er die Möglichkeit dieser Denkfigur als integratives G estaltungsprinzip der Poesie aus. Anders als Fontane, der sich dieselbe als erzählerisches Mittel angeeignet hat, um sich selbst als dem künstlerischen Subjekt den künstlerischen Raum zu eröffnen, markiert Keller die Ironie als lebensweltlich, aber nicht kunstzugehörig, kunstfremd. D ies ist vor dem Hintergrund verständlich, daß Poesie für Keller eine affirmative gesellschaftliche Praxis zur vernünftigen Konstruktion der Lebenswelt bedeutet. In dieser affirmativ ausgerichteten Kunst hat die Ironie, das Negative oder das Heraustreten aus dem Ideal kein Wohnrecht. Zwar wurde die Ironie von Keller als das politisch und historisch Relevante anerkannt, aber nicht in seiner ästhetischen Relevanz, als künstlerisches Gestaltungsprinzip. Sie bleibt außerästhetisch und kategorial anders. Man kann sagen, daß Keller in der Ironie keine ästhetische Lösungsmöglichkeit zum Überleben der Kunst gesehen hat.

Die fatale Konsequenz der Ausschließung der Ironie manifestiert Keller gerade in der Figur der Myrrha. Erstens ist diese „Muse eines poetischen Realismus", „der sein Poetisches nicht thematisch machen kann, der in dieser Hinsicht reflexionslos ist",111 irrsinnig. Zweitens riecht die irre Muse Myrrha noch stark nach der eben genossenen Wurst. Kellers Verbildlichung der Kunst in Myrrha ist dahingehend zu verstehen, daß der reflexionslos gewordenen Kunst, der Ironie unfähig, „das Reale der Realität absolut gegeben“112 bleibt. Während die „Frühlingsluft", die der Vater sich in Myrrhas Gegenwart einbildet, auf die Idealität der Kunst als Wegbereiterin der besseren Zukunft anspielt, signalisiert der Wurstatem im Gegenzug dazu die auf Faktizität reduzierte Wirklichkeit einer der Zukunft beraubten, ironiefremden Kunst.

Im folgenden versuche ich, dieser heiklen Situation der Kunst, die in Myrrha repräsentiert wird, auf der konkreten Ebene der erzählerischen Praxis auf die Spur zu kommen.

\section{Der auktoriale Erzähler}

Im M artin Salander hört man einen auktorialen Erzähler, welcher sich von der sonst ausgeprägten humoristischen Persönlichkeit des Kellerschen Erzählers abhebt.113 Das letzte Bild vom Schifflein bildet die Ausnahme. Es ist insofern problematisch, als es eindeutig der erzählerischen Leistung des humoristischen Erzählers zuzuordnen ist. Der Erzähler verläßt seine neutrale Perspektive und tritt nun der erzählten Welt gegenüber versöhnend und vermittelnd auf. Während andere Bilder und Metaphern entweder eindeutig dem Bewußtsein der Figuren zuzurechnen sind oder über ihre Zugehörigkeit zur Erzählerschaft wenigstens nicht klar zu entscheiden ist, liegt es auf der Hand, daß das letzte Schifflein-Bild allein auf das Bewußtsein des Erzählers, auf seinen humoristischen Charakter zurückzuführen ist. Das Zurückfallen auf den humoristischen Eingriff ist aber

108 G. Keller, An Berthold Auerbach, 25.6.1860, in: G esammelte Briefe, Bd. 3,2, S. 195; Keller hat dieser Idealvorstellung der Kunst im Rahmen der Ö ffentlichkeit mit der D arstellung des Tell-Festspiels im Grünen Heinrich Plastizität verliehen.

109 F. Schlegel, Ü ber das Studium der griechischen Poesie, in: ders., Kritische Schriften. Hrsg. v. W. Rasch. München² 1964, S. 119.

110 P. Szondi, F riedrich Schlegel und die romantische Ironie, in: ders., Schriften. 2 Bde. Frankfurt/ M. 1978, Bd. II, S. 24.

111 G. Kaiser, G. Keller, S. 588.

112 Ebd., S. 588.

113 Zum humoristischen Erzählen Kellers wie der anderen Realisten vgl. W. Preisendanz, H umor als dichterische E inbildungsk raft. Studien zur E rzählk unst des poetischen Realismus. 
nur temporär und beweist indirekt das prinzipielle Ablegen des humoristischen Charakters des Erzählers im großen und ganzen. Diese nicht-humoristische Eigenart des Erzählers steht mit der bisher behandelten Problematik der klassischen Ästhetik im engen Zusammenhang. Wenn das Vertrauen in die Welt bzw. Wirklichkeit der zukunftsträchtigen geschichtlichen G egenwart in der Myrrha-Figur als verloren verkündet wird, scheint es nur folgerichtig, daß vom auktorialen Erzähler der Humor konsequent gemieden wird. Aber dies muß letztendlich auch durch die nähere Charakterbestimmung des auktorialen Erzählers bestätigt werden.

\section{D er neutrale Reflexionsraum}

Es kann als guter Ausgangspunkt dienen, die formalistisch generalisierende These, daß die auktoriale Erzählerschaft unseres Romans eine verbindliche Sicht einer objektivierbaren Wirklichkeit für sich reklamiere, ${ }^{114}$ anzuzweifeln. Im Gegenteil bleibt die weltanschauliche ,Verbindlichkeit' auf den Fall des persönlich-auktorialen, d.h. humoristischen Erzählers beschränkt. Um von einer gültigen Weltsicht sprechen zu können, fehlt es in Martin Salander allzu offensichtlich an einer klaren Perspektive. Eine Perspektive, die in der Lage wäre, die O bjektivität der Wirklichkeit zu verbürgen. Die eingehaltene Rahmenbedingung des

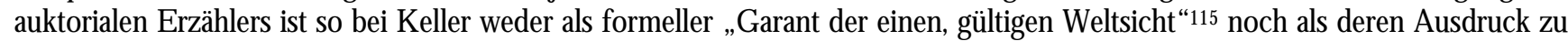
sehen. Der nicht-humoristische auktoriale Erzähler in Martin Salander tendiert nun zur Perspektivenübernahme von Figuren. Dies geschieht ähnlich wie bei Entpersönlichungsvorgängen auktorialen Erzählens in Richtung auf neutrale oder gar personale Erzählsituationen, welche die Entwicklungsgeschichte des modernen Romans kennzeichnen. Die gelegentliche Übernahme der Perspektive der Figuren durch den auktorialen Erzähler ist gerade ein wichtiger Charakterzug des auktorialen persönlichen Erzählers in seiner Schwundstufe. Bekanntlich ist der Übergang zwischen der entpersönlichten auktorialen Erzählerschaft und der personalen Perspektive fließend. Jedoch ist der Perspektivismus, welcher in Martin Salander hauptsächlich bei der Figur Martin Salander und seiner Frau Marie zutage tritt, keine subjektivistische und potentiell relativistische Angelegenheit, wie diese einen Grundzug des modernen Romans ausmacht. Der Perspektivismus hat in unserem Roman vielmehr eine eigentümlich komplementäre Funktion. So ermöglicht er dem auktorialen Erzähler, dem Leser die Schwächen und Stärken der jeweiligen Sichtweise Martin Salanders und Marie Salanders näherzubringen, und zwar, um die beiden Seiten eng miteinander zu verzahnen: Es verhält sich die Perspektive Maries in erster Linie ergänzend zu der Perspektive des Protagonisten. Maries Kritik rückt daher seine törichte Sichtweise immer wieder zurecht, spielt eine rettende und korrigierende Rolle, ob es nun um Wohlwends Machenschaften, um die unheilvollen Liebschaften der Töchter mit den Zwillingen oder um Myrrhas Schönheit geht. So bleibt Maries Wahmehmungsbereich, der assistierenden Bedeutung ihrer Perspektive entsprechend, erheblich eingeschränkt. Wiewohl ihre Perspektive als kritischer "Spiegel“ (S. 301) des Protagonisten bei dem Leser einen verbindlicheren Status erhält, versperrt Kellers bürgerlich-patriarchalisch anmutende Sichtweise'116 dem auktorialen Erzähler am Ende die letzte Konsequenz der eingeschlagenen Perspektivenübernahme von Marie. D er auktoriale Erzähler macht zunächst die zwischen Vater und Mutter Salander bestehenden perspektivischen Differenzen deutlich. Diese Differenzen sprengen sicherlich einen humoristisch einheitlichen Horizont, was sie letztlich zu einer Angelegenheit von Kompromissen macht. Beim Schließen von Kompromissen ist bekanntlich eine dritte Perspektive unabdingbar. Und diese dritte Perspektive ist tatsächlich die weitere Dimension des auktorial-vermittelnden Erzählers in Martin Salander. Er ist eine die einzelnen Figurenperspektiven mediatisierende auktoriale Erzählinstanz. Dabei zeigt sich der auktorial-vermittelnde Erzähler an dem Kompromiß subtil beteiligt, indem er eine sich zwischen identifizierender Nähe und kritischer Distanz hin und her bewegende Haltung zur Hauptfigur einnimmt. Durchaus Mitleid, gar Betroffenheit schwingen daher mit, wenn beispielsweise der E rzähler angesichts der ,pedantischen' Liebelei Martins von einem „schwachen Schrei, wie eines erwürgten Kaninchens" (S. 385), redet. Es liegt nahe, daß sich der auktoriale Erzähler gerade in der Preisgabe der humoristischen Haltung als offenes, weltanschaulich unbesetztes - d.h. nicht humoristisch eingefärbtes - Medium anbietet, in den erst die Wirklichkeit als perspektivische hereingeholt wird, um sodann die divergierenden Perspektiven der Figuren miteinander auszusöhnen.

Diese innere Struktur trennt den Erzähler im M artin Salander von anderen erzählperspektivischen Formen und Trends der Epoche. Gemeinsam war für die Zeit das Problem, die zunehmende Kluft zwischen Objektivität und Subjektivität zu überbrücken. Während in den meisten realistischen Romanen "die Wirklichkeit erst recht problematisch geworden"117 ist, weil sich die Autoren in ihrem Streben nach der D arstellung der objektiven Wirklichkeit in die individuelle Subjektivität verstrickt haben und weil als Ergebnis dieses Strebens „mehr und mehr das Einzelsubjekt und seine spezifische Wirklichkeit in den Mittelpunkt treten",118 ist Keller mit derselben Sachlage, wie bereits gezeigt, anders umgegangen. Dieser gewisse AntiSubjektivismus war der G rund dafür, daß Keller im M artin Salander, wie häufig konstatiert, gerade auf Spielhagens Romantheorie zurückgreift, die ein ähnliches Repertore bereitstellte. ${ }^{119}$

114 Vgl. E. Graef, M artin Salander, S. 131.

115 Ebd., S. 132.

116 So schreibt A. Muschg: „Im Martin Salander wird die Frau, wenn sie nicht, wie Marie, resolut ist in ihrem Dienst am Mann, entweder als leere Schönheit (Myrrha) oder als törichtes Stückgut (die Salander-Töchter) behandelt.“ (A. Muschg, ,M artin Salander', S. 84.)

117 R. Brinkmann, W irk lichk eit und Illusion, Tübingen ${ }^{3}$ 1977, S. 313.

118 Ebd., S. 319.

119 Diesbezüglich läßt sich die Forschungsmeinung grob in zwei Richtungen zusammenfassen. Die erste Richtung betont die Nähe von Kellers Durchführung zu Spielhagens Forderungen als Gewinnung an erzählerischer Objektivität (Vgl. J. M. Ritchie, Martin Salander. E ine Untersuchung von 
Um die viel beschworene Affinität zwischen den beiden Autoren kritisch zu überprüfen, ist hier ein knapper Blick in die Spielhagensche Theorie angebracht. Spielhagen konzentrierte sich, darin dem westlichen Zeitgeist gemäß, auf die Objektivierung im Sinne der wahrgenommenen Wirklichkeit. Wie die französischen Realisten und Naturalisten, darunter besonders Flaubert, bemüht sich auch Spielhagen um objektive Kategorien des Erzählens, denen zufolge sich der Roman - der, so Spielhagen, wie „kein anderer Zweig der Dichtkunst die furchtbare Konkurrenz der Wissenschaften so gut aushalten kann" 120 - ästhetisch verwissenschaftlichen müsse. Anstatt die Subjektivität des Erzählers im Sinne von Flauberts impassibilité zu beseitigen, wird sie bei Spielhagen in den Helden verlagert, der nun als Sprachrohr des Autors dienen soll, und zwar so, daß letzterer völlig aus dem Erzählgefüge eliminiert wird. Die Objektivität wird bei Spielhagen im Gegensatz zu den Franzosen nicht als geistige Haltung des Erzählers und Autors verstanden,121 sondern zu einer erzähltechnischen Fertigkeit schematisiert, wobei die Ausschaltung der Erzählerschaft als ein erzähltechnischer Trick die explizite Subjektivität durch Erzählerreflexion, bericht und -beschreibung unterdrücken soll. Die Eliminierung des Erzählers, die der Versachlichung, eben dem zeitgenössischen O bjektivitätsideal zu dienen hat, zielt jedoch hier in Wirklichkeit auf den literarischen Illusionismus ab. Dieses Erzählprinzip soll nämlich dem Leser ermöglichen, die Romanwirklichkeit unmittelbar, gegenwärtig - vergleichbar mit dem Drama - zu erleben. Da die Romanwirklichkeit in allem direkt, d.h. über die Figuren, durch ihr Sprechen und Handeln, vermittelt werden muß, ist das einzige Darstellungsmittel, „dessen ,ich' der Romandichter“, so Spielhagen, „solange er Dichter sein will, bedienen darf "122, die Aufreihung, geradezu die Häufung von äußeren Vorgängen und Tatsachen. Es bleibe dem Dichter nichts anderes zu tun, als „in seiner Dichtung G estalten über G estalten [vorzuführen], Ereignisse auf Ereignisse, Fakta auf Fakta [zu häufen], Handlung in Handlung [zu schlingen]". ${ }^{123}$ D er O bjektivierungsdrang tendiert so bei Spielhagen zum rein Q uantitativen. Die Hauptfigur, die für Spielhagen mit dem Dichter selbst zusammenfällt und die als „die Verwandlung des naiven ,Ich' in ein reflektierendes ,Er'“124 bezeichnet wird, soll deswegen nicht ein Individuum sein, sondern „Repräsentant der ganzen Menschheit". ${ }^{25}$ Spielhagen konstruiert so den totalen Helden, der alles in einer Person sei, alles, was gerade vom dem Dichter als „unablässige, scharfe Beobachtung der realen Welt zusammengebracht [werde]“. ${ }^{126}$ In dieser Vielseitigkeit hat der Held die Zeit in ihrer Totalität zu repräsentieren. ${ }^{127}$

Im großen und ganzen handelt es sich also bei Spielhagen um zwei Punkte: Zum einen geht es um die Beseitigung der persönlichen, subjektiven Erzählerschaft, der sinnschaffenden und -vermittelnden Instanz. Zum anderen ist es die erhöhte Bedeutung des Helden als Zentralpunkt der gesamten Darstellung, mit der die dergestalt auf der Erzählebene verdrängte Weltanschauung des Autors zurückgeholt wird. D aher ist die Spielhagensche Objektivität eine „technische[ ] O bjektivität",128 mittels derer die Subjektivität des Autors noch effektiver, ja in prätendierter Allgemeingültigkeit präsentiert werden kann. D amit fällt das Spielhagensche Romankonzept weit hinter das Problembewußtsein zurück, zu dem andere zeitgenössische Romanciers wie Fontane und Raabe mittlerweile gelangt sind, indem ihre Erzählwerke in verschiedener Form eine subtile Abrechnung mit jener Verklärungsästhetik ${ }^{129}$ leisten.

Und Keller? Wie bereits am Fehlen des Humors gezeigt, besteht Kellers Weltobjektivität längst nicht mehr als intakte Angelegenheit des alten Glaubens, während Spielhagen an seiner die organische Gesamtheit des Seins beschwörenden Kunstvorstellung festhält. Stellt sich die Eliminierung des Erzählers bei Spielhagen als ins Schematische übertriebene

Kellers A lterswerk. Diss. Tübingen 1954, S. 53; M. Merkel-Nipperdey, ,M artin Salander', S. 15). Die andere problematisiert die Strukturverwandtschaft des Objektivitätsbegriffs bei Spielhagen und Keller gerade im Sinne des „Widerspruch[s] zwischen dem normativen Anspruch und der subjektivierten Umsetzung“ (E. Graef, Martin Salander, S. 126). Die zweite Richtung stimmt insofern mit der generellen These überein, daß die Ausschaltung des vermittelnden Erzählers im Deutschland des 19. Jahrhunderts als episches Stilelement nicht gelungen sei, und zwar aufgrund der übermächtigen Tradition der idealistischen Ästhetik (Vgl. ebd., S. 121-135).

120 F. Spielhagen, Beiträge zur Theorie und Technik des Romans. Faks. Druck der 1. Aufl. von 1883. Mit einem Nachwort von H. Himmel. Deutsche Neudrucke. Reihe Texte des 19. Jahrhunderts. Hrsg. v. W. Killy. Göttingen 1967, S. 40 f.

121 Zur Affinität und Differenz zwischen Spielhagen und Flaubert siehe G. Rebing, D er H albbruder des D ichters. Friedrich Spielhagens Theorie des Romans. (Literatur und Reflexion, Bd. 8.) Frankfurt/ M. 1972, S. 135-163.

122 F. Spielhagen, Beiträge, S. $67 f$.

123 Ebd., S. $67 f$.

124 Ebd., S. 174

125 Ebd., S. 73.

126 Ebd., S. 154

127 Somit wird bei Spielhagen im Zeichen des objektiven, totalen Helden „das Hegelsche Totalitäts-Edikt quantifiziert und damit pervertiert." (B. Hillebrand, D as 19. Jahrhundert: D er Konflikt zwischen Individuum und G esellschaft, in: ders., Theorie des Romans. München 1980, S. 192-276, hier S. 269.) Hegel fordert für den Roman die sittliche Totalität, „die Totalität einer Welt- und Lebensanschauung" (G.W.F. Hegel, V orlesungen über die Ä sthetik III. S. 393., in: ders., W erke in zwanzig Bänden. Auf der Grundlage der Werke von 1832-1845 neu edierte Ausgabe. E. Moldenhauer / K. M. Michel (ed.). Frankfurt/ M. 1970. Bd. 15), die in der zentrierenden Individualität, also in einem Helden als Mittelpunkt der Darstellung, übersichtlich wird. D emgegenüber wünscht Spielhagen für den Roman eine objektive Totalität wie im griechischen Epos. Für ihn unterscheidet sich die moderne von der antiken Welt nur durch ihre Erstreckung, also bloß quantitativ.

128 G. Rebing, D er H albbruder, S. 276.

129 Neben dem Konzept der quantitativen Totalität tritt dann bei Spielhagen der Anspruch auf 'Verklärung', 'Versöhnung' auf. Allerdings stellt die Frage, inwiefern die Verklärung des programmatischen Realismus als mit der „Totalität einer Welt- und Lebensanschauung“ in der Individualität im Sinne Hegels einhergehend zu betrachten ist, ein Problem an sich dar, auf das hier nur nebenbei hinzuweisen ist. Ich stimme der Ansicht U. Eiseles zu, daß für die aus den sehr verschiedenartigen Quellen erst zu konstituierende Theorie des literarischen Realismus in Deutschland Hegels Identitätsphilosophie als historischer Hintergrund bedeutend ist. Jedoch zweifele ich wie Fues, daß Verklärung, die wesentliche Form der Realitätsbewältigung in den Programmen der realistischen Literaturtheorie, mit der spekulativen Dialektik Hegels schlechthin identifiziert werden kann. (Vgl. W. M. Fues, Poesie der Prosa, Prosa als Poesie. E ine Studie zur G eschichte der G esellschaftlichk eit bürgerlicher L iteratur von der deutschen Klassik bis zum A usgang des 19. Jahrhunderts. Heidelberg 1990, S. 161, Fn. 8.) 
Konzession an das Objektivitätsprinzip dar, derzufolge die Schranke zwischen Fiktion und Realität möglichst aufgehoben werden soll, so signalisiert eine beibehaltene Erzählerschaft in Martin Salander das Bewußtsein der narrativ-künstlerischen Tätigkeit. D ies wird wohl gemeint sein, wenn Keller über seinen Plan des Martin Salander an Paul Heyse schreibt:

Von dem Romanchen kann ich Dir nicht viel sagen, da ich selbst noch nicht viel davon weiß. Wenn Du dich an die Erzählung „Das verlorne Lachen“ erinnerst, so hast Du ungefähr den Grund und den Boden, eine politisch oder sozial moralische Entwicklung aus der aktuellen Misère heraus in versöhnliche Perpespe (oho!) Perspektiven, wenn ich's herausbringe! Es handelt sich darum, vor Torschluß noch aus dem ewigen Referieren heraus und in das lebendige Darstellen hineinzukommen, ohne daß ich just auf endlose Dialoge hinausgehe [...].130

Ist ,dem ewigen Referieren' wohl das Berichten des auktorialen Erzählers zuzuordnen, dann bezieht sich ,das lebendige Darstellen' auf die szenische Darstellung. Verbunden ist damit die Illusion des Lesers, er habe unmittelbar Einblick in das G eschehen; sie entsteht durch das Nichthervortreten des Erzählers. D iese Illusion ist nach Stanzel das Produkt der

Ablöse [sic] der auktorial berichtenden Erzählung von Vorgängen der Außenwelt durch personale Darstellung von Vorgängen der Innenwelt bzw. die Spiegelung von Vorgängen der Außenwelt im Bewußtsein eines personalen Mediums, das als Reflektorfigur die Vermittlungsfunktion der auktorialen Erzählerfigur übernimmt.131

Erzähltechnisch konkret geschieht dies durch die Zunahme der dialogischen Teile, in denen, so Stanzel, „die Präsenz des auktorialen Erzählers auf knappe, unpersönliche Regieanweisungen beschränkt ist, andererseits aber auch kein personales Medium in ihnen aufscheint." "132 Wie schon erwähnt, erfüllt diesen Z weck etwa bei Spielhagen der Held als Identifikationsfigur des Autors. Während bei ihm aufgrund der zentralen Stellung des Helden der Illusionismus überhand nimmt, wird bei Keller die lebendige Darstellung nicht so weit getrieben. Er will nämlich ,in das lebendige Darstellen hineinkommen, aber, ohne auf endlose Dialoge hinauszugehen'. D ie lebendige D arstellung bleibt also bei Keller im Rahmen der auktorialen Erzählerschaft. So gesehen liegt der Kellersche auktoriale Erzähler von dem zeitgenössischen ,O bjektivismus' à la Spielhagen ebenso weit entfernt wie von dem auktorialen Erzähler in seinem Übergang zu dem modernen subjektivistischen Perspektivismus. Diese literarästhetische Abgrenzung soll im folgenden romangeschichtlich und -poetologisch verdeutlicht werden.

\section{L iterarische $\mathrm{G}$ renz e eines Ö ffentlichk eitsverständnisses}

D ie auktoriale Erzählerschaft in Martin Salander ist, wie schon gezeigt, keineswegs unter jener Kategorie subsumierbar, die den Erzähler, noch über den Verzicht auf humoristische Brechung hinaus, in den personalen Perspektivismus übergehen läßt. Dies ist nicht zuletzt daran zu sehen, daß in unserem Roman auch Stilmittel wie erlebte Rede und innerer Monolog ausbleiben, die man zu Kellers Zeit zur Perspektivierung des Dargestellten zunehmend und systematisch verwandte, und zwar mit dem Ausblick auf den personalen Perspektivismus. Die Erzählform in Martin Salander ist - trotz des Aufgehens der auktorialen Erzählperspektive in der subjektiven Figurenperspektive - daher weder auf der Schwundstufe des auktorialen Erzählers auf dem Weg zur personalen Innenperspektive der Moderne anzusiedeln, noch unter diesem Blickwinkel zu bewerten. Dies provozierte gerade viele Kritiker, für die das einzige obligatorische Endziel der Romankunst im 19. Jahrhundert die personale Innenperspektive darstellt, heraus. Aus der Entwicklungsgeschichte des modernen Romans auf den personalen Bewußtseinsroman zurückblickend, urteilt z.B. E. Graef, daß Kellers auktorialer Erzähler „auf dem Weg in die Moderne auf der Strecke geblieben" ${ }^{133}$ sei. Sie behauptet, daß die auktoriale Erzählerschaft, die im Romananfang noch eine ruhig und distanziert beobachtende Außenperspektive einnehme, sich im Verlauf der Handlung zunehmend die Perspektive des Protagonisten zueigen mache. Diese „erkenntnistheoretische[] Unstimmigkeit, die sich als erzählperspektivischer Riß durch den Roman zieht", wird von Graef schließlich auf Kellers inneren Widerspruch zurückgeführt, auf die „Aporie des bürgerlich-liberalen Autors, der die Überlebtheit und den Verfall seiner Ideale reflektiert, ohne indes von ihnen abzurücken". 134

Diese Sichtweise verabsolutiert die Subjektivierung des modernen Romans als die einzig mögliche und notwendige Entwicklung. Alles andere, was nicht in jene vorgeschriebene Bahn paßt, wird als Defizit bzw. Noch-Nicht hinsichtlich der kommenden Moderne verurteilt. Eine solche die Subjektivierungs- bzw. Verinnerlichungstendenz des modernen Romans zur einzig legitimen Entwicklung der $\mathrm{G}$ attung verabsolutierende Position ist jedoch problematisch. Die im modernen Roman sich durchsetzende Erzähl- und Kommunikationssituation ist nicht der Ausgangspunkt, sondern die Antwort auf eine historische Problemstellung und somit in ihrer häufig angenommenen gattungspoetologisch regulativen Bedeutung zu relativieren.

$\mathrm{Ob}$ die erzählerischen Symptome in Martin Salander den Roman von der perspektivischen Erzählhaltung des Schreibromans in Richtung auf den modernen Bewußtseinsroman wegführen? Und nähert sich damit der Roman eher dem Typ des epischen Romans, der von avangardistischen Schrifstellern vertreten wurde? Die grundlegende Kommunikationssituation ist

130 G. Keller, An Paul Heyse, 30.1.1882, in: ders., G esammette Briefe, Bd. 3,1, S. 69.

131 F. Stanzel, Theorie des E rzählens. Göttingen 2., verb. Aufl. 1982, S. 243.

132 Ebd., S. 244

133 E. Graef, M artin Salander, S. 135.

134 Ebd., S. 126. Dabei räumt sie zwar die Reflektiertheit und Gebrochenheit des Verhältnisses zwischen Erzähler und Protagonisten ein, die sich deswegen von dem im Dienst der Versöhnungsästhetik stehenden Spielhagenschen Objektivitätsanspruch unterscheide. Jedoch deutet sie die Zwiegesichtigkeit des Verhältnisses des auktorialen Erzählers zum idealistischen Protagonisten als „eine Handhabe, die in sich widersprüchliche doppelte Darstellungsintention seines [Kellers; J.-H. B.] Romans formal zu vermitteln." (Ebd.) Mit der doppelten Darstellungsintention meint sie, daß Salanders idealistisches Bewußtsein sowohl als Medium der D arstellung wie auch als G egenstand der kritischen Betrachtung dient. 
zumindest den beiden Tendenzen gemeinsam. Wie für den neuen Epiker des epischen Romans ${ }^{135}$ war das Erzählen für Keller immer eine öffentliche Angelegenheit. Er versteht sich niemals als Privatgeschichten-Erzähler. Das holistische Menschenverständnis Kellers ist von Grund auf mit der Entwicklungstendenz des Schreibromans nur schwer vereinbar, dessen Konzentration auf subjektive Wirklichkeitserfahrung nicht zuletzt ein Ausdruck der nicht-kommunikativen, autonomen Kunst ist. Daher zielt die Kritik, daß Keller an einem auktorialen Erzähler mit der verbindlichen Sicht einer objektivierbaren Wirklichkeit festhalte, ohne zu bemerken, daß er diese nur vermittels einzelner, subjektiver Perspektiven zu entwerfen vermöge, ${ }^{136}$ an dem erzählerischen G rundprinzip der Kellerschen Poesie, besonders mit Blick auf die Erzählerschaft in Martin Salander, vorbei: Nicht die Ablösung der auktorialen Erzählerschaft durch subjektive Perspektiven, die einer objektivierbaren Wirklichkeit zugute kommen sollen, ist für diesen bestimmend, sondern gerade deren Engführung mit den subjektiven einzelnen Perspektiven zum Z weck der Mediatisienung. D arin, daß der auktoriale Erzähler in Martin Salander zwar des Humors beraubt wird, aber als E rzählinstanz nach wie vor intakt bleibt, spiegelt sich eine geschichtliche und mentale Situation wider; die ursprünglich bürgerlich-liberale Konsensvorstellung hat ihre geschichtspraktische Integrations- und Überzeugungskraft verloren. ${ }^{137}$ Zugleich klingt aber in dem aufbewahrten Rahmen der auktorialen Erzählerschaft mit der persönlichen Stimme das Verlangen nach Harmonie nach: D er Erzähler in Martin Salander trägt zutiefst in seinem Inneren den zähen Wunsch, daß es, auch nach der Zurücknahme des Fortschrittsglaubens, immer noch ein mögliches Zukunftsbild der Gemeinschaft geben möchte. Die Sprache und die Stimme des Erzählers bedauern den fehlenden gesellschaftlichen und politischen Konsens, den er in seinem durchgehenden Verzicht auf Humor, doch als neutraler Vermittler zwischen divergierenden Perspektiven zu suggerieren versucht. Die Öffentlichkeit bleibt so bei Keller in der engen Vorstellung der staatsbürgerlichen, politischen Handlungsebene verhaftet. Das hebt Keller von dem neuen Epiker freilich ab, bei dem die Gesellschaft als die moderne ,Medienkultur' zu verstehen ist. ${ }^{138}$ Der Unterschied läßt sich noch ausweiten. Im programmatischen epischen Roman wird die Stimme des E pikers durch die bewußte Konfrontation mit der verwirrenden Vielfalt von Stimmen und der Unübersichtlichkeit des modernen Lebens gebrochen. Damit zusammenzuhängen scheinen die enorme erzähltechnische Innovationskraft und Offenheit bei den Avangardisten des epischen Romans.

\section{Maries Märchen: eine andere Geschichtsschreibung - ein anderes Erzählen}

Ist damit alles über die heikle Situation des Schönen, der Kunst, in unserem Roman gesagt? Es scheint doch, daß Kellers Vorstellung vom Schönen breiter angelegt ist, als daß sie im klassischen bzw. klassizistischen Schönen völlig aufgehen könnte. So wie der Erzähler innerlich an dem Glauben, der Gutmütigkeit der Hauptfigur beteiligt ist, teilt er Amolds Position gegenüber Myrhha, dessen „kalte Ruhe“ (S. 399), nicht. Der Erzähler zeigt eine Sympathie mit der Schönen, die mit keinem politischen Enthusiasmus mehr liiert sein kann. D ies wird deutlich, wenn der Erzähler die Szene kommentiert, auf die sich Amolds spätere scharfe Verspottung von Myrrhas Wurstgeruch bezieht: Sie habe "trotz der Bedrängnis mit trauten Worten, von Jugend zu Jugend, wie wenn sie da vor die rechte Schmiede gekommen wäre in einer verworrenen höchst bedenklichen Angelegenheit" (S. 397) gesprochen. So mildernd tritt der Erzähler gegenüber Myrrha nicht nur hier auf. Schon von Anfang an schildert der Erzähler Myrrha als ,schön', was mit der trügerischen Schönheit, die Martin Salander in ihr sieht und die künftig als solche von Arnold enthüllt werden soll, wenig zu tun hat. Myrrhas Schönheit entfaltet sich eher mit dem Erzählen selbst, ja als ein Glanz des Erzählens. Der ,Glanz' der Sprache des Erzählers, dank dessen Myrrhas Schönheit auch nach Arnolds scharfer Bloßstellung als schönes Bild auf den Leser weiterwirkt, ist weniger auf den schönen Schein hinsichtlich der Idee als auf die wirkungsästhetische, rhetorische Dimension der ästhetischen Erscheinung bezogen.139 In dieser zutiefst mit Kellers Erzählsprache selbst verbundenen Schönheit sieht Fues das Hintergehen der Erzählung durch das Erzählen angelegt, also den Widerstand der (Erzähl-)Sprache gegen die (Erzähl-)Intention:

Um das Bild zu zerbrechen, seine Weisungskraft zu lähmen, müßte er diesen Glanz erzählend zerstreuen und austilgen. Von solchem Erzählen fehlt im Text jede Spur. Unfähig, gegen seine Erzählung Myrrhas zu sprechen, macht der Erzähler schließlich Arnold zu seinem Sprecher. Aber Amold existiert wie Myrrha nur durch Erzählung. Wie soll er sie vernichten, wenn das, was auch sein D asein bedingt, sie unablässig schützt?140

135 Alfred Döblin benutzt in A n Romanautoren und ihre Kritiker. Berliner Programm (1914) für das Erzählen das Wort „öffentliche Angelegenheit". (A. Döblin, Schriften zu Ä sthetik, Poetik und L iteratur. Hrsg. v. E. Kleinschmidt. Olten; Freiburg 1989, S. 119-123, hier S. 120)

136 V gl. E. Graef, Martin Salander, S. 131.

137 Wie ich hinsichtlich der bürgerlichen Zukunft bei Arnold gezeigt habe und in Maries Märchen zeigen werde, gibt es jedoch verschiedene, zum Teil einander widersprechende und einander modifizierende Textbezüge hinsichtlich der G eschichte und der Zukunft.

$138 \mathrm{Vgl}$. A. Poltermann, Künstlerisch avancierte V erfahren perspektivischen E rzählens in der deutschsprachigen Literatur des 18. und 19. Jahrhunderts. H istorische Beobachtungen und poetologische Ü berlegungen, in: D. Kullmann (Hrsg.), E rlebte Rede und impressionistischer Stil. E uropäische E rzählprosa im V ergleich mit ihren deutschen Ü bersetzungen. Göttingen 1995, S. 29-69, hier S. 35.

139 Es war Nietzsche, der als Begründer des konsequenten ahistorischen Ästhetizismus die Frage nach dem Schein des Schönen jenseits der Wahrheitsfrage gestellt hat. Siehe dazu K. H. Bohrer, Ä sthetik und H istorismus: N ietsches Begriff des ,Scheins', in: ders., Plötzlichk eit. Zum A ugenblick des ästhetischen Scheins, Frankfurt/ M. 1981, S. 111-138.

140 W. M. Fues, A bbildentstellung?, S. 178. 
Schützt der Erzähler in seiner, unkontrollierten' Sprache wirklich das Schöne an der schönen Gestalt Myrrha, auf dessen Zerstörung hin die Handlung aufgebaut ist? Der Erzähler scheint die schöne Myrrha, wenn er sie unablässig zu salvieren versucht, nicht als Schönheit im klassischen und idealistischen Sinne, nicht als den schönen Schein mit Wahrheits- und Wesensanspruch, zu schützen. Myrrhas vor der völligen Austilgung bewahrte Schönheit ist die auf den Dingen wie auf Metallen, Wassern, Flüssen liegende Schönheit, also eine materielle, sinnliche Schönheit, jenseits der idellen, idealistischen Prämissen. ${ }^{141}$ Myrrhas Schönheit ist, anders gesagt, als Moment des ästhetischen Phänomens, als Kunst aufzufassen, nicht als ein Überzeitliches - als ein solches wird sie ja zerstört - , sondern als im verbalen Vollzug, also im ,Scheinen' selbst begriffen. ${ }^{142} \mathrm{D}$ as so verstandene ästhetische Phänomen steht auch bei Plato nicht zufällig mit dem Wort ,Glanz' in Verbindung. ${ }^{143}$

Diese materielle, phänomenale und isolierte Schönheit, die im Gegensatz zur klassischen Schönheit die Idee, das allgemeine Gesetz, vermeidet, behauptet ihrerseits ihre bescheidene Existenz: Solange die schöne Erscheinung als Erscheinung noch schön ist, ist sie im Reich der Kunst, wenigstens im Kellerschen Erzählen, immer noch von Geltung, obwohl dies nur auf eine beschränkte Weise des Nicht-ausgetilgt-Seins stattfindet. Ob dieses geltungsberechtigte Schöne nicht doch als Indiz dafür steht, daß Keller sich noch andere Möglichkeiten von der Kunst erhofft, nämlich ein anderes Erzählen, ein anderes Erzählverhalten und einen anderen Erzählzustand, ja überhaupt einen anderen Weltzustand als den der Welt des Romans? Dies ist zu bejahen. Das andere Schöne ist in einem kleinen Ort beherbergt, in dem nicht der eigentliche Erzähler wohnt.

Die erzählerisch nicht eingelöste Sympathie für die Schönheit sucht sich in einem anderen, zweiten Erzähler Zuflucht. Es ist dies eine Figur, die in der Erzählung kurz die Erzähler-Rolle spielt und dabei vorführt, was dem eigentlichen Erzähler versagt ist, was ihm verloren geht. Es ist Marie, die Märchenerzählerin, die der schönen Poesie eine Nische gewährt.144 Daß Marie in vielerlei Hinsicht Kellers eigene Position transportiert, ist in der Forschung oft hervorgehoben worden. Daß sie aber auch als Märchenerzählerin eine Konzession Kellers an die Poesie ist und daß darin Keller sein Alter ego als Erzähler auslebt, ist ein Befund der neuesten Forschung, zu dem es noch einiges zu ergänzen gibt.

Die folgende Untersuchung dreht sich in ihrem Kern um das Dreiecksverhältnis zwischen Autor, auktorialem Erzähler und der märchenerzählenden Marie. Es drängt sich die Vorstellung auf, daß zwischen dem Roman als Zeitroman und dem in ihn integrierten Teiltext ,Märchen' ein Beziehungsgefüge besteht, welches ich als eine Art Intertextualität auffasse. Es ist eine Korrespondenzbeziehung, welche sowohl Entsprechung als auch Differenz und Spannung einschließt: Derselben Realität entsprungen wie der Roman als Zeitroman und auf dieselbe bezogen wie dieser, ist das Märchen doch einem anderen Schreibduktus unterworfen als der Roman als Zeitroman mit objektiver Erzählerschaft. Im Unterschied zur auktorialen Erzählerschaft des Romans, welche die divergierenden Perspektiven mediatisierend aufzuheben versucht und dieses doch am Ende nicht kann, kennt die auktoriale Erzählerschaft in Maries Märchen weder Objektivitätsprinzip noch die - damit zusammenhängende - perspektivische Gebrochenheit der Welt. Die Erzählerschaft in Maries Märchen ist eben mütterlichintegrativ-auktorial. Aus diesem Gleich- und zugleich Ungleichsein nährt sich der Dialog zwischen Zeitroman und Märchen. Die eigentliche poetologische Stellung Kellers bildet sich m.E. erst mit diesem Gesprächscharakter aus. ${ }^{145}$ Die enge Verbindung zwischen Mutter und Sohn auf der Ebene der Handlung und Figuration wird zur Korrespondenz zwischen der Märchenwelt der Mutter und der Zukunftswelt des Sohnes transformiert: Die von der unmittelbaren Realität abgehobene Fiktionswelt namens Märchen und die "Geschichte als utopischer und illusionärer Raum“146 nach dem Zerfall der Zukunftserwartung korrespondieren miteinander. So entfaltet sich zwischen dem Märchen und der offenen, unsicheren Zukunft ein Transformations- und Vermittlungsverhältnis. Mit dem Märchen wird nämlich ein anderes Modell des Umgangs mit der G eschichte entworfen und zugleich auch ein anderes Modell des Dichtens zugrundegelegt. So findet man in Maries Märchen den geschichtsphilosophischen Exkurs von Arnold in eine andere, phantastische Sprache übersetzt und weitergeführt.

Wodurch zeichnet sich dieses Vermittlungsverhältnis des Märchens zu Arnolds Version des ,Nach der Geschichte' aus? Grob und annäherend läßt sich davon zunächst nur negativ sprechen, d.h. im Weg des das Märchen umgebenden Romans. Etwa so: D as Märchen verhält sich zur realisierten Romanform und zu deren geschichtlicher Haltung ergänzend, korrigierend und sogar teilweise Widerstand leistend. Handelt es sich dort um die Geschichte als ,Neubeginn', ,Abbrechen' und „Durchführung', dann steht hier die Geschichte mehr im Zeichen des Wiederanfangens, der Wiedergeburt oder Renaissance einer ,Histoire', sofern man darunter nicht die Emeuerung aus der Kraft utopischer Entwürfe, sondern die Erneuerung aus der Kraft nachfolgender Durcharbeitungen versteht. ${ }^{147}$ Wie dieses genau als Märchen artikuliert ist, wird sich im folgenden zeigen.

\section{Märchen: die, schöne F orm' bei Keller}

141 Vgl. M. Fues, A bbildentstellung?, S. 177f. Fn. 104.

142 Vgl. K. H. Bohrer, Ä sthetik und H istorismus, S. 114.

143 V gl. ebd., S. 114, 115.

144 Vgl. G. Kaiser, G. Keller, S. 596; E. Graef, Martin Salander, S. 91, 105.

145 Dieses Sachverhältnis habe ich durch die schon besetzte Terminologie ,Paratext' zu bezeichnen versucht.

146 D en Ausdruck übernehme ich von G. Kaiser. (Kapitel: G eschichte als utopischer und illusionärer Raum; das handelnde V olk als U topie, in: G. Kaiser/ F. A.

Kittler, D ichtung, S. 162f.)

147 Vgl. H. Turk, V om Klassischen A ltertum, S. 467. 
Während auf der Ebene des Zeitromans die Schönheit als Formschönheit der Klassik und als schöne Erscheinung der sich verabsolutierenden Aufklärung in Zweifel gezogen wird, gilt im Märchen die Schönheit, diesmal vom geschichtsphilosphischen Implikat gereinigt, als G estaltungsordnung.

Der ,schönen Form' als gediegenem Kunstideal bei Keller steht dessen Schaffensperiode der L eute von Seldwyla im ersten Band am nächsten. Es ist die volkstümliche Stilhaltung, verbunden mit dem Zukunftsvertrauen, die schon Fontane halb polemisch, halb bewundernd als ,Keller-Ton' bezeichnet hat und der etwas Märchenhaftes eigen ist.148 Daraus folgt, daß die schöne Form bei Keller eine gewisse Strukturverwandtschaft mit dem Märchen aufweist.

Was ist das Poetische bzw. das Schöne an der Form des Märchens? Spezifisch auf Martin Salander und dessen O szillieren zwischen Zeitroman und Märchen bezogen lautet die Frage: G ewährt das Poetische oder Schöne in der Form des Märchens ein anderes Verhältnis zur G egenwart, zur Zukunft als das in und durch den Roman als Zeitroman Repräsentierte? Noch genauer formuliert: Wodurch läßt sich das Spezifische der Märchenform in der Art und Weise des Umgangs mit der Realität und damit mit der Zukunft charakterisieren? Um die Annäherung an diesen Problemkomplex leichter zu machen, soll hier zunächst kurz auf Kellers Verwendung der literarischen Form des Märchens eingegangen werden.

Für diesen Aspekt kann die letzte Erzählung des ersten Bandes der L eute von Seldwyla aufschlußreich sein, da Keller sie ausdrücklich mit einer Gattungsbezeichnung versehen hat: Spiegel, das Kätzdhen. E in Märchen. Dennoch gilt hier den märchenhaften Elementen im allgemeinen Sinne nicht das primäre Interesse des Autors. Seine relative Ignoranz gegenüber dem Märchenhaften läßt sich ohne weiteres feststellen. Keller hat nämlich im Zusammenhang mit dieser Erzählung keine allgemeinen Reflexionen darüber angestellt, was die Form ,Märchen' zu bedeuten haben soll. Die Substanz der Märchenform, das spezifisch Märchenhafte, das im Sinne der Romantik das Wunderbare bedeutet, ist nicht das, worauf sich Kellers Märchen stützt. Vielmehr spielt beim Kellerschen Märchenschaffen das Verhältnis des Märchens zur Rahmen- bzw. Binnenerzählung, also die Verknüpfung von Märchen und Wirklichkeit, die entscheidende Rolle. Die Welt der Rahmen- und Binnenerzählung ist die, die der Logik der Nicht-Märchenwelt, nämlich der bürgerlichen Realität, restlos unterworfen ist. Es ist eine gewisse Art von Spannungs- und Distanzverhältnis zur Realität, um derentwegen Keller auf das Märchen zurückgreift. D er vom Märchen zu gewährleistende erzählerische Gestus gegenüber der Realität, der für Keller das Poetische bzw. die Schönheit dieser Form bedeutet, ist eine über die „realistische oder naturalistische Stilisierung", d.h. eine über "die Anpassung an das Sujet oder den Stoff " ${ }^{149}$ hinausgreifende sprachliche Repräsentation. Das Märchen illustriert in seinem Wesen das, was Keller für seine Kunst selbst beansprucht hat. Es erhebt nämlich Anspruch darauf, als eine Art Hermeneutik für Kellers Poetik zu gelten.150

Verglichen mit dem Spiegel-M ärchen zeigt Maries Märchen bezüglich der Problematik des poetischen Erzählens eine gewisse Tonverschiebung. Es sei hier daran erinnert, daß zwischen dem Spieglel-M ärchen und M artin Salander immerhin einige Jahrzehnte liegen, die für Keller hinsichtlich der eigenen Poetik eher eine Zeit defensiver Erfahrungen als eine Zeit des Ausbauens und der Bestätigung der frühen Ansätze bedeuten. O bwohl Keller hier wie dort in märchenhafter Verhüllung die Rolle der erzählenden Kunst, der Poesie überhaupt, im modernen, prosaisch bürgerlichen Leben darstellt,151 fällt in Maries Märchen der Idealcharakter des Märchenerzählens als Prototyp eines eigenen Poesie-Ideals deswegen viel schärfer aus, weil das Märchen in einen in der avancierten Schreibweise der Epoche geschriebenen Z eitroman hineingeschoben wird. In diesem Sinne kann, so das Ziel der folgenden Auslegung von Maries Märchen, die Diskrepanz zwischen dem realen Schaffen als Zeitroman und dem eigenen Ideal des Autors verschärft vor Augen geführt werden.

In einem ersten Schritt werde ich versuchen zu beleuchten, in welchem Maß, in welcher Form Maries Märchen im D etail den Roman repräsentiert bzw. wiedergibt. Meine Verfahrensweise unterscheidet sich dabei von der früheren Forschung, die das Märchen in die Interpretation des Romans miteinbezogen reflektiert, und zwar indem sie den Zusammenhang bzw. die Gemeinsamkeit von Roman und Märchen hauptsächlich in der pessimistischen apokalyptischen Vision sieht. Die Resignation als geschichtliches Bewußtsein, die einer solchen Interpretation zufolge sowohl dem Märchen als auch dem Roman insgesamt zugrunde zu liegen hat, habe ich bereits zu relativieren versucht. Wie in den der Figur Arnold gewidmeten Passagen gezeigt wurde, erschöpft sich die sogenannte geschichtliche Perspektive des Romans nicht in dem Rückzug vom liberalen Fortschrittsglauben. Gemäß der von mir beleuchteten Zukunftsperspektive bei Amold lese ich das Märchen auch nicht apokalyptisch im Sinne des tragischen Endes der G eschichte.

In den „kleinen Leutchen aus dem Berge“ (S. 36) im Märchen wird die (früh)-bürgerliche Welt gespiegelt, eine intakte, harmonisch zusammenlebende Gemeinschaft.152 Diese ist geprägt von der Ordnung eines „G oldschüsselchen[s]" (S. 39), das jedes Erdmännchen „in einem seidenen Säcklein“ „auf dem Rücken“ (S. 37) trägt. Symbolisiert ist damit der individuelle Wohlstand, das unantastbar private Eigentum. Wie die Erdleutchen im Umgang untereinander zeigen, z.B. in ihrem

148 Näheres zu Kellers Märchen-Ton findet sich bei Roy C. Cowen, Spiegel und W iderspiegelung: zu Kellers Märchen, Spiegel, das Kätzchen, in: H. Steinecke (Hrsg.), Interpretationen; J. Rothenberg, Gottfried Keller. Symbolgehalt und Realitätserfassung seines E rzählens. bes. IV. D iminuierte W elt. Zu Q ualität und W irk ungsweise des ,Keller-T ons', Heidelberg 1976.

149 H. Turk, V om Klassischen A ltertum, S. 469.

150 Dieser poetologische Stellenwert des Märchens, des Märchenhaften innerhalb des Kellerschen Realismus ist der Schlüsselsatz für die Interpretation des Märchens Spiegel, das Kätzchen von B. Neumann. So hat Neumann das diesem Märchen gewidmete Kapitel seiner KellerMonographie „Kellers ,Märchen' ,Spiegel, das Kätzchen' als Hermeneutik in eigener Sache: zur G enese und zur Funktion poetischen E rzählens“ genannt. Die Einsichten, die Neumann vom Spiegel-Märchen für Kellers Poetik gewonnen hat, können der folgenden Interpretation von Maries Märchen als O rientierung dienen.

151 Vgl. B. Neumann, Gottfried Keller, S. 344.

152 Vgl. E. Graef, M artin Salander, S. 92. 
nachbarlichen Handschlag, ist ihr goldener Teller zugleich G rundlage für das friedliche und freie Miteinander, denn, für Keller wie für seinen Protagonisten Martin Salander, verleiht „nur ein mäßiger Besitz“ (S. 76) eine ausgeprägte Persönlichkeit und individuelle Unabhängigkeit.

Dieser physiognomischen Symbolisierung des Bürgertums, der bürgerlichen Schicht in der Gestalt von Erdleutchen werden noch andere Symbolisierungsverfahren hinzugefügt. Neben die Erdleutchen tritt noch "das große Volk im Lande" (S. 37), nämlich die breite untere Bevölkerungsschicht. Die Erdleutchen, die kleine soziale Schicht des alten Bürgertums, werden nebenbei mit der exklusiven G ruppenbezeichnung „Geschlecht" (ebd.) gekennzeichnet. Die Opposition von Bürgertum und Volk wird in der Unterscheidung zwischen „gescheiten Leutlein unten“(ebd.) und dem großen Volk, das „auszuarten und dumm und schlecht zu werden" (ebd.) anfängt, noch verlängert, was einiges über Kellers Verhältnis zur vollzogenen Demokratisierung seines Landes aussagt. Der Bezug auf die Erde bezieht sich andererseits metaphorisch auf die Bodenständigkeit, die Festigkeit, die Keller dem alten Bürgertum als Fundament der Nation zuwies. So gelesen zeigt sich, daß das Märchen mit mehr Realitätsbezogenheit ausgestattet ist, als in der Forschung üblicherweise angenommen und erkannt wird. Die Parallelität von Zeitroman und Märchen gewinnt nun mehr an Substanz.

Wie im Roman die Abrechnung mit einer Epoche vorgetragen wird, so steht auch in der Märchenerzählung der Untergang, der Abschied im Zentrum. Als Anlaß für den Abschied der Erdleutchen in den Regenbögen werden zweierlei Gründe genannt. Ein unmittelbarer Zusammenhang mit einer Zeitdiagnose, wie sie im Zeitroman versucht wird, liegt hier nahe. D ie Erdleutchen kommen zum Abschied zusammen, so sagt das Märchen, „wenn sie merken, daß ihr G eschlecht ausstirbt in einer G egend“. (S. 37) Aber „[a]uch noch aus einem andern Grunde sollen sie einen solchen Abschied feiern; nämlich wenn das große Volk im Lande anfängt, auszuarten und dumm und schlecht zu werden, dann beschließen sie, auszuwandern und dem Ende aus dem Wege zu gehen." (Ebd.) Die Diagnose schwankt zwischen dem fast naturgesetzlich, organistisch zu verstehenden Aussterben jenes G eschlechtes und dem emphatisch festgestellten moralischen Verfall des großen Volkes. Marie erzählt: „Sei dem, wie ihm wolle, so weiß ich nicht, welchen Anlaß wir hier vor uns haben." (Ebd.) Jedoch rückt sie im nächsten Augenblick leise der ersten Version näher: „Es wird sich wohl um ein Aussterben handeln, und da sind es, wie gesagt, höchstens hundert Männlein und ihre Frauen, die dort sind." (Ebd.) D aß Marie, im Unterschied zum Roman, das natüliche Sterben des Geschlechtes als Ursache des gesamten Untergangs anführt, ist für den weiteren Verlauf des Märchens von geringer Bedeutung. Es verweist eher auf die märchenhafte Milde, auf die wesentliche Abgehobenheit vom Roman als G egentext.

Dieser beiläufige Unterschied kann als ein Anzeichen dafür genommen werden, daß zwischen dem Zeitroman und dem Märchen, trotz der offensichtlichen Sinnparallelität, eine Sinndifferenz besteht. Im folgenden versuche ich, diese Sinndifferenz von Zeitroman und Märchen herauszuarbeiten.

D en Realitätsbezug, unter dessen Zeichen der Zeitroman steht, habe ich bereits mit dem Begriff des Objektivitätsprinzips einzufangen versucht. Das Märchen verhält sich zu der im Roman geschilderten Lebenswelt nicht als ihre ,Duplikation'. Schon die Situation, in der das Märchen erzählt wird, enthält das ursprüngliche - im Sinne des Anthropologischen - Motiv dieser uralten menschlichen Tätigkeit des Erzählens, welches nicht auf ein ,Nachahmen' des Gegebenen reduzierbar ist. Dieses hängt vielmehr mit einer menschlichen Grundsituation zusammen: Die Motivation zum Erzählen ist bei Marie die notwendige, aber auch illusorische Befriedigung eines sinnlich-elementaren Bedürfnisses. Mutter Marie erzählt ihren Kindern, um deren Hunger zu stillen und sie über die Abwesenheit des Vaters hinwegzutrösten. Sie erzählt so, daß die Zuhörer ihre Begehrlichkeit auf das Erzählte richten können. „So fuhr sie mit eifriger Mühe fort, nicht nach den Geboten der Wahrscheinlichkeit, sondern nach ihrer Kenntnis der kindlichen Gelüste das Bankett der Wichtelmännchen auszumalen, [...]." (S. 38)

Erinnert man daran, daß seit der Novellensammlung D ecameron und bereits davor in den E rzählungen aus $1001 \mathrm{~N}$ acht die menschliche Not als Legitimation des Erzählaktes in der literarischen Tradition verankert ist, erscheint Maries Erzählsituation noch in einem anderen Licht. Erzählt wird in den E rzählungen aus $1001 \mathrm{~N}$ acht oder dem D ecameron, um die Bedrohung der Außenwelt zu vergessen, um die Todesangst zu bekämpfen, um den Tod zu verschieben und zu verdrängen. Als Vorform des Romans, speziell der Novellen, formt sich das D ecameron als Abwehr der Todesangst. Seine Leistung ist die Todesverdrängung. Dies sagt nun allerdings nicht wenig über die weitere Entwicklung des Romans als Schreibroman. Maries Märchen ist demgegenüber ausschließlich lust- und oralitätsbezogen; mündlich erzählt, orale Lust ersetzend. In seiner Lustbetonung, in seiner kommunikativen und geselligen Situation des Essens rückt Maries Märchen in die Nähe der Vorform des romantischen Romans. Maries Märchen illustriert Kellers Erzählprinzip: Die Kunst muß, wie B. Neumann für Keller herausgefunden hat, „den Menschen nach dem Munde reden, um überhaupt gehört zu werden, d.h. um überhaupt überleben und als Kompensation einer unzureichenden Wirklichkeit wirken zu können. ${ }^{153}$

Die Bedeutung der Poesie, wie sie in Maries Märchen reflektiert wird, erschöpft sich jedoch nicht allein in diesem illusorischen, die Not der Realität mildernden Charakter. Die Kompensationsfunktion des Erzählens für die als Mangel empfundene Realität wächst hier bis zur magischen Funktion der Schöpfung einer neuen Wirklichkeit. Keller beschwört hier einen schier unmittelbaren Übergang des Märchens zur Realität. Im folgenden versuche ich, dies an der Nahtstelle von Märchen und Romanwirklichkeit konkret zu zeigen.

Nachdem das Märchen, in dem der Goldschatz, der goldene Teller der Erdleutchen, am Ende des Festes vergraben wird, zu Ende erzählt worden ist, gräbt man auf der Ebene der Romanwirklichkeit einen vergessenen Schatz aus: Die Erzählerin erinnert sich durch ihr eigenes Erzählen prompt an einen Besitz, den sie einst bei der Taufe als Patengeschenk ins Wickelband

153 B. Neumann, G ottfried Keller, S. 345. 
gelegt bekommen hatte. Es ist ein „glänzendes goldenes Regenbogenschüsselchen“, „eine uralte Hohlmünze, Barkteat genannt" (S. 40), deren Verkauf die unerwartete glückliche Rettung vor der drohenden Hungersnot bedeuten wird. Diese unmittelbar lebensrettende Funktion des Märchenerzählens ist kennzeichnend für die Situation, in der sich Marie mit ihren Kindern befindet, allein und von der Außenwelt abgeschnitten. Die Erzählerin erinnert sich, und durch den Akt der Erinnerung verknüpft sie das Reale in der Vergangenheit und das Irreale in der G egenwart miteinander. Als Vermittlerin zwischen der Welt des Märchens und der Romanwirklichkeit agierend, beschwört Marie nämlich eine neue Wirklichkeit herauf. Dieser Moment gehört zwar äußerlich der Romanwirklichkeit an, jedoch fällt er namentlich ,märchenhaft' aus: die (Wieder)-Findung des vergrabenen, in Vergessenheit geratenen Schatzes ist ein häufig im Märchen ausgespieltes Motiv und daher signifikant für diese Gattung. Der Moment, in dem der goldene Teller des Märchens als Mutters Goldmünze erkannt wird, ist real und zugleich irreal, illustriert dadurch ein Z wischenland, einen O rt, wo eine derart lebensrettende Funktion der Poesie, die nicht zur bürgerlichen Welt bzw. zu deren realistischer Darstellung gehört, erfüllt wird. ${ }^{154}$ Gerade eine solche Unwahrscheinlichkeit hat Keller als Inbegriff des Poetischen hervorgehoben, wenn er P. Heyse im Zusammenhang mit dem Sinngedicht anvertraut:

Die Unwahrscheinlichkeit betreffend [...] Auch die Geschichte mit dem Logauschen Sinngedicht, die Ausfahrt Reinharts auf die Kußproben kommt ja nicht vor; niemand unternimmt dergleichen, und doch spielt sie durch mehrere Kapitel. Im stillen nenne ich dergleichen die Reichsunmittelbarkeit der Poesie, d.h. das Recht, zu jeder Zeit, auch im Zeitalter des Fracks und der Eisenbahnen, an das Parabelhafte, das Fabelmäßige ohne weiteres anzuknüpfen, ein Recht, das man sich nach meiner Meinung durch keine Kulturwandlungen nehmen lassen soll. 155

In dem Moment, als Marie als die Erinnernde das Märchen unmittelbar auf sich, auf die eigene und der Kinder Wirklichkeit, wirken läßt, verkörpert sie jene „Reichsunmittelbarkeit der Poesie“. Die Unwahrscheinlichkeit drückt sich in der Reaktion der Kinder aus, wenn die Mutter sagt: „Nun ist's gut! [...] [N]och diese kurze Nacht heißt es gefastet oder vielmehr geschlafen; morgen früh aber reisen wir in die Stadt, verkaufen den Denkpfennig und leben wie an der Kirchweih!" (S. 41) Worauf die Kiner "sie zweifelhaft an[blickten]; sie mochten die Rede für eine Fortsetzung des Märchens halten, dessen Glaubwürdigkeit mit dem wieder erwachenden Hunger abzunehmen schien." (E bd.)

Dieser traumhafte Moment, in dem das Reich der Poesie präsentiert wird, ist ein Interimistikum. Die von dem Märchen inspirierte Idee der Rettung bleibt im weiteren Verlauf der Handlung unverwirklicht. In das Reich der Poesie bricht die phantasie- und poesiefeindliche Realität ein:"Da klang die Hausglocke" (S. 41). Mit diesem Läuten taucht unerwartet der Versorger auf. Die märchenhafte Lösung der Hungersnot wird somit unerprobt zurückgerufen, ihre zerbrechliche Glaubhaftigkeit verblaßt für immer. Das Charakteristische bei diesem Übergang besteht in dem Paradox, daß das „Realitätsprinzip', das sogenannte Reale, durchlöcherter, fragiler ist als das vom Märchen her Überkommene, das Phantastische. D enn der Vater täuscht sich und seiner Familie eine Weile lang eine glückliche Heimkehr vor. D iese inszenierte Rückkehr ist in Wirklichkeit, wie der Heimkehrende kurz nach seiner Ankunft erfahren mußte, nichts anderes als der erneute Bankrott. Es ist der abermalige Verlust der hart erworbenen Existenzbasis des Protagonisten und seiner Familie. Der Erzähler schildert die Situation wie folgt:

Es war Martin Salander, der nach allen Umtrieben wegen seines Vermögens noch seine Reisekoffer und Kisten auf dem Bahnhofe geholt und durch zwei Männer hatte herbringen lassen, um nicht ganz ohne Habe bei den Seinigen zu erscheinen, eine seltsame aber verzeihliche Selbsttäuschung. (S. 41)

Das Reich der ,Poiesis', unter dessen Schirmherrschaft die Mutter zwischen Fiktion und Wirklichkeit frei wandert und eine andere, neue Wirklichkeit hervorbringt, schwindet in diesem Moment gleichsam davon, für immer und unwiderrufbar. Die O rdnung des Märchens, welche sinnlich, poetisch, aber deswegen keineswegs unvernünftig ist, weicht vor der hereinbrechenden Macht des trügerischen Realitätsprinzips in Gestalt des Vaters aus, der selbst ein Opfer von diesem Prinzip ist. Es ist die Ära der Finanzwirtschaft, die undurchschaubar, unsinnlich und unvernünftig ist und welche die von Marie verkörperte Wirtschaftsordnung zurückdrängt. Die poetische, ja imaginär erzeugte Wirklichkeit verschwindet auf diese Weise im Reich des Irrealen, Unnötigen und deswegen Unmöglichen.

\section{M aries Märchen und der Z eitroman: Sinnidentität und Sinndifferenz}

Bis jetzt habe ich gezeigt, wie sich in Maries Märchen das Reich der Poesie zu dem Realitätsprinzip verhält. Miteinander verflochten, gegeneinander rivalisierend sind die zwei Welten einander gegenübergestellt. Das sich so gegenseitig beleuchtende Verhältnis zwischen Märchen und Wirklichkeit läßt sich im Sinne des Kontrastes von Märchenerzählen und ZeitromanSchreiben verstehen. Wie geht nun das Märchen, in dem das Prinzip ,Poiesis' regiert, mit der Zeitgeschichte um? Wie repräsentiert das Märchen die G eschichte?

D as Verhältnis des Märchens zur (Roman)-Wirklichkeit kann als ,mimetisch' im ursprünglichen Sinne verstanden werden. Nach dem ursprünglichen, d.h. aus dem kultischen Tanz kommenden Wortsinn ist Mimesis als Darstellung von Imaginiertem

154 H. Poser, Spiegel, D as Kätzchen - Bürgerliche W elt im Spiegel des Märchens, S. 42, in: Amsterdamer Beiträge zur neueren Germanistik. Bd. 9. 1979. Zur Literatur der D eutschsprachigen Schweiz. S. 33-43.

155 G. Keller, an Paul Heyse, 3.1.1881, in: ders., G esammelte Briefe. Bd. 3,1, S. 57. 
zu denken: Demnach bedeutet Mimesis im Verhältnis zur vorhandenen Wirklichkeit weniger ein Nachmachen als ein Vormachen, so wie etwa der Jagdzauber und Jagdtanz archaischer Kulturen vorführt, was geschehen soll. 156

D as so verstandene ,mimetische' Verhältnis zur Wirklichkeit ist gerade das, was die Kunst für Keller in seinem früheren ästhetischen Konzept für die Wirklichkeit und das Leben zu bedeuten hat. Es ist das Postulat an die Kunst, als „Bildwerk[]” zu fungieren, als ein Spiegelbild, das "die Keime der Zukunft"157 überhöht reflektiert und damit katalytisch wirksam wird. Die G rundlage für dieses Postulat ist aber der Glaube an den Fortschritt, das Vertrauen in die Geschichte als zukünftige Erfüllung des utopischen Entwurfes, dessen Verlust $M$ artin Salander als Zeitroman doch gerade dokumentiert.

An dieser Stelle sei auf den Arnold-Teil zurückverwiesen, in dem versucht wurde, herauszuarbeiten, welche Sinn- und Zukunftsperspektive jenseits des Fortschrittsgedankens von der Figur des Arnold getragen wird. Vom Fortschrittsglauben kann auch beim Märchen keine Rede sein. Jedoch scheint das Märchen in sich ein anderes Zukunftsbild zu bergen als der nach dem O bjektivitätsprinzip konzipierte Zeitroman. Vor diesem Hintergrund soll die Märchenfigur des Weibleins noch näher betrachtet werden, denn sie ist im gewissen Sinne als Präfiguration von Arnold zu verstehen, die aber zugleich auch in manchen Punkten über die in diesem verkörperte $G$ eisteshaltung hinauszugehen scheint.

Es ist „[e]in einziges lediges Weiblein, das allerjüngste von etwa zweihundert Jahren, was bei unsereinem einer Person von ungefähr zwanzig Jahren gleichkäme" (S. 39). Es ist nach dieser Rechnung so alt wie Amold am Ende des Romans und bleibt ebenfalls ledig. Eine vergleichbare Aufgabe wie dieser hat das Weiblein auch innerhalb seiner Gemeinde nach dem Abschiedschmaus: „Es hat die Pflicht, das ganze Geschirr zu reinigen, trocken zu reiben und in eine eiserne Truhe zu verschließen, die sie an der Stelle, wo der Regenbogen stand, in den Boden vergräbt." (S. 39)

Das die nationale Grenze Überschreitende in der Figur Arnolds wird hier in Maries Weiblein noch einen Schritt weitergetrieben. Im Gegensatz zu Arnold, der im Grundsatz des Patriotismus mit seinem Vater einverstanden ist, steckt im Weiblein etwas Radikales; das Weiblein wandert in die Ferne, wenn die zehn Ritter, die dem Weiblein beim Aufräumen geholfen haben, fortgehen, um „sich schlafen zu legen“ (S. 39). Und wenn es heißt, das Weiblein bleibe unverheiratet, weil „eine solche Person sich in der Fremde noch glücklich verheiraten konnte bei einem jüngeren Geschlechte" (S. 39), mutet dies als grundradikale Verneinung jeglicher Möglichkeit an, die Zukunft in dem alten Heimatland zu finden, ja sie dort überhaupt zu suchen. Diese Bereitschaft, das Vaterland lieber untergehen als dahinvegetieren zu lassen, eine Ambivalenz zwischen Liebe und Lust am Untergang, dürfte ihre Quelle in Kellers persönlicher politischer Radikalität, dem zutiefst persönlichen Charakter seines Vaterlandsbildes, seinem durch das liberale Glaubensbekenntnis legitimierten Junktim mit eigenem Wert haben.158

Neben diesem persönlichen Charakter ist dem Märchen, besonders seinem radikalen Ende, eine zeitgenössische topologische Dimension zuzuweisen. Keller teilt nämlich diese Radikalität mit den anderen zeitgenössischen Künstlem und Intellektuellen. ${ }^{159}$ Die Bildsprache von Kellers Märchen erweist sich gerade als für die Zeit typisch. Z.B. läßt sich das Bild, welches das letzte Weiblein auf seinem Weg bei der Auswanderung abgibt (das Weiblein „nimmt das Säcklein, worein sein eigenes Goldschüsselchen gewesen, auf den Rücken, einen Stecken zur Hand und wandert seelenallein in die Ferne."), bei einem anderen, zur gleichen Zeit entstandenen G edicht wiederfinden. 160

D em Bild des Auswandernden, gleich, ob in Maries Märchen bei Keller oder im erwähnten Gedicht mit romantischer Stimmung, liegt die Erfahrung der Entfremdung zugrunde: Jene Wurzel der antischweizerischen Tendenz, die in der Folgezeit in den Werken vieler der besten schweizerischen Schriftsteller zutage trat. 161 Was hier wie dort als Verlust empfunden wird, ist das Kulturleben des ,G oldenen Z eitalters' des Züricher Liberalismus in den 50er und 60er Jahren. Es ist der Materialismus ihrer Gesellschaft und ihrer Zeit, den die schweizerischen Schriftsteller als Ursache ihrer Klage über das G efühl der Atemnot, des Erstickens unter einer Dunstglocke der Scheinheiligkeit identifizieren. ${ }^{162}$ D as Verlustgefühl wird dadurch noch spürbarer gemacht, daß viele große Geister jener Goldenen Epoche inzwischen alle fortgezogen waren: Theodor Mommsen 1856, Richard Wagner und Jacob Burckhardt 1858, Francesco De Sanctis 1860, Hermann Köchly 1864, Friedrich Theodor Vischer und Georg Herwegh 1866 usw. ${ }^{163}$ Es ist nicht ohne historisches Beispiel, wenn sich jene ,antischweizerische Tendenz' in Maries

156 Vgl. G. Kaiser / F. A. Kittler, D ichtung als Sozialisationsspiel, S. 7.

157 G. Keller, An Berthold Auerbach, 25.6.1860, in: ders., G esammelte Briefe, Bd. 3,2, S. 195.

158 Vgl. A. Muschg, G. Keller: , M artin Salander', S. 165.

159 G. A. Craig geht in seinem dem Züricher Liberalismus gewidmeten Buch gerade auf diese kulturkritischen Auswirkungen der Krise des Liberalismus ein. (ders., $\mathrm{G}$ eld und $\mathrm{G}$ eist, besonders das zehnte Kapitel: $\mathrm{G}$ eld und $\mathrm{G}$ eist $\mathrm{D}$ ie Krise des $\mathrm{L}$ iberalismus.

160 Es ist ein Gedicht eines schweizerischen Dichters der Zeit, Heinrich Leuthold, das Craig zur Veranschaulichung der Entfremdung des Künstlers vom neuen Zürich anführt. Leuthold erschrak über das veränderte geistige Klima in Zürich, als er in den 1870er Jahren aus München dorthin zurückkehrte:

Wo sind die Enkel jener Gefeierten,

Die dir den Namen Limmat-Athen verliehen

Und dir zum Ruhm der freien Heimat

Kronen tragen im Reich der Schönen?

Du fragst umsonst. Setz' weiter den Wanderstab!

Den Sänger nährt der heimische Boden nicht...

Zugvögel mögen dich geleiten

Über die Berge nach fernen Zonen. (Zitiert nach G. A. Craig, G eld und G eist, S. 279)

161 Ebd., S. 280.

162 Vgl. ebd., S. 279.

163 Vgl. ebd., S. 279. 
Märchen wie in Leutholds Gedicht in dem gemeinsamen, der Zeit typischen Auswanderungsmotiv niederschlägt. Mit dieser Feststellung verfolge ich die Art und Weise und das Ziel der Radikalisierung im Märchen sowie in der Figur des Weibleins weiter.

Ähnlich wie die Aufgabe Arnolds in der Rettung und Bewahrung des Erreichten besteht, ist das Weiblein allem Untergehenden verpflichtet. An patriotischem $G$ efühl, das bei Amold gemildert und von jeglichem Enthusiasmus entbunden auftritt, hat das Weiblein noch weniger zu tragen. Seine Bestimmung liegt lediglich darin, „einem andern Volk dieser Art das G edächtnis des ausgestorbenen [Volkes; J.-H. B.] zu überbringen“" (S. 39).

Jedoch erfüllt das Weiblein neben der erklärtermaßen kulturellen, geistigen Mission noch eine andere Aufgabe, die Keller symptomatischerweise herunterspielt. D iese bezieht sich auf die Wirtschaft. D as Weiblein hat nämlich in dem seidenen Säcklein sein eigenes Goldschüsselchen, das bürgerliche Eigentum, mitgenommen. O hne davon zu erzählen, was das Weiblein mit dem ererbten Eigentum machen wird, endet zunächst Maries Märchen. Etwas zögernd wird die Zukunft des ins Ausland mitgenommenen Schatzes jedoch wieder ins Erzählen eingespannt, wenn Marie, scheinbar ganz nebenbei, bei der Entdeckung ihres Besitzes der Hohlmünze auf ihr Märchen zurückkommt:

Sie wunderte sich, daß sie nicht früher an diese Zuflucht gedacht hatte. Beinahe kam sie sich vor, als ob sie das ausgewanderte Erd- oder Bergweibchen wäre, das im fremden Lande ein Trüppchen Kinder erworben hat und nun die ererbte Goldschüssel verkaufen muß, um sie füttern zu können." (S. 40f.)

Man könnte meinen, daß Marie das Märchen weitererzählt. Genauer betrachtet, gehört diese Sequenz aber nicht zum Märchen, ihrer Märchenerzählung. In der Begeisterung identifiziert sich Marie spontan mit der Figur des Märchens, läßt diese Figur gemäß ihrer eigenen Situation weiterhandeln; alles spielt sich aber bloß im Bewußtsein der Erzählerin ab. So projiziert Marie ihre Realität auf das Märchen zurück. Für das Märchen öffnen sich in diesem Moment eine vorher nicht vorhandene Handlungsperspektive sowie eine vorher nicht geahnte Zukunftsperspektive. Das Weiblein handelt hier über das Kulturelle hinaus ökonomisch.

Die ökonomische Handlung, die von der Märchenerzählerin nicht einmal ausgesprochen, sondern nur ,simuliert' wird, ist anders beschaffen als die von Arnold. Während Amold die Firma der Familie rettet und das Geschäft weiterführt, verkauft das Weiblein die ererbte Goldschüssel für die Kinder in der Fremde. Caritas und Mildtätigkeit gegenüber dem Fremden ist des Weibleins ökonomisches Handlungsmotiv. Hierin liegt m.E. die utopische Dimension des Märchens, welche die Zukunftsperspektive eines Arnold sprengt. Der höchste Wert für das ausgedehnte Gemeinschaftsleben läßt sich hier als Altruismus und mütterliche Liebe entwerfen. Diese Perspektive, die als Maries spezifisch mütterliche Version ins Märchen eingeht, ist die befreiende, fortschrittliche Bedeutung der bürgerlichen Familie als Gegenstruktur der Gesellschaft, und vor allem die in ihr tendenziell „erhöhte Sensibilität für menschliche Bedürfnisse und Beziehungen“. ${ }^{164}$

Nachdem die G eschichte als Fortschritt nicht mehr erlebbar und das politische Individuum als Träger einer Geschichte, die sich progressiv zu entwickeln scheint, unterhöhlt worden ist, wird die Geschichte als ,D urcharbeitung' an die Stelle der G eschichte als ,D urchführung' gesetzt. Als Zeuge dieses Übergangs zieht sich Kellers Poesie, eine zutiefst mit der ,Geschichte der Durchführung' verbundene Ästhetik, selbst an einen O rt der nachfolgenden D urcharbeitung zurück. Diesen O rt sah Keller allein und ausschließlich in der bürgerlichen Familie, der Akkumulations- und Vermittlungsinstanz des kulturellen Gedächtnisses und des materiellen Reichtums. Das Märchen der Mutter ist so betrachtet die Poesie der Epoche der ,Durcharbeitung'. Am Rande dieser Poesie wird eine neue Art der ökonomischen Handlung imaginiert, aber, kaum vorgestellt, soll jene Assoziation schon wieder verschwinden, möglicherweise deswegen, weil diese ökonomische Handlungsweise zu Kellers eigenem Schrecken die Selbstzerstörung der Familie, des Privateigentums zu bedeuten hätte.

Die manifeste und immanente Radikaliät in dem auswandernden und dazu karitativ handelnden Weiblein macht Maries Märchen gegenüber dem Zeitroman spannungsvoll. Der poetologische Charakter der Spannung liegt m.E. darin, daß das Märchen das versteckte Ideal von Kellers Erzählen ist und als solches ein Korrektiv zum Zeitroman darstellt. Darüber hinaus könnte dem Auswanderungsmotiv des Märchens eine gewisse poetologische Bedeutsamkeit für Kellers Erzählkunst insgesamt eingeräumt werden. Das Auswanderungsmotiv stellt dann gerade die Kontrafaktur zu dem früheren Element im $\mathrm{G}$ rünen $\mathrm{H}$ einrich dar, mit dem Kellers Romanwelt sich öffnet: der Ankunft eines jungen Mannes vom Alter von 26 Jahren, der „seine lange Wanderschaft ruhmvoll beendigt" und „als ein förmlicher Herr" „zurückkehrte“. 165 Es handelt sich hierbei um Rudolf Lee, Heinrichs früh verstorbenen Vater, einen Bauernsohn, der jetzt als Baumeister aus Deutschland ins heimatliche Dorf zurückkehrt. Hier sind Ankunft und Niederlassung nach der Wanderschaft ein Zeichen für,Welthaben'; man kehrt zurück mit der Hoffnung auf ein Goldenes Zeitalter, „auf eine bessere, schönere Zeit der Wirklichkeit", die man „mit erhöhtem Fleiß und Mäßigkeit" 166 in der Heimat realisieren will. D ort, in Maries Märchen, wandert man aus, da die erhoffte Zukunft bereits als entfremdete Welt realisiert ist; so ist die Auswanderung ein Zeichen des ,Weltverlierens'. Soweit erweist sich Maries Märchen als Umkehrung des G rünen $\mathrm{H}$ einrich. Mit Maries Märchen beansprucht $\mathrm{M}$ artin Salander, ein poetologisches Erzählen durchzuführen, das den epischen Raum Kellers insgesamt nicht nur chronologisch, sondern auch symbolisch schließt.

164 H. Rosenbaum, Formen der Familie, S. 380.

165 G. Keller, D er grüne H einrich, in: ders., Sämtliche W erk e. Hrsg. v. J. Fränkel / C. Helbling. 22 Bde. Bd. 16, S. 76.

166 Ebd., S. 77. 


\section{ZUSAMMENFASSUNG UND AUSBLICK}

Die Weite und Vielgestaltigkeit der Spannung zwischen dem realistischen Roman und dem modernen Erzählen sprengt die Begrenztheit der Aspekte, die dem Kanon des modernen Romans zugerechnet werden - so lautete der Ausgangspunkt der vorliegenden Arbeit. Ihr Ziel war demzufolge, das literarisch Modeme in den realistischen Romanen als solches zu präsentieren und einzugrenzen. Anders gesagt: Die Arbeit hat sich zur Aufgabe gemacht, das Moderne des späten Realismus ,aus der Sache selbst' zu entwickeln, d.h. es sowohl in Übereinstimmung zu modernem Erzählen als auch in Abweichung von diesem zu legitimieren.

Dies wurde versucht durch die Eruierung der realistischen Spannung zwischen Erzählinhalt und Erzählstil, welche man als einen spezifischen Fall der Spannung - nämlich die durch eine für die „Beziehung zwischen der O rdnung in der Erzählung und der O rdnung im Leben“ fundamentale „Verschiebung“167 gekennzeichneten Spannung - im Sinne Todorovs verstehen kann. Dabei diente die phänomenologische Beobachtung als Zuordnungsrahmen, „daß Kellers Realismus der Fabel in republikanischen Sujets zur Durchführung kommt, Fontanes Realismus des schönen Scheins die Gesellschaftsordung des „Ancien Régime' voraussetzt, der humorische Realismus Raabes den ,homme universel' in der Gestalt des Bildungsbürgers wählt". ${ }^{168}$ Allerdings sollte diese skizzierte innere Struktur der jeweiligen Spielarten des Realismus sich ex negativo gerade an solchen Texten wie den von mir zur Interpretation herangezogenen bewähren, die nicht dem poetischen Realismus Kellers, dem ästhetischen Realismus Fontanes sowie dem humoristischen Realismus Raabes zugeordnet werden. Es sind jene, die die Autoren als letzte Werke hinterlassen haben, in denen sie jeweils nicht nur neue Wege der Darstellung gingen, sondern sich auch von den eigenen Realismusprogrammen distanzierten, statt diese fortzuschreiben.

Es scheint nicht gegen, sondern für die oben ausgeführte Korrespondenz zwischen Sujetwahlen und Darstellungsweise zu sprechen, wenn sich in jenen Texten die Sujetwahl als ebenfalls ,verwandelt' herausstellt. Verwandelt in dem Sinne, daß in den Romanen die Sujets von der bisherigen realistischen Bedeutung entfernt und in ein neues Licht gerückt, nämlich vom jeweiligen Autor als historisch abgelöst präsentiert werden. Dargestellt wurde im späten realistischen Roman also vor allem, wie das republikanische Ideal des Citoyen unterhöht wurde, wie die genuin antiaristokratische bürgerliche O rdnung sich an die alte aristokratische Herrschaft- und Lebensform anglich und diese zugleich ablöste und wie dem bildungsbürgerlichen humoristischen Ideal jegliche Verwirklichungsbasis entzogen wurde.

D iesem sujetbezogenen Wandel lag die Gründerzeit als zeitgeschichtliche Rahmenbedingung zugrunde. Die Grüderepoche war, wie es nahelag, von der ihr vorangegangenen Erfahrung der Moderne nicht im Wesen unterschieden. Sie wurde eher durch eine in ungeahnte Richtung sich immer mehr ausdehnende Konsequenz der modernen Lebensformen gekennzeichnet, d.h. durch die Intensität eines Lebengefühls des Verlustes von Unmittelbarkeit und Selbstverständlichkeit. Die Interpretation hat gezeigt, um welche konkrete gründerzeitlich ausgeprägte Erfahrung der Moderne es sich in den jeweiligen Romanen handelte. Dabei wurde das Konkrete im Rahmen der vorliegenden Arbeit nicht im engen Sinne, d.h als Einzelfaktisches, aufgefaßt, sondern vielmehr in der Bedeutung von etwas Kategorischem, welches zwar auf den empirischen Bereich der Sujets zurückführbar ist, sich jedoch schließlich in die symbolische Form transformieren läßt.

Rekapituliert man das Ergebnis der so angelegten Untersuchung, läßt sich folgendes feststellen: Raabes humoristischer Realismus in seinem ,Endstadium' griff sujetmäßig auf den ökonomischen Ursprung des modernen Subjekts, auf die Kategoie des Eigentums, zurück. Die Analyse konnte zeigen, daß es sich hier um einen (Re)-Aktualisierungs- bzw. Potenzierungsversuch der klassischen bürgerlichen Aneignung der besitzbürgerlichen Subjektivität handelt. D es weiteren baute sich das Bild des unversehrten bürgerlichen Subjekts in Raabes Roman in Gestalt der öffentlich handelnden Hauptfigur aus. Parallel zu dieser erneuten Verfestigung des bürgerlichen Subjektbegriffs parallel, ja praktisch als dessen Kontrastbild wurde die spätbürgerliche Subjektivität vorgeführt. Die Verschiebung zwischen der bürgerlichen und der spätbürgerlichen Subjektivität schlug sich auch im E rzählerischen nieder. Das Erzählen geriet hier zu einer endlosen Reise ins eigene Innere des heimatlosen Wanderers, in die ruhelose Kreisbewegung der befangenen modernen Existenz, während dort das humoristische Erzählen das O ralitätsprinzip und damit die ursprüngliche, höchste Stufe der epischen Kunst darstellt.

Der gesellschaftliche Wandel hat Fontane weniger im Sinne von einzelnen Schicksalen, denn als wachsende Macht der Bourgeoisie interessiert. In seiner Vertrautheit mit der alten Gesellschaftsordnung und deren Formwelt war Fontane bemüht, Eindrücke von der modernen bürgerlichen Ordnung zu gewinnen und ihnen ästhetische Formen zu verleihen. In seiner Sensibilität für den Kontingenzcharakter in allen menschlichen Ordnungen näherte sich Fontane dem theoretischen Verständnis der Moderne seiner und der späteren Zeit an, demzufolge die zunehmende Kontingenz das Bewegungsprinzip der modernen Welt bedeutet.

Kontrastiv zu Fontanes Offenheit gegenüber der modernen O rdnung stand Keller in seiner holistischen Weltanschauung der Atomisierung der modernen Welt zutiefst beunruhigt gegenüber. In seinem Beharren auf Handlung richtete sich sein Erzählen ebenfalls gegen die Strategie der Verinnerlichung, die das moderne Erzählen kennzeichnet. Das Konzept der Handlung nahm bei Keller mit dem Stillstand der republikanischen Nationalgeschichte praktisch ein Ende. Kellers Distanz

167 T. Todorov, D ie Kategorien der literarischen E rzählung, in: H. Blumensath (Hrsg.) Struk turalismus in der Literaturwissenschaft. Köln 1972, S. 263-294, hier S. 264.

168 H. Turk, D ie Schrift, S. 400. 
gegenüber einem solchen - inzwischen als die literarische Moderne überhaupt großgeschriebenen - modemen Erzählen fehlte aber eine andere, vorwärtsgewandte Perspektive, die der Restitutionsbewegung des Epischen zugrundegelegen hätte. Eine mögliche Erklärung dafür wäre, daß Keller, anders als etwa Alfred Döblin, nicht über die grundlegende Erfahrung der Moderne verfügte, nämlich über die Großstadterfahrung - die radikale Umgestalterin menschlicher Wahrnehmungsweisen und deren literarischer Formel. Es bleibt zu überlegen, ob man hier nicht mit einer vom schweizerischen 19. Jahrhundert geprägten Spielart solcher Bemühungen zu tun hat, die versuchen, die über das Individuum hinausgehende Dimension in der modernen Welt zu episieren.

Was den oft als überraschend wahrgenommenen modernen Zug bei den Realisten anbelangt, konnte vor dem Hintergrund dieser Forschungsergebnisse ergründet werden: Raabe bereitete gerade in - nicht trotz - seiner Insistenz auf dem bildungsbürgerlichen humoristischen Subjektbild dessen kommenden Wandel vor. Ebenfalls gewann Fontane wegen - nicht trotz - seines politisch-ästhetischen Verpflichtetseins gegenüber dem Alten ein für die Literatur der Zeit außerordentliches Sensorium für die Funktionsweise der modernen G esellschaft. Keller ist es gelungen, gerade in seinem Haften an einer über das Individuum hinausgehenden gesellschaftlichen Dimension - nicht trotz einer gewissen Antiquiertheit, die sich den Individualisierungstendenzen der Moderne entgegenstellte - die Entwicklungsrichtung der modernen Welt zu erkennen.

Es wurde, so kann man resümieren, im späten realistischen Roman der einstige Zusammenhang von Sujetwahl und ästhetischen Erscheinungsformen aufgehoben. Die ästhetischen Erscheingsformen des humoristischen, ästhetischen und poetischen Realismus sind ,transparent' geworden. Ein parodistischer, reflexiver Bezug zu jenen ästhetischen Erscheinungsformen konstituierte in den behandelten Romanen einen je spezifischen Erzählstil, der sich mit der literarischen Moderne in verschiedener Perspektive vergleichbar machte. Dies alles, so hat die Untersuchung gezeigt, resultierte aus veränderten Weltbezügen, die mit den empirischen D arstellungsgegenständen einhergingen. In diesem Sinne hat meine Arbeit die selbst gestellte Aufgabe erfüllt: die Geschichtlichkeit der literarischen ,Form' aus der geschichtlichen ,E rfahrung' der Moderne zu begründen.

Was der Vermittlung zwischen diesen beiden Bereiche zugute kam, die starke Konzentration auf den einzelnen Roman, hatte freilich zur Folge, daß das G esamtwerk des jeweiligen Autors zugunsten scharf umrissener Einzelanalysen zurückgestellt worden ist. Dieser Tendenz trägt auch die Textauswahl Rechnung, bei der nicht die autorenbezogene Repräsentativität, sondern die Deutlichkeit der Modellfunktion das entscheidende Kriterium war. Was in dieser Arbeit ebenfalls nicht erschöpfend behandelt werden konnte, sind die verschiedenen Figurationen bzw. Optionen der Moderne. Sie wurden von mir zwar aufgegriffen und interpretiert, aber ihre weitergehenden Bedeutungen blieben im Interesse der E inzelinterpretation eingegrenzt.

Besonders Schmidts ,Hummer-oder-Krebs'-Option im Frau Jenny Treibel kann als Figuration der modemen Wahrnehmungsweise weiter verfolgt werden, und Wohlwends ,Proteuscharakter' im M artin Salander läßt sich ebenfalls in seiner konzeptionellen Bedeutung für die Moderne weiter fundieren. Die Fortführung dieser Perspektive könnte zu einem interessanten Versuch führen, eine an den realistischen Texten entwickelte Skala der Perspektiven der Moderne herauszuarbeiten, also eine realistische Theorie der Moderne zu entwickeln. 


\section{LITERATURVERZEICHNIS}

\section{Werke und Q uellen}

\section{Autoren der behandelten Romane}

Fontane, Theodor, W Werke, Schriften und Briefe. Hrsg. v. Walter Keitel / Helmuth Nümberger. München 1962f. A bt. I: Romane, E rzählungen, G edichte (I, 1-7); A bt. II: W anderungen durch die M ark Brandenburg (II, 1-3); A bt. III: E rinnerungen, ausgewählte Schritten und Kritik en (III, 1-5); A bt. IV : Briefe (IV , 1-4).

ders., $\quad$ SämtlicheW erke. 36 Bde. Hrsg. v. Edgar G roß / Kurt Schreinert u.a. München 1959-1975.

ders., $\quad$ Aus dem N achlaß von Th. Fontane. Hrsg. v. Josef Ettlinger. Berlin 1908.

Keller, Gottfried, Sämtliche W erke. Auf Grund des Nachlasses besorgte und mit einem wissenschaftlichen Anhang versehene Ausgabe. Hrsg. v. Jonas Fränkel / Carl Helbling. 22. Bde. Bern; Leipzig 1931-1948.

ders., $\quad$ G esammelte Briefe. 4 Bde. Hrsg. v. Carl Helbling. Bern 1950-1954. Bd. III-1.

Raabe, Wilhelm, $\quad$ Sämtliche W erk e, i.A . der Braunschweig. W issenschaftl. G esellschaft. Hrsg. v. Karl Hoppe. 20 Bde. 3 Erg.Bde. (mehr bisher nicht ersch.), Freiburg; Braunschweig (ab 1960 Göttingen) $1959 f$.

\section{Andere Autoren}

Boeckh, August, Encyklopädie und Methodologie der philologischen Wissenschaften. Leipzig 1877.

Döblin, Alfred, D er Bau des epischen W erks, in: ders., A ufsätze zur L iteratur.Olten; Freiburg 1963. S. 103-132.

ders.,Schriften zu Ä sthetik, Poetik und L iteratur. Hrsg. v. Erich Kleinschmidt. O lten; Freiburg 1989.

Freytag, Gustav,G esammelte W erk e. 22 Bde. 2. Aufl. Leipzig 1896-1898. Bd. I.

Hegel, Georg Wilhelm Friedrich, W erke in 20. Bdn. Hrsg. v. Eva Moldenhauer / Karl Markus Michel. Frankfurt/ M. 1986. Bd.7 (G rundlinie der Philosophie des Rechts). Bd. 13, 15 (V orlesungen über die Ä sthetik I. III.).

Herder, Johann Gottfried, W erke 10 Bde. Hrsg. v. Jürgen Brummack / Martin Bollacher. Frankfurt/ M. 1984. Bd. 4 (Schritten zu Philosophie, Literatur, Kunst und A ltertum 1774-1787. A uch eine Philosophie der G eschichte). Bd. 6 (Ideen zur Philosophie der G eschichte der M enschheit).

Locke, John, Z wei A bhandlungen über die Regierung. Hrsg. v. Walter E uchner. Frankfurt/ M. 1977.

Mann, Thomas, Joseph und seine Brüder. E in V ortrag, in: ders., G esammete W erke. 12 Bde. Oldenburg 1960. Bd X I. Reden und A ufsätze 3. S. 654-669.

Mill, John Stuart, D ie F riheit. Hrsg. v. Adolf G rabowsky. Zürich 1945.

Musil, Robert, D er M ann ohne E igenschaften, in: G esammette W erk e in E inzelausgaben. Hrsg. v. Adolf Frisé. Bd. 1, Hamburg 1952.

Nietzsche, Friedrich, U nzeitgemäße Betrachtungen. W erk e in drei Bänden. Hrsg. v. Karl Schlechta. München $1954 f$.

ders., N achgelassene Schriften 1870-73. F ünf V orreden zu funf ungeschriebenen Büchern, in: ders. G esamtausgabe. Dritte Abteilung zweiter Band. Hrsg. v. Giorgio Colli und Mazzino Montinari. Berlin; New York 1973.

Novalis, W erke, Tagebücher und Briefe Friedrich von H ardenbergs. Hrsg. v. Hans Joachim Mähl / Richard Samuel. 2 Bde. Mit einem Kommentar-Bd. München 1978f. Bd. I.

Plessner, Helmuth,D ie verspätete N ation. Ü ber die politische V erfuhrbark eit bürgerlichen G eistes (1935/1959), in: ders. Gesammelte Schriften. Hrsg. v. Günter Dux. 10 Bde. 1980-85. Bd. VI (1982). 
ders., U ngesellige G eselligk eit. A nmerk ungen zu enem Kantischen Begriff (1966), in: G esammelte Schriften. Bd. VIII. Conditio humana, S. 294306.

Schlegel, Friedrich, Ü ber G oethes M eister; V ersuch über den Styl in G oethes früheren und späteren W erk en, in: Kritische Friedrich-SchlegelA usgabe. A bt. I. Bd. 2. Charakteristik en und Kritik en I (1796-1801). Hrsg. u. eingeleitet. v. Hans Eichner. Darmstadt 1967, S. 126146, S. 339-351.

ders., Ü ber das Studium der griechischen Poesie, in: ders., Kritische Schriften. Hrsg. v. Wolfdietrich Rasch. München ${ }^{2} 1964$.

Schopenhauer, Arthur, D er handschrifliche N achlaß. Band 2. Frankfurt/ M. 1967.

Spielhagen, Friedrich, Beiträge zur Theorie und Technik des Romans. Faks. D ruck der 1. Aufl. von 1883. Mit einem Nachwort von Hellmuth Himmel. D eutsche Neudrucke. Reihe Textes des 19. Jahrhunderts. Hrsg. v. Walter Killy. Göttingen 1967.

Tocqueville, Alexis de, Ü ber die D emok ratie in A merika $(1835,1840) .2$ Bde. Zürich 1987. Bd. 1. D er alte Staat und die Revolution (1856).

\section{Sekundärliteratur}

Adorno, Theodor W., Kierk egaard. Konstruk tion des Ä sthetischen. Frankfurt/ M. 19862.

ders., N oten zur L iteratur I. Frankfurt/ M. 1963.

Arendt, D ieter, W ilhelm Raabe und der „R omantische Schlachtruf: Krieg den Philistern!“, in: JbdRG 1981, S. 55-83.

ders., Künstler-Figurationen im W erk W ilhelm Raabes oder: „E r war überhaupt keine ausgesprochene Künstlernatur“, in: JbdRG 1987, S. 4683.

Auerbach, Erich, M imesis D argestellte W irk lichk eit in der abendländischen L iteratur (1946). Bern $1988^{8}$.

Aust, Hugo, A nstößige V ersöhnung? Z um Begriff der V ersöhnung in Fontanes „F rau Jenny Treibe", in: ZfdP 92 (1973), Sonderheft, S. 101-126.

Bänsch, D orothea, D ie Bibliothek W ilhelm Raabes nach Sachgebieten geordnet, in: JbdRG 1970, S. 87-165.

Beaucamp, Eduard, L iteratur als Selbstdarstellung. W ilhelm Raabe und die M öglichk eiten eines deutschen Realismus. Bonn 1968.

Becker, Claudia, Zimmer-Kopf-W elten. M otivgeschichte des Intérieurs im 19. und 20. Jahrhundert. München 1990.

Benjamin, Walter, D er E rzähler. Betrachtungen zum W erk N ikolai L esskows; Krisis des Romans. Zu D öblins ,Berlin A lex anderplatz', in: ders., G esammelte Schriften (1977). S. 438-45 und Bd. III (1972). S. 230-237.

Beutin, Ludwig, D as Bürgertum als Gesellschaftsstand im 19. Jahrhundert (1953), in: ders., G esammelte Schriften zur W irtschafts- und Sozialgeschichte. Köln 1963.

Binder, Julius u.a., E infuhhrung in H egels R echtsphilosophie. Berlin 1931.

Blinn, Hansjürgen, E manzipation und L iteratur. Frankfurt/ M. 1984.

Blumenberg, Hans, W irk lichk eitsbegriff und M öglichk eit des Romans, in: Hans Robert Jauß (Hrsg.), N achahmung und Illusion. Poetik und H ermeneutik Bd. I. München 1969. S. 9-27.

Bödeker, Hans Erich, M enschheit, H umanität, H umanismus, in: Otto Brunner / Werner Conze / Reinhard Koselleck (Hrsg.), $\mathrm{G}$ eschichtliche $\mathrm{G}$ rundbegriffe. Historisches L ex ik on zur politisch-sozialen Sprache in D eutschland. Bd. 3. S. 1063-1128.

Boeschenstein, Hermann, G ottfried Keller. Stuttgart 1969.

Bohrer, Karl Heinz, Plötzlichk eit. Zum A ugenblidk des ästhetischen Scheins. Frankfurt/ M. 1981. 
Brandt, Reinhart, E igentumstheorien von G rotius bis Kant. Stuttgart; Bad Cannstatt 1974.

Brewster, Philip J., 0 nk el Ketschwayo in N euteutoburg. Z eitgeschichtliche A nspielungen in Raabes Stopfk uchen, in: JbdRG 1983, S. 96-118.

Brinkmann, Richard, W irklichkeit und Illusion. Studien über G ehalt und Grenzen des Begriffs Realismus für die erzählende Dichtung des neunzehnten Jahrhunderts. Tübingen. 19662 .

ders., Theodor F ontane. Ü ber die V erbindlichk eit des Unverbindlichen. Tübingen 19772.

ders., D er angehaltene M oment. Requisiten - $G$ enre - T ableau bei Fontane, in: DVjs 53. 1979. S. 429-462.

Brocker, Manfred, Arbeit und E igentum. D armstadt 1992

ders., Kants Besitzlehre. Zur Problematik ener transzendentalphilosophischen E igentumslehre. Würzburg 1987.

Brodk haus E nzyk lopädie in 20 B den. Siebzehnte völlig neubearbeitete A uflage 8. Bd. Wiesbaden 1969.

Brüggemann, Diethelm, F ontanes A llegorien, in: ders., N eue Rundschau L X X X II (1971). S. 290-310 (I) u. 486-505 (II).

Buck, Theo, A m Rande des inneren M onologs - Zur E rzählk onstruktion von Raabes „A ltershausen“, in: JbdRG 1987. S. 24-45.

Bucher, Max / Hahl, Werner, Realismus und G ründerzeit. Manifeste und D ok umente zur deutschen L iteratur 1848-1880. 2 Bde. Stuttgart $1975 f$.

Cambon, Glauco, D er Kampf mit Proteus. Untersuchungen über Sprache und Sein in der modernen L iteratur. München 1970.

Conze, Werner, V om Pöbel zum Proletariat. Sozialgeschichtliche V oraussetzungen fur den Sozialismus in D eutschland, in: Vierteljahresschrift für Sozial- und Wirtschaftsgeschichte. 41 (1954). S. 334-364.

Cowen, Roy C., Spiegel und W iderspiegelung: zu Kellers Märchen, Spiegel, das Kätzchen, in: Hartmut Steinecke (Hrsg.), Zu G ottfried Keller. Stuttgart 1984, S. 68-78.

Craig, G ordon A., D eutsche G eschichte 1866 - 1945. V om N orddeutschen Bund bis zum E nde des D ritten Reichs. München 1980.

ders., G eld und G eist. Zürich im Zeitalter des L iberalismus 1830-1869. München 1988.

D ann, Otto, H erder und die deutsche B ewegung, in: Gerhard Sauder (Hrsg.), J. G . H erder 1744-1803. Hamburg 1984. S. 308-340.

D emetz, Peter, F ormen des Realismus: Theodor F ontane Kritische U ntersuchungen. München 1964.

D er neue Pitaval. E ine Sammlung der interessantesten Criminalgeschichten aller L änder aus älterer und neuerer Z eit. Hrsg. v. Julius Eduard Hitzig und Wilhlem Häring (W. Alexis). Ab Band 31 fortgesetzt von Anton Vollert. 60. Bde. Leipzig: Brockhaus 1842-1860.

D erks, Paul, RaabeStudien. Beiträge zur A nwendung psychoanalytischer Interpretationsmodelle: Stopłk uchen und das O dfeld. Bonn 1976.

D etroy, Peter, W ilhelm Raabe. D er H umor als G estaltungsprinzip im Stopfkuchen. Bonn 1970.

Dießelhorst, Malte, Zum V ermögensrechtssystem Samuel Pufendorfs. Göttingen 1976.

D umont, Louis, Individualismus. Z ur Ideologie der M oderne. Frankfurt/ M. 1991.

Ehrensperger, Armin, Individuum und öffentliche G emeinschatt bei G ottfried Keller. Zürich 1972.

Eisele, Ulf, Realismus und Ideologie. Z ur Kritik der literarischen Theorie nach 1848 am Beispiel des „D eutschen M useums". Stuttgart 1976. ders., D er D ichter und sein D etek tiv. Raabes „Stopkkuchen“ und die F rage des Realismus. Tübingen 1979. 
Elias, Nobert, Studien über die D eutschen. Machtkämpfe und Habitusentwidk lung im 19. und 20. Jahrhundert. Hrsg. v. Michael Schröter. Frankfurt/ M. 1992.

Emrich, Wilhelm, Protest und V erheißung. Frankfurt/ M. 1960.

Euchner, Walter, E goismus und G emeinwohl. Frankfurt/ M. 1973.

ders., N aturrecht und Politik bei John L odk e. Frankfurt/ M. 1979.

Folkers, Gert, Besitz und Sicherheit. Ü ber E ntstehung und Z erfall einer bürgerlichen Illusion am Beispiel G oethes und Raabes. Kronberg/ Ts. 1976 .

Fues, Wolfram M., A bbildentstellung? A nmerk ungen zu Gottfried Kellers Martin Salander anhand neuester Literatur, in: Internationales Archiv für Sozialgeschichte der deutschen Literatur. Bd. 9, 1984, S. 152-179.

ders., Poesie der Prosa, Prosa als Poesie. E ine Studie zur G eschichte der G esellschaftlichk eit bürgerlicher L iteratur von der deutschen Klassik bis zum A usgang des 19. Jahrhunderts. Heidelberg 1990.

G aede, Friedrich, Realismus von Brant bis Bredht. München 1972.

Gethmann-Siefert, Annemarie, D as Klassische als das U topische. Ü berlegung zu einer Kulturphilosophie der Kunst, in: Rudolf Bockholdt (Hrsg.), Ü ber das Klassische, S. 47-76.

G oetz-Stankiewicz, Margarette, D es D idhters, Pflicht'. G edank en zu Raabes E instellung zum Kunstwerk, in: JbdRG 1971, S. 21-48.

Goody, Jack / Watt, Ian / Gough, Kathleen, Entstehung und Folgen der Schriftkultur. Mit ener E inleitung von H einz Schlaffer. Frankfurt/ M. 1991.

Graef, Eva, M artin Salander. Politik und Poesie in G ottfried Kellers G ründerzeitroman. Würzburg 1992.

G raevenitz, Gerhart v., D er D idk e im schlafenden Krieg. Zu einer Figur der europaiischen M oderne bei W ilhelm Raabe, in: JbdRG 1990. S. 121.

Habermas, Jürgen, Struk turwandel der Ö ffentlichk eit: U ntersuchungen zu einer Kategorie der bürgerlichen G esellschaft. Frankfurt 1968.

ders., D ie neue U nübersichtlichk eit. Klëne politische Schriften V . Frankfurt/ M. 1985.

Hagemann, Hans Rudolf, Stichwort „E igentum“, in: Adalbert Erler u.a. (Hrsg.), H andwörterbuch zur deutschen Rechtsgeschichte. Bd. 1. Berlin 1971. 883f.

Haltern, Utz, Bürgerliche G esellschaft. Sozialtheoretische und sozialhistorische A spek te. D armstadt 1985.

Heldt, Uwe, Isolation und Identität. D ie Bedeutung des Idyllischen in der E pik W ilhelm Raabes. Frankfurt/ M. 1979.

Henrich, D ieter, H egel. Philosophie des Rechts. Frankfurt/ M. 1983.

Heselhaus, Clemens, D as Realismusproblem, in: Begriffsbestimmung des literarischen Realismus. Hrsg. v. Reinhard Brinkmann. Darmstadt 1969. S. 337-364.

ders., Poesie als Synthese. A usbreitung eines deutschen Realismus-V erständnisses in der Mitte des 19. Jahrhunderts. Frankfurt/ M 1973.

Hillebrand, Bruno, D as 19. Jahrhundert: D er Konflikt zwischen Individuum und G esellschaft, in: ders., Theorie des Romans. München 1980, S. 192-276.

Hobsbawm, Eric John., D ie Blütez eit des Kapitals. E ine Kulturgeschichte der Jahre 1848-1875. München 1977.

Izenberg, Gerald. N., D ie ,A ristokratisierung' der bürgerlichen Kultur im 19. Jahrhundert, in: Peter Uwe Hohendahl/ Paul .Michael Lützeler (Hrsg.), L egitimationsk risen des deutschen A dels 1200-1900. Stuttgart 1979. S. 233-244. 
Jardin, André, A lex is de Tooqueville. L eben und W erk. Frankfurt/ M. 1991.

Jauß, Hans Robert, L iteraturgeschichte als Provok ation. Frankfurt/ M. 19744.

Jeziorkowski, Klaus, Gottfried Keller. München 1969.

ders., L iterarität und H istorismus. Beobachtungen zu ihrer E rscheinungsform im 19. Jahrhundert am Beispiel G ottfried Kellers. Heidelberg 1979. Jung, Winfried, Bildergespräche. Zur F unk tion von Kunst und Kultur in Theodor F ontanes „L'A dultera“. Stuttgart 1991.

Kant, Immanuel, M etaphysik der Sitten, Rechtslehre, in: der., W erk e in sechs Bänden. Hrsg. v. Wilhelm Weischedel. Frankfurt 1991, 9. Aufl. Bd. IV .

Kafitz, Dieter, Figurenk onstellation als Mittel der W irklichk eitserfassung. D argestellt an Romanen der zweiten Hälfte des 19. Jahrhunderts (F reytag. Spielhagen. F ontane. Raabe). Kronberg/ Ts. 1978.

ders., D ie A ppellfunk tion der A ußenseitergestalten: Z ur näheren Bestimmung des Realismus der mittleren und späten Romane W ilhelm Raabes, in: Leo A. Lensing / Hans-Werner Peter, W ilhelm Raabe. Studien zu seinem L eben und W erk. Braunschweig 1981. S. 51-76.

ders., D ie Kritik am Bildungsbürgertum in Fontanes Roman ,Frau Jenny Treibel', in: ZfdP 92 (1973). Sonderheft Theodor Fontane. S. 74-101.

Kahler, Erich v., U ntergang und Ü bergang. E ssays. München 1970.

Kahrmann, Cordula, Idyll im Roman: Theodor Fontane. München 1973.

Kaiser, Gerhard, G . Keller. D as gedichtete L eben. Frankfurt/ M. 1981.

ders. u.a., D ichtung als Sozialisationsspiel. Studien zu G oethe und G ottfried Keller. Göttingen 1978.

Kaiser, Michael, L iteratursoziologische Studien zu G. Kellers D idhtung. Bonn 1965.

Kayser, Wolfgang, D ieA nfänge des modernen Romans im 18. Jahrhundert und seine heutige Krise, in: DVjs 28, 1954. S. 417-446.

Kersting, Wolfgang, W ohlgeordnete F reiheit. Immanuel Kants Rechts- und Staatsphilosphie. Berlin; New York. 1984.

ders., E igentum, V ertrag und Staat bei Kant und L odke, in: Martyn P. Tompson (ed.), John L odke und/ and Immanuel Kant. Berlin 1991. S. 109-134.

Kocka, Jürgen, Bürger und Bürgerlidhk eit im 19. Jahrhundert. Göttingen 1987.

Kohlschmidt, Werner, D er Z eitgeist in „G ottfried Kellers ,M artin Salander" , in: Orbis Litterarum, Vo1. XXII. Kopenhagen 1967, S. 93-100.

Kricker, Gottfried, Th. Fontane. V on seiner A rt und epischen T echnik. Berlin 1912.

Künzli, Amold, M ein und D ein. Z ur Ideengeschichte der E igentumsfeindschaft. Köln 1986.

Lämmert, Eberhard, Bürgerlichk eit als literarhistorische Kategorie, in: J. Kocka (Hrg.), Bürger und Bürgerlidhkeit im 19. Jahrhundert. Göttingen 1987. S. 196-219.

Lehrer, Mark A., Intellek tuelle A porie und literarische 0 riginalität. W issenschaftsgeschichtliche Studien zum deutschen Realismus: Keller, Raabe und F ontane. Berkeley 1986.

Lethen, Helmut, L ob der Kälte. E in M otiv der historischen A vantgarden, in: Dietmar Kamper u.a. (Hrsg.), D ie unvollendete V ernunft: M oderne versus Postmoderne. Frankfurt/ M. 1987. S. 282-290.

Loster-Schneider, Gudrun, D er E rzähler Fontane. Seine politischen Positionen in den Jahren 1864-1898 und ihre ästhetische V ermittlung. Tübingen 1986. 
Lugowski, Clemens, D ie F orm der Individualität im Roman. Frankfurt/ M. 1976.

Lukács, Georg, Probleme des Realismus I-III (1964), in: G. L. Werke, Bd. 4-6. Neuwied $1964 f$.

ders., D ie G rablegung des alten D eutschland. E ssays zur deutschen Literatur des 19. Jahrhunderts. A usgewählte Schriften I. Reinbek bei Hamburg 1967.

ders., D ie Theorie des Romans. D armstadt; Neuwied 1972 (1920).

Maatje, Frank C., D er Raum als k onstituierendes M oment in W ilhelm Raabes „H ungerpastor", in: Herman Helmers (Hrsg.), Raabe in neuer Sicht. Stuttgart 1968. S. 185-191.

Macpherson, Crawford Brough, D ie politische Theorie des Besitzindividualismus. Frankfurt/ M. 1990.

Makropoulos, Michael, M odernität als ontologischer A usnahmezustand? Studien zur Theorie der M oderne in den Schriften W alter Benjamins. Göttingen 1989.

ders., T endenzen der Z wanziger Jahre. Zum D isk urs der Klassischen M oderne in D eutschland, in: DZfPh 39 (1991). H. 6. S. 675-683.

ders., Konstellation und Synthese. Kracauer, L azarsfeld und die Konstruktion soziologischer Wirklidkeit um 1930, in: Jahrbuch fur Soziologiegeschichte 1992. O pladen 1994. S. 147-159.

Martini, Fritz, D eutsche L iteratur im bürgerlichen Realismus 1848-1898. Stuttgart 19621술. $1981^{4}$.

ders., W eltleid und W eltversöhnung. W ilhelm Raabe in seinem Jahrhundert, in: JbdRG 1985. S. 7-26.

Mayer, Hans, D er deutsche Roman im 19. Jahrhundert, in: ders., V on L essing bis Thomas M ann. Pfullingen 1959. S. 297-316.

Mecklenburg, Norbert, E insichten und Blindheten, in: Heinz Ludwig Arnold (Hrsg.), Text + Kritik Sonderband Theodor Fontane. München 1989, S. 148-162

Meyer, Herman, Raum und Z it in W ilhelm Raabes E rzählkunst (1953), in: Hermann. Helmers (Hrsg.), Raabe in neuer Sicht. Stuttgart 1968. S. 98-129.

M eyers Konversations-L ex ik on, 6. Aufl., Leipzig/ Wien 1908, Bd. II.

Merkel-Nipperdey, Margarete, G ottried Kellers ,M artin Salander'. U ntersuchungen zur Struk tur des Z eitromans. Göttingen 1959.

Meyer, Jochen, H ie W df! H ie W aiblingen! W ilhelm Raabe in Stuttgart 1862-1870, Marbacher Magazin 20/ 1981.

Meyer-Krentler, Eckhardt, D er Bürger als Freund. E in sozialethisches Programm und sene Kritik in der neuen deutschen E rzählliteratur. München 1984.

Mittelmann, Hanni, D ie U topie des weiblichen G lüdks in den Romanen Theodor F ontanes. Frankfurt/ M. 1980.

Mittenzwei, Ingrid, D ie Sprache als Thema. U ntersuchungen zu Fontanes G esellschaftsromanen. Bad Homburg; Berlin; Zürich 1970.

Moormann, Karl, Subjektivismus und bürgerliche $\mathrm{G}$ esellschaft. Ihr geschichtliches V erhältnis im früheren Prosawerk Gottfried Kellers. Bern 1977.

Müller-Seidel, Walter, Besitz und Bildung. 1. Frau Jenny Treibel, in: ders., Theodor Fontane. Soziale Romank unst in D eutschland. 1975 Stuttgart. S. 300-318.

Muschg, Adolf, G . Keller: ,Martin Salander', in: Hartmut Steinecke (Hrsg.), Z u G ottfried Keller. Stuttgart 1984, S. 158-166.

Negt, O skar / Kluge, Alexander, Öffentlichk it und E rfahrung. Zur Organisationsanalyse von bürgerlicher und proletarischer Öffentlichk eit. Frankfurt/ M. 1972. 
Neumann, Bernd, G ottfried Keller. E ine E inführung in sein W erk. Königstein/ Ts. 1982.

Nipperdey, Thomas, D eutsche G eschichte 1800 -1866. Bürgerrecht und stark er Staat. München 1983.

Nunner-Winkler, Gertrud, Identität und Individualität, in: Soziale W elt 36. Göttingen 1985. S. 466-482.

O hl, Hubert, E duards H eimk ehr oder L e V aillant und das Riesenfaultier. Zu W ilhelm Raabes Stopfkuchen, in: Hermann Helmers (Hrsg.), Raabe in neuer Sicht. Stuttgart 1968.

ders., Bild und W irk lichk eit, Studien zur Romank unst Raabes und Fontanes. Heidelberg 1968.

Olivecrona, Karl, The Term Property in L odke's Two Treatises of G overnment, in: Archiv für Rechts- und Sozialphilosophie. 1975. LXI/ 4, S. 109-115.

O ng, Walter, O ralität und L iteralität. D ie T echnologisierung des W ortes. O pladen 1987.

Petsch, Robert, W esen und Formen der E rzählkunst. Halle 2. Aufl., 1942.

Pieper, Annemarie, Klassisches D enk en heute, in: Rudolf Bockholdt (Hrsg.), Ü ber das Klassische. Frankfurt/ M. 1987, S. 36-46.

Plumpe, Gerhard, E igentum - E igentümlichk eit. Ü ber den Zusammenhang ästhetischer und juristischer Begriffe im 18. Jahrhundert, in: Archiv für Begriffsgeschichte 23 (1979). S. 175-201.

Poltermann, Andreas, Künstlerisch avancierte V erfahren perspektivischen E rzählens in der deutschsprachigen Literatur des 18. und 19. Jahrhunderts. H istorische Beobachtungen und potologische Ü berlegungen, in: D orothea Kullmann (Hrsg.), E rlebte Rede und impressionistischer Stil. E uropäische E rzählprosa im V ergleich mit ihren deutschen Ü bersetzungen. G öttingen 1995, S. 29-69.

ders., „F Frau Jenny Treibel“ oder D ie Profanierung der hohen Poesie, in: Heinz Ludwig Arnold, Text + Kritik Sonderband Th. Fontane. München 1989, S. 131-147.

ders., G enreszene in der Stadt. Fremderfahrung am Beispiel einer D idk ens-Ü bersetzung, in: Jahrbuch für Internationale Germanistik. Jg. XXII / Heft 1. S. 56-97.

Poser, Hans, Spiegel, D as Kätzchen - Bürgerliche W elt im Spiegel des M ärchens, in: Amsterdamer Beiträge zur neueren Germanistik. Bd. 9. 1979. Zur Literatur der Deutschsprachigen Schweiz. S. 33-44.

Preisendanz, Wolfgang, H umor als dichterische E inbildungsk ratt. Studien zur E rzählk unst des poetischen Realismus. München 1963.

Rausch, Heinz, Klassiker des politischen D enk ens. Bd. II. V on L odke bis M ax W eber. München $1968^{1}$.

Rebing, Günter, D er H albbruder des D ichters. Friedrich Spielhagens Theorie des Romans (Literatur und Reflexion, Bd. 8). Frankfurt 1972.

Reinhardt, Hartmut, D ie W ahrheit des Sentimentalen. Bemerk ungen zu zwė Romanschlüssen bei Theodor F ontane, in: Wirkendes Wort 29 (1979). H. 5. S. 318-326.

Reuter, Hans-Heinrich, Fontane 2. Bde. München 1968.

Riedel, Manfred, Theorie und Praxis im D enk en H egels. Stuttgart 1965.

ders., Studien zu H egels Rechtsphilosophie. Frankfurt/ M. 1969.

ders., Bürgerliche $\mathrm{G}$ esellschaft und Staat bei $\mathrm{H}$ egel. Neuwied 1970.

ders., System und G eschichte. Studien zum historischen Standort von H egels Philosophie. Frankfurt/ M. 1973.

Riesman, David, D ie einsame M asse. Reinbeck 1962. 
Rincón, Carlos, Borges und Garáa Márquez oder: das periphere Zentrum der Postmoderne, in: Robert Weimann / Hans Ulrich G umbrecht (Hrsg.), Postmoderne - globale D ifferenz, Frankfurt/ M. 1991. S. 246-264.

Ritchie, James M., M artin Salander. E ine U ntersuchung von Kellers A lterswerk. Diss. Tübingen 1954.

ders., The Plaœ of ,M artin Salander' in Gottfried Keller's E volution as a Prose W riter, in: The Modern Language Review LII, 1957, S. 214-222.

Ritter, Joachim, H eyel und die französische Revolution. Köln 1957.

ders., M etaphysik und Politik. Studien zu A ristoteles und H egel. Frankfurt/ M. 1969.

Ritter, Gerhard A./ Kocka, Jürgen, D eutsche Sozialgeschichte, Bd. 2: 1870-1914. München 1974.

Roebling, Irmgard, W ilhem Raabes doppelte Buchführung. Paradigma einer Spaltung. Tübingen 1988.

Rohe, Wolfgang, Roman aus D iskursen. G ottfried Keller ,D er grüne H einrich' (E rste Fassung; 1854/ 55). München 1993.

Rosenbaum, Heidi, F ormen der Familie. Untersuchungen zum Zusammenhang von Familienverhältnissen, Sozialstruktur und sozialem W andel in der deutschen G esellschaft des 19. Jahrhunderts. Frankfurt/ M. 1990.

Rosenfeld, Hans -Friedrich, Zur E ntstehung F ontanescher Romane. Groningen 1926.

Rothenberg, Jürgen, Gottfried Keller. Symbolgehalt und Realitätserfassung seines E rzählens. bes. IV . D iminuierte W elt. Zu Qualität und W irk ungsweise des ,Keller-T ons'. Heidelberg 1976.

Saage, Richard, E igentum, Staat und G esellschaft bei Immanuel Kant. Stuttgart 1973.

Sander, Volkmar, Illusionszerstörung und W irk lichk eitserfassung im Roman Raabes, in: R. Grimm, D eutsche Romantheorien. Beiträge zu einer historischen Poetik des Romans in D eutschland. Frankfurt/ M. 1968, S. 218-246.

Sautermeister, Gert, Gottfried Keller - Kritik und A pologie des Privateigentums. Möglichkeiten und Schranken liberaler Intelligenz, in: Gerhard Mattenklott / Klaus Scherpe (Hrsg.), L iteratur im historischen Prozeß. 2 Bde., Kronberg/ Ts. 1973. Bd. 2.

Schäfer, Rudolf, Theodor F ontane. Unterm Birmbaum/ Frau Jenny T reibel. Eine Reihe: Interpretationen zum Deutschunterricht. Hrsg. v. Rupert Hirschenauer / Albrecht Weber. München 1974.

Scheuer, Helmut, H istorismus - Positivismus - Realismus, in: D eutsche Literatur. E ine Sozialgeschichte. Bd. 7, V om N achmärz zur G ründerzeit: Ręlismus 1848-1880. Hrsg. v. Horst Albert Glaser, Hamburg 1982.

Scheunemann, Dietrich, Romankrise. D ie E ntstehungsgeschidhte der modernen Romanpoetik in D eutschland. Heidelberg 1978.

Schieder, Theodor, Staatensystem als V ormacht der W elt 1848 - 1918, Frankfurt/ M. 1982.

Schlaffer, Heinz, D as Schick salsmodell in Fontanes Romanwerk. Konstanz und A uflösung, in: G RM Neue Folge. 16 (1966), S. 393f.

Schweizer, Urs, Feier des F estes. D as F est in der D ichtung G ottfried Kellers. Diss. Zürich 1973.

Sloterdijk, Peter, N ach der $\mathrm{G}$ eschichte, in: W. Welsch (Hrsg.), W ege aus der M oderne. Schlüsseltex te der PostmoderneD isk ussion. Weinheim 1988. S. 262-274.

Schönert, Jörg , Kriminalgeschichten in der deutschen L iteratur zwischen 1770 und 1890. Zur E ntwidklung des G enres in sozialgeschichtlicher Perspek tive, in: Geschichte und Gesellschaft 9 (1983). Heft 1. S. $49 f$.

Schramke, Jürgen, Zur Theorie des modernen Romans. München 1974.

Schorn-Schütte, Luise, Karl L amprecht. Kulturgeschichtsschreibung zwischen W issenschaft und Politik. Göttingen. 1984.

Schweckendiek, Adolf, W ilhelm Raabes ,Stopfkuchen'. E ine k ezzerische Betrachtung, in: JbdRG 1974. S. 75-97. 
Sengle, Friedrich, D eutsche Literatur im Spannungsfeld zwischen Restauration und Revolution 1815-1848. Bd. 1 (Biedermeierzeit I). Stuttgart 1971.

Sprengel, Peter, Interieur und E igentum. Zur Soziologie bürgerlicher Subjektivität bei W ilhelm Raabe, in: Jahrbuch der Jean Paul Gesellschaft. 9. Jg. München 1974. S. 127-176.

Stanzel, Franz, Theorie des E rzählens. Göttingen 1982.

Stein, Gert, Philister - Kleinbürger - Spießer. N ormalität und Selbstbehauptung. Frankfurt/ M. 1985.

Steinecke, Hartmut, T heorie und Technik des Romans im 20. Jahrhundert. Tübingen 1979.

Szemkus, Karol, D er gesellschaftliche Bedeutungswandel Seldwylas. Untersuchungen zur Dichtung G ottfried Kellers. Reihe: Germanistische Abhandlungen 26. Stuttgart 1969.

Szondi, Peter, Friedrich Schlegel und die romantische Ironie, in: Peter Szondi, Schriften. 2 Bde. Frankfurt/ M. 1978. Bd. II.

Theologische Realenzyklopädie. Hrsg. von Gerhard Krause und Gerhard Müller. Berlin; New York. Bd. 3. A nselm von L aon A risteteles/ A ristotelismus. 1978.

Todorov, Tzvetan, Die Kategorien der literarischen E rzählung, in: Strukturalismus in der L iteraturwissenschaft. Hrsg. v. H. Blumensath. Köln 1972. S. 263-294.

Tully, James, A D isourse on Property. Cambridge 1980.

Turk, Horst, U rszenen. L iteraturwissenschaft als D isk ursanalyse und D isk ursk ritik. Frankfurt/ M. 1977.

ders., D ie Schrift als O rdnungsform des E rlebens. D isk ursanalytische Ü berlegungen zu A dalbert Stifter, in: Jürgen Fohrmann / Harro Müller (Hrsg.), D iskurstheorien und L iteraturwissenschaft. Frankfurt/ M. 1988. S. 400-417.

ders., Realismus in Fontanes $\mathrm{G}$ esellschatssroman. Zur Ro-mantheorie und zur epischen Integration, in: Jahrbuch der Wittheit zu Bremen 9 (1965). S. 407-456.

ders., V om Klassischen A ltertum zu den Klassik ern der M oderne, in: Wilhelm Voßkamp (Hrsg.), Klassik im V ergleich. N ormativität und H istorizität europäischer Klassik er (D F G -Symposium 1990). Stuttgart 1993. S. 466-492.

Ueding, Gert, Rhetorik des Kitsches, in: Jürgen Schulte-Sasse, Literarischer Kitsch. Texte zu seiner Theorie, Geschichte und E inzelinterpretation. Tübingen 1979, S. 65-88.

Wandrey, Conrad, Theodor F ontane, München 1919

Wehler, Hans Ulrich, D as D eutsche Kaiserreich 1871-1918. Göttingen 1973.

Wedereit, Gerhard, L eitmotivische W iederholung. Beobachtungen zu Technik und E thos in F ontanes ,Frau Jenny Treibel', in: Acta Germanica 7 (1972). S. 117-126.

Wiese, Leopold v., A rt. John Stuart M ill, in: HdSW VII.

Widhammer, Helmuth, Realismus und klassizistische T radition. Zur Theorie der L iteratur in D eutschland 1984-1860. Tübingen 1972.

Winter, Carl, G ottfried Keller. Z eit - G eschichte - D ichtung. Bonn 1971.

Wirschem, Karin, D ie Suche des bürgerlichen Individuums nach seiner Bestimmung. Frankfurt/ M. 1986.

Wood, Neal, John L odke and A grarian Capitalism. Berkeley 1984.

Worthmann, Joachim, Probleme des Z eitromans. Heidelberg 1974. 
Zirbs, Wieland, Strukturen des E rzählens, Studien zum Spätwerk W ilhelm Raabes. Frankfurt/ M. 1986.

Zmegac, Viktor, D er wohltemperierte M ord. Z ur T heorie und G eschichte des D etek tivromans. Frankfurt/ M. 1971.

ders., Zum Problem der Romantheorie, in: Paul Michael Lützeler (Hrsg.), D eutsche Romane des 20. Jahrhunderts. N eue Interpretationen. Königstein/ Ts. 1983. S. 15-30

\section{ABKÜRZUNGEN}

DVjs = Deutsche Vierteljahrsschrift für Literaturwissenschaft und Geistesgeschichte

$\mathrm{DZfPh}=$ Deutsche Zeitschrift für Philologie

$\mathrm{GRM}=\mathrm{G}$ ermanisch-Romanische Monatsschrift

HdSW = Handwörterbuch der Sozialwissenschaft. Hrsg. v. Erwin v. Beckerath. Stuttgart 1956-1965

IASL = Internationales Archiv für Sozialgeschichte der deutschen Literatur

JbdRG = Jahrbuch der Raabe-Gesellschaft 